
(¥) WORLD BANK GROUP

\title{
Impact of Refugees on Hosting Communities in Ethiopia A SOCIAL ANALYSIS
}

\author{
Varalakshmi Vemuru, Aditya Sarkar, and Andrea Fitri Woodhouse
}


(c) 2020 International Bank for Reconstruction and Development/The World Bank

1818 H Street NW, Washington, DC 20433

202-473-1000 | www.worldbank.org

Some rights reserved.

The findings, interpretations, and conclusions expressed in this work do not necessarily reflect the views of The World Bank, its Board of Executive Directors, or the governments they represent. The World Bank does not guarantee the accuracy of the data included in this work. Nothing herein shall constitute or be considered to be a limitation upon or waiver of the privileges and immunities of The World Bank, all of which are specifically reserved.

\section{Rights and Permissions}

The material in this work is subject to copyright. Because the World Bank encourages dissemination of its knowledge, this work may be reproduced, in whole or in part, for noncommercial purposes as long as full attribution to this work is given. Any queries on rights and licenses, including subsidiary rights, should be addressed to World Bank Publications, World Bank Group, 1818 H Street, Washington, DC 20433, USA; fax 202-522-2625; email: pubrights@worldbank.org.

Authors: Varalakshmi Vemuru, Aditya Sarkar, and Andrea Fitri Woodhouse

Cover photo: Photo: Natalia Cieslik / World Bank

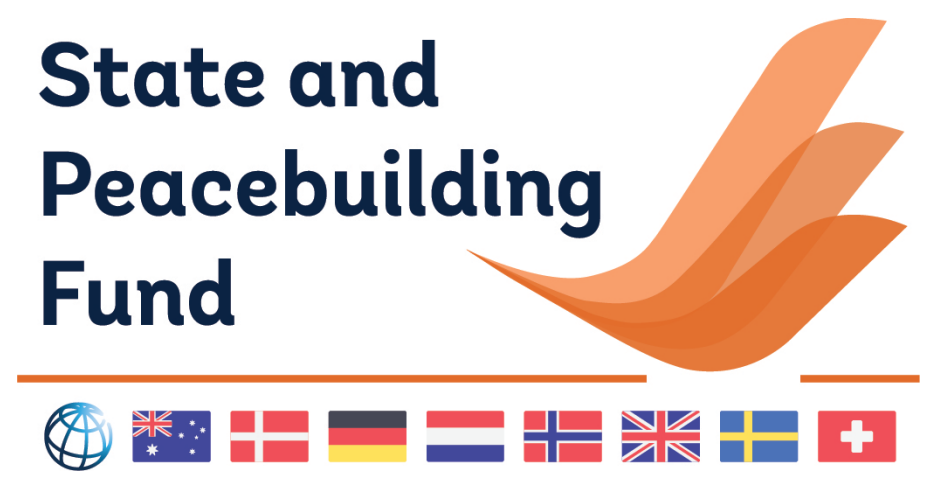

The State and Peacebuilding Fund (SPF) is a global fund to finance critical development operations and analysis in situations of fragility, conflict, and violence. The SPF is supported by Australia, Denmark, France, Germany, the Netherlands, Norway, Sweden, Switzerland, the United Kingdom, and International Bank for Reconstruction and Development. 


\section{Contents}

Abbreviations and Acronyms...............................

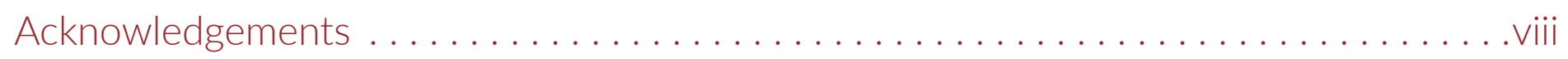

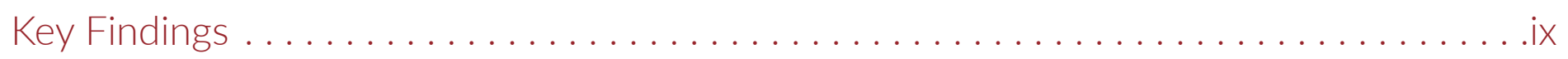

\section{Part I. Impact of Refugees on Hosting Communities in Ethiopia}

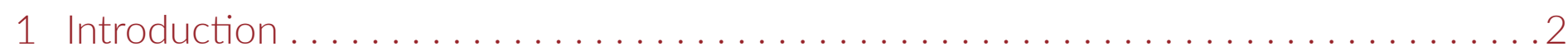

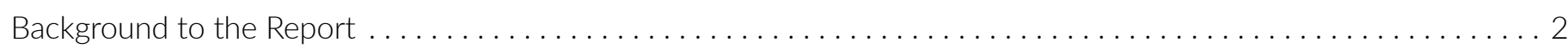

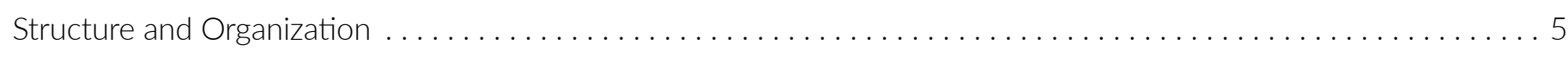

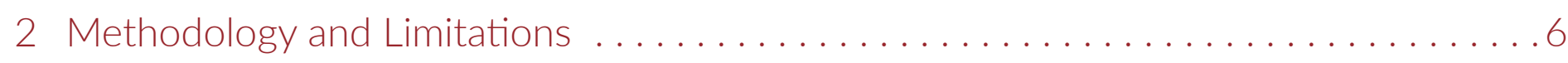

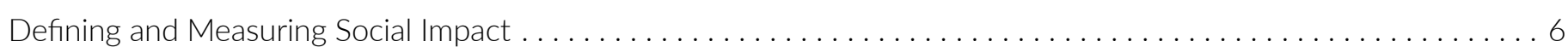

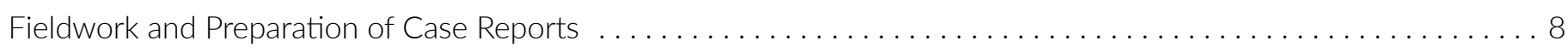

Limitations and Caveats ................................................. 8

3 A Brief History of Displacement in Ethiopia and Its Refugee-Hosting Regions . . . . .10

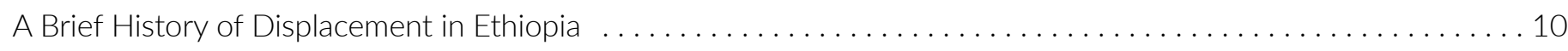

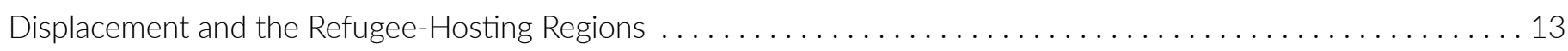

4 Understanding Refugees and Hosts in the Ethiopian Context . . . . . . . . . . . 23

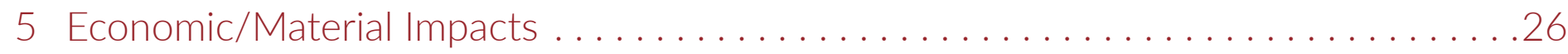

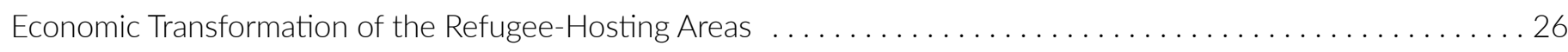

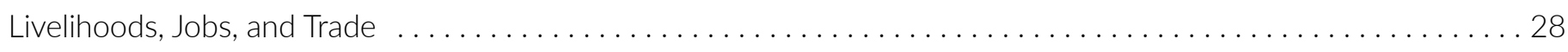

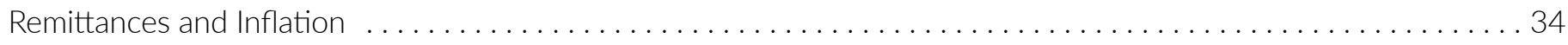

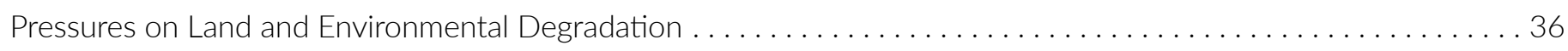


6 Social Impacts of Displacement . . . . . . . . . . . . . . . . . . . . . . 38

Overall Relationships Between Refugees and Hosts . . . . . . . . . . . . . . . . . . . . . . . . . . . . . 39

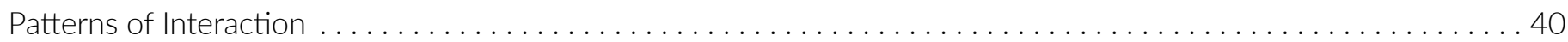

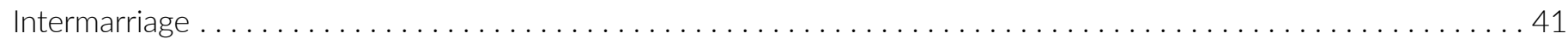

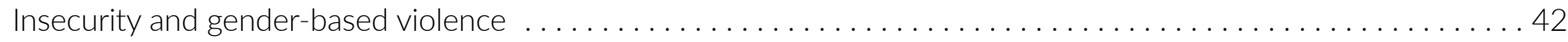

Changing Forms of Social Organization and Gender Roles $\ldots \ldots \ldots \ldots \ldots \ldots \ldots \ldots \ldots \ldots \ldots \ldots \ldots \ldots \ldots \ldots \ldots \ldots$

7 Access to Services and Development Responses . . . . . . . . . . . . . . . . . .46

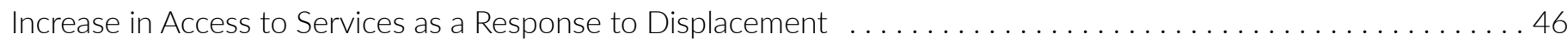

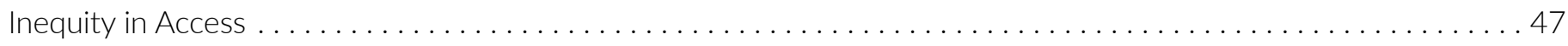

8 Policy Implications ......................................49

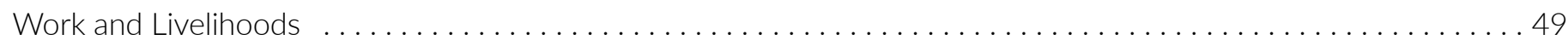

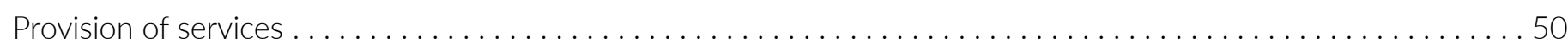

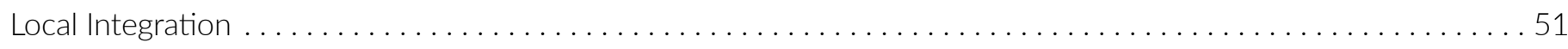

References .........................................52

\section{Part II. Case Studies}

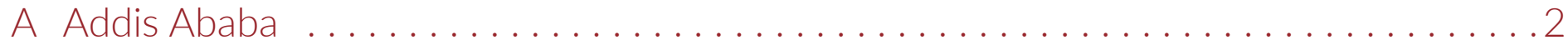

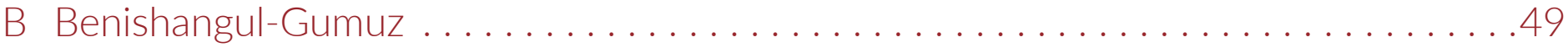

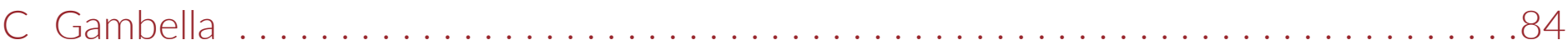

D Somali Region ......................................... 130 


\section{Boxes}

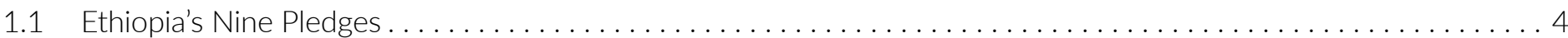

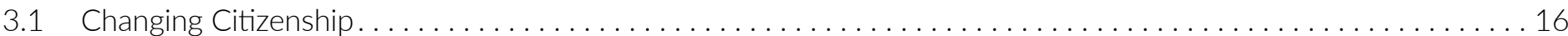

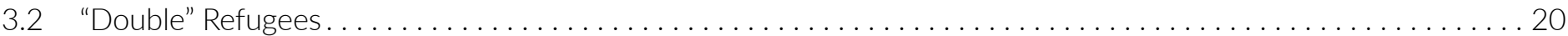

5.1 A Codependence Underpinned by Legal Status and Bureaucratic Obstacles . . . . . . . . . . . . . . . . . 34

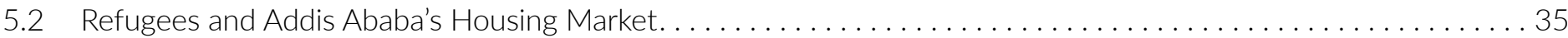

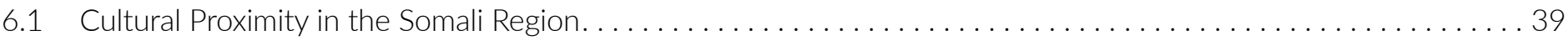

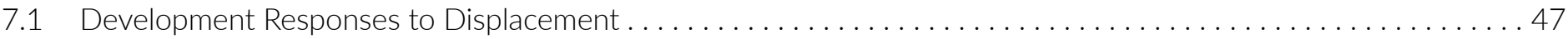

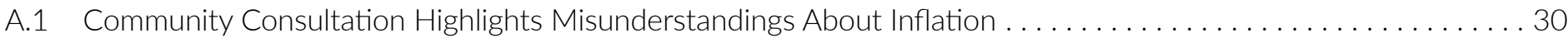

A.2 A Focus Group Discussion on the Tensions Around Rental Prices . . . . . . . . . . . . . . . . . . . . . . . . . . . . . 31

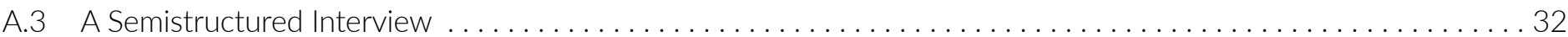

A.4 A Community Consultation: "There is no place where people do not interact" ....................42

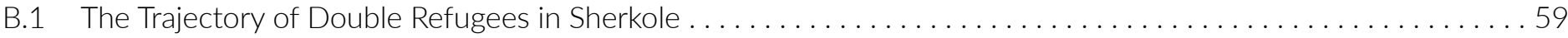

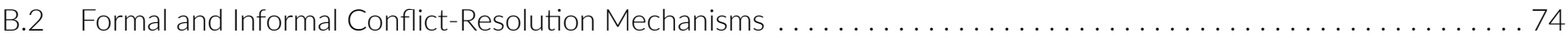

B.3 Building a Relationship of Mutual Trust Through Refugee-Host Exchanges $\ldots \ldots \ldots \ldots \ldots \ldots \ldots \ldots \ldots \ldots$

C.1 Blurred Lines: Citizens and Refugees and the Acquisition of Services. . . . . . . . . . . . . . . . . . . . . . . . . . . . . . 107

\section{Figures}

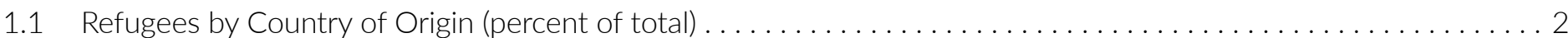

2.1 Life History Collection of a Sudanese Refugee Living in Addis Ababa $\ldots \ldots \ldots \ldots \ldots \ldots \ldots \ldots \ldots$

3.1 Displacement in and from Ethiopia: A Timeline of Selected Events $\ldots \ldots \ldots \ldots \ldots \ldots \ldots \ldots \ldots \ldots \ldots \ldots$

3.2 Historical Tensions Between the Anywaa and the Nuer in Gambella $\ldots \ldots \ldots \ldots \ldots \ldots \ldots \ldots \ldots \ldots \ldots$

5.1 Bole Michael (magnified-bottom left) showing changes between 2004 and $2020 \ldots \ldots \ldots \ldots \ldots \ldots \ldots$

5.2 Sources of Livelihood Currently and Before Displacement. . . . . . . . . . . . . . . . . . . . . . . . . . . . . . . 29

5.3 Labor Force Participation and Employment Status . . . . . . . . . . . . . . . . . . . . . . . . . . . . . . . . . . . . . . . . . 29

5.4 Environmental Degradation Between 2015-20 Around Nguenyyiel Refugee Camp, Gambella . . . . . . . . . . . . . 36

6.1 Interpersonal Relationships Between Refugees and Host Communities . . . . . . . . . . . . . . . . . . . . 38 


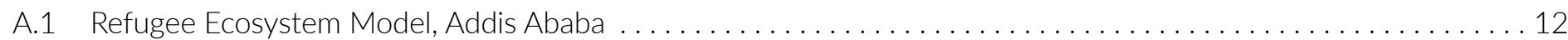

A.2 Host Community Ecosystem Model, Addis Ababa . . . . . . . . . . . . . . . . . . . . . . . . . . . . . . . . . . . . . . . 14

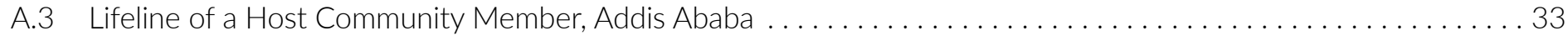

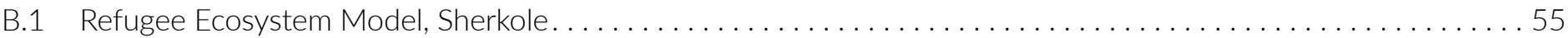

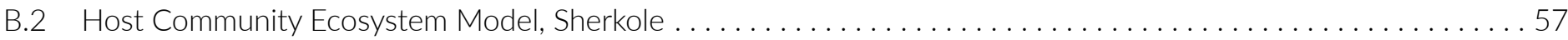

B.3 Lifeline of a Host Community Member, Benishangul-Gumuz $\ldots \ldots \ldots \ldots \ldots \ldots \ldots \ldots \ldots \ldots \ldots \ldots \ldots \ldots$

C.1 Refugee Ecosystem Model, Gambella . . . . . . . . . . . . . . . . . . . . . . . . . . . . . . . . . . . . . 99

C.2 Host Community Ecosystem Model, Gambella. . . . . . . . . . . . . . . . . . . . . . . . . . . . . . . . . . . . . . . . . . . . . . . 100

C.3 Lifeline of a Host Community Member, Gambella . . . . . . . . . . . . . . . . . . . . . . . . . . . . . . . . . . . . . . . 105

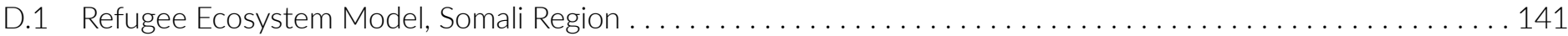

Maps

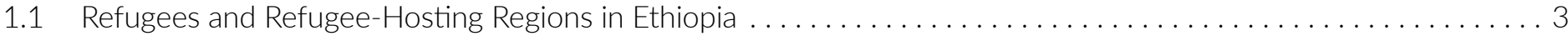

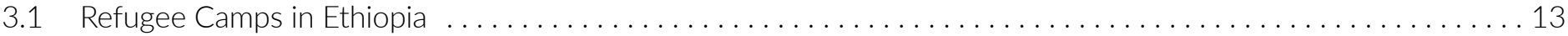

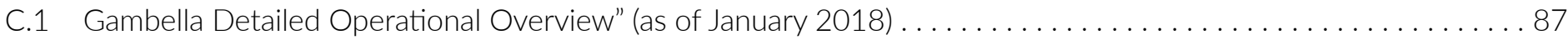

\section{Tables}

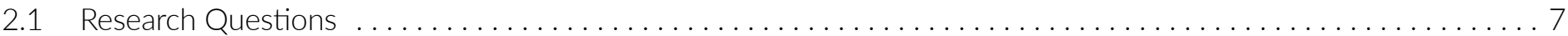

A.1 Economic Indicators for Addis Ababa: Comparison Across Groups $\ldots \ldots \ldots \ldots \ldots \ldots \ldots \ldots \ldots$

D.1 Somali Region: Demographics . . . . . . . . . . . . . . . . . . . . . . . . . . . . . . . . . . . . . . . . . . . . . . . . . . 130 


\section{Abbreviations and Acronyms}

ARRA Agency for Refugee and Returnee Affairs

NGO nongovernmental organization

CC community consultation

NRC Norwegian Refugee Council

CRRF Comprehensive Refugee Response

NRDEP National Resource Development and

Framework

Environmental Protection Department

DICAC Development and Inter-Church Aid

RCC Refugee Central Committee

Commission

RDPP Regional Development and Protection

FGD focus group discussion

Programme

ID identification

SPLM/A Sudan People's Liberation Movement/ Army

IRC International Rescue Committee

SSI semistructured interview

KII Key informant interview

UNHCR United Nations High Commissioner for

LLI L Life line interview

Refugees

MSF Médecins Sans Frontières

\section{Currency}

$\mathrm{Br}=$ Ethiopian birr 


\section{Acknowledgements}

This study was undertaken by a World Bank team led by Varalakshmi Vemuru and comprising Aditya Sarkar and Andrea Fitri Woodhouse. Aditya Sarkar led the writing of this report. Samuel Hall conducted the field research and wrote the case studies that are being published with this overview. The team would like to especially acknowledge the contributions of Nassim Majidi, Rebecca Frischkorn, Eleonore Thenot, Saadia Ali, and Dean Muraya, without whom the research could not have been completed. Bisrat Kassahun contributed research to the background review for the paper, and Freddie Carver was kind enough to share his research findings, which helped inform the research conducted for this study.

We would also like to thank the enumerators, translators, and research assistants in the field who made this research possible, and we would like to specifically thank the numerous people interviewed-refugees, members of the host community, and officials alike who, regardless of their situation, generously shared their knowledge, experiences, attitudes, and hopes with us.

Laura Johnson was responsible for copy editing and design of the paper. Yara Cumbi and Bruno Bonansea supported the team with map design.

For discussions and support on the study, we are grateful to Rebecca Lacroix, Audrey Sacks, Benjamin Petrini, and Erina Iwami. For overall guidance we are thankful to Xavier Devictor and Robin Mearns. We acknowledge funding provided by the State and Peacebuilding Fund (SPF) that made this report possible. 


\section{Key Findings}

\section{Background}

- As of March 30, 2020, Ethiopia was hosting 758,199 registered refugees and asylum seekers, making it the second largest refugee-hosting country in Africa. Most of these refugees (about 99 percent) come from four countries: South Sudan, Somalia, Eritrea, and Sudan.

- Ethiopia is in the process of making far-reaching changes to its refugee policies. In 2016, it made "nine pledges" at the Leaders' Summit on Refugees held in New York aimed at helping refugees gain greater mobility; improving access to services, especially education; expanding access to livelihoods, jobs, and irrigable land; and facilitating the local integration of long-term refugees.

- In February 2019, the Ethiopian parliament adopted a new refugee proclamation (no. 1110/2019) to facilitate the implementation of its pledges. Secondary legislation that will give effect to the proclamation is under preparation. This report, commissioned during this changing policy context, examines the social impacts of protracted displacement on the lives of refugees and host communities.

\section{Context Is Critical}

- The social impacts of displacement differ across and within each refugee-hosting region. They are shaped by each region's history of displacement; by how different communities have settled, traded, and interacted; and by the development and humanitarian responses to displacement. The impact on individuals and communities is further shaped by markers of identity such as class, age, nationality, ethnicity, and gender.

- The social and political context in Gambella is exceptionally complicated due to a long history of conflict among groups over land and political power. The presence of refugees is a significant component of these dynamics.

\section{Refugees and Hosts}

- It can be difficult to distinguish between refugee and host in Ethiopia due to cross-border cultural and economic connections; common ties of kinship, language, and ethnicity; and relatively fluid attachments to national identity. This is true for almost all of its refugee-hosting regions, which are, other than Addis Ababa, situated at or near the country's border.

- In many places, "Host" communities have emerged in response to the arrival of refugees and related humanitarian operations, creating new opportunities for commerce and trade.

- Intragroup conflict among hosts (and to some extent refugees) can be a significant determinant of the social impact of displacement. This is particularly true in Gambella, Benishangul-Gumuz, and the Somali Regional State (or "Somali Region), where there are preexisting tensions among various ethnic groups and among residents treated as "indigenous" and those perceived to be later migrants from the Abyssinian highlands. 
- There remain significant differences between refugees and hosts. Refugees are, on average, poorer than hosts, live in inferior housing, and have less access to electricity. However, refugee households have access to water and sanitation, health, and education services that is on par with-or better than-host community households.

- An individual with better social networks is usually more able to take advantage of displacement-associated changes; this is true for both refugees and hosts. In some areas-such as Gambella and, to a lesser extent, the Somali Region-some host communities and households may be more deprived than refugees.

\section{Economic/Material Impacts}

- Although the economic impacts of displacement have been disparate across the refugee-hosting areas, the arrival of refugees-as well as the associated relief operations-has generally been associated with the expansion of commercial activity and trade.

- The arrival of refugees has also led to cultural changes; and refugees bring to the hosting areas their skills in the construction, interior-decoration, and information technology sectors, among others.

- Accessing reliable income-earning opportunities is a challenge for refugees and hosts across the refugee-hosting areas, although there are significant differences between urban and rural areas. Of the areas studied Addis Ababa is the most economically dynamic context, while camp settings have varying degrees of deprivation. Refugee livelihoods are the most constrained in Gambella and Benishangul, which in turn spurs contestation over resources, environmental degradation, localized insecurity, and theft. Refugees are more likely to rely on aid than are hosts, whose primary source of livelihood is from agriculture and wage-earning employment.
- The presence of refugees has increased pressure on the local environment, as refugees cut down trees and grass and collect firewood for use as cooking or heating fuel. Environmental degradation has led to tensions between refugees and hosts, but refugees report having little alternative given their highly constrained livelihoods.

- Livelihood patterns are highly gendered across the different refugee-hosting areas, with women and girls involved in petty trade, as well as collecting wood and materials from forests, making them disproportionately vulnerable to gender-based violence.

- Remittances received by refugees create demand for local businesses, but some hosts perceive remittances to be inequitable (since they are not "earned") and believe that they have caused local inflation, price increases, and increased khat and alcohol consumption, especially in Addis Ababa.

- The economic relationships between refugee and host communities are delicately balanced. The old/existing refugee regime creates precarity among the refugees but is also the basis on which economic co-dependencies have been created between the refugees and the hosts. Changes to the legal regime will likely transform these dynamics.

\section{Social Impacts}

- Generally, refugees and hosts enjoy positive relationships, but there are significant differences between the groups. Somali refugees report having the best relationships with host community members, while South Sudanese are least likely to report positive relationships with hosts.

- During periods of social tension, ethnolinguistic and gender identities have become more salient. During 
interethnic tensions in Addis Ababa, Eritrean refugees reported feeling targeted based on their ethnicity rather than on their identity as refugees. Similarly, gender-based violence affects women from host and refugee communities alike.

- Refugees and hosts interact while conducting trade; at religious ceremonies; at social occasions such as weddings and funerals; at sports events; and when they access shared social services. Both groups note that relationships of trust are constructed through repeated social and material exchanges.

- Trade and meetings in markets is the single most important form of social interaction for refugees and hosts in camp contexts, but it is less important in Addis Ababa.

- Intermarriage plays an important role in creating social connections between communities (although its role is complex in Gambella). It can also have material significance for individuals in terms of their access to livelihoods and services. The Somali Region reported the highest number of mixed marriages, probably due to common culture, language, and religion.

- Instances of localized insecurity, including petty theft and some violence, were noted in each of the study sites. The most significant and widespread issues are in Gambella, where attacks and retaliatory violence structured along ethnic lines has led to insecurity; but petty theft (often attributed to economic precarity) was also observed in Benishangul.
- Almost all the impacts of displacement are gendered, with differentiated impacts on men and women with respect to access to services, including health and livelihood opportunities. Violence and insecurity are also gendered, with women disproportionately affected. Notably, the presence of refugees and relief operations is sometimes associated with improvement in the access to services for women. Further, nongovernmental organizations and international organizations seem to have raised community awareness about women's rights, child marriage, and early pregnancy.

\section{Access to Services}

- The presence of refugees is associated with improvement in access to services-especially education and health-across the research sites, but there are localized tensions around perceived inequities in access to and quality of services for refugees and hosts, except in Addis Ababa where both groups use integrated public systems.

- None of the three types of services provided to refugees-water, education, and health-are fully integrated across the research sites, but to varying degrees, hosts and refugees can access services such as schools, hospitals, and water sources that are meant for the other group. Refugees would like greater access to electricity, finance, and justice.

- Even as hosts recognize the role of refugees in the expansion of service delivery, inequities in the quality of services that can be accessed by hosts and refugees remain sources of tension, especially because of the real and perceived environmental, economic, and social pressures associated with hosting refugees. 

Part I.

Impact of Refugees on

Hosting Communities

in Ethiopia 


\section{Introduction}

\section{Ethiopia is the second largest refugee-hosting country in}

Africa. As of March 31, 2020, the United Nations High Commissioner for Refugees (UNHCR) estimated that the country had 758,199 registered refugees and asylum seekers. ${ }^{1}$ Almost 99 percent of these refugees come from four countries (figure 1.1): South Sudan (338,250); Somalia (198,670); Eritrea (171,876); and Sudan $(42,119)$. The majority of refugees in Ethiopia are in situations of protracted displacement-that is, they have been displaced for five or more years. Most live in camps located in five regional states: Afar, Benishangul-Gumuz, Gambella, the Somali Regional State (or "Somali Region"), and Tigray, near the borders of their respective countries of origin (Carver, Gebresenbet, and Naish 2018) (see map 1.1). ${ }^{2}$ Apart from Tigray, the other four refugee-hosting regional states are designated as "emerging regions" and are

\section{"the least developed regions in Ethiopia, character- ized by harsh weather conditions, poor infrastructure, low administrative capacity, a high level of poverty and poor development indicators." (UNHCR 2020b)}

Refugee camps tend to be in the least-developed areas of these states.

\footnotetext{
1. Data are available at "Operational Portal: Ethiopia," https://data2.unhcr.org/en/ country/eth. See also UNHCR 2020a. UNHCR estimates that Ethiopia was the second largest refugee-hosting country in Africa (after Uganda) based on data from mid-2018; time series data are available at "UNHCR Population Statistics" at http://popstats.unhcr.org/en/time_series. It is generally quite difficult to accurately estimate the number of refugees in a country. Refugees may choose to avoid registration or may assimilate into local communities, drawing on ties of ethnicity and kinship (see Crisp 1999, which remains relevant). In Ethiopia, the exercise of counting refugees is particularly complex due to the existence of highly mobile groups with a very fluid connection to national identity, whose kinship and livelihood networks extend across national boundaries (Carver, Gebresenbet, and Naish 2018).

2. Ethiopia, a federal democratic republic, comprises nine regional states: Tigray, Afar, Amhara, Oromia, Somali Region, Benishangul-Gumuz, Gambella, Harari, and Southern Nations Nationalities and Peoples Region (SNNPR), as well as two administrative regions: Addis Ababa city administration and Dire Dawa city council. In November 2019, the Sidama (the largest ethnic group in the SNNPR) voted to establish their own regional state.
}

\section{Figure 1.1. Refugees by Country of Origin (percent of total)}

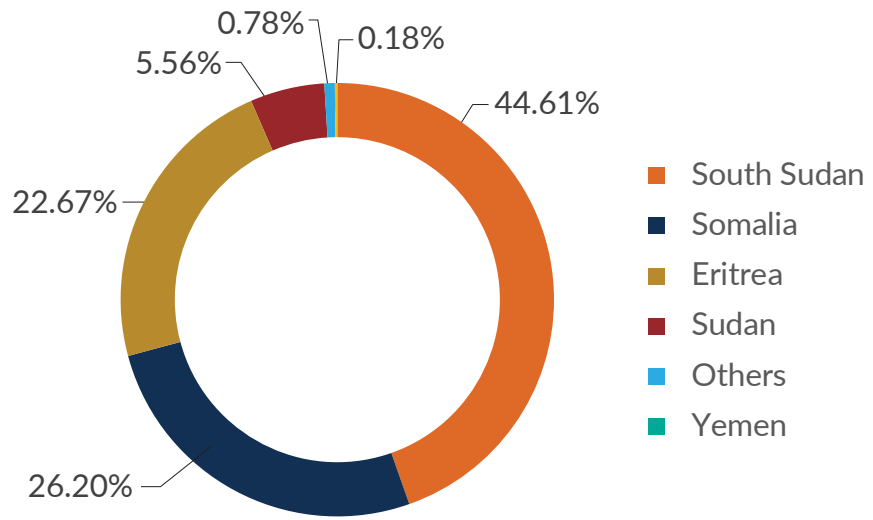

Source: UNHCR's Operational Portal Ethiopia at https://data2.unhcr.org/en/ country/eth.

\section{Background to the Report}

Ethiopia has a long history of hosting refugees, but it is in the process of making far-reaching changes to its refugee policies. In September 2016, the Ethiopian government cohosted the Leaders' Summit on Refugees in New York, where it outlined a new strategic approach toward refugees in "nine pledges" (Nigusie and Carver 2019). Among its aims are to expand Ethiopia's existing "out-of-camp policy," issue work permits to refugees, especially in areas open to foreign workers, increase the enrolment of refugee children in education, expand the provision of basic services to refugees, and allow for the local integration of refugees (UNHCR 2018-see box 1.1).

Ethiopia is in the process of making policy changes to
support durable solutions for refugees. These changes are in line with the global Comprehensive Refugee Response Framework (CRRF). The Ethiopian government 


\section{Map 1.1. Refugees and Refugee-Hosting Regions in Ethiopia}

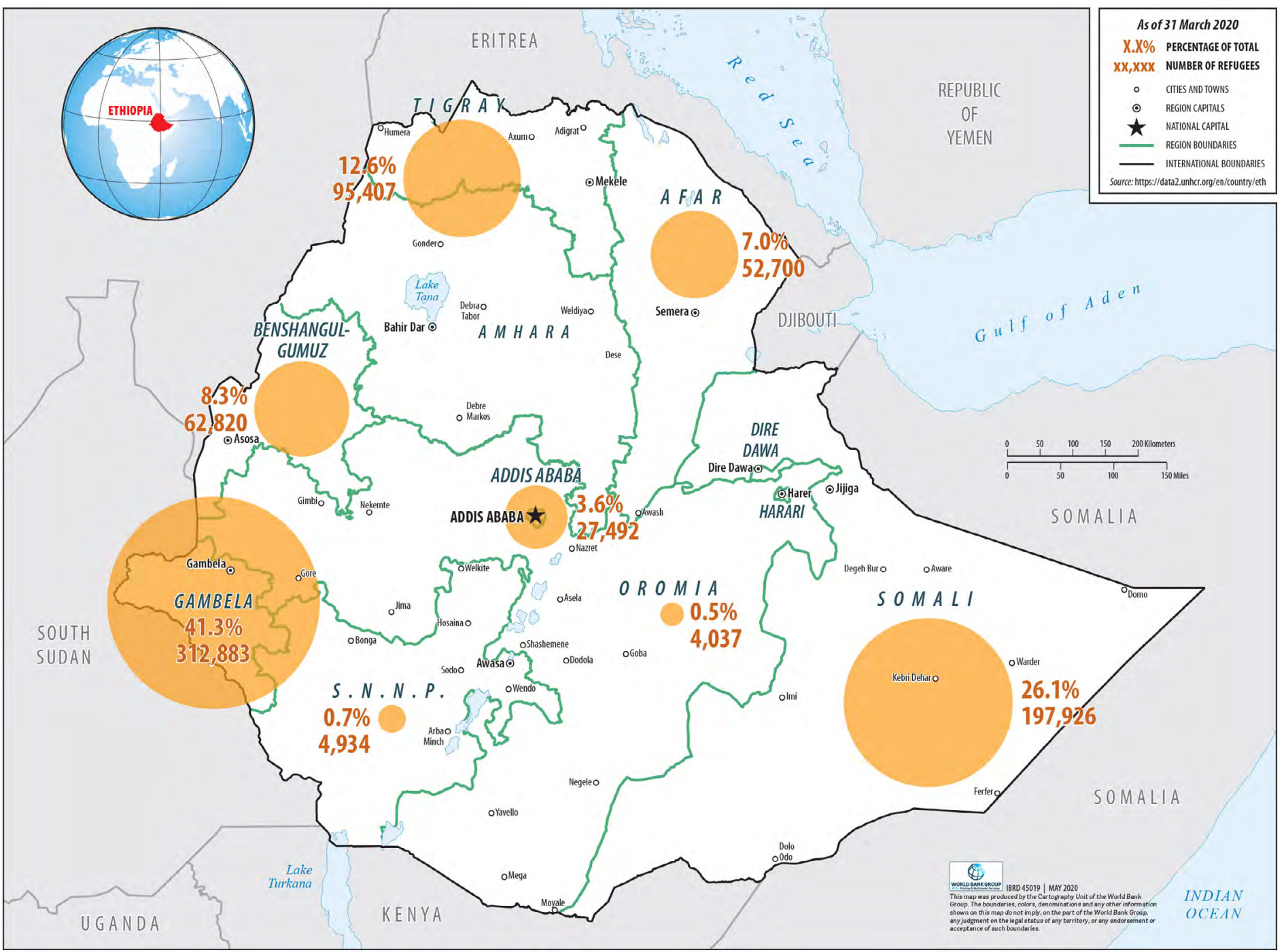

Source: UNHCR's Operational Portal Ethiopia at https://data2.unhcr.org/en/country/eth.

was one of the champions of the framework and made these pledges a day after the adoption of the New York Declaration for Refugees and Migrants. ${ }^{3}$ CRRF implementation was initiated in February 2017, and the Ethiopian government has since outlined a strategic approach aimed at improving rights and enhancing services to benefit both refugees and host communities. ${ }^{4}$ This process is supported

3. See UNGA-United Nations General Assembly, 2016, New York Declaration for Refugees and Migrants, Resolution adopted by the UN General Assembly, October 3, 2016, A/RES/71/1, www.refworld.org/docid/57ceb74a4.html. 4. The CRRF was officially launched in Ethiopia in November 2017. See UNHCR 2018. by a new legal framework, the Refugee Proclamation 1110/2019, which was adopted by parliament in February 2019. ${ }^{5}$ Broadly, the Ethiopian government seeks to move away from a purely camp-based approach toward a more sustainable response aimed at enabling refugees to become more self-reliant and integrated into society and the economy-toward "durable solutions." The approach includes providing wider support to host communities through effective service delivery and by delivering

5. See Refugees Proclamation (1110/2019) at https://www.refworld.org/country,,,ETH,,44e04ed14,0.html. 


\section{Box 1.1. Ethiopia's Nine Pledges}

\section{Out-of-camp pledge}

1. To expand the existing out-of-camp policy to benefit 10 percent of the current total refugee population.

\section{Education pledge}

2. To increase enrolment of refugee children in pre-school, primary, secondary, and tertiary education without discrimination and within the available resources.

\section{Work and livelihoods pledges}

3. To provide work permits to refugees and to those with permanent residence identification.

4. To provide work permits to refugees in the areas in the areas permitted for foreign workers.

5. To make 10,000 hectares of irrigable land available, to enable 20,000 refugees and host community households ( 100,000 people) to grow crops.

6. To work with industrial partners to build industrial parks to employ up to 100,000 individuals, with 30 percent of the jobs reserved for refugees.

\section{Documentation pledges}

7. To provide other benefits, such as issuance of birth certificates to refugee children born in Ethiopia, and the possibility of opening bank accounts and obtaining driving licenses.

\section{Social and basic services pledge}

8. To expand and enhance basic and essential social services for refugees.

\section{Local integration pledge}

9. To allow local integration for refugees who have lived in Ethiopia for over 20 years. support to hosts as well as refugees, promoting peaceful coexistence and greater inclusion of refugees in national development plans, and coordinating with and involving a broader array of stakeholders.

The nine pledges are being elaborated into four key pledge areas: (1) livelihoods; (2) education; (3) energy/ environment; and (4) and protection/capacity; and they are being translated into a national strategy (World Bank 2019). Work is also underway to develop secondary legislation to assist with the implementation of the new law, and subnational governments have made progress toward establishing cross-government coordination structures for CRRF implementation, which are reportedly functioning at the regional and woreda levels in the Somali Region (for refugees based around Jigjiga).

The 2019 Refugee Proclamation could be at the root of a complete overhaul of Ethiopia's refugee policies, but it is uncertain how it will be implemented. For instance, the law provides refugees with freedom of movement, but also states that the Agency for Refugee and Returnee Affairs (ARRA) "may arrange places or areas within which refugee and asylum-seekers may live"-which could result in the retention of some elements of the encampment-based policy. Similarly, in most cases, refugees will have the right to work only in line with the "most favorable treatment accorded to foreign nationals," which will require significant governmental coordination and the simplification of complex bureaucratic procedures. ${ }^{6}$

This report was commissioned in response to this changing policy context. It aims to help the Ethiopian government in its efforts to promote the self-reliance and socioeconomic integration of refugees by examining the social impact of displacement on the lives of refugees and

6. The only exceptions to this are "rural and urban projects jointly designed by the Ethiopian government and the international community to benefit refugees and Ethiopian nationals, including in environmental protection, industry and small and micro enterprises," where refugees will have the same rights and entitlements ('equal treatment') as Ethiopian nationals. 
host communities. It tries to answer the following broad questions:

- How has displacement changed the lives of refugees and host community members?

- How do refugees relate to and interact with host community members?

- How has the presence of refugees changed refugeehosting areas?

Ethiopia is going through a complex political transition; and sustaining the very rapid pace of economic growth and increased service delivery has proved challenging. Levels of unemployment, and more crucially underemployment and precarious employment, are high, especially among youths (see Ronnås and Sarkar 2019). Answering these questions may help reveal how revised refugee policies could be rolled out in the current context.

The overarching goal of the research is to empower refugees and host communities in Ethiopia to live lives of dignity. This report forms part of broader research commissioned by the World Bank on forced displacement in Ethiopia. The findings from this report will inform and enable development and relief experts, policy makers, and social scientists to better understand the evolution of refugee-host relationships in Ethiopia. It also holds lessons for other parts of the world confronting similar challenges.

\section{Structure and Organization}

The remainder of this report briefly discusses the methodology used to conduct the research; situates displacement within its local geographic, political, and historical context across the refugee-hosting regions; analyzes the categories of refugee and host; discusses the economic and social impacts of displacement; briefly touches on access to services and developmental responses; and concludes with some implications for policies aimed at promoting refugee self-reliance and integration. In each of the substantive sections, key findings are highlighted.

Four background papers based on field research findings have provided the empirical basis for this report. Where they are referenced, they are referred to as the Addis Ababa, Benishangul-Gumuz, Gambella, and Somali case studies. They are presented in part II of this report. 


\section{Methodology and Limitations}

\section{Defining and Measuring Social Impact}

\section{What does social impact mean? How can it be measured?}

Although these questions can be answered in several ways, in this report, the term social impact analysis refers to the assessment, evaluation, and analysis of the complex interactions between refugees and host communities (Vemuru et al. 2016: 5).7 These interactions have both positive and negative outcomes, and take place within a much broader setting that includes: (1) the existing socioeconomic context; (2) the complex political context and developmental history of refugee-hosting regions; and (3) relief operations and governmental responses. Diverse groups of refugees enter into an existing set of dynamics in Ethiopia, adapting to and transforming it in multiple ways, at the same time host communities adapt and respond to the presence of refugees and aid operations. This report focuses on these adaptations and transformations, as well as the relationships and interactions between refugees and hosts. These issues were investigated through a series of subthemes and subquestions, described in table 2.1.

\section{Since the early 1980 s, there have been numerous efforts to measure the costs and benefits associated with hosting refugees, especially in the policy arena (Deardorff Miller 2018). Early research into the topic can be very broadly categorized into two groups-that which highlights the burden placed on host country resources and infrastruc- ture and that which claims that the benefits and oppor- tunities accompanying refugee flows generally outweigh such burdens (Kibreab 1991; Whitaker 1999: 6). Refugee- related research has since moved away from trying to}

7. The complexities around classifying people as "refugees" or as "hosts" are explored in the next section. calculate the impact of refugee populations on host countries as a whole (Milner 2016), instead acknowledging that displacement has both positive and negative consequences: while refugees might impose a burden on local infrastructure, the environment, and resources, they also provide inexpensive labor, bring new skills and networks, expand consumer markets, and result in increased foreign aid (Betts et al. 2014; Whitaker 2002; Chambers 1986). Refugees can have different impacts on diverse classes, genders, sectors, and regions within a country, depending on the context (Deardorff Miller 2018; Chambers 1986). The key, then, is to disaggregate the question: Who benefits and who loses from forced displacement, and why?

The impact of refugees varies greatly over time, with markedly different short- and long-term impacts. Pioneering research from Western Tanzania suggests that over longer periods, some hosts are able to draw on the movement of refugees and the resources from humanitarian aid to improve their economic positions, while others become increasingly impoverished (Waters 1999; Whitaker 2002). Displacement can have implications for social, economic, and political organization in the host countries and regions where the refugees are hosted (Landau 2003; Jacobsen 2002; World Bank 2018; Segatti and Landau 2011). Further, displacement crises are shaped by, and in turn shape, development and humanitarian responses (Ward 2014). Such crises result in environmental degradation (Berry 2008), affect livelihood patterns, and impact markets for food and shelter (Porter et al. 2008; AlixGarcia and Saah 2010; UN-Habitat and UNHCR 2018). ${ }^{8}$

8. Some papers find that economic changes can be attributed more to broader macroeconomic changes than displacement or humanitarian policies (see, for example, Landau 2004). 


\section{Table 2.1. Research Questions}

\begin{tabular}{|c|c|}
\hline IS & \\
\hline \multirow[t]{4}{*}{$\begin{array}{l}\text { Who are the } \\
\text { refugees? Who } \\
\text { are the hosts? }\end{array}$} & $\begin{array}{l}\text { Identity and aspirations. Where are the refugees from? When and why did they arrive? What are their intentions for } \\
\text { the future? } \\
\text { Where are the hosts from? How long have they been living in this community/region? What does it mean to be a } \\
\text { "host community"? }\end{array}$ \\
\hline & $\begin{array}{l}\text { Self-reliance. What are the means of livelihood, access to capital, skills training, and markets for the hosts and refu- } \\
\text { gees? How have they evolved? What are the characteristics of vulnerable households? Who is better and worse off } \\
\text { among hosts and refugees? }\end{array}$ \\
\hline & $\begin{array}{l}\text { Services. What access to services (e.g., education, health, water, and energy) do hosts have? Which services are } \\
\text { integrated? } \\
\text { How do refugees and hosts feel about integrated service delivery? }\end{array}$ \\
\hline & Coping mechanisms. What do the hosts need? What positive and negative coping strategies have they adopted? \\
\hline \multirow[t]{4}{*}{$\begin{array}{l}\text { How do } \\
\text { refugees, host } \\
\text { communities, } \\
\text { and local actors } \\
\text { interact? }\end{array}$} & $\begin{array}{l}\text { Impact on local actors. What are the implications of the presence of refugees on local actors, whether public or } \\
\text { private, formal or informal? } \\
\text { How have social organizations and structures changed in the host community? In what ways have the arrival and } \\
\text { protracted stay of refugees impacted this evolution? What changes have been triggered by the arrival and presence } \\
\text { of refugees? }\end{array}$ \\
\hline & $\begin{array}{l}\text { Conflict-sensitive analysis. Who sees the refugees as essential? Who stands out as a main obstacle to refugees? } \\
\text { What are the existing frustrations and tensions that require mitigation? What conflict-resolution and peacebuilding } \\
\text { mechanisms and institutions currently exist? How effective are they? What recent changes have been implemented } \\
\text { in the prevalent rules, incentives, and social norms that govern interactions? }\end{array}$ \\
\hline & $\begin{array}{l}\text { Social organization. How and where do refugees and hosts interact? What are the "places of connection" for refu- } \\
\text { gees and hosts? How are refugees and hosts spread out or organized? What formal and informal leadership struc- } \\
\text { tures exist? What are the roles and functions of community organizations? What is the level of interaction among } \\
\text { groups and with key stakeholders (e.g., kebele development committees)? }\end{array}$ \\
\hline & $\begin{array}{l}\text { Economic interactions. What trade systems and organizations are in place between hosts and refugees? What formal } \\
\text { and informal livelihood activities do refugee and host communities pursue? Do they complement or compete with } \\
\text { each other? What are the constraints to economic participation? How do refugees and hosts access financial services } \\
\text { and resources? How do refugees and hosts save; how do they borrow? }\end{array}$ \\
\hline \multirow[t]{3}{*}{$\begin{array}{l}\text { What is the } \\
\text { context in which } \\
\text { refugees and } \\
\text { hosts interact? }\end{array}$} & $\begin{array}{l}\text { Security. What is the recent history of forced displacement in the local area? What are the major events and drivers? } \\
\text { What is the overall security situation for the host community, given the geographic location? What types and how } \\
\text { prevalent is conflict and violence between communities? What are the causes and drivers? How do these drivers fit } \\
\text { into historical, political, and conflict dynamics? }\end{array}$ \\
\hline & $\begin{array}{l}\text { Governance and programming. What do the hosts and refugees know of and how do they perceive the different pol- } \\
\text { icy measures and actors on refugee integration? What expectations do the hosts and refugees have of development } \\
\text { interventions? }\end{array}$ \\
\hline & $\begin{array}{l}\text { Ecosystem. What does the microsystem, mesosystem, and macrosystem look like around communities? Who are the } \\
\text { most relevant stakeholders? What is the dominant discourse around refugees? }\end{array}$ \\
\hline
\end{tabular}


Building on this body of research, the World Bank has taken a disaggregated approach to understanding the social impact of displacement. The report "Refugee Impacts on Turkana Hosts: A Social Impact Analysis for Kakuma Town and Refugee Camp, Turkana County, Kenya" (Vemuru et al. 2016) uses such an approach; 9 and this this study uses an adapted version of that methodology. This study uses qualitative methods to examine the ways in which social and cultural context shapes decision making, choices, and interpersonal relations; and how motivations, perceptions, and agendas shape responses to and impacts of development interventions.

\section{Fieldwork and Preparation of Case Reports}

Field research for this report was carried out in four different refugee-hosting regions-Addis Adaba, BenishangulGumuz, Gambella, and Somali Region-using a combination of qualitative research instruments. Except for Benishangul-Gumuz, data were collected in each region from multiple refugee-hosting areas to allow for the broadest comparison possible within and across regions. In Addis Ababa, the field research focused on two neighborhoods: Gofa Mebrat Hail, where a large Eritrean refugee community lives, and Bole Michael, to reach the Somali refugee community. In Gambella, research was carried out at two camps, Kule and Nguenyyiel, both located in Itang woreda, and both of which are relatively close to the town of Gambella, as well as at Pinyudo, the oldest refugee camp in the region. In Somali Region, field research was carried out at Aw Barre and Sheder refugee camps; in Benishangul-Gumuz, research was carried out at one location: Sherkole refugee camp. At each location, data were collected using semistructured interviews (SSIs), focus group discussions (FGDs), key informant interviews (KIIs), and a collection of life histories (lifeline interviews, or LLIS) (see figure 2.1). Community consultations were also carried out to verify the data collected, and a total of

9. See also Sanghi, Onder, and Vemuru 2016.
152 interviews were conducted. Four case studies were prepared based on the field research; they are published as part II of this report. This report draws extensively on those case studies, on primary data collected by the Ethiopian government and various multilateral organizations, and on other secondary materials collected as part of a targeted literature review.

\section{Limitations and Caveats}

Research on forced displacement poses unique ethical challenges (see Block et al. 2013; Jacobsen and Landau 2003). Refugee-related research is often undertaken in a fraught political landscape with conflicting interests of host and home governments, humanitarian agencies, and research institutions, all of which can shape access to populations. Refugees may have experienced significant trauma and may have to navigate persistent vulnerabilities, such as precarious legal status and extreme poverty. Challenging settings-from refugee camps to urban locationsmeans that the research process can create or increase risks for research participants in unintended ways. Further, unequal power dynamics between researchers and subjects must be recognized, understood, and considered to remove or, at minimum, reduce bias.

The context in Ethiopia is no different. Refugee issues are closely connected to foreign policy and security concerns, and can be sensitive. Further, fieldwork was undertaken in Ethiopia in the latter half of 2019, during the continued national-level political transition, which briefly resulted in sporadic and localized violence and the internal displacement of many Ethiopians. ${ }^{10}$ Due to the sensitive nature of the questions and volatility of some research areas, respondents were selected using snowball sampling. Finally, researchers encountered "research fatigue" in some of the fieldwork locations: it was clear that refugee communities are used to being approached for research

10. Internal displacement falls outside the scope of this report. 


\section{Figure 2.1. Life History Collection of a Sudanese Refugee Living in Addis Ababa}

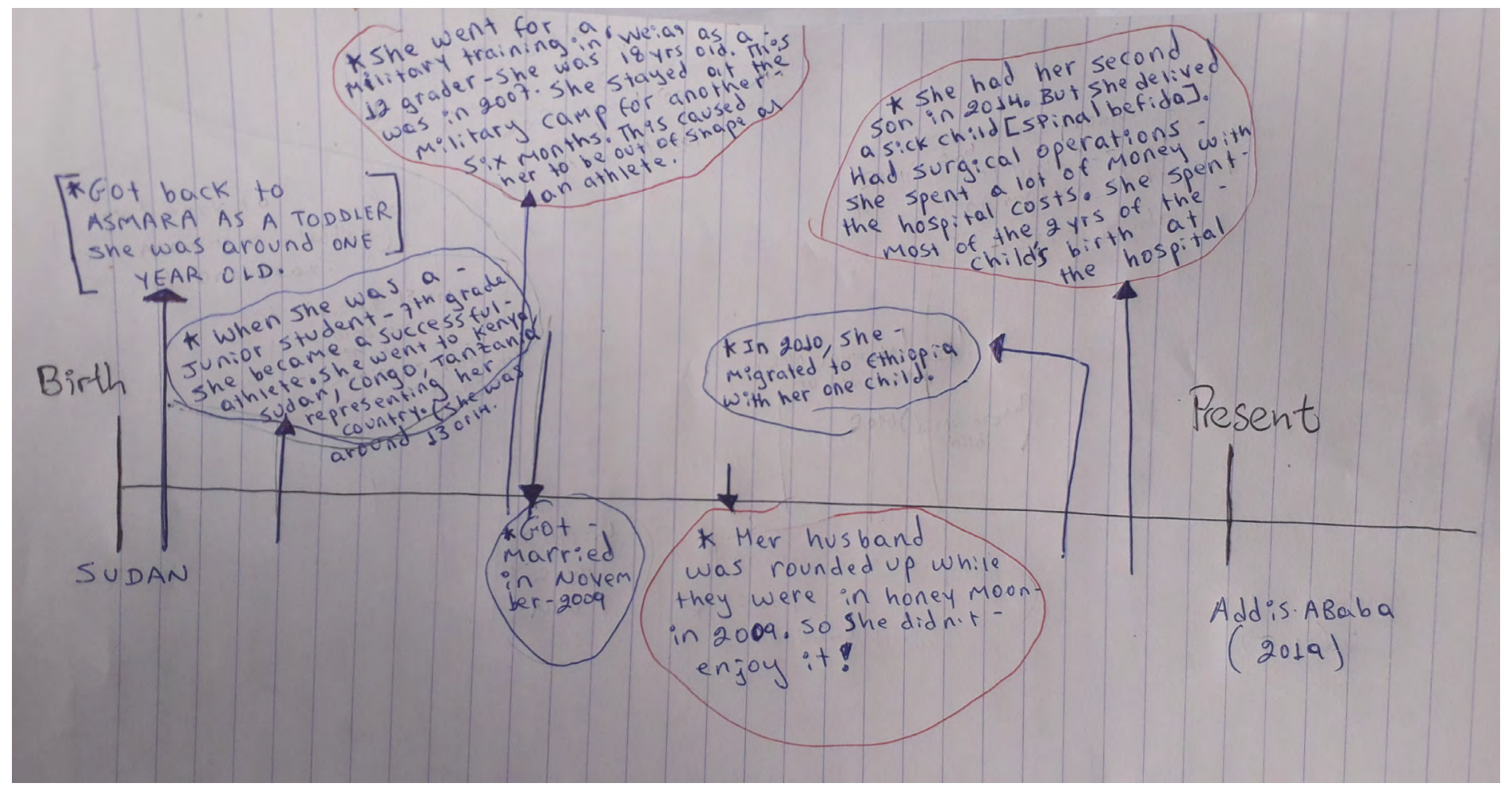

purposes by third parties due to the length of their presence in Ethiopia.

These risks were mitigated using a combination of methods. First, procedures were followed for informed consent and voluntary participation and protection of informants. The risks of within-group bias resulting from snowball sampling were mitigated by drawing respondents from different ethnic, religious, social, political, and economic groups. Throughout the fieldwork period, the quality of the responses was checked by verifying responses within and between groups. Where respondents are quoted in this text, their original statements have been adhered to as closely as possible.
A final caveat about the specificities of each camp and settlement: previous research on refugees in Ethiopia suggests significant differences between various camps in the same region-for example, Sheder and Kebrebiyah in the Fafan Zone of the Somali Region (see Carver, Gedi, and Naish 2018). Field research reaffirms this finding. In this report, therefore, references to empirical findings from a refugee-hosting region should be understood as references to the specific contexts of the camps where data were collected. With these caveats, the next section turns to a discussion of the context of displacement and refugee-hosting regions in Ethiopia. 


\section{A Brief History of Displacement in Ethiopia and Its Refugee-Hosting Regions}

Over the last 50 years, Ethiopia has been a country of origin for significant numbers of refugees as well as a country of destination for the region's displaced. ${ }^{11}$ Each wave of displacement is closely connected to periods of political turmoil within the country, or to regional instability and conflict, as well as climatic crises. This history of periodic displacement, the response of humanitarian and development organizations, and the responses of various Ethiopian governments form an integral part of the contemporary context of refugee-host relationships in Ethiopia. Because most of the refugee-hosting areas in Ethiopia were absorbed into Ethiopia in the 19th and early 20th centuries, the dynamics of displacement have been overlaid onto the broader history of Ethiopian state formation, governance, and center-periphery relationships. The history of Ethiopian state formation is, of course, relatively well researched, but remains deeply contested and is still a part of the country's contemporary political debate. Understanding this intertwined history of state formation and displacement is essential to making sense of the contemporary political context of Ethiopia's refugee-hosting regions.

The overview that follows is divided into two parts. The first provides a schematic outline of displacement in the Ethiopian context, and the second sets out a more detailed history for each of the study regions and sites.

11. Ethiopia has not, however, been a country of origin for significant numbers of refugees since the early 1990 s.

\section{A Brief History of Displacement in Ethiopia}

\author{
Statebuilding and displacement in the \\ imperial era
}

The imperial Ethiopian state originated in the northern highlands, ${ }^{12}$ but most refugee-hosting regions in Ethiopia were only absorbed into the empire in the late 19th and early 20th centuries. In the 19th century, Emperor Menelik II (1889-1913) expanded his territory through the conquest of vast areas to the south, to the east, and to the west of the highlands (Berhe and Gebresilassie 2017; Markakis 2011). Territorial expansion allowed the imperial Ethiopian state to compensate for the loss of territory to colonizers in the north and provided it with a much broader economic base, including control over export crops, such as coffee (Clapham 2019; Zewde 2001; Donham and James 2002). As a result, Ethiopians of the Abyssinian highlands remember Menelik as the ruler who preserved their country's ancient sovereignty, while many from the southern parts of the country categorize him as a colonizer who overran and seized their lands and maintained them in subjugation through outposts of highland riflemen (neftegna) ${ }^{13}$ (Berhe and Gebresilassie 2017). For many who were absorbed into the Ethiopian state during this period, Ethiopia was "invented" in that era in the same manner as other states that had been conquered by

12. Multiple other state-like political forms are associated with other regions
that make up contemporary Ethiopia; however, the Abyssinian highlands were
the heartland of empire. 13. The term neftegna remains pejorative. 


\section{Figure 3.1. Displacement in and from Ethiopia: A Timeline of Selected Events}

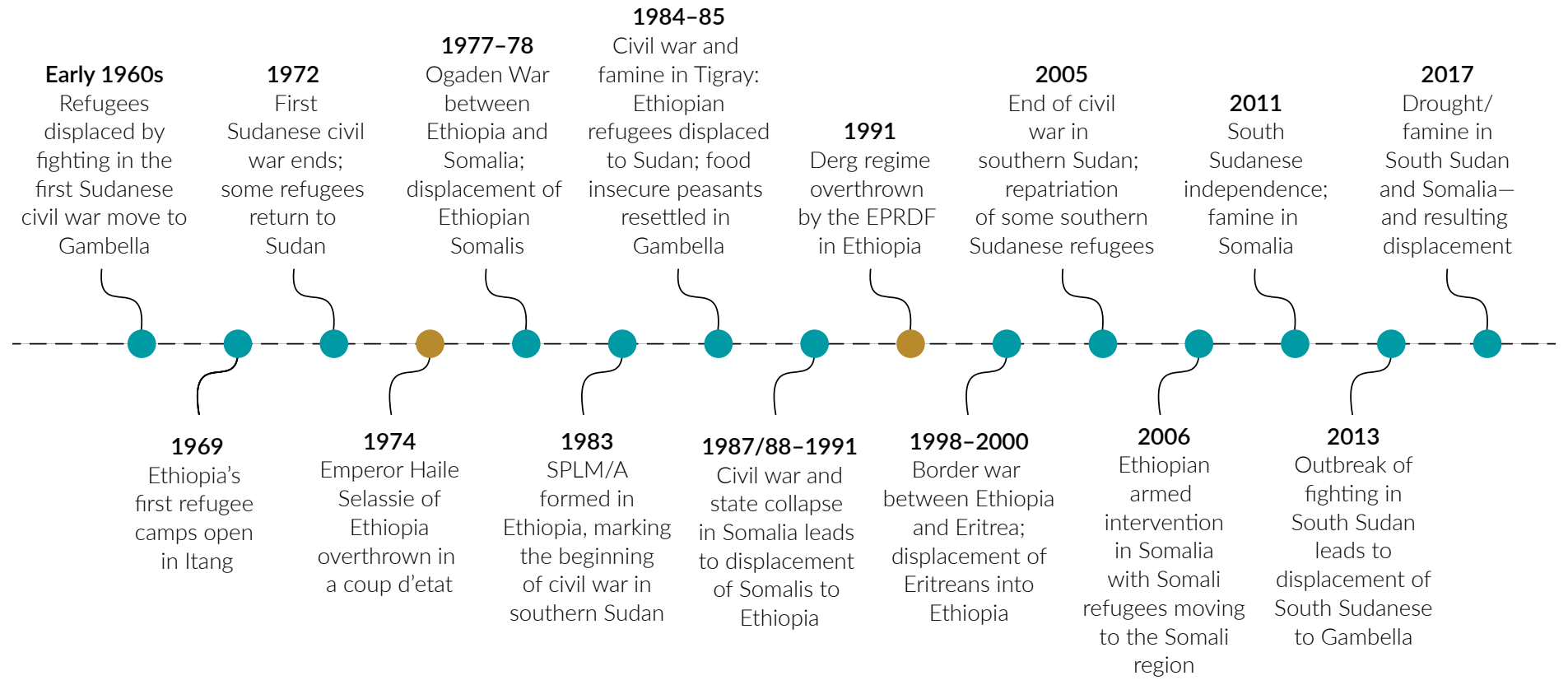

SPLM/A = Sudan People's Liberation Movement/Army

European colonizers (Hassen 1990; Holcombe and Ibssa 1990). See figure 3.1 for a timeline of selected events.

Control over land was central to the imperial political economy, which was dominated by an ethnically defined ruling class into which some other elites assimilated (Vaughan and Tronvoll 2003: 82). The imperial regime reinforced perceptions of cultural superiority by suppressing the identity of subordinate ethnic groups situated in politically peripheral areas. The government took some steps to modernize the economy during this period, including through foreign direct investment in commercial agriculture, but was focused on attracting external expertise and funds, often based on the belief that politically peripheral lowland areas constituted "virgin lands" that were suitable for state-directed, top-down development. Development schemes were therefore inconsistently implemented, and with little concern for the interests of indigenous residents or their land-use techniques. This trend continued, giving rise to local resentment in some areas (Ronnås and Sarkar 2019; Clapham 2018; Feyissa 2011, 2015).
This history contributes to three major tensions in the refugee-hosting areas. ${ }^{14}$ First, it contributes to control over land/territory remaining a major source of contention. Second, the history of border formation through conquest and annexation means that each of the refugee-hosting border regions is closely connected to territories outside the Ethiopian state through strong economic, social, and cultural ties sustained by migration across national boundaries (see, for instance, Carver et al. 2020). Third, the specific histories of each of the refugee-hosting regions can complicate notions of who should be considered an outsider. In Gambella, both highlanders ${ }^{15}$ and refugees may be considered outsiders; while in the Somali Region, highlanders are more likely than refugees to be considered outsiders (see Gambella and Somali case studies). ${ }^{16}$

14. The point here is not that the history of imperial governance is solely or directly responsible for these tensions but that they form the basis on which multiple Ethiopian governance regimes have formulated their policies. These governance techniques are, in turn, responsible for the contemporary form of the tensions.

15. Highlander is an amorphous category that includes multiple groups associated with the Ethiopian highlands. In practice, the term includes the Amhara, the Oromo, the Gurage, and the Tigray, among others.

16. There is a long history of conflict in eastern Ethiopia between the Somali and highlanders. The former often refer to the latter as "Amhara" or "habeshi," even though they include a variety of groups (see Hagmann and Abdi 2020). 
Displacement during Derg rule (1974-91)

In 1974, the imperial government in Ethiopia was overthrown by a military regime known as the Derg. Although the rule of the Derg began as a popular reaction to an autocratic ruler, it rapidly transformed into a brutal military dictatorship accused of extrajudicial executions, torture, and disappearances (ICG 2009; Clapham 2002; Africa Watch 1991). The Derg regime had several major impacts on displacement: two longstanding regional conflicts with Eritrea ${ }^{17}$ and Somalia ${ }^{18}$ escalated (Bariagaber 2012: 113-14); and within Ethiopia, armed opposition movements emerged, notably in Tigray and Oromia, but also in other regions (Berhe 2020).

\section{During this period, conflict in the Horn of Africa region} caused an increase in refugee flows. Refugees fled southern Sudan and Somalia into Ethiopia while fighting between the Derg forces and rebel movements in Tigray and Eritrea, compounded by drought and famine, especially in 1984-85, led scores of Ethiopian refugees to seek shelter in Sudan (Hammond 2004). ${ }^{19}$ The Derg also continued a policy of treating politically peripheral regions as "virgin lands." In the aftermath of the 1984-85 famine in the north, it forcibly resettled peasants in those regions, including some 60,000 in Gambella (Carver, Gebresenbet, and Naish 2018: 9). Even though these "new settlers" were impoverished peasants (unlike earlier settlers in the

17. Eritrea had been an Italian colony from 1890 to 1941, and a British Protectorate from 1941 to 1952. It then became an autonomous unit within the Ethio-Eritrean Federation from 1952 to 1962, before being formally incorporated into Ethiopia in 1962. Many Eritreans thought this incorporation to be illegal, and the Eritrean Liberation Front began a struggle for independence after 1961. The Ethiopian People's Liberation Front was formed in the early 1970s, and the struggle escalated post-1974 (see Kibreab 2009; Tesfagiorgis 2017). 18. The conflict in Somalia, however has its roots in the division of Somalispeaking areas in the Horn of Africa by European powers and the occupation of part of the Somali peninsula by Emperor Menelik of Ethiopia. In 1960, when Italian and British Somaliland achieved independence, uniting to form the Republic of Somalia, Somali nationalists immediately laid claim to the other Somali-speaking regions-Djibouti, the Ethiopian Ogaden, and Somali-speaking regions in Kenya. (For a detailed discussion, see Hagmann 2014a; de Waal 2015.)

19. The most visible and convenient culprit of the 1984-85 famine was the absence of rainfall, but careful examination of how the famine unfolded-which areas were worst hit and when-reveals a close association with the offensives mounted by the Ethiopian army, including its forced displacement of people, destruction of crops and villages, and looting of livestock (de Waal 2018: 139). imperial period), indigenous populations perceived them as outsiders to whom they were losing resources. ${ }^{20}$

\section{Displacement in the post-1991 era}

The Derg were overthrown in 1991 by the Ethiopian People's Revolutionary Democratic Front. Political instability, recurring conflict, and climatic crises in the Horn of Africa has meant that refugees, especially southern/South Sudanese and Somalis, continue to flee to Ethiopia at periodic intervals.

The largest group of refugees in Ethiopia is South Sudanese. In the mid-1980s, refugees from southern Sudan fleeing conflict between the Sudanese government and the Sudan People's Liberation Movement/Army (SPLM/A) moved to camps in Gambella and BenishangulGumuz. Some of these refugees returned to southern Sudan after the fighting ended with the signing of the Comprehensive Peace Agreement in 2005. Another wave of fighting broke out in 2013 after South Sudanese independence and a famine, largely caused by conflict, was declared in parts of South Sudan in 2017 (see Boswell et al. 2019; UN News 2017). These events led to widespread displacement: the largest group of refugees in Ethiopia today are South Sudanese, mostly residing in Gambella (although some have since been moved to camps in Benishangul-Gumuz due to overcrowding). Their presence has profoundly altered the region's social, economic, and demographic context.

Somali refugees began to move to the Somali Region in Ethiopia in significant numbers after the 1987-88 outbreak of civil war in Somalia, and then again after the collapse of Siyad Barre's regime in 1991. Since then, periods of increased fighting and humanitarian crises, including drought and famine in 2011 and 2017, have

\footnotetext{
20. Highland settlers in lowland regions during the imperial territorial expansion were not a homogenous group-they comprised administrators, governors, and soldiers, as well as fortune seekers, tenants, peasants, and slaves (Donham and James 2002: 3). Nonetheless, they were identified with the ruling class of that era.
} 
been the primary drivers of displacement from Somalia (see Lindley 2010, 2013; Hammond 2014; Maxwell and Majid 2016).

\section{Ethiopia also hosts many Eritrean refugees who have} been fleeing to Ethiopia since the 1998-2000 Ethiopia-

Eritrea border war. They are seeking to escape the program of mandatory conscription into national service, originally for 18 months, which has reportedly been extended to an indefinite length in recent years, as well as restrictions on movement (see Feyissa and Mohamed 2018). Most Eritrean refugees live in camps in Tigray or Afar, or reside in Addis Ababa as part of the government's out-of-camp policy. Finally, a smaller number of Sudanese refugees who have fled periodic fighting between the
Sudanese government and rebel movements in the Blue Nile region remain in camps in Benishangul-Gumuz.

\section{Displacement and the Refugee-Hosting Regions}

The impact of refugees and the dynamics of refugeehost relationships vary between and within regions. In each of the refugee-hosting sites, the presence of refugees interacts with broader structural factors, including social, economic, and political tensions and fault lines (see map 3.1 for refugee camps in Ethiopia). Nowhere are these factors more significant than in Gambella.

\section{Map 3.1. Refugee Camps in Ethiopia}

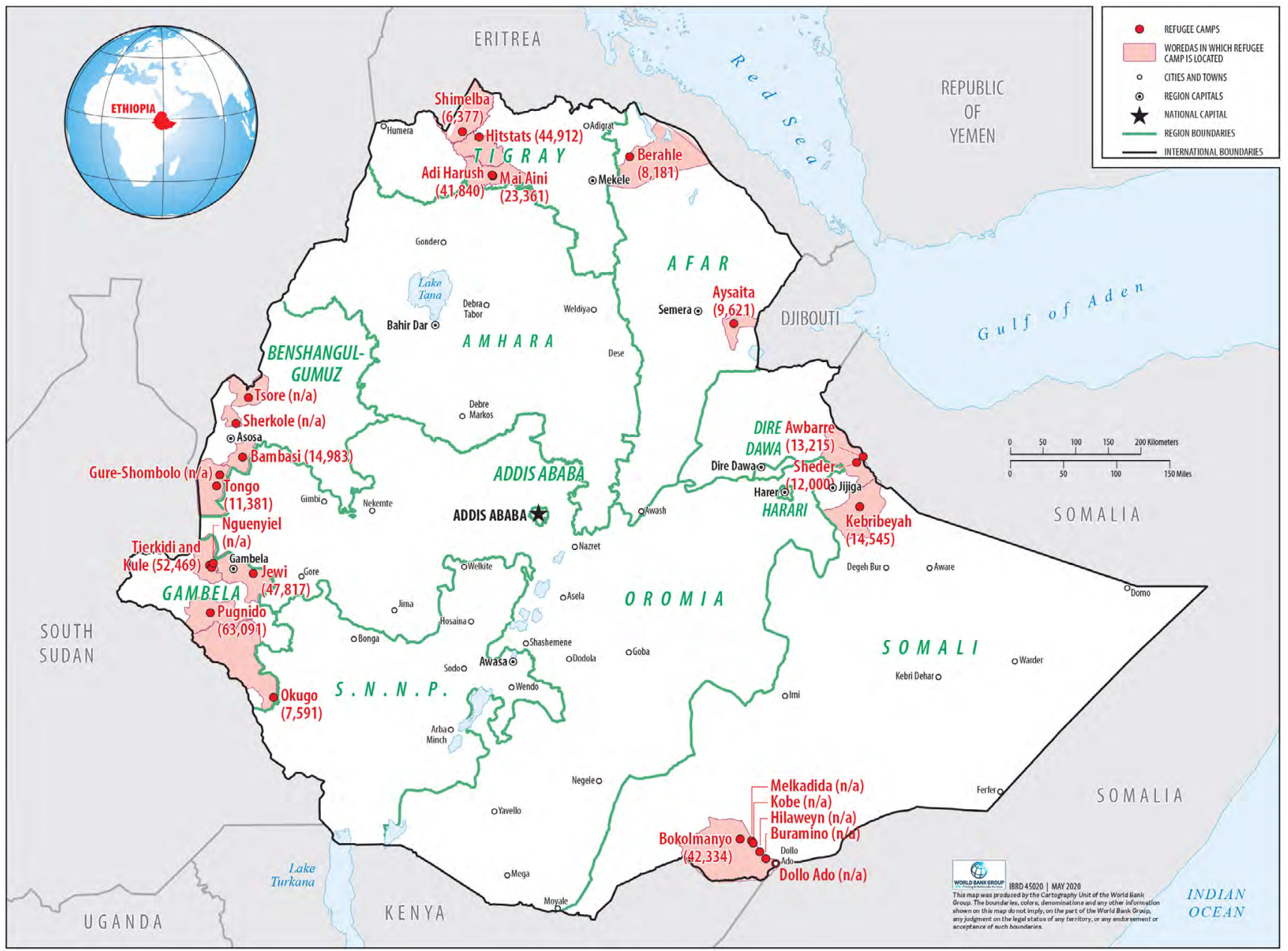

Source: https://data2.unhcr.org/en/documents/download/76841. 
Gambella

Gambella, a region in southwestern Ethiopia along its border with South Sudan, is among the country's most

remote peripheral regions. It is a hot, lowland area with a mixture of dense tropical forest, savannah, grasslands, and marshes. State infrastructure is poor, and access to services limited. The region has five ethnolinguistic groups that are categorized as "indigenous" in post-1991 Ethiopia: the predominantly agropastoralist Nuer, the primarily agrarian Anywaa, ${ }^{21}$ the Majangir, the Opo, and the Komo. Many "highlanders," a category defined by skin color and ethnic origin, also live in the region (Feyissa 2006; Markakis 2011). Unemployment and underemployment are widespread, but indigenous groups are disproportionately affected compared with the highlanders.

\section{A history of communal conflict rooted in contestation for land/territory}

The two largest ethnic groups in Gambella, the Nuer and Anywaa, have a long history of connection and intermarriage as well as conflict and contestation, primarily over territory. After the border between Sudan and Ethiopia was demarcated in 1902, most of the Nuer and a section of the Anywaa found themselves in Anglo-Egyptian Sudan, while most of the Anywaa were placed in Gambella, Ethiopia (Feyissa 2010; Young 1999). Over time, the Nuer treated the border as a material resource, crossing it to escape British campaigns and access weapons, and even opportunistically claiming (and changing) citizenship to get better access to services. Between the 1940s and 1970s, for example, when Sudan provided better health and education services, the Nuer oriented themselves toward Sudan (Feyissa 2013). Militarily, territorially, and demographically threatened, the Anywaa have campaigned to make the border less permeable, arguing that anyone who moved to the region after the 1902 border agreement is a "foreigner."22

21. Also referred to as the Anuak, or the Anyuak.

22. In political discourse among the Anywaa, the 1902 border was instrumentalized to further the claim that the Nuer are not native to Gambella, regardless of how many moved across the border since 1902. This argument is used by the
These differing attitudes around territory reflect the underlying social organization of the Anywaa and the Nuer. The social and political organization of the Anywaa is highly linked to specific land or territory, and those residing outside their village of birth are permanently treated as guests (Gambella Case Study; Feyissa 2015). Selfidentification is therefore linked to ownership of land and to ancestry. Nuer identity, on the other hand, is crafted around mobility and is highly assimilationist-individuals are actively encouraged to cross tribal boundaries (Feyissa 2010: 325). The Anywaa thus see the border between Sudan/South Sudan and Ethiopia as strictly defined and bounded, while the Nuer treat it as permeable. Figure 3.2 provides a historical perspective of these tensions. For various geopolitical and strategic reasons, successive regimes in Ethiopia have encouraged border crossings, complicating the dynamics between these groups (Feyissa 2013). Refugees and humanitarian operations have further exacerbated these dynamics.

\section{Refugees in Gambella}

The first wave of refugees into what is now the Gambella regional state crossed the border from southern Sudan into Ethiopia in the early 1960s, a few years after the outbreak of the first civil war in Sudan in 1955 (Thomas 2015: 116). ${ }^{23}$ When the war ended, many of the refugees returned to Sudan, but some remained and established permanent settlements (Bayissa 2010: 103).

\section{Gambella began to host many refugees after the second} Sudanese civil war began in southeastern Sudan in 1983. Ethiopia's Derg government and the nascent SPLM/A saw the regime in Khartoum as a common enemy. As a result, southern Sudanese rebels operated freely in Gambella and established it as their most important training base

Anywaa to counter Nuer claims of greater political representation based on their demographic majority.

23. Although initially framed in racial and religious terms, the first civil war in southern Sudan was also about resources. Geopolitics also played a role in attracting refugees to Gambella; toward the end of the 1960s, the imperial Ethiopian government began to support the Anyanya I rebels in response to the government of Sudan's political and military support for the Eritrean liberation movements (Feyissa 2013: 115). 
(Carver et al. 2020). Refugee camps such as Itang became a critical part of the local political and economic infrastructure, with nongovernmental organizations (NGOs) providing some social services, such as health care and education, at the camps.

There are several documented examples of refugees becoming Ethiopian citizens and of Ethiopian citizens claiming refugee status. This was made easier by the difficulties in distinguishing between residents and refugees, especially because of their common language (Feyissa 2013; Carver, Gebresenbet, and Naish 2018). The threats and opportunities associated with different national identities over time have driven this fluidity. For instance, the deterioration of the security situation in Gambella's border regions in the mid- to late-1980s, as well as better access to education and resettlement programs, led to multiple cases of Ethiopian Nuer moving to the camps and claiming refugee status. ${ }^{24}$

Displacement from South Sudan has fundamentally transformed the sociopolitical context in Gambella, contributing to a narrative of marginalization among the Anywaa in three ways.

1. Demographic changes. The arrival of refugees from South Sudan has tilted the demographic balance toward the Nuer. Nuer-speaking peoples have been the largest refugee group since the 1980 s, and especially since the start of the 2013 civil war. Between 1984 and 2007, the number of people identifying as Nuer-speaking increased more than twice as quickly as the Anywaa (GoE 1984, 2007; Carver et al. 2020). Combined with the resettlement of famine-affected highlanders from Oromia, Amhara, and Tigray (and others from southern Ethiopia), this means that in 2007, about 46 percent of

24. It is difficult to know how widespread this process was, but regardless, it appears to have decreased over time. Cases of Ethiopian Anywaa claiming refugee status has also been documented, although the practice appears to be more widespread among the Nuer.
Figure 3.2. Historical Tensions Between the Anywaa and the Nuer in Gambella

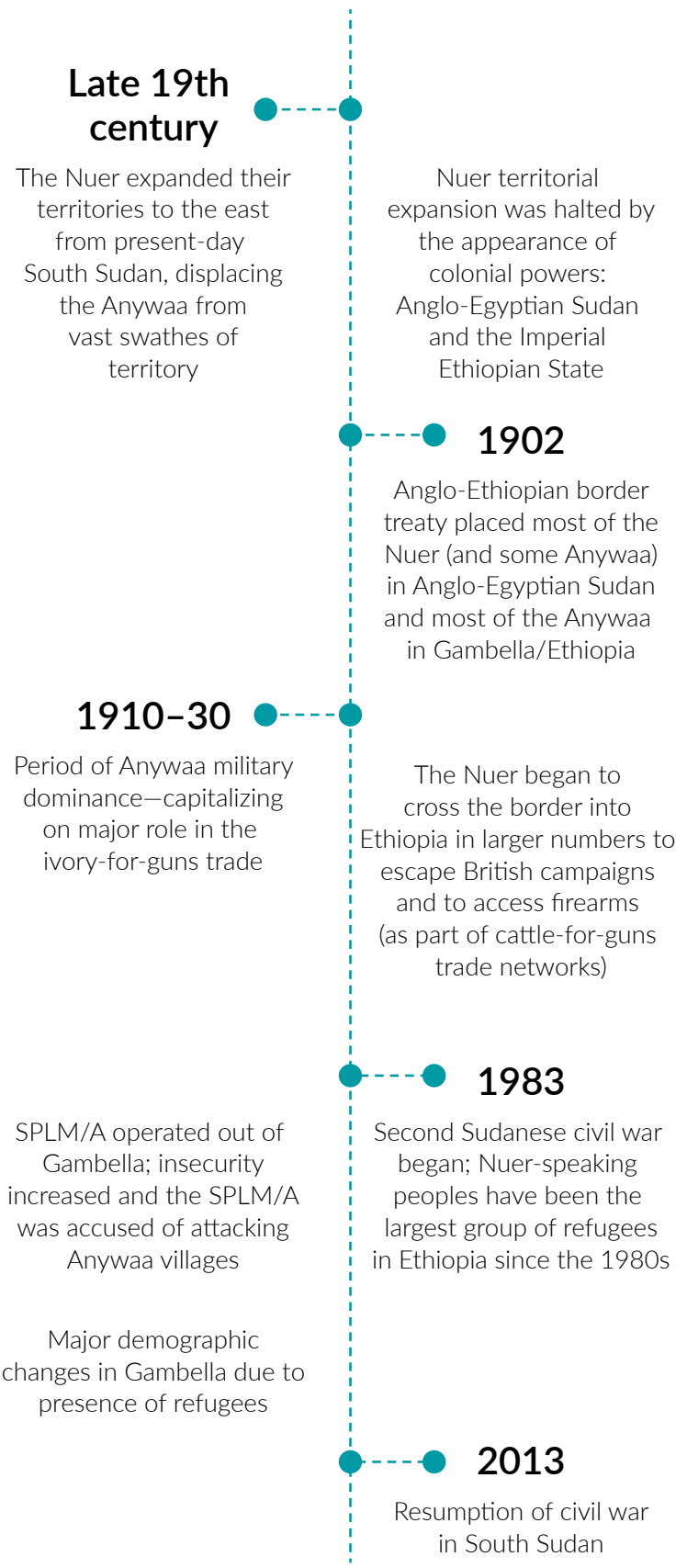

Source: Markakis 2011; Feyissa 2010, 2013; Carver, Gebresenbet and Naish 2018; Young 1999

SPLM/A = Sudan People's Liberation Movement/Army 


\section{Box 3.1. Changing Citizenship}

A 28-year-old man in Gambella recounted how he had spent most of his adult life in a refugee camp because of the economic challenges faced by his family. This is not merely opportunistic; it points to the difficulties faced by the region's residents in accessing services.

"In 2004, we moved to the refugee camp to stay there permanently. It was my parents, especially my father, who decided that we should move to the refugee camp. He thought since he couldn't provide us with school materials, it was better if we went to stay in the refugee camp where food and other items are available for free."

The man benefited greatly from the provision of free food, education, and school materials, allowing him to pursue an education and become an assistant lecturer at the university:
"The teaching in refugee schools helped us tremendously because their curriculum was good and English was the medium of instruction."

However, there were psychological trade-offs that highlight the difficulties associated with giving up one's own citizenship:

"The weird thing about this was the fact that I gave up my Ethiopian citizenship status to be a refugee in my own country, which is not good and also affects your mind."

The man no longer lives in the refugee camp and considers himself a member of the host community.

"Yes, of course. I identify with the host community because that is where I belong. No feeling of exclusion at all. I only chose to live like a refugee in the camp because of economic hardship, but I am still a host though." the population were Nuer, 27 percent were highlanders, and only about 21 percent were Anywaa.

This had serious implications in terms of who holds political power in Gambella (and associated benefits such as jobs) under Ethiopia's system of ethnic federalism. ${ }^{25}$ When Ethiopia was reorganized on

25. The advent of ethnic federalism in 1991 created new political space for local empowerment and the inclusion of previously marginalized regions of the country, such as Gambella, into the state apparatus. However, it also had the effect of complicating tensions by politicizing the conflict between the two communities. The new system, which could be described as a form of ethnic federalism, created a new local bureaucratic class, and ethnic identity became the sole logic of political competition. Moreover, political control of regional administrative units (especially woredas) meant access to food aid (in some cases), jobs, and other state resources. Power over these administrations was distributed based on the size of the respective ethnic groups, therefore giving demographics new saliency in local politics. ethno-federal lines, political space in the newly created regional state of Gambella was dominated by the Anywaa (Feyissa 2013: 119). By the early 2000s, the balance had shifted again, with the introduction of a new power-sharing agreement that tried to balance the historic claims of the Anywaa with the demographic majority of the Nuer.

2. Educational disparities. Since the Nuer were able to access the educational opportunities in the refugee camps more easily than the Anywaa in the 1980s, the former soon surpassed the latter in educational attainment. However, highlanders are perceived as the most economically powerful group in the region. 
3. Increased insecurity. The operation of the SPLM/A in Gambella in the 1980s coincided with an increase in insecurity across the region-with the SPLM/A accused of attacking Anywaa villages and killing many (Tadesse 2007).

The relationship beteween the groups has continued to deteriorate ever since, but particularly since 2016 . Competition over resources and environmental degradation caused by displacement has been exacerbated by a proliferation of weapons and a cycle of retaliatory attacks and killings. The context has been further complicated by the acquisition of land for commercial agriculture in the region and projects aimed at "villagization" (Meckelburg 2014; Hammond 2008).

The camps and the region today

Field research was conducted at three camps in the region: Kule, Nguenyyiel, and Pinyudo-I (see map 3.1). Kule and Nguenyyiel are in Itang woreda. Kule, set up in 2014, hosts 44,745 refugees; Nguenyyiel, set up in 2017 , hosts 82,758 refugees (UNHCR 2020a, as of February 2020). In times of peace, travel from and between the camps was possible, but since 2016, and especially since the spurts of violence in 2018 and 2019, movement has been restricted due to insecurity. Pinyudo-I, opened in 1993, is the oldest existing refugee camp in Gambella. It currently hosts 42,297 refugees and other persons of concern (UNHCR 2020b, as of February 2020). Its two sections house South Sudanese Nuer and Anywaa refugees, with the Anywaa located closer to Pinyudo town (a 10- to 15-minute drive-i.e., walking distance) and the Nuer living further away (about a 30- to 40-minute drive from Pinyudo town), separated from the town by forest (Gambella Case Study). This layout and spatial configuration affect the area's social dynamics, as explored in more detail later.
The Somali Region

The Somali Region in southeast Ethiopia, formerly known as the Ogaden, has a challenging climate and living conditions. The region was absorbed into the Ethiopian nation through military campaigns in the late 19th and early 20th centuries, which was met with fierce local resistance (Hagmann 2014a, b). The region finally came under Ethiopian administrative control in 1927, only to be subsequently annexed by Italian forces. After World War II, it was handed over to Ethiopia in two stages between 1948 and 1954 by the British, who had defeated the Italians in the region. The region's political history is complex: it was the fulcrum of geopolitical competition between Ethiopia and Somalia (in the 1960s and 1970s), and it has witnessed multiple armed rebel movements, most significantly the longstanding armed movement of the Ogaden National Liberation Front (ONLF), which ended when it signed a peace agreement with the Ethiopian government in 2018 (see Conciliation Resources 2018).

The region's terrain is diverse, with most of it classified as semiarid, although cultivation is possible and is practiced in the region around Jigjiga. In general, there has been limited government intervention in the region, and droughts regularly result in the internal displacement of those unable to meet their basic needs. ${ }^{26}$ Infrastructure, including roads, economic opportunities, and resources, are limited because the private sector is underdeveloped. Unemployment and underemployment are therefore high, especially among educated youths who migrate to other countries in substantial numbers.

\section{Refugees in the Somali Region}

The region has hosted refugees since the 1977-78 border war between Ethiopia and Somalia over the Ogaden region. Those most affected were people living close to the contested border where the fighting was concentrated, and an estimated 650,000-1,000,000

26. However, there has been significant development in Jigjiga (see Hagmann 2020). 
Ethiopian Somalis sought shelter in Somalia as a consequence (Hammond 2014; Samatar 1985). The Ogaden War proved to be disastrous for Siyad Barre's regime in Somalia: civil war broke out in the mid-1980s, and hundreds of thousands sought shelter in Ethiopia and, to a lesser extent, Djibouti. In 1988, the Hartisheikh camp (in the plains surrounding Jigjiga) hosted around 400,000 people, and for a brief period was the world's largest refugee camp (Ambroso 2002b; Hammond 2014). By 1991, when Siyad Barre's regime finally collapsed, there were 628,526 registered refugees in Ethiopia.

\section{At various times, both Somali refugees and Ethiopian} Somalis have claimed refugee status. Camps have been organized largely along clan lines, with smaller numbers of "self-settled" refugees in local settlements due to the close clan affiliations among the displaced Somali populations and the Ethiopian Somalis. Significantly, many destitute Ethiopian Somalis have reportedly moved into the camps and registered as refugees to access services and food aid, and the camps have received Ethiopian Somalis displaced to Somalia during the Ogaden War, now being displaced again back to Ethiopia (Ambroso 2002b).

\section{Such fluidity reflects the close cultural and genealogical affinities and longstanding trade links among groups.} The Somali-speaking regions in eastern Africa have long operated as a single economic and cultural space even though they are divided by national boundaries (Hagmann and Stepputat 2016; Carver, Gedi, and Naish 2018; Betts et al. 2019b). This claiming of refugee status reflects the intertwined reality lived by many Somali families, a reality that does not neatly map onto the labels or categories of the refugee protection regime in international law (see Van Brabant 1994: 59). In addition to its history of hosting refugees, therefore, the region has a long history of mobilitymany Somali families move back and forth across the region in search of refuge and livelihood opportunities, making the task of distinguishing between refugee and host extremely difficult.
Between 1994 and 2005, all camps in the region, except Kebrebeyah, were closed due to a combination of repatriation and "dispersal" into local areas. ${ }^{27}$ However, the number of refugees from Somalia increased again after 2006, with persistent instability and recurrent climate crises acting as primary drivers. These refugees have been settled in two parts of the vast Somali Region: first in camps in the Fafan zone around Jigjiga ${ }^{28}$ and, once these were deemed full, in the south, close to Dollo Ado.

\section{The camps and the region today}

\section{The camps from which data were collected (Aw Barre and} Sheder) are both in the Jigjiga area; they were reopened in 2007 and 2008, respectively. They host similar groups of refugees who are originally from urban areas in southern and central Somalia. Some of the refugees were moved into these camps from other camps due to overcrowding. Most have been living in the region for almost a decade, living in situations of protracted displacement (see Somali Region Case Study).

The broader political context in the Somali Region has changed dramatically over the past two years. Between 2010 and 2018, President Abdi Mohamoud Omar "lley" governed the region, exercising highly centralized control over the Somali Region's economy and politics. His removal in August 2018, as part of a broader political transition in Ethiopia, has led to an opening of the political and economic space but has also coincided with a broader political reorientation in the region, which has led to large numbers of people being internally displaced, especially along the long border between the Somali Region and Oromia. The continued reorganization of the region's and national-level politics has resulted in the region witnessing increased interethnic violence, including between

27. When Aisha camp, situated near the Djibouti border, was closed, residents were given the option of being dispersed throughout local areas or being repatriated because there was a recognition that many Ethiopian citizens in the camps were likely ineligible for repatriation. In practice, this became a form of local integration (da Rugna 2005, c.f. Carver, Gedi, and Naish 2018).

28. The broader Jigjiga area is more economically integrated into the Ethiopian state and has a longer history of agropastoralism and farming than other parts of the Somali Region. 
Somali and "highlanders"-a catch-all term that can include the Amhara, the Oromo, the Gurage, the Tigray, and others. ${ }^{29}$ Similar group-based conflict driven by reorientation within Ethiopia's political system has also been visible in other regions of Ethiopia, including Gambella, as well as another of the study sites: the regional state of Benishangul-Gumuz.

\section{Benishangul-Gumuz}

\section{The Benishangul-Gumuz region has long been the shift-} ing and historic borderland between the highlands of Ethiopia and the plains of Sudan (James 2013). Today, it marks the tri-border between Sudan, South Sudan, and Ethiopia. Like Gambella, Benishangul-Gumuz witnessed underdevelopment and limited governmental intervention until the advent of the Derg, despite having substantial gold reserves. As in Ethiopia's other "peripheral" regions, this underdevelopment was due to the limited capacity of the central imperial state as well as the difficulties in building transport systems to and in such remote and inhospitable areas (Young 1999: 323).

Benishangul-Gumuz is ethnically mixed. The main ethnic groups are the Berta (25.4 percent), the Amhara (21.69 percent), the Gumuz (20.88 percent), the Oromo (13.55 percent), and the Shinasha (7.73 percent). Of these, the Berta, the Gumuz, and the Shinasha are considered "indigenous" to the region, which means that they receive a degree of preferential treatment under Ethiopia's federal system, such as in the appointment to official positions. The region has a history of insecurity and violence (see Abbink 2011), significantly constraining development. In recent years, tensions over land use and investments have proved to be major drivers of conflict.

29. Most interethnic conflict emerged from a combination of resource-related and political issues, which are closely intertwined in the Ethiopian lowlands. In recent years, scholars and commentators have argued that conflict has been driven by political entrepreneurs who strategically mobilize collective identities for political gain within the broader national political transition (see Hagmann and Abdi 2020).
Since the end of the 2000s, the lowlands of BenishangulGumuz have been considered by some federal authorities to be suitable areas for large-scale agricultural investment. Authorities consider unfarmed land to be "free" (a continuation of the broader "virgin lands" trend in Ethiopian development planning); this contradicts the land-use patterns of the Gumuz, who practice a form of shifting cultivation. Land investment therefore plays into existing tensions between the Berta and the Gumuz on the one hand, and various highland populations on the other (Moreda 2017). ${ }^{30}$ In 2018, large-scale internal displacement resulted from interethnic violence (Davison and Sew 2018). The dynamics of hosting refugees are largely subsumed under these broader regional tensions.

\section{Refugees in Benishangul-Gumuz}

The Benishangul-Gumuz region has always been a zone of refuge for those escaping the Blue Nile areas of Sudan, and it has seen waves of cyclical displacement since the late 1980s. The first group of refugees fled to the region in 1987-89, escaping fighting between the SPLM/A and the Sudanese forces, only to have to flee again as tensions escalated in the region during the uprising against the Derg (James 2013). After the end of the Sudanese civil war in 2005, many were repatriated to Sudan, and by 2007-08, those who wished to return had done so. However, the provisions of the peace agreement that ended the civil war were not implemented in the Blue Nile region (nor in Abyei or Southern Kordofan). Conflict broke out again after South Sudanese independence in 2011, with refugees fleeing sustained aerial bombardment to Benishangul. Most took shelter in the reopened Sherkole camp, where interviews were conducted for this study. The life history of $B_{---}$, a 47-year-old female refugee (see box 3.2) illustrates how complex the life histories are of some of these refugees and how important is their access to services, especially education and health care-themes that arose across all study areas.

30. There were reported conflicts between Gumuz and highland populations, particularly in Oromo in 2007, 2009, and 2011 (Labzae 2019). 


\section{Box 3.2. "Double" Refugees}

Sherkole camp is unique because it hosts individuals who arrived from Sudan as refugees in the late 1980 s, returned to Sudan in the early 2000s, and then returned again to Ethiopia as refugees after 2011. $B_{---}, 47$ is one such person.

"We ran away to Ethiopia in 1987 from Sudan. We stayed in Ethiopia from 1987 to 2003. In 2003 we went back to Sudan and we stayed up to 2011, and in 2011 we ran away again and came back to Ethiopia."

Sudanese refugees, who have similar paths of circular migration, are exceptional in that they have lived in more than one refugee camp in Ethiopia. B first settled in Sore camp, before fleeing to Itang, and then finally settling in Sherkole in 2011. She recounted how, upon returning to Sudan, the limited educational opportunities prompted her desire to return to Ethiopia.
"When we returned back to Sudan our children were not getting an education. Also the country was politically unstable, our government would make an agreement today only to change it tomorrow."

She herself has benefitted from the education provided at the camp, enrolling in school as an adult which allowed her to work for NGOs.

"Something which makes me happy is that our children get more education and if they get their education the NGOs here can also give you the work for training for HIV AIDS, training to work in the health center to work at IRC [International Rescue Committee] and UNHCR ... These things make me happy ... if you are finished with training you can help your community."

Source: Benishangul-Gumuz Case Study.

\section{The camp}

Originally established in 1997, Sherkole is among the oldest remaining refugee camps in Ethiopia. Although it was originally set up to accommodate Sudanese refugees, in 2005, the Ethiopian government decided to relocate all asylum seekers and refugees from the Great Lakes (primarily fleeing fighting in the Democratic Republic of Congo) to Sherkole (JRS 2005). Post-2011, displacement also led to the establishment of two additional camps in BenishangulGumuz: Bambasi and Tongo. Since 2017, large numbers of South Sudanese refugees have been relocated from overcrowded Gambella camps to Benishangul-Gumuz to a new camp-Gure-Shembola-established in May 2017 for this purpose. As of March 2020, Sherkole camp was housing 10,598 refugees from Sudan, South Sudan, the Democratic Republic of Congo, Burundi, Uganda, and other African countries. ${ }^{31}$ Sudanese refugees originating from the Blue Nile and South Kordofan State, and belonging to the Funj, Uduk, or Nuba tribes, make up the majority of the camp's population. Only the South Sudanese refugees, who have stayed in Ethiopia since 1997 have technically experienced protracted displacement. ${ }^{32}$

31. See UNHCR's "Ethiopia: Comprehensive Registration" data at https://data2. unhcr.org/en/dataviz/58?sv=0\&geo=160.

32. See KII28 (Benishangul-Gumuz Case Study). Sherkole has also hosted Congolese refugees since 2004. 


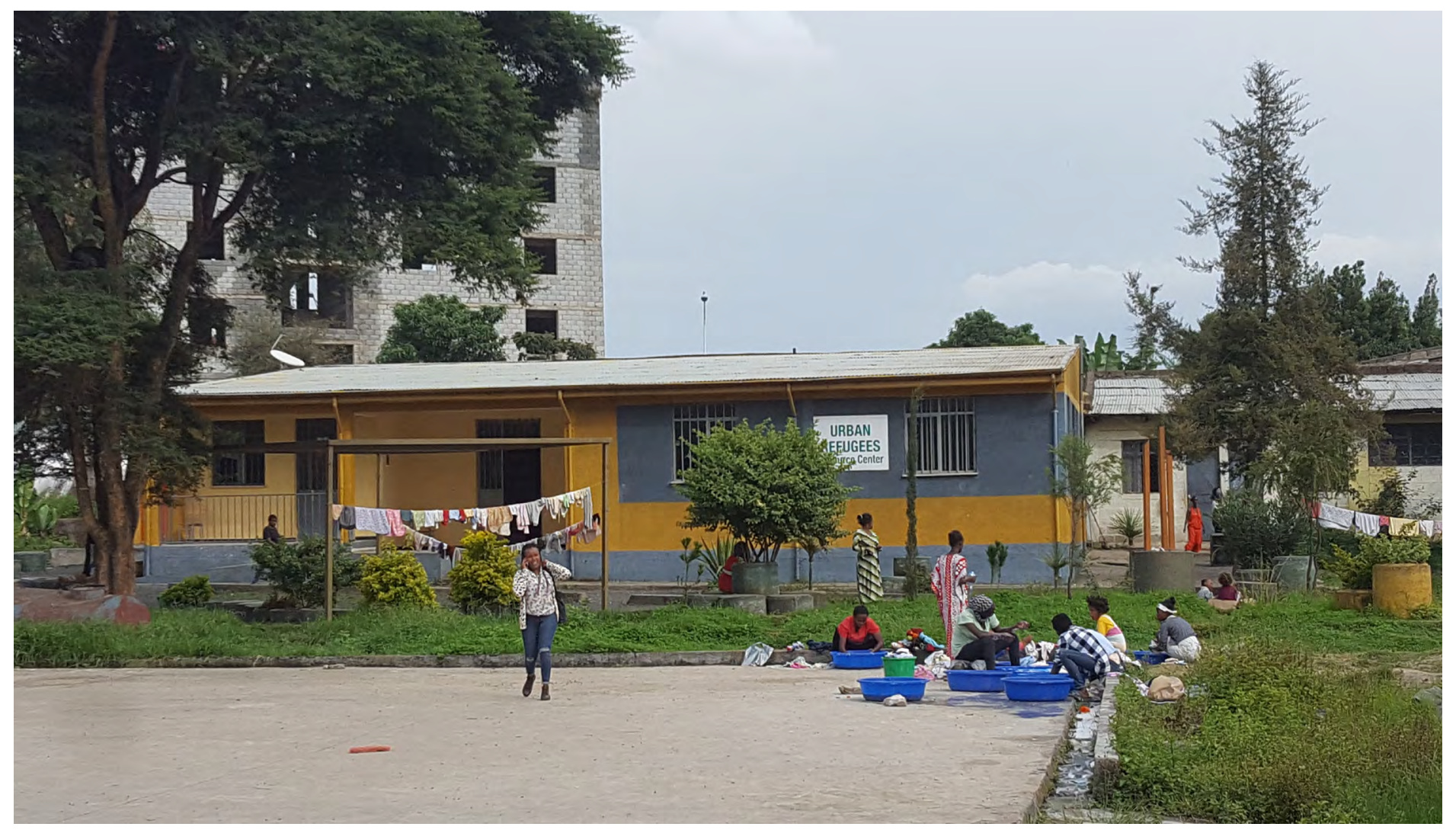

Urban Refugees Resource Centre, Bole Michael, Addis Ababa

\section{Addis Ababa}

The capital city of Addis Ababa has witnessed rapid growth and significant inward migration over the previous decade. In general, urban centers in Ethiopia are characterized by better infrastructure and access to services; this is also the case for Addis Ababa. On average, households are better off, and both male and female literacy and education rates are higher. Labor force participation rates are lower than in rural areas, but this is because of the predominance of agricultural livelihoods in rural areas. Wage employment in Ethiopia is concentrated in urban areas, especially Addis Ababa, but at the same time, large numbers of the newly urbanized earn their livelihoods in the informal sector in occupations such as mobile street trading, shoe shining, and coffee vending, or as informally contracted workers in the construction sector (Ronnås and Sarkar 2019). The urban landscape has been extensively overhauled in recent years as the government tries to provide housing for the rapidly expanding urban population (Planel and Bridonneau 2017). ${ }^{33}$

\section{Refugees and the city}

As of March 2020, Addis Ababa was hosting 27,000 registered refugees, although this is likely an undercount. As with other refugee-hosting urban centers, some refugees do not receive (or seek) assistance from UNHCR, relying instead on personal networks, remittances, and informal trade activities, preferring invisibility because legal status and documentation might only offer limited protection in their informal environments (see Polzer and Hammond 2008; Landau 2014). It is therefore difficult to research or provide differentiated services to these populations. An

33. The last available statistics (from the 2013 National Labour Force Survey) suggests that 44.4 percent of the total population in urban areas were migrants (Central Statistical Agency 2014). 
unknown number of unregistered refugees live in Addis Ababa (Addis Ababa Case Study; Betts et al. 2019a; Brown et al. 2018).

\section{Addis Ababa has hosted refugees for over 40 years, begin-} ning with those fleeing the collapse of Zaire (presentday Democratic Republic of Congo). Since then, the refugee population in the city has grown, predominantly due to the arrival of Eritreans and Somalis, but also due to other nationalities, such as South Sudanese, Yemenis, Syrians, Congolese, and others from the Great Lakes region. The refugees who live in Addis Ababa can be divided into three categories: (1) those who fall under the out-of-camp policy; (2) those who are part of the Urban Assistance Programme; and (3) others. The last category includes refugees who are unregistered, those (such as Syrians or Yemenis) who do not have designated camps, refugees benefiting from an educational scholarship, and those visiting to process visas or other paperwork (see Addis Ababa case study).

\section{The out-of-camp policy is a legal framework developed} by the Ethiopian government in 2010. It aims to build self-reliance among Eritrean refugees. To be considered under the policy, a refugee must have a sponsor who guarantees covering the refugee's living expenses in the relevant city. The sponsor is usually a relative (and an Ethiopian citizen) and must sign an agreement with the Agency for Refugee and Returnee Affairs (ARRA). The process continues with a check by ARRA to confirm that the sponsor can provide for the refugee and ultimately to approve the city of residence. In exchange, refugees under the out-of-camp policy cannot access formal wage labor or access assistance services provided to urban refugees by UNHCR (see Samuel Hall 2014; see also Mallett et al. 2017). Refugees registered under the Urban Assistance Programme are also not allowed to work, but they do receive a monthly allowance from UNHCR. They are usually individuals who have been permitted by ARRA to live in an urban area, generally Addis Ababa, for security, medical, or family reunification reasons (see Addis Ababa case study).

\section{Neighborhoods studied}

Data were collected for two areas: Bole Michael and Gofa Mebrat Hail. Both are home to poor and middleclass Ethiopians, and both have experienced inflation and rapid population growth in recent years. These areas have also witnessed a broader process of gentrification, which is pushing some in the host community further out to the suburbs of Addis Ababa, although it is difficult to disaggregate the impacts of refugees from that of inflation and rising living costs. Bole Michael is predominantly known as a Somali neighborhood. It is located in woreda 1 of Bole subcity (near the international airport), with both refugees and Ethiopian Somalis. Gofa Mebrat Hail is considered a predominantly Eritrean neighborhood-it has long been a hub for both Eritreans and Tigrinya-speaking Ethiopians. Research was conducted at a time when tensions in the city were relatively high, reflecting the broader tensions of the national transition. This affected the ability of the researchers to conduct mixed focus group discussions. Nonetheless, the findings from Addis Ababa both complicate and reaffirm the findings from the other research sites. The next section turns to the first set of these findingsthe complexity of defining the terms host and refugee in the Ethiopian context. 


\section{Understanding Refugees and Hosts in the Ethiopian Context}

The definition of the term refugee is clearly specified in the 1951 Refugee Convention ${ }^{34}$ and in the 1969 Organization of African Unity Convention Governing the Specific Aspects of Refugee Problems in Africa. There is no equivalent definition of the term host under international law, but for the purposes of this report, the following formulation provided by UNHCR will suffice:

\begin{abstract}
"A host community in this context refers to the country of asylum and the local, regional and national governmental, social and economic structures within which refugees live. Urban refugees live within host communities with or without legal status and recognition by the host community. In the context of refugee camps, the host community may encompass the camp, or may simply neighbor the camp but have interaction with, or otherwise be impacted by, the refugees residing in the camp." (UNHCR Resettlement Service)
\end{abstract}

\footnotetext{
34. Article 1(A)(2) of Convention Relating to the Status of Refugees, 1951, defines a refugee as a person who "owing to well-founded fear of being persecuted for reasons of race, religion, nationality, membership of a particular social group or political opinion, is outside the country of his nationality and is unable or, owing to such fear, is unwilling to avail himself of the protection of that country." Recognizing the specificities of Refugee Crises in Africa, Article 1(2) of the Organization of African Unity's Convention Governing the Specific Aspects of Refugee Problems in Africa, 1969, states that the term refugee "shall also apply to every person who, owing to external aggression, occupation, foreign domination or events seriously disturbing public order in either part or the whole of his country of origin or nationality, is compelled to leave his place of habitual residence in order to seek refuge in another place outside his country of origin or nationality." In this report, the term refugee is also used to refer to unregistered refugees and asylum seekers. The distinction between these categories is less relevant to this research because Ethiopia grants prima facie refugee status to most refugee groups resident in the study areas. There is a broader and continued debate on the strict bifurcation between forced displacement, and other forms of mobility, but that is beyond the scope of this paper (see Turton 2003: Bakewell 2010; Van Hear, Bakewell, and Long 2017).
}

Ethiopia's refugee policy continues to be based on the 2004 Refugee Proclamation, which requires encampment. Although the 2019 Refugee Proclamation will potentially provide for greater freedom of movement and livelihoods among refugees, there is need for secondary legislation for its implementation. This policy depends on being able to distinguish between refugees and hostswhich then determines how individuals are categorized; what rights and services they have access to; and, more broadly, what legal regime they are governed by. This is a complex task. ${ }^{35}$

It can be difficult to distinguish between refugees and hosts because of cross-border connections and common ties of language, kinship, and ethnicity.

Each of the refugee-hosting regions in Ethiopia have a long history of mobility and cultural connections to other communities across regional borders, and relatively fluid/ flexible attachment to national identity. In both Gambella and the Somali Region, there have been many documented instances of refugees claiming Ethiopian citizenship, and of Ethiopian citizens claiming refugee status. Interviews suggest that the practice has become less prevalent over time, and UNHCR has recently completed a large-scale

35. Others have reached similar conclusions. See studies by Carver, Gebresenbet, and Naish 2018; Carver, Gedi, and Naish 2018; and Feyissa and Mohamud 2018, which were commissioned as part of a single research project. 
refugee-registration (and verification) process, ${ }^{36}$ which may further deter the practice. Nevertheless, common ties of language, kinship, and ethnicity make distinguishing between refugees and citizens difficult. The local politics of each of the refugee-hosting regions further complicates matters. In Gambella, some Anywaa elites have branded all Nuer, whether Ethiopian or from southern/South Sudan, as "foreigners," while in the Somali Region, clan divisions and preexisting patterns of social exclusion (targeted at some occupational groups) remain salient, notwithstanding cultural affinities.

\section{Some "host" communities only emerged in response to the arrival of refugees and related humanitarian operations.}

\section{There were instances across the case study sites where the identity of an individual as either refugee or host is subsumed by other forms of identity. ${ }^{37}$ In Addis Ababa,} for instance, during the increase in tensions on the Somali-Oromo border, ethnic identity acquired primacy, and Somali refugees felt that non-Somali Ethiopians were targeting them:

"They [locals] view them [refugees] as Somalis and do not care that they [refugees] were Somalis from Somalia and not the Somali Region." (FGD10, Addis Ababa Case Study)

Similarly, and also in Addis Ababa, Tigrinya-speaking Eritrean refugees felt that they were being profiled on the basis of ethnicity rather than their status as refugees

\footnotetext{
36. This registration process resulted in a large decrease (of about 200,000) in the numbers of refugees thought to be hosted by Ethiopia.

37. It long been accepted in academic literature that ethnic identities are socially constructed and strategically used by both elites and common people (see Fearon and Laitin 2000, generally; and for the Ethiopian context, see Hagmann and Mulugeta 2008). Ethnic conflict is not, therefore, to be understood as the manifestation of primeval differences but instead contestation and competition driven by multiple structural and political factors, such as cross-border movement, settlement, and access to resources.
}

during recent tensions between the Tigrayans and the Amhara and Oromo.

\begin{abstract}
"You see we speak Tigrinya, and they [Amharas and Oromos] really can't differentiate who is the local and who is the refugee. So, they confuse us with the local Tigrinya speakers. And they don't see us in good terms. There is the tendency for the locals to confuse us with Tigrayans." (SSI8, Addis Ababa Case Study)
\end{abstract}

\section{A host community suggests a preexisting setting into which refugees have inserted themselves. ${ }^{38}$ In many} of the fieldwork sites however, the host community in its present form was a direct result of displacement and the accompanying humanitarian operation. In the Somali Region, Somali refugees have contributed to the financialization and commoditization of the local economies due to their access to finance, urban backgrounds, and skills (see also Carver, Gedi, and Naish 2018). Both Sheder and Aw Barre used to be small villages with only a few houses and shops and limited services. Now they have grown to become business centers, attracting others from the region and beyond. Local traders and business owners have especially benefited.

\section{"Aw Barre was a small district before the refugees came; now it's hugely increased after the arrival of these refugees. This has benefited local traders who have accumulated wealth because of the many people buying their items and have expanded their business." (SSI20, Somali Region Case Study)}

This is not to say that all the impacts of the refugee presence have been positive, merely that many in the "host community" had not actually resided in the area prior to the arrival of refugees.

\footnotetext{
38. The word host derives from two historical roots: one connotes "master of the house" (in a male-gendered sense), and another suggests the notion of hospitality (see Benveniste 1973: 74).
} 
On average, refugees are poorer than hosts, live in worse housing and have poorer access to electricity. However, refugee households' access to water and sanitation, health, and education services are on par with, or better than, host community households.

Similarly, in Gambella, the creation of refugee camps (Kule, Nguenyyiel, and Pinyudo 1) have transformed their neighboring areas-Pinyudo town and Pulkot (Tharpam) kebele. ${ }^{39}$ In fact, the arrival of refugees transformed Pulkot kebele from a small village into a town with much more economic clout than the larger Itang woreda (district), of which it is a part.

"It [only] became a town now because of [refugees]."

(FGD27, Gambella Case Study)

While Pulkot is struggling to provide services to its burgeoning population, by contrast, Itang town, which is the capital of the woreda, has languished due to its distance from the refugee camps. Similar dynamics are visible in Addis Ababa, and perhaps to a lesser extent near Sherkole camp in Benishangul-Gumuz.

\section{Neither refugees nor hosts are a monolithic category. In the} Somali Region, Gambella, and Benishangul-Gumuz, conflict between different groups of "hosts" is as significant (if not a greater) concern, than conflict between refugees and hosts. In other regions, there are tensions between different groups of refugees, divided by factors such as when they arrived in Ethiopia, their ethnic identity, their class, or their perceived wealth. In Sherkole camp, for instance, the Agency for Refugee and Returnee Affairs (ARRA) has organized refugees into separate zones to manage conflict among ethnic groups. One refugee explains:

39. A kebele is the smallest administrative unit in Ethiopia. It is similar to a ward, a neighborhood, or a localized and delimited group of people.
"My tribe, we are living in zone ... with another tribe from Dinka, Funj ... Before, we were living there in zone ____, every day we had fighting, but now we are living by peace." (SSI 59, Benishangul-Gumuz case study)

This does not, however, mean that there are no differences between refugees and hosts, or that these categories are irrelevant. As an interviewee in Gambella noted (see box 3.2), even where individuals switch between statuses of "refugee" and "citizen," they generally self-identify as one or the other. And, for the most part, even where the two groups have frequent and amicable interactions, their social institutions remain separate (with some exceptions).

Socioeconomic disparities among refugees and hosts are significant (based on World Bank data from 2017see Pape, Petrini, and lqbal 2018). On average, refugee households are significantly poorer than host community households, with female-headed households poorer across both groups. About two out of three refugees live below the international poverty line of US\$1.90 per day per person at 2011 PPP, compared with about one in four host communities. There are also major differences between the different groups of refugees: Eritrean refugee households have the lowest incidence of poverty (38 percent); South Sudanese refugees have the highest (72 percent). Many more refugees depend on food aid, an expected result of the existing legal restrictions on their working; ${ }^{40}$ fare worse on housing indicators; and have far less access to electricity. On the other hand, access to services such as water and sanitation, health, and education among refugees is on par with or in some cases better than that of host community households (see also Guyatt et al. 2018).

40. The 2019 Refugee Proclamation will likely allow refugees greater freedom to access livelihoods, but it is not yet in effect. 


\section{Economic/Material Impacts}

The economic impacts of displacement have been heter-

ogenous. Nonetheless, some common themes emerge from the case studies. Overall, the presence of refugees and the humanitarian responses to displacement has transformed refugee-hosting regions, although the precise impact depends on several factors, including the regional political context, intergroup dynamics, patterns of trade, and the geography and the spatial layout of the camps themselves. In contexts characterized by persistent underdevelopment, humanitarian and development operations have added economic dynamism and created some job opportunities.

The arrival of refugees has transformed the refugee-hosting areas-creating new opportunities for commercial activity and trade, but also increasing pressure on the local environment.

These material and economic impacts have not been evenly distributed: those-whether host or refugeewith better social networks and access to resources have benefited while the poorest have, for the most part, seen their economic situation deteriorate. The impacts of changes to economic activity include inflation, environmental degradation, competition for low-skilled jobs, and pressures on existing patterns of land use, affecting some members of the host community more than others. The case studies also point to the relatively fragile nature of the economic relationships among refugees and hosts, which can be described as a form of "legally created codependence." The underlying legal regime governing refugees prohibits them from accessing most forms of formal employment. In many areas, therefore, refugees and hosts enter into economic relationships with roles based on what each is allowed to do; refugees may have greater access to skills or capital, while hosts are more easily able to travel and comply with legal requirements.

These themes manifest themselves in various ways across regions. In Gambella, political tensions overshadow economic dynamics, although some localized trade still exists. By contrast, the economic relationship between refugees and hosts in the Somali Region is characterized by mutual interdependence, and driven by different skills and capacities. Benishangul-Gumuz has witnessed some competition for resources driven by precarity, but refugees and hosts have generally complementary economic roles under the current legal system. Addis Ababa is characterized by a predominance of informal livelihoods. There are, of course, variations within each region, as well as some tensions among refugees and hosts. The remainder of this section expands on each of these themes, including implications for the future self-reliance of refugees.

\section{Economic Transformation of the Refugee-Hosting Areas}

Each of the study sites has been economically transformed by refugees and large-scale humanitarian operations. These effects are most clearly visible in the Somali Region, where the presence of refugees has increased economic and trading opportunities and expanded settlements. Interviewees pointed out that Aw Barre and Sheder looked very different before 2007/08, when the first wave of refugees arrived: both areas were primarily inhabited by agropastoralist groups and had only a few shops and 


\section{Figure 5.1. Bole Michael (magnified-bottom left) showing changes between 2004 and 2020}

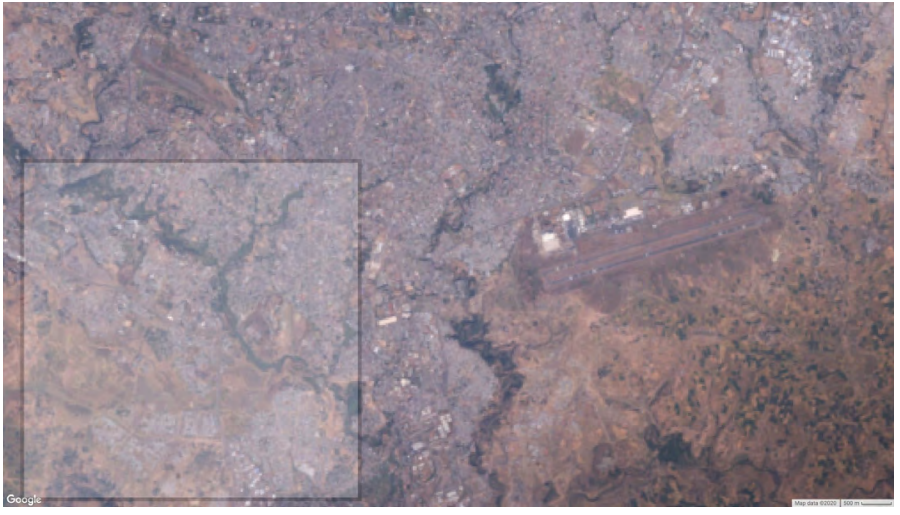

Source: European Union/ESA/Copernicus.

houses. Sheder was a particularly small agricultural village characterized by extremely limited money circulation:

"In Sheder, when we arrived ... it was a very small village. The buildings that you have seen here were not previously here, there were [only] old buildings and ... just plants growing everywhere ... you could count the number of shops, it was a small number, there was only one marketplace with a limited number of goods, and if you were to buy you might not receive change. For example, if you were to buy a [packet of] biscuits whose price was $\mathrm{Br} 5$ and you gave $\mathrm{Br} 10$, you couldn't get the change because they rarely had that much cash flow. You'd have to come back the following day to get your change or you'd have to buy more goods." (SSI32, Somali Region Case Study)

\section{Some of these changes were a result of refugee-related operations, but refugees have also played a crucial role in} transforming the region. Unlike the local rural community, many refugees come from urban backgrounds, originating from cities such as Mogadishu and Baidoa. As part of the broader Somali diaspora, they are able to draw on social networks as well as capital, contributing to increased economic activity in the area. Refugees are more skilled

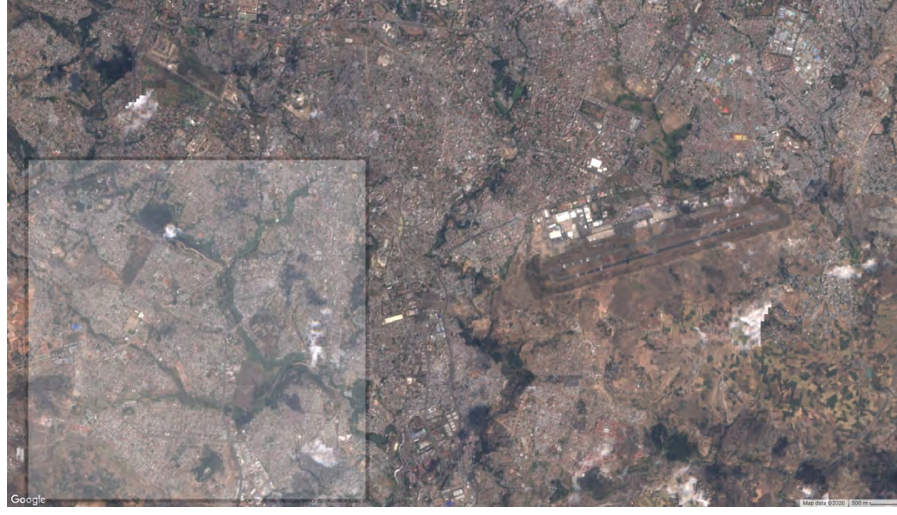

in sectors such as construction, electrical maintenance, and plumbing; have transferred their knowledge to hosts; and provide essential services (KII6, Somali Region Case Study). Local producers have adapted and diversified their production to grow different fruits and vegetables to meet the consumption habits of refugees. Refugees have even been a source of sartorial innovation. As one local business owner points out:

\section{"They have really opened our eyes to new ways of making dresses (dira). Before, the community would all have their clothes tailored the same way. When I see them sometimes, I try to copy their clothing designs." (SSI26, Somali Region Case Study)}

Similar dynamics are visible in the other refugeehosting regions. For instance, before refugees arrived, Bole Michael (in Addis Ababa) was a largely residential area with open tracts of farmland interspersed with low-quality and often unsanitary housing. It has since been transformed into a dynamic commercial area, with many refugees opening guesthouses, shops, and restaurants to support themselves (see figure 5.1). ${ }^{41}$ Refugees

41. The circumstances in Gofa, the other neighborhood where data were collected, are quite different. Gofa Mebrat Hail has long been a lower- to middleclass neighborhood with condominiums, which for a long time provided a less costly housing alternative in Addis Ababa. 
have drawn on diaspora connections to increase trading opportunities and have been the motivation for landlords to construct better housing. In Benishangul-Gumuz, too, the arrival of refugees has been accompanied by substantial investments in the region around Sherkole camp (Benishangul-Gumuz case study). These economic transformations have been mediated by the political context and by distance; places closer to the refugee settlements are more likely to benefit than others. In Gambella, the presence of refugees has spurred economic development in the areas closest to the camps, with greater availability of goods; while urban centers further from the refugee settlements have languished.

Spatial design and geography also matter. Consider Pinyudo I camp, which is divided into two sections. The section closest to Pinyudo town is where the Anywaa refugees are located; it is a 10- to 15-minute drive (in other words, walking distance) from the town. The camp has essentially been absorbed into the town. The second section of the camp hosts Nuer refugees. It is about a 30- to 40-minute drive from Pinyudo town, and the two sections are separated by a stretch of forest. During periods of insecurity, access to town is limited for refugees. Even when they can travel to town, only those able to afford transportation can engage in trade. Economic development that is dependent on trading opportunities for both refugees and hosts decreases in situations of increased insecurity.

Accessing reliable income-earning opportunities is a challenge for both refugees and hosts across the refugeehosting areas, although there are differences between the rural and urban contexts.
Not everyone benefits from these economic transformations. As the next three sections (on livelihoods, remittances, and inflation) demonstrate, it is those who have access to capital or other resources through social networks (whether refugee or host) who are more able to benefit than others.

\section{Livelihoods, Jobs, and Trade}

Refugees are much more likely to make a living through aid than hosts who have other opportunities. Eightythree percent of refugees derive their livelihood from aid, in stark contrast to host populations, who mainly derive their livelihood from agriculture (39 percent), or wages and salaries (28 percent), with one in five occupied in services or the retail industry (see figure 5.2). Among refugees, richer households and households headed by men are slightly more likely to depend on wages and salaries for their livelihood (each group with an estimated 15 percent) than the poorest quintile and women-headed households ( 2 and 4 percent, respectively). With respect to nationality, all groups overwhelmingly depend on aid, except the Somalis: 66 percent of Somali refugees are aiddependent; one in five obtains their livelihood from salaries and wages; and 15 percent earns a livelihood from other sources, including services, retail, and agriculture) (see Pape, Petrini, and lqbal 2018: 31).

\section{Women refugees are less likely to participate in the labor}

force. Few working-age refugees (ages 15-64) are in the labor force, but the gender differences are striking, with most women being classified as inactive (see figure 5.3). This trend is true for all four of the major refugee groups, ranging from 47 percent of South Sudanese refugee women who are inactive and not attending school or college to 72 percent of Eritrean refugee women in the same situation (Pape, Petrini, and lqbal 2018: 32). The implication is that this trend also makes it less likely that refugee women will participate in the labor force in the future. 
Figure 5.2. Sources of Livelihood Currently and Before Displacement

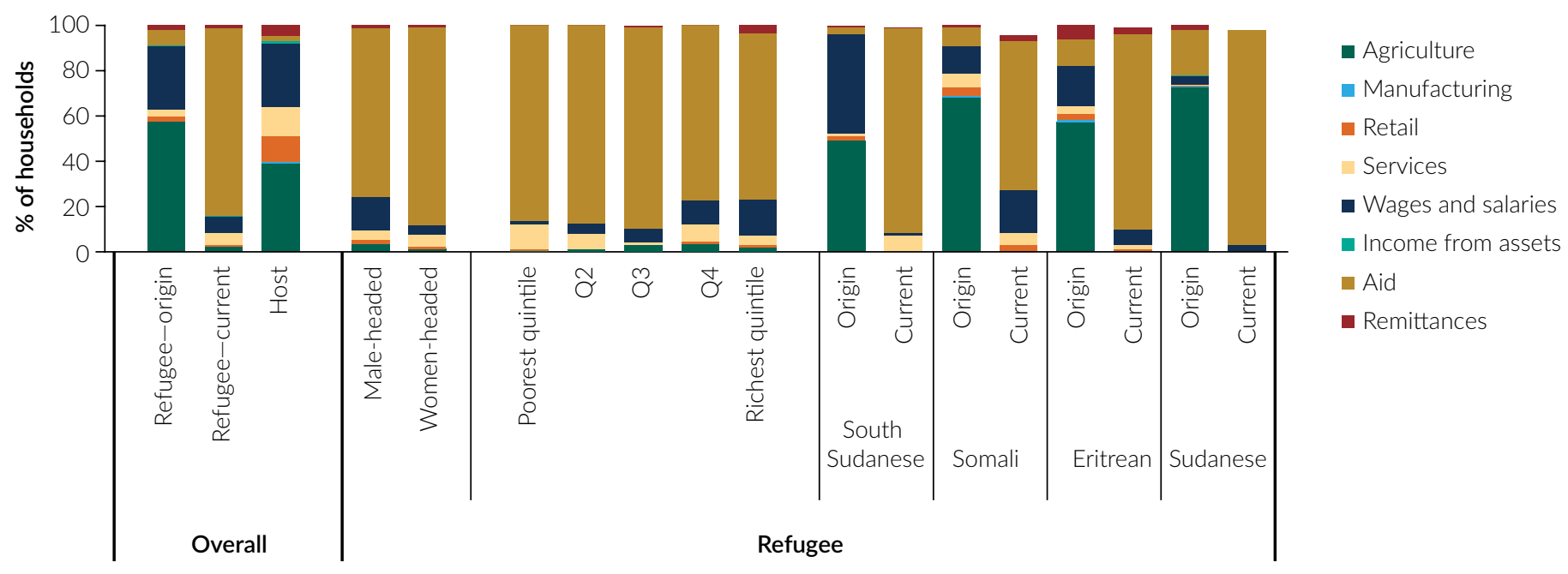

Source: Pape, Petrini, and lqbal 2018.

Figure 5.3. Labor Force Participation and Employment Status

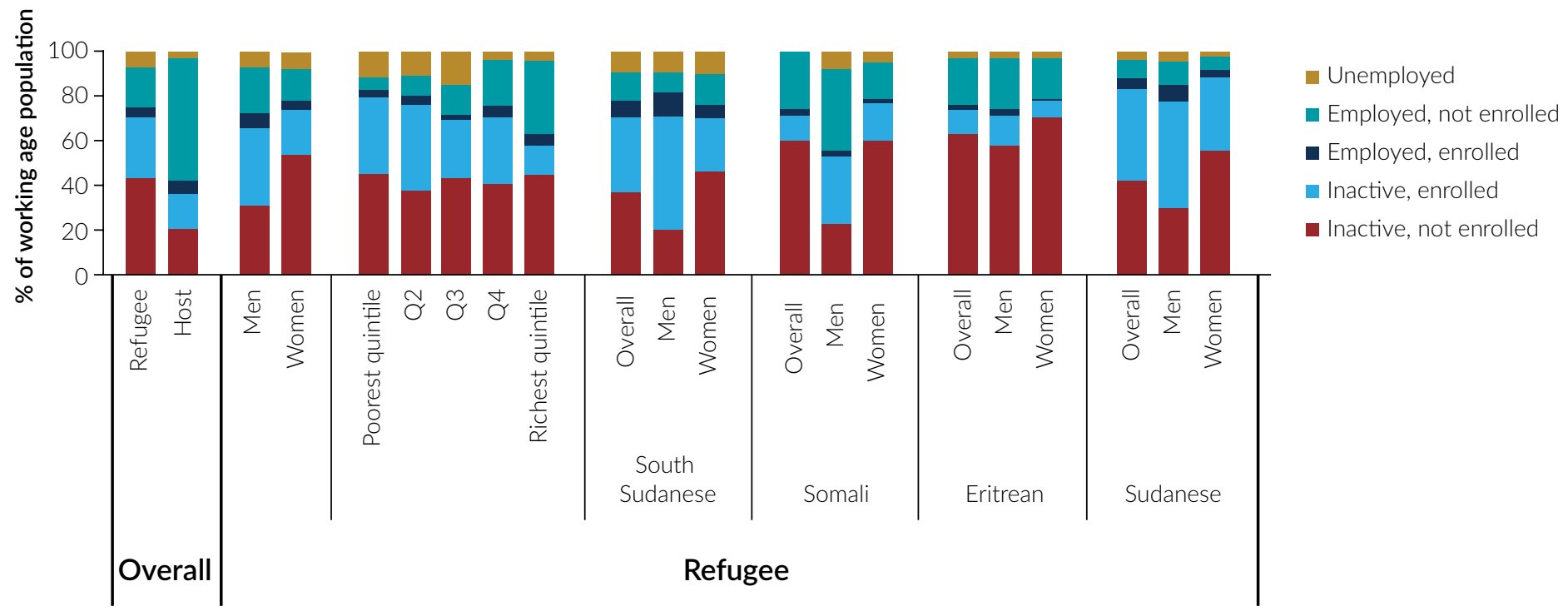

Source: Pape, Petrini, and lqbal 2018. 
Relatively few people in Ethiopia are formally employed, especially in refugee-hosting areas. $^{42}$ As a result, a consistent challenge facing all the groups living in these regions is a lack of reliable income-earning opportunities. ${ }^{43}$ Refugees are especially disadvantaged because the 2004 Refugee Proclamation, which will remain in effect until the 2019 Refugee Proclamation is implemented, prohibits them from taking up most forms of formal employment. Instead, they resort to several different (gendered) strategies to earn livelihoods and income over and above the food aid that they receive.

\section{Somali Region}

In the Somali Region, the local economy relies very heavily on cross-border trade-and refugees and hosts sometimes have complementary economic roles.

Refugees have greater access to capital and have skills that are in high demand, such as construction, decorating, and even tutoring in English, allowing them to earn additional income. On the other hand, hosts have historically been able to travel through the region more easily-particularly to key border trading posts, which allows them to dominate the trading of goods and materials into towns. Refugees therefore tend to partner with hosts to bring products from Wajale (located at the border with Somalia) or from Jigjiga.

In the Somali Region, refugee and

host livelihoods have been historically interdependent. That may be changing, and tensions have emerged around competition for low-skilled jobs such as construction.

42. Only 10 percent of the total number of employed persons in 2013 (when the last labor force survey was conducted) were wage workers. Only 3.9 percent were in rural areas. (See table 5.3; Ronnås and Sarkar 2019: 40).

43. This was recognized by interviewees across all the study sites.
Refugees and hosts commonly start livestock businesses together because the former rely on the latter for access to land. Refugees and hosts with better access to land, capital, and social networks are better able to capitalize on such opportunities.

\begin{abstract}
"The people in the area are ... socially interlinked ... refugees stay at the camp and there are some of them who own small businesses in the camp, these businesses have connections with local businesses in Sheder town. Refugee business owners have no permission to buy goods from Jigjiga or Wajale towns, they depend on what the local people bring in Sheder and then refugees will take goods from them, as second-hand. Host community members are wholesalers and refugees are connected to their stores." (SSI29, Somali Region Case Study)
\end{abstract}

Refugee livelihoods are constrained and highly gendered-but vary widely between the different refugee-hosting areas. Economic precarity contributes to tensions with hosts, for example, due to an increase in deforestation and petty theft.

This dynamic of economic interdependence may be changing. Since being issued identity cards by UNHCR in 2018, refugees have begun to travel more widely across the region. At the same time, a new market has emerged in the refugee camp over the past five years, driven by the demand for goods. This provides refugees with a local market for their daily needs, but also creates competition with the host community's market and undermines host traders' existing business model. Other livelihood strategies involve the trading of food rations or working in lower skilled or unskilled jobs. Some refugee women work 
as domestic workers in the households of local residents, while some refugee men seek out work as daily laborers, especially in the construction sector.

Job scarcity has led to competition over low-skilled jobs, such as those in construction, and even for some comparatively skilled jobs, such as teaching, emerging as a source of tension.

"It causes tension yes, there have been some incidents, some fights in the construction area because they feel that this is a threat to the host community." (KII6, Somali Region Case Study)

Intrahost rivalry also manifests itself in the competition for the highly coveted jobs with humanitarian organizations or nongovernmental organizations (NGOs). Local residents believe that most of these jobs go to highlanders because these positions are recruited at the headquarters in Addis Ababa. A respondent at the community consultation opined:

\begin{abstract}
"There are many graduates from national universities sitting around with no employment opportunities. Organizations are based in Addis Ababa and hire staff from the highlands-Oromos and Amharas and other non-Somalis. There are many employment opportunities in humanitarian organizations. Opportunities are given to people from the highlands. We share this problem with the refugees. Drivers are brought from the highlands where local drivers are not given [a] chance." (CC2.21, Somali Region Case Study).
\end{abstract}

\section{Gambella and Benishangul-Gumuz}

\section{Refugee livelihoods in Gambella and Benishangul-Gumuz are even more constrained than in the Somali Region. In} Gambella, refugees primarily engage in three livelihood activities: (1) cutting down wood or collecting grass for sale; (2) brewing local alcohol; and (3) selling/trading items that they receive in their rations (see Gambella Case Study). Deforestation is a major source of tension with the host community, and refugees are often accused of destroying the environment. For their part, refugees contend that even though they understand the need for environmental protection, they are compelled by their precarity: firewood is both a form of fuel and a source of income that enables refugees to cook and buy goods not found in their rations. ${ }^{44}$ In Itang, the collection of firewood and grass for sale has become increasingly less viable with an increasing refugee population, and refugees also report being increasingly concerned about security threats when they go on these trips. Respondents cite incidents of assault, murder, and rape (see Gambella Case Study; see also Carver, Gebresenbet, and Naish 2018).

\section{Brewing alcohol to sell in local towns is another popular livelihood source for female refugees at all three camps in} Gambella. Even though the activity is taxed in the camps, it allows women to acquire essentials and lets them avoid confrontation with the host community over allegations of deforestation. Refugee women go to Mazoria in Itang or Pinyudo town to sell alcohol to the host community, typically selling 1 liter of alcohol for $\mathrm{Br} 20$. In Itang, host community members capitalize on the limited mobility of refugees and resell the alcohol in other woredas, such as Lare. Female Nuer refugees have been barred from accessing Pinyudo town for the past three years; this form of livelihood is therefore currently only practiced by female Anywaa refugees. Limited mobility due to insecurity has thus had a disproportionate impact on Nuer refugees-who have found their sources of income dwindling. Finally, even the trading of rations has become more challenging after UNHCR decreased the quantity of rations provided to refugees, although some trade does still take place with the host communities.

44. Note that the Anywaa are allowed to cut down trees in Pinyudo, unlike Nuer refugees in Kule and Nguennyiel. 


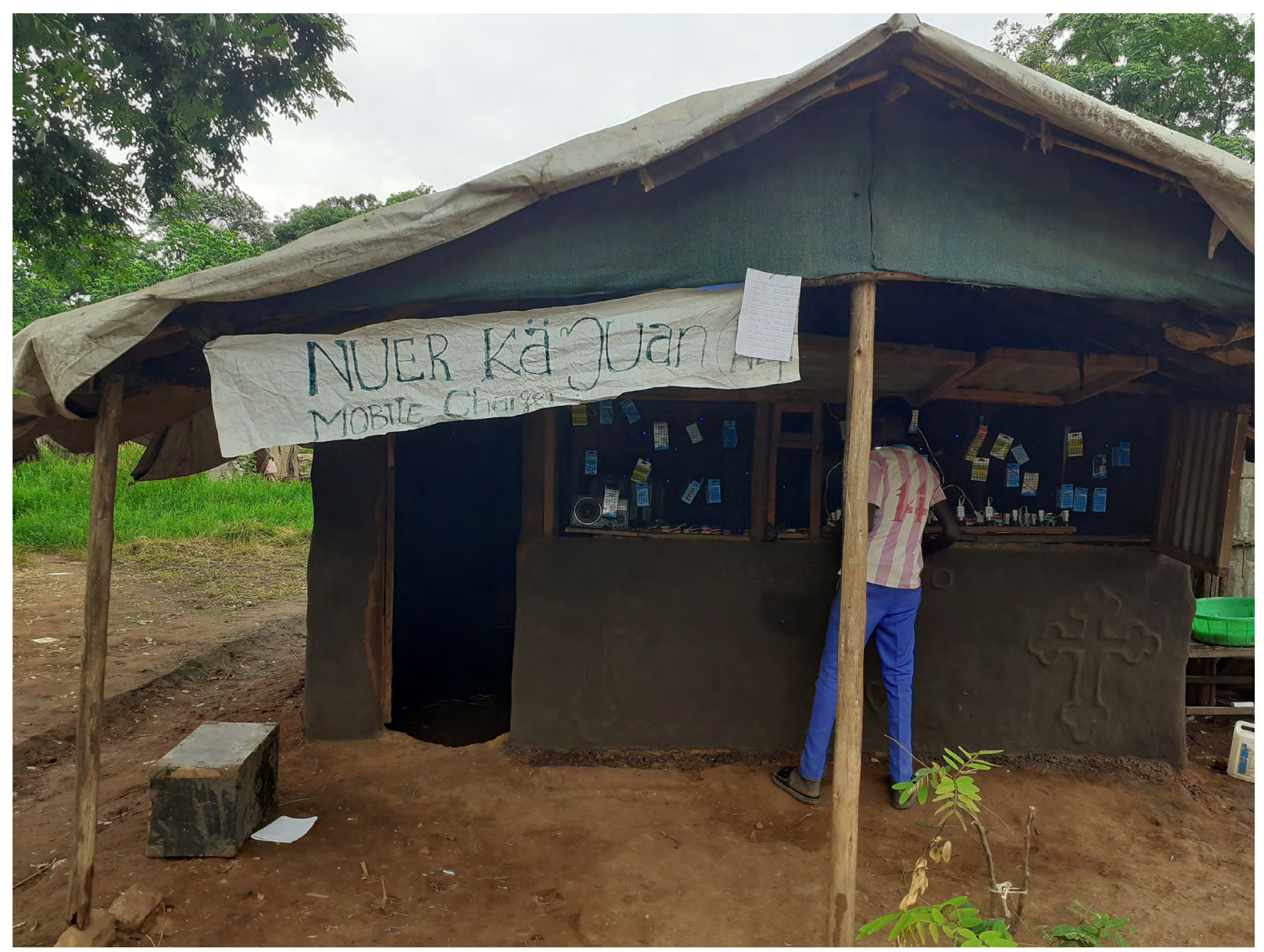

Shop offering power charging facilities in Kule camp, Gambella

Other existing income opportunities in Gambella relate either to the refugee operation through formal employment with ARRA or one of its implementing partners or through trade at economic hubs. Both sectors are dominated by highlanders, who not only are the major traders in the region but who own the majority of shops, restaurants, banks, and commercial buildings, and occupy most positions in UN agencies, NGOs, and federal institutions. Some refugees are able to access small amounts of capital through their social networks to create businesses inside the camps, including small shops which sell goods or provide cell phone or other power-charging facilities. Even fewer refugees engage in cross-border trade for textiles or bracelets. NGOs and ARRA sometimes employ refugees as incentivized workers-as teachers, health workers, and social workers. This scheme is a major point of contention for refugees, even though it provides important livelihood opportunities in the camps' straitened circumstances. This is because refugees are severely underpaid as incentive workers compared with Ethiopian citizens, even if the job and qualifications are the same. Wages are capped at $\mathrm{Br} 700-800$ per month. One interviewee points out: 
"Their (refugees) salaries are $\mathrm{Br} 700$ only. They are paid all equally, it is the same even if you have a masters, even if you are PhD holder. And that is the case for all organizations." (SSI46, Gambella Case Study)

Across the region, members of the indigenous host community (which, to be clear, includes the Nuer and Anywaa as well as others) may have less overall access to economic opportunities than refugees despite having the right to work and own land. Refugees may have greater access to social networks and remittances due to their long histories of displacement and some resettlement programs that have operated in the camps; they also make greater use of the local natural resources, while highlanders dominate the formal economic sector. As a result, some indigenous hosts have found themselves increasingly economically marginalized.

\section{In Benishangul-Gumuz, refugees face similar challenges} as in Gambella, although some earn a living from artisanal gold mining. ${ }^{45}$ For refugees, gold mining is an activity fraught with danger; because refugees are not legally allowed to undertake this work, they are often exploited. Interviewees report being robbed of their earnings by a network of mine owners and local authorities (BenishangulGumuz Case Study). Some refugees also report working as daily laborers for food and wages on local farms or leasing small plots of land from local farmers. Cross-border trade plays an important role in Benishangul-Gumuz; refugees and hosts living in and around Sherkole benefit from it. Hosts, in particular, have access to more dynamic markets in Sudan as a consequence of trade with refugees.

\section{Notwithstanding some localized tensions, refugees and hosts share a largely amicable relationship. This is perhaps} because, unlike Gambella, there is no history of communal animosity that maps onto "refugee" and "host" identities. As a result, there is a great deal of trade between the two groups. Excess demand generated by refugees has

45. All mining in Benishangul-Gumuz is currently artisanal, since large-scale mines in the region have been closed since 2018. benefited local merchants who have seen prices for their goods increase. Further, the NGO sector employs both highlanders and locals, even though highlanders tend to dominate the sector.

Addis Ababa

Refugees are most economically active in Addis Ababa, where, like other regions, refugees and hosts depend on each other for their livelihoods. Nonetheless, refugees struggle to find work and to survive in the city. Since refugees cannot comply with most of the legal requirements for starting businesses or obtain business licenses, they must either enter into partnerships with Ethiopians or pay them to obtain the licenses to start a business, such as an Internet center, a restaurant, or a butcher shop (see Addis Ababa case study). Refugees engage in a range of other livelihoods as well. They run small businesses such as roadside kiosks, beauty salons for women, shoe shops, and other small stores that sell everyday goods. Some work as laborers in urban construction, as nurses in clinics, or as translators assisting others in overcoming language barriers. In Bole Michael, refugees import goods from Somalia, such as specific Somali cultural clothes, cosmetics, perfume, and shoes. ${ }^{46}$ For the most part, however, refugee women report being largely marginalized from economic activities.

Refugees often struggle to negotiate the bureaucratic procedures required for them to earn livelihoods. This is not merely because the legal provisions proscribe the economic participation of refugees: as the narrative in box 5.1 demonstrates, obstacles can emerge from nonuniform implementation of legal provisions. This suggests that the success of the 2019 Refugee Proclamation will depend not only on the content of secondary legislation but also on the ability of government actors and development agencies to coordinate their approaches to implementation.

46. It should be noted that the Somali community in Addis Ababa is not composed primarily of refugees, but the distinction between migrants and refugees is often blurred. 


\section{Box 5.1. A Codependence Underpinned by Legal Status and Bureaucratic Obstacles}

An Eritrean refugee woman explains that even when changes were made to ostensibly increase selfreliance among refugees, poor implementation and bureaucratic confusion made it difficult for her to earn a livelihood. Initially, she worked as a hair stylist in a salon owned by an Ethiopian, but she felt isolated at her workplace. She later heard about new guidelines issued by ARRA for refugees to work or start businesses, but she was unable to negotiate the procedures required to take advantage of the opportunity.

"I don't think most of them are forthcoming in helping you out with your situation as a refugee. Later I tried to open my own hair salon following new guidelines issued by ARRA for refugees to work. Even though I obtained the proper supporting letter from ARRA, when I got halfway through my application, it was denied. Imagine! I wasted time and energy navigating through these bureaucratic offices and got to a dead end. Apparently, the law isn't that clear cut. The laws passed by a certain agency is completely alien to another office. So, when that didn't work out, I had to lease a license from an Ethiopian and that costs a lot of money-you have to bribe your way to get it. That's why most Eritreans stay home all day long-because of this problem, not because they hate work. I have spent a couple of months without a job the first time I got here."

Source: Addis Ababa Case Study.

\section{Remittances and Inflation}

Remittances play a critical role in the lives of refugees, especially in Addis Ababa and the Somali Region. In Gambella and Benishangul, they are less important but still significant. A recent study estimated that 32 percent of Somali refugees and 69 percent of Eritrean refugees in Addis Ababa receive remittances, a "lifeline" to help cope with the cost of living in the city (see Betts et al. 2019a). ${ }^{47}$ On average, more Somali and Eritrean refugees receive remittances than do South Sudanese or Sudanese (Pape, Petrini, and lqbal 2018).

Remittances are seen to have both positive and negative effects, resulting in inequity and inflation but also providing capital for refugee businesses and generating demand for local goods and services. The same applies to financial support from UNHCR. As one respondent notes:

\begin{abstract}
"The refugees use transport, they buy food items from the community, they rent from the local host community. We are useful to the hosts and to the government, thanks to the money we bring."
\end{abstract}

However, some respondents see remittances as encouraging drug and khat use, commonly as part of a narrative that paints refugees as living off others' money while hardworking hosts toil to earn a living. Significantly, even as some hosts blame inflation on remittances, others recognize that remittances received by refugees only play a minor role in the increasing cost of living in the city.

47. These figures are rounded to the nearest percent. 


\section{Box 5.2. Refugees and Addis Ababa's Housing Market}

The presence of refugees in Bole Michael and Gofa Mebrat Hail has resulted in each area becoming a "heaven for landlords," benefiting property brokers at the expense of local residents. Alongside rapid economic growth, refugees are perceived as having contributed to increasing rents, resulting in some hosts

"moving to the suburbs and newly emerged neighborhoods like Bole Arabesa and more peripheral neighborhoods. An individual who earns $\mathrm{Br} 4,000$ monthly salary, must pay $\mathrm{Br} 3,000$ for rent, and the remaining $\mathrm{Br} 1,000$ is not enough for food and transport. Thus, the only option to the individual is to leave Bole Michael and find relatively affordable rent in the suburbs."
In Gofa Mebrat Hail, the willingness of refugees to share accommodations is seen as having contributed to the exorbitant rents in the area.

A housing broker, 36, himself a migrant to the city, told us about how his primary clients were refugees. Brokers play a crucial role in securing access to housing for both hosts and refugees. For refugees, they offer a solution to two major constraints: poor access to information and lack of social networkstwo resources necessary to secure housing in a city struggling to accommodate its residents. At the same time, brokers are seen as agents of gentrification, pushing out locals who cannot afford to match the price that refugees are willing to pay.

Source: Addis Ababa Case Study.
Remittances are seen as having both positive and negative effects. Some see remittances as driving inequity and inflation and fueling khat and alcohol-consumption, while others see them as a source of capital which creates demand for local goods and services.

Remittances are thought to drive inflation through various mechanisms. Those who do focus on refugees and remittances as a source of inflation argue that one cause is a lack of awareness among refugees of the cultural context, which leads them to simply accept inflated prices without negotiating. As one interviewee observes:

\begin{abstract}
"They do not know how to haggle with prices at the market-they simply hand over whatever is asked by the merchant-but again money is remitted to them from abroad, but we haggle with prices at the marketplace. This usually affects prices during the holiday season and the effect isn't exactly the same for both of us." (FGD2.R3, Addis Ababa Case Study)
\end{abstract}

Remittances to refugees may play a role in some localized price increases. The willingness of many Eritrean refugees to share housing is perceived as having contributed to rent increases in Gofa Mebrat Hail (see box 5.2). However, these effects are difficult to disentangle from the broader macroeconomic context in Ethiopia, which has experienced relatively high inflation in recent years, including due to periods of currency depreciation and political turmoil (see Ronnås and Sarkar 2019: 19-20). 
Perceptions of the role played by refugees are important because they shape local attitudes toward refugees and the opportunities refugees have for self-reliance. Poorer hosts and refugees without access to remittances are similarly affected by these inflationary pressures.

The findings from the Somali Region were similar. The arrival of refugees is associated with the opening up of financial services, especially money transfer agents and mobile money services. For many refugees, remittances are the main source of livelihood and capital. Critically, the pattern of remittances received in the region has changed over time: a recent study noted that the volume of remittances around Sheder had fallen substantially, with many refugees having moved or been resettled. While remittances were initially used as capital to fund trade or set up small businesses, in more recent years, the role of remittances has changed to livelihood support, suggesting that those who remain in the camp have far less access to cash. Even in the Somali Region, refugees are seen as driving inflation because they have more money and do not bargain:

\begin{abstract}
"The refugees [have] had a negative impact on the market prices and the destruction of the forest. There are price hikes, for example, the sack of rice or pasta is now much more expensive. 1 kilogram of rice was $\mathrm{Br} 5$, and it is up to $\mathrm{Br} 20$ now. One kilogram of sorghum was $\mathrm{Br}$ 1.50; it is now $\mathrm{Br} 10$. A cup of milk was $\mathrm{Br} 1$, now it is $\mathrm{Br} 15$... Everything went up. [This is because] the refugees are better off in terms of income sources, some get remittances and do not even bargain [over] prices and pay whatever they are told." (SSI27, Somali Region Case Study)
\end{abstract}

\footnotetext{
In Gambella and Benishangul, where remittances play a less important role, those with access to remittances are still better off, able to trade and start small businesses. The presence of refugees and the increased economic dynamism and circulation of goods is associated with
}

increasing prices in both areas, affecting poorer locals, and is indirectly seen as benefiting highlanders at the expense of the indigenous hosts.

\section{Pressures on Land and Environmental Degradation}

Environmental degradation associated with the presence of refugees is a commonly reported theme across the study areas. In Gambella and Benishangul, this is associated with refugees' extremely constrained livelihood opportunities; while in the Somali Region, where camps are not connected to the national electricity grid, refugees are associated with deforestation due to their gathering of wood to provide for lighting, cooking, heating, and sometimes construction needs (see figure 5.4). NGOs have

\section{Figure 5.4. Environmental Degradation Between 2015-20 Around Nguenyyiel Refugee Camp, Gambella}
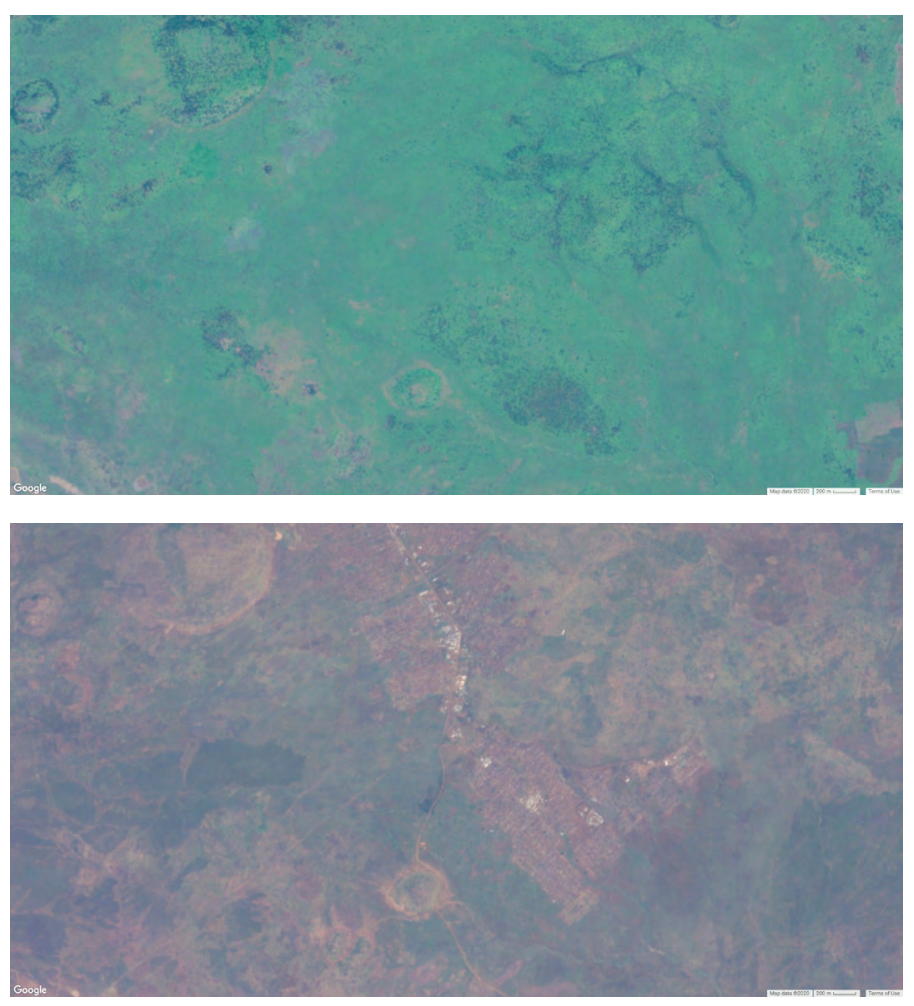

Source: European Union/ESA/Copernicus. 
provided refugee households with cooking gas, but supply is irregular, and refugees argue that they sometimes have no other option than to cut down trees. As in Gambella and Benishangul, this has created tensions between refugees and hosts. Refugees report feeling compelled to gather firewood from any available source, including private farms, despite the risk of violence (Somali Region Case Study). A related issue in Addis Ababa and the Somali Region is environmental degradation due to accumulation of waste around refugee settlements, with local residents calling for projects to rehabilitate the local environment.

Competition over land was reported in each of the study sites, indicating that the land pledge in the new refugee policy is likely to increase social risk. Refugees commonly report wanting greater access to land despite the risk of aggravating existing tensions. In Gambella, the agropastoralist lifestyle of the Nuer is likely to be incompatible with the largely sedentary lifestyle of the Anywaa, and some local residents have already been relocated to make space for the refugee settlements. Tensions around land ownership also have implications for implementing the new refugee policy because one of the pledges relates to making land available to refugees for cultivation. It is unlikely that the pledge can be implemented equally in each of the refugee-hosting areas without causing and/or aggravating local tensions. 


\section{Social Impacts of Displacement}

Existing survey data suggest that refugees and hosts enjoy broadly positive relationships. Only a small proportion (17 percent of refugees and 11 percent of host community members) describe the relationship as negative (see Pape, Petrini, and lqbal 2018). Somalis report having the best relations with host community members, followed by Eritreans and Sudanese, although over 85 percent of all three groups report having generally good relations (see figure 6.1). Among the four largest groups of refugees, South Sudanese are least likely to report good relations, with nearly one in three believing that the relationship is negative.
The social impact on individuals and communities are different in each of refugee-hosting regions; it depends on the specific context of interactions, patterns of settlement, trade, and history, as well as individual markers of identity such as class, age, nationality, ethnicity, and gender.

Figure 6.1. Interpersonal Relationships Between Refugees and Host Communities

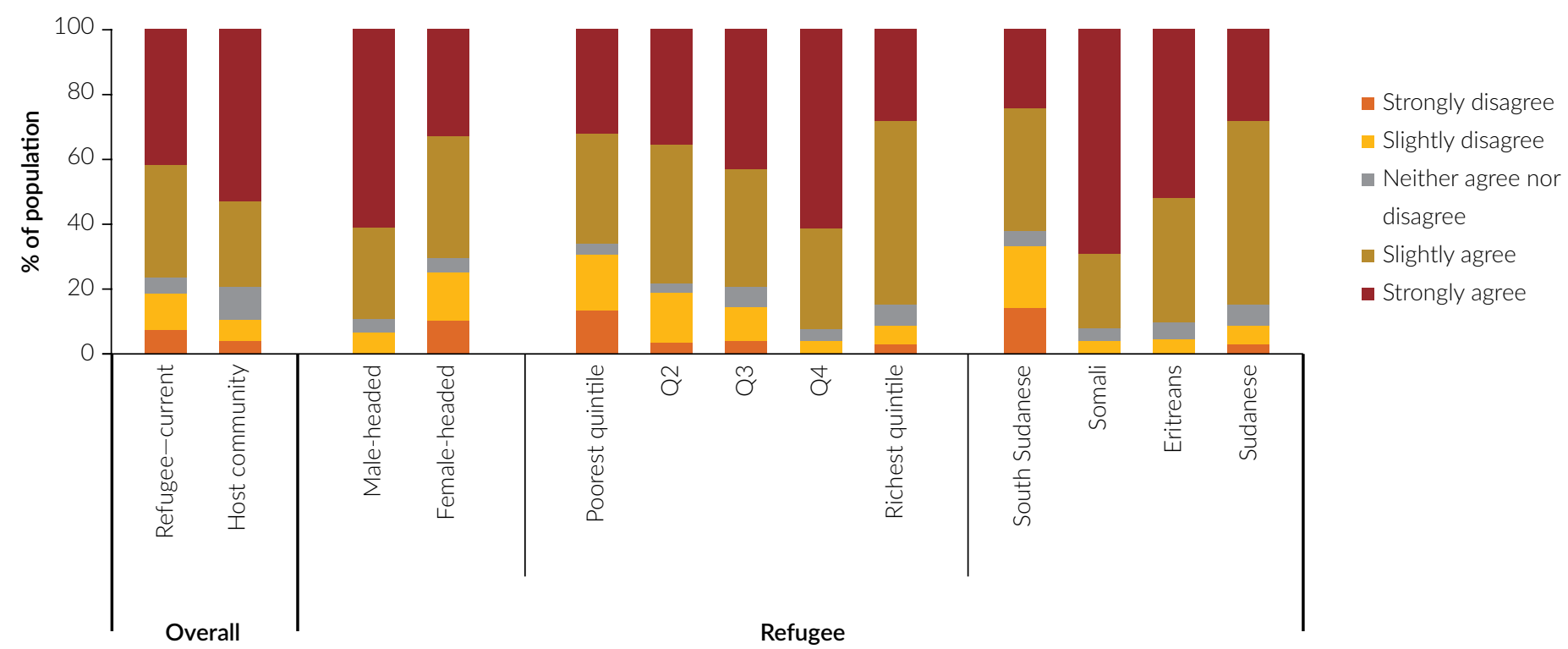

Source: Pape, Petrini, and lqbal 2018. 
Box 6.1. Cultural Proximity in the Somali Region

In the Somali Region, cultural proximity, shared language and religion, and-crucially-long periods of interaction and exchange have helped facilitate peaceful existence among refugees and hosts, despite their different socioeconomic backgrounds. One respondent notes:

"There is no cultural problem since there is no difference between the host and refugee communities in terms of culture, religion, color, and language. They are Somalis. That is why the integration is good ... we also intermarry. I hope as time goes by, this integration will continue and there will no longer be refugees. The people who arrive as refugees but stay a long time become part of the community, and you cannot differentiate unless you ask someone whether they have a refugee card or not. They integrate and they become families. There are children aged 10 who have one host and one refugee as parents."

Source: SSI27, Somali Region Case Study.
These data seem to suggest that common ethnicity determines the degree of social cohesion among groups, but they mask extreme heterogeneity. Across the refugeehosting sites, the social impact on individuals and relationships also depends on the specific context of interactions as mediated by broader structural factors, such as patterns of settlement, trade, and history, as well as individual markers of identity, such as class, age, nationality, ethnicity, and gender.

Refugees and hosts interact most frequently through trade; when accessing services; and during socioreligious activities, which are sometimes structured along gendered lines. Intermarriage is common, including in Gambella, with material and cultural implications. Each study site is characterized by local insecurity and opportunistic theft (which host respondents perceive as being motivated by economic precarity), with only Gambella experiencing more widespread violence. Finally, host community members think the presence of refugees has led to social changes-usually negative, such as the rise of youth gangs-although it is difficult to disentangle whether these have been caused by the presence of refugees or by broader societal changes.

\section{Overall Relationships Between Refugees and Hosts}

Relationships between refugees and hosts are largely amicable, except in Gambella. In Benishangul-Gumuz and in the Somali Region, incidences of community-wide violent conflict between refugees and hosts are rare to nonexistent. A long history of displacement, shared ethnic identity, and shared cultural ties, along with other structural factors, ${ }^{48}$ have fostered some forms of solidarity between the groups (see box 6.1). In Benishangul, the majority of refugees and host community members are proud of the peaceful reputation that Sherkole camp has compared with camps in neighboring Gambella (Benishangul-Gumuz Case Study). ${ }^{49}$

Nevertheless, refugees and hosts sometimes perceive each other negatively. For example, refugees complain about the unwillingness of hosts to lease land to refugees

\footnotetext{
48. It is not only shared ethnicity that creates the conditions for peaceful coexistence; multiple instances of conflict within the same ethnic group were documented during the course of data collection.

49. It is worth noting that refugees from the Democratic Republic of Congo in Benishangul-Gumuz report feeling extremely marginalized due to differences with language, food, and culture, even as they report having generally positive relationships with hosts.
} 
for cultivation and the fact that some hosts act violently toward refugees when they try to work informally as artisanal miners. In the Somali Region, a consultation process helped allay the fears of the local communities, and a ceremony was organized to welcome refugees upon their arrival. Refugees in the Somali Region camps note that they had been warmly welcomed and helped in settling down and starting businesses in the area (Somali Region Case Study).

\section{In Addis Ababa, conflicts exist, but they are mostly between individuals rather than communities. This is} peace as the absence of conflict: some host community members express their disapproval at the lifestyles of some recent refugees, including their frequenting of bars; the inequities created by remittances, which are not thought as being "earned," and the transient nature of refugees' relationships to the city. Refugees in Addis Ababa are seen as temporary residents; and indeed many refugees treat the city as a waystation on their journey to the United States or Europe. These observations are consistent with studies of urban displacement in other African cities that show how refugees and residents create "communities of convenience" (Landau 2018). In Addis Ababa (as in Nairobi and Johannesburg), these communities are also characterized by latent tensions over, for example, refugees being accused of being unsanitary. Such complaints appear largely focused on recent arrivals rather than longstanding community members. As with the other regions, shared cultural, linguistic, and religious ties, as well as a long history of settlement, can help ameliorate potential tensions.

"[T]here is an impact on tranquility and sanitation. They are not accustomed to our waste disposal system. They drop waste materials on the road. They don't put it in the garbage tin. Moreover, they don't participate in communal cleaning initiative. Most of them consider it as if it doesn't concern them." (FGD3, Addis Ababa Case Study)
Even in Gambella, most refugee and host community respondents point out that, during times of peace, the Anywaa and Nuer have positive relations with each other. They trade and visit each other, intermarry, and display forms of solidarity. Insecurity emerges out of a long history of mutual grievances and broader structural factors and processes, including national-level changes and state-level contests over access to resources (Gambella Case Study)..$^{50}$ This, however, varies markedly by area, with the relationships between refugees and hosts particularly troubled in Pinyudo, less so in Itang.

\section{Patterns of Interaction}

Refugees and hosts report predominantly interacting in the context of trade, religious ceremonies, or celebrations, and during social and sports events. Another point of contact is if the two groups share access to social services.

Trade and meetings in the marketplace represent the single most important form of social interaction for refugees and hosts in camp contexts, but it is less important in Addis Ababa. A complex set of relationships have evolved around these economic interactions, including both cooperation and competition in making a profit, as well as the provision of credit by shopkeepers to refugees waiting on remittances or rations. Refugees and hosts alike note that relationships of mutual trust are constructed through repeated exchanges. As a result, insecurity and movement restrictions in Gambella, especially for Nuer refugees in Pinyudo camp, not only result in a loss of economic opportunities but may also exacerbate existing cycles of mistrust. It is likely that implementation of the new refugee proclamation will alter these dynamics, at least over the short term. Depending on the precise formulation of secondary legislation and how it is enforced, competition between the groups may increase, or they may simply interact less often with one another.

50. The regional politics in Gambella also do not necessarily neatly map onto ethnic lines. 
Refugees and hosts interact at religious events and ceremonies across all the study regions. In the Somali Region, the arrival of refugees has resulted in the significant upgrading of religious buildings; while in Gambella, church has become a major site of connection, especially in Itang. Refugees and members of the host community in Itang have held joint prayer conferences, both in Kule camp and Mazoria, which are organized with the permission of ARRA.

"Both communities also interact through religion. They interact through joint prayer programs in the form of [a] conference. Refugees can go to the host community and the host community can also come to Kule here to have conferences in the refugee camp. Church leaders can simply ask for a permission letter from ARRA and join refugees in the refugee camp until their conference is over." (KII11, Gambella Case Study)

The overwhelming majority of the Nuer are Protestant Christians, but refugees celebrate with highlanders on special Orthodox holidays.

"On the occasions of Timkat (Holy Baptism) and Mesqal celebrations, refugees accompany host communities and celebrate with us. Specifically, this year Timkat was special in that many refugees celebrated the festivity until 12:00 a.m. They spent the night dancing and playing alongside the host communities. This indicates that our interaction is very strong and our needs are similar. We eat and drink together. We invite them for food, and they invite us some other day in return." (SSI43, Gambella Case Study)

In all locations, respondents saw sports, notably soccer, as a major forum for interaction. This applied across genders: encouraged by the success of soccer competitions for boys, organizations have started organizing similar games for girls. Refugees and hosts also interact for social events, such as weddings, funerals, and births; through savings associations, including those which help cover costs for funerals and deaths; and by going to integrated schools. Despite these interactions, though, social organizations for refugees and hosts remain separate, with the notable exceptions of the customary dispute resolution mechanisms established in the Somali Region and Unitythe one social organization formed by refugees and Nuer host community members. Unity seeks to promote cohesion between the two groups. It includes leaders from the refugee community who organize cultural celebrations for all four subgroups of Nuer from both refugee and host communities.

Refugees and hosts interact in the course of trade, religious ceremonies, social occasions (weddings, funerals, etc.), sports events, and when they access shared social services. Both groups noted that relationships of trust are constructed through repeated social and material exchanges.

In some locations, women have formed their own associations to address gendered challenges specifically. Near Sherkole camp, women's associations for refugees and hosts have come together to raise awareness about the dangers of child marriage and early pregnancy.

\section{Intermarriage}

Intermarriage is both symbolically and materially important to creating connections between the refugees and the host community. Cases of mixed marriages are found in all research locations, but with clear differences among 
them. The highest number of reported mixed marriages is in the Somali Region, probably the result of common culture, language, and religion. In Jigjiga, participants recounted how intermarriage helped develop stronger bonds between the two communities.

\begin{abstract}
"At the beginning we were a little isolated, after a while, when we stayed here for a while and understood each other, we see people getting intermarried, when marriage happens between us people, we became ... family." (SSI33, Somali Region Case Study)
\end{abstract}

In Gambella, marriages between refugees and hosts from the same ethnic group are common; marriages between the Anywaa and the Nuer are less frequent. There are more cases of Nuer men marrying Anywaa women than Anywaa men marrying Nuer women for several possible reasons, including that Anywaa men lack the cattle needed to pay a dowry and that children born through these intermarriages are more likely to be considered Nuer given the Anywaa's purist sense of lineage. As tensions have increased between the Anywaa and Nuer communities, intermarriages continue but have become more secretive. Within the Anywaa group, Anywaa refugees easily marry Anywaa from the host community without losing their refugee status, and such marriages provide strong economic benefits for refugee men. Meanwhile, in Sherkole, intermarriage mainly happens between Sudanese refugees and the host community because of the common culture. However, there were no reported accounts during the research of refugees from the Congo or the Great Lakes marrying someone from the host community. There are several reported cases of mixed marriage In Addis Ababa, although mostly between refugees and hosts who speak the same language.

\section{Insecurity and gender-based violence} Instances of localized insecurity, including petty theft
and some violence, were noted in each of the study sites. The most significant and widespread issues are in Gambella, where attacks and retaliatory violence structured along ethnic lines has led to a vicious cycle of insecurity. In Itang, diverging conceptions of land and conflict over natural resources, particularly firewood, are the main catalysts for the attacks committed by the Anywaa. Forms of insecurity are deeply gendered as many of the attacks have been committed in forests where women go to collect firewood. ${ }^{51}$ Refugees report instances of killings, assault, and rape, but despite these attacks, cannot avoid the forest-the collection of firewood remains one of their only available forms of livelihood and sources of energy.

Insecurity is deeply gendered. In some cases, it is a direct consequence of economic precarity (petty theft). In other cases, it is a consequence of livelihood choices made by refugees to cope with economic precarity (e.g., firewood collection and artisanal gold mining)

In turn, this has led to closer links between Nuer hosts and Nuer refugees, with Nuer men forming informal militias to patrol the forests around camps.

\footnotetext{
"It is like that on both sides. Anywaa themselves do not sleep at their homes at night. They sleep in the bush because we do not trust each other. At night, you can't be sure you are safe unless you see the daybreak." (FGD28.R1, Gambella Case Study)
}

51. This is also a function of the demographic imbalance at these camps. An assessment of Itang woreda found that 80 percent of the South Sudanese refugees in the area were women (see BDS Center for Development Research 2018). 
Anywaa refugees and the host community also report suffering from frequent attacks committed by Nuer refugees. To mitigate this, the Anywaa host community has pressed for restrictions on the movement of Nuer refugees, who are now barred from accessing Pinyudo town and the surrounding forest. These measures have not been successful in quelling the violence, and certain zones in the Anywaa section of Pinyudo have been abandoned due to insecurity. In fact, hosts and refugees alike suggest that relocation may be the only way to actually end the violence. Given the Anywaa's cultural attachment to land, this provides an insight into how pervasive and debilitating insecurity has become. This will have significant implications for the implementation of the new refugee policy that may include some relaxation of the requirements for encampment and increased access to livelihood opportunities.

The region has also witnessed a significant increase in theft, especially of money, goods obtained from refugee rations, and livestock. Livestock theft is a main source of intraethnic tension within Itang woreda. Cattle are extremely important to the Nuer community for their livelihoods as well as for cultural processes such as marriage. With a large number of young Nuer men in the area seeking to get married, the demand for cattle to be used for dowry is likely to increase, further exacerbating livestock theft within Itang. As a result, the region has also witnessed significant waves of conflict among Nuer subgroups.

Similar forms of petty theft can be observed in Benishangul-Gumuz. Around Sherkole, the increase in theft is usually attributed to increased food insecurity among the refugees, who have seen their rations reduced and sometimes receive them irregularly. The consequence, however, is that theft has become a major point of contention for the refugee and the host communities. Some-but not all-hosts acknowledge and recognize that refugees steal because of their economic precarity.
"We have a good relationship with the refugees but, even so, most of them disturb us with theft. They steal our maize, goats, and all our property. The reason is because the ration is not given to them on time." (FGD38, Benishangul-Gumuz Case Study)

Ration sizes are insufficient. One host community member explains:

"... the food that is given to them is only 7 kilograms. That is not enough for a whole month, and sometimes it is not brought on time. So that is why sometimes they steal things so that they can find something to eat to save their lives." (SSI66, Benishangul-Gumuz Case Study)

Since deforestation (and the struggle over forest resources) is a major issue in Benishangul-Gumuz as well, the forests are perceived as being very insecure. Refugees report facing violent attacks while cutting down wood in the forest; and women from the host community report incidences of rape. Some refugees who try to take part in artisanal mining have also reported being robbed of their earnings.

Theft is not mentioned as an issue in the Somali Region, although firewood collection is a point of tension between refugees and hosts. Most refugees report that the Jigjiga area is largely peaceful, although there have been sporadic acts of violence against refugees. Among the study camps, Aw Barre is thought to be insecure because of the presence of youth gangs in the area, especially in the valley between the camp and the town. This sense of insecurity is greater among women and girls, who are particularly at risk when they walk around the camp collecting firewood. Several women refugees mentioned cases of harassment and rape. 
"The host youth are a big safety issue for us young girls living in the camps. We fear for our lives because they are always hanging around in gangs around the valley. This makes me feel unsafe. There are so many girls who have been chased from the valley when they are going to collect wood." (FGD13, Somali Region Case Study)

This does not only apply to refugees-host community members have also been victimized by some of these groups:

"The insecurity caused by the young violent groups is a general issue; it is not specific to one group-refugees or hosts. They [gangs] are composed of refugees and host communities, and they are harming both sides in the same way." (FGD13, Somali Region Case Study)

This could also be related to the general increase in insecurity after the removal of the former regional president, who was said to have exercised strong, if repressive, control over the region. ${ }^{52}$

In Addis Ababa, the insecurity associated with the political upheaval due to the the national transition was more salient than refugee-host violence, which was mostly individual, not community-wide. In general, tensions between refugees and host groups appear to have increased over time, subsumed within the broader trend of increasing urban crime in Addis Ababa. Women report instances of sexual harassment, but this appears to be connected to gendered insecurity in Bole Michael at night rather than refugee-host dynamics.

\section{Changing Forms of Social Organization and Gender Roles}

In some regions, refugees are associated with societal

change. In the Somali Region, hosts note that the arrival of refugees led to local society becoming more complex. Changes associated with refugees, such as the transformation of Aw Barre into a significant town, also have consequences for safety and security. Referring to the youth gangs mentioned above, one respondent notes:

"[t]hese youth gangs are a new phenomenon here in Aw Barre. We did not have this culture previously, and our youth never acted in groups. You'd always find individuals (youth) who acted alone, but now this is something we have observed. We have some of the host communities who have formed their own gangs, and now as we speak, we have a few of them in jail. These gangs commit all kinds of crimes, and there is also an equally notorious gang from the refugee camp." (FGD12, Somali Region Case Study)

In Gambella, too, urbanization and economic growth associated with the presence of refugees is thought to be responsible for Anywaa youth abandoning their education and seeking opportunities for quickly earning money (Gambella Case Study). 
Displacement is a highly gendered phenomenon. For instance, about 80 percent of the South Sudanese refugees are women and children, with attendant impacts on livelihoods and services. This study thus examines the effect of displacement on gender roles. Most respondents in the study sites refer to the differentiated impacts on men and women with respect to access to services, including health, livelihood opportunities, and the particular marginalization of women. In Benishangul-Gumuz, however, interviewees speak about changes in gender roles associated with the presence of refugees from the Democratic Republic of Congo. Respondents note, for example, that the way Congolese women dress and interact with men is slowly beginning to influence locals (Benishangul-Gumuz Case Study).

Local women also associate improvements in women's education with the presence of refugees. Respondents perceive nongovernmental organizations (NGOs) and international organizations to have raised community awareness of women's rights, child marriage, and early pregnancy. Women from the host community are inspired by the skills brought by refugee women, especially in tailoring. None of this is to suggest that traditional gender roles have been upended: refugee women argue that women are still largely marginalized and relegated to domestic roles. In the Somali Region, too, respondents note that, although livelihoods and jobs are still largely structured along traditional gender lines, women have acquired a greater degree of independence by default, since they have either arrived alone to the camps or have to fend for themselves when men migrated elsewhere in search of livelihoods.

"The change that we are seeing now is that, for example, women, long time ago, we were not allowed to learn, but nowadays there are opportunities for women to go to school. For example, ... even though I am old, I am learning three days a week. Which means in a month I may learn for 12 days." (SSI65, Benishangul Gumuz Case Study) 


\section{Access to Services and Development Responses}

\section{Consistent with the broad picture of access to services} set out in section 4 , host community members at all four research sites perceive refugees as receiving better services than they do. But the impact of displacement on services has two elements. The growth in services in some of the study sites is clearly a consequence of the humanitarian and development response to displacement. At the same time, real and perceived inequities in access to services remain a driver of tension between refugees and hosts, even though it is not the only, or even the most important, source of intercommunity tension in the study areas. The government remains a key actor, especially the Agency for Refugee and Returnee Affairs (ARRA), as well as other agencies such as the police and regional security forces.

\section{Increase in Access to Services as a Response to Displacement}

In each of the study sites, the response to displacement is critical to the expansion of access to services, even though the services themselves are reportedly of uneven quality. In Gambella, for instance, educational opportunities have expanded significantly as a result of NGO intervention. Plan International and the Development and Inter-Church Aid Commission (DICAC) collaborate in the provision of education. Plan provides pre- and primary school education, and DICAC provides secondary school education. In fact, refugees interviewed in Kule and Nguenyyiel refugee camp constantly mentioned education as a crucial service motivating refugees to remain in Ethiopia. Hosts also benefit significantly from these services, with expanded educational opportunities. The World Bank-supported
The presence of refugees is associated with improvement in access to services across the study sites, but there are localized tensions around perceived inequities in access to, and quality of services for refugees and hosts (except in Addis Ababa where integrated public systems are used by both groups).

Development Response to Displacement Impacts Project (DRDIP), in particular, has been credited with improving education services in Pulkot kebele (box 7.1).

Historically, the Sherkole area in Benishangul-Gumuz has been characterized by extremely poor service provision, and the presence of refugees is perceived as having a positive impact. There were no education or health facilities prior to the arrival of the refugees.

"The benefit that we have got from the stay of refugees is that before, our children would walk kilometers to go to school, but when the refugees came here, a school was built for them and one was built for the host community. This is one thing that we have benefited from. The second thing is the health center. The health center here was constructed because of refugees. The third is we were told that if there is a woman that wants to deliver, or a child with a nutrition problem, we have to take them to the refugee health center." (SSI66, BenishangulGumuz Case Study) 
Box 7.1. Development Responses to Displacement

The World Bank's Development Response to Displacement Impacts Project (DRDIP) focuses on addressing the impact of the protracted presence of refugees on host communities in four countries: Djibouti, Ethiopia, Uganda, and Kenya. The project invests in historically underresourced, marginal areas that are hosting refugees by promoting shared prosperity focused on human capital, resilience, income enhancement, and rehabilitated environments.

The effort is based on the perspective that this approach is more holistic and sustainable than a purely humanitarian approach that creates parallel service delivery systems. The DRDIP, by contrast, recognizes the protracted nature of the refugee situation by adopting an area-based, community-driven development approach led by local governments and communities.

Beneficiaries belong to both refugee and host communities. Local communities identify and prioritize investments, meet regularly, discuss outstanding issues, resolve problems, jointly devise solutions, and monitor progress. As a result, all DRDIP investments are directly identified, procured, managed, and used by the intended beneficiaries.
Similar dynamics are observed in the Somali Region, where schools and health services increased dramatically after the arrival of refugees. Addis Ababa is something of an outlier in this regard, pointing to the differences between urban and rural contexts. In Addis Ababa, integrated public systems are used by both refugees and hosts, and both complain about the lack of quality of these systems. Nonetheless, hosts note that the presence of refugees has led to an increase in schools and hospitals in the refugee-hosting areas across the regions.

Despite this expansion of services, some respondents are dissatisfied with some elements of service delivery. In Sherkole, for instance, refugees complain about the state of health centers, the difficulties faced by refugee students in accessing secondary and tertiary education, and the quality of schools compared with camps in neighboring Gambella. In reality, the context of insecurity and constraints on movement in Gambella have made it extremely difficult for Nuer refugees to access secondary education. Similar issues exist for access to health care, with refugees only able to cross over to the Anywaa side of town with escorts.

\section{Inequity in Access}

None of the three types of services provided to refugees-water, education, and health-are fully integrated across the research sites. Even as hosts recognize the role of refugees in the expansion of service delivery, inequities in the quality of services that can be accessed by hosts and refugees remain sources of tension, especially because of the real and perceived environmental, economic, and social pressures associated with hosting refugees. These tensions must be understood within the broader context of inequality and economic deprivation in Ethiopia.

To varying degrees across the research areas, hosts and refugees can access services such as schools, hospitals, and water sources meant for the other group. Numerous interviews speak of host community members obtaining refugee ration cards and accessing rations in a similar way to how Eritrean refugees in Addis Ababa access coupon schemes that allow Ethiopian citizens to obtain subsidized goods. 


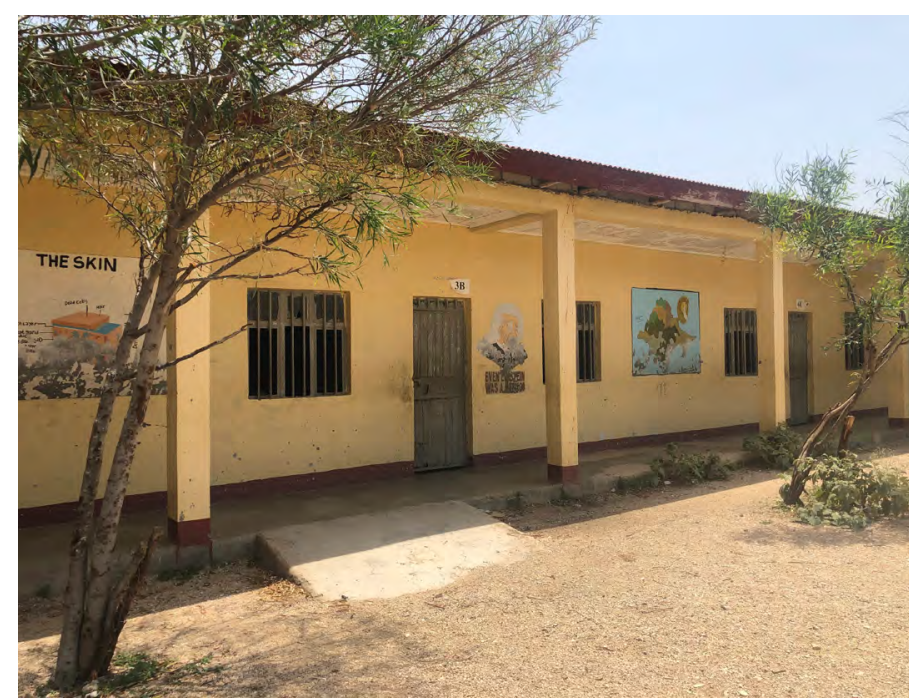

Primary School operated by ARRA, in Aw Barre, Somali Region

\section{Clear inequities in the quality of services, however, can} be a source of grievance. For instance, in Sherkole, locals voice specific dissatisfaction regarding the fact that refugee schools have a feeding center while schools in the host community do not. Members of the host community find this disparity incomprehensible.

\footnotetext{
"They provide exercise books while the host community have no exercise books. So, even sometimes during break time, because they all break at the same time, our children may decide to go through a fence and watch while the refugee children are being fed. We requested several times from the organizations that because we are near the refugees and our children are always watching refugee children feeding ... we also want to be fed, why not
}

also give our children a chance to be fed like the refugee children? We get no reply from the organization because they said this is only for refugee children and the budget is only for the refugees not the host community." (FGD39, Benishangul-Gumuz Case Study)

Across the areas, most members of the host community are aware of the 70/30 services split to be provided to refugees and hosts by development and humanitarian organizations. Although most host respondents believe that they receive 30 percent of services, they do not feel that this is adequate. Further they feel that NGOs favor refugees, especially in the delivery of vocational and skills training. For their part, refugees resent their exclusion from financial services; their inability to access justice delivery mechanisms, especially in Addis Ababa, where refugees do not feel "protected" by ARRA as they are at the camps; and that they are not connected to the national electricity grid. Here again there is a substantial difference between urban and rural contexts: in Addis Ababa, because the system is common to refugees and hosts, improvements and shortages affect both groups equally. Improvements to the electricity supply in Bole Michael are therefore widely praised, while access to water remains uneven in both Bole Michael and Gofa Mebrat Hail.

Context matters. Beyond these broad generalities, the role of service delivery in shaping the relationship between refugees and hosts can only be understood by appreciating extremely localized contextual specificities. If there is a single thread that runs through this report, it is this. 


\section{Policy Implications}

From the perspective of developmental interventionsthe key refugee pledges made by the Ethiopian government are those related to work and livelihoods, including access to land; increased provision of social and basic services; and local integration for protracted refugees. This concluding section points to key implications for policy makers as the new refugee regime takes shape in Ethiopia. These pledge areas are interrelated. As this report has already demonstrated, policies on livelihoods and access to services are closely connected to issues of local integration and security.

\section{Clear consultation and communication with refugees and} hosts is critical. An overarching point emerging from the report is that clear communication and consultations are critical to shaping intergroup dynamics between refugees and hosts. Across the study sites, however, a common finding was that neither refugees nor hosts seem to have a clear sense of what the policy changes under the new refugee proclamation will entail-this should be remedied even as the policy changes take effect.

\section{Work and Livelihoods}

Increasing refugee self-reliance may be at odds with the facilitation of local integration in the study sites. In some areas, increasing self-reliance through expansion of livelihood opportunities, settlement patterns, and access to land will upend the current economic roles and dynamics and lead to a fundamental reconfiguration of economic relationships. In the Somali Region, for instance, the increased ability of refugees to engage in cross-border trade has meant that economic codependence between refugees and hosts has decreased and resulted in increased, although still relatively amicable, competition over trade.
There may be increased competition for lower-skilled jobs. There are relatively few formal employment opportunities in the refugee-hosting areas. As a result, there is already significant competition among different groups of hosts for the highly coveted jobs with humanitarian organizations and nongovernmental organizations (NGOs), and between refugees and hosts for jobs in sectors such as construction (as in the Somali Region) or tutoring. These tensions are exacerbated by perceived discrimination between refugees and hosts, and between "indigenous hosts" and "highlanders" in the hiring and payment policies of humanitarian and development agencies. Some of these tensions could be somewhat mitigated by ensuring that both refugees and hosts receive equitable livelihood training and, if the legal regime permits, by restructuring hiring practices in the areas. Humanitarian and development agencies need to be mindful of the local context and dynamics while making staffing decisions.

Giving refugees access to land for cultivation may exacerbate competition for land, especially in Gambella but also to some extent in Benishangul-Gumuz. ${ }^{53}$ The history of conflict around access to land in those areas means that the pledge related to making irrigable land available to refugees (and others) will require carefully calibrated responses, which may include a phased rollout of policies (perhaps starting with the Somali Region) and targeted support programs for economically marginalized groups. The risks of such a policy are that it could exacerbate regional inequalities and rivalries and possibly intensify intraelite competition. There is a case for an especially calibrated response in Gambella, given its specific history of conflict and violence, which could include a much

53. Implementation of this pledge currently appears focused on the Dollo Ado area of the Somali Region. 
broader and political consultation process to help defuse existing tensions.

Refugees and hosts across all study sites have pointed out that creating greater and more extended opportunities for interaction and exchange is likely to help build intergroup trust. The new refugee policies could be implemented with a view toward facilitating such connections, especially intercommunity trade, which is how refugees and hosts most commonly interact.

Constraints on refugee livelihoods have exacerbated localized conflict and insecurity. In turn, conflict and insecurity have negatively affected livelihoods. In Gambella, for instance, a lack of livelihood opportunities, combined with a lack of access to fuel sources, has led to environmental degradation as refugees have sought to access resources from forests. This has aggravated intercommunity tensions. Policy responses, such as cutting off refugees' access to the forest-a site where attacks often occur-without creating alternate livelihood opportunities, could lead to other maladaptive livelihood choices.

Facilitating refugee livelihoods will require government agencies and development actors to act together. Legislative changes are will likely be only the first step toward transforming the current refugee regime. Giving full effect to such changes will require significant coordination between and across government agencies as refugees and hosts seek to navigate complex bureaucratic procedures around starting businesses, obtaining permits, and accessing credit, among other concerns.

\section{Provision of services}

Increased and improved access to services as well as the pledges related to expanding educational opportunities remain critical areas for policy intervention. Across the study sites, the presence of refugees is credited with an expansion in access to services, particularly educational institutions and health facilities. None of the three types of services provided to refugees-water, education, and health-are fully integrated across the study sites, even though hosts and refugees can, to some extent, access services meant for the other group. Clear inequities in the provision or quality of services can be a source of grievance for both groups-and is the single clearest area for continued developmental involvement and intervention. Research in Addis Ababa, where refugees access public services, albeit in much lower numbers than in rural camp settings, suggests that integrated systems could reduce perceived inequities and grievances around differential access to services.

Refugees would like greater access to justice delivery mechanisms, electricity, and financial services; in a similar vein, hosts do not believe that they have adequate access to services. These are possible areas of intervention that could also have implications for intergroup relations and local integration. Lack of access to electricity, for instance, is one reason why refugees have sought to use forest resources as fuel or for cooking. Improving their access to electricity could help slow environmental degradation and positively impact refugee-host relationships. Refugees are also excluded from social protection services in Ethiopia, although it may be difficult to extend these to refugees unless all eligible hosts are also covered.

Shared services facilitate social interaction between refugees and hosts and can be a factor in improving intergroup relationships. Across the study sites, respondents note that hosts and refugees interact in the course of accessing common services, and that this led to better relationships between the two groups-especially among children who attend school together (with exceptions). This has implications for moving toward more integrated service delivery under the new refugee proclamation. 


\section{Local Integration}

Local integration involves three interrelated processes.

There is a legal process through which refugees attain a wider range of rights in the host state, an economic process of establishing sustainable livelihoods, and a process of social and cultural adaptation in the host country (ReDSS 2018). Each of these processes is closely related to the implementation of the other pledge areas.

The legal frameworks that would relate to local integration have yet to be elaborated. Refugees are notably enthusiastic about the prospects of increased mobility, as well as increased access to livelihoods, but there is greater ambivalence around losing their legal status, especially if they believe that their chances of resettlement would likely be affected. In Addis Ababa, for instance, many refugees note that they view the city as a point of transit as they wait to move elsewhere. From a policy perspective, this could mean that there is a need to craft policies that allow for multiple degrees and forms of integration.
There are clear differences between the contexts within which integration might take place. Among the study areas, the context for local integration is most conducive in the Somali Region, followed perhaps by Addis Ababa, and then perhaps to a lesser extent, Benishangul-Gumuz. The context for integration is most fraught in Gambella, where both refugees and hosts note that relocation of refugees might be the only possible response.

Policies need to be sensitive to the particular "winners" and "losers" created by displacement. It is critical that some policies specifically target the group with the lowest access to resources and social networks, whether refugee or host. This could take the form of a differentiated rollout of the pledges in the different areas or area-based development programming driven by community-based needs assessments. More generally, the needs of refugees and displacement-affected communities must be integrated into national and local government development planning, something which is not currently taking place. 


\section{References}

Abbink, Jon. 2011. "Ethnic-based Federalism and Ethnicity in Ethiopia: Reassessing the Experiment after 20 years." Journal of Eastern African Studies 5 (4): 596-618.

Africa Watch. 1991. Evil Days: 30 Years of War and Famine in Ethiopia. Africa Watch. https://www.hrw.org/sites/default/files/ reports/Ethiopia919.pdf.

Alix-Garcia, Jennifer, and David Saah. 2010. "The Effect of Refugee Inflows on Host Communities: Evidence from Tanzania." The World Bank Economic Review 24 (1): 148-170.

Ambroso Guido. 2002a. "Clanship, Conflict and Refugees: An Introduction to Somalis in the Horn of Africa." https:// pdfs.semanticscholar.org/9770/bd0979b9622bf-

74b0659043af1488640f5e8.pdf.

Ambroso, Guido. 2002b. Pastoral Society and Transnational Refugees: Population Movements in Somaliland and Eastern Ethiopia. New Issues in Refugee Research, Working Paper 65. Brussels: UNHCR.

Bakewell, Oliver. 2010. "Some Reflections on Structure and Agency in Migration Theory." Journal of Ethnic and Migration Studies 36 (10): 1689-708.

Bariagaber, Assefaw. 2012. "Nationalist, Sub-nationalist, and Region-wide Narratives and the Quest for Integration-promoting Narratives in the Greater Horn Region." In Regional Integration, Identity and Citizenship in the Greater Horn of Africa, Kidane Mengisteab and Redie Bereketeab (eds.), 111-32. Oxford: James Currey (an imprint of Boydell and Brewer).
Bayissa, Regassa. 2010. War and Peace in the Sudan and its Impact on Ethiopia: The Case of Gambella, 1955-2008. Addis Ababa: Addis Ababa University Press.

BDS Center for Development Research. 2018. "Development Response to Displacement Impacts Project (DRDIP): Baseline Survey Findings at Woreda and Kebele Level." Mimeo.

Benveniste, Emile. 1973. Indo-European Language and Society. Translated by Elizabeth Palmer. Coral Gables, FL: University of Miami Press.

Berhe, Mulugeta Gebrehiwot. 2020. Laying the Past to Rest: The EPRDF and the Challenges of Ethiopian State-Building. London: Hurst and Co.

Berhe, Mulugeta Gebrehiwot, and Fiseha Haftetsion Gebresilassie. 2017. "The Norms and Practices of Nationalism and Selfdetermination in Contemporary Ethiopia." Paper presented at workshop on Nationalism and Self-determination in the Horn of Africa, Cambridge, UK, February. Mimeo.

Berry, Leah. 2008. The Impact of Environmental Degradation on Refugee-Host Relations: A Case Study from Tanzania. New Issues in Refugee Research, Research Paper 151. Geneva: UNHCR. https:// www.refworld.org/pdfid/4c2325620.pdfhttp://www.refworld.org/ pdfid/4c2325620.pdf.

Betts, A., L. Bloom, J. Kaplan, and N. Omata. 2014. Refugee Economies: Rethinking Popular Assumptions. Oxford: Refugee Studies Centre, University of Oxford. https://www.rsc.ox.ac.uk/ files/files-1/refugee-economies-2014.pdf. 
Betts, A., L. Fryszer, N. Omata, and O. Sterck. 2019a. Refugee Economies in Addis Ababa: Towards Sustainable Opportunities for Urban Communities? Oxford: Refugee Studies Centre, University of Oxford. https://www.rsc.ox.ac.uk/publications/refugee-economies-in-addis-ababa-towards-sustainable-opportunities-for-urban-communities.

Betts, A., R. Bradenbrink, J. Greenland, N. Omata, and O. Sterck. 2019b. Refugee Economies in Dollo Ado: How Somalis Use Aid and the Cross-Border Economy. Oxford: Refugee Studies Centre, University of Oxford. Center, University of Oxford. https://www. rsc.ox.ac.uk/publications/refugee-economies-in-dollo-ado-development-opportunities-in-a-border-region-of-ethiopia.

Block, Karen, Deborah Warr, Lisa Gibbs, and Elisha Riggs. 2013. "Addressing Ethical and Methodological Challenges in Research with Refugee-Background Young People: Reflections from the Field." Journal of Refugee Studies 26 (1): 69-87.

Boswell, Alan, Nanaho Yamanaka, Aditya Sarkar, and Alex de Waal. 2019. The Security Arena in South Sudan: A Political Marketplace Study. December. London: London School of Economics and Political Science and Medford, MA: World Peace Foundation. http://eprints.Ise.ac.uk/id/eprint/102894.

Brown, Alison, Peter Mackie, Kate Dickenson, and Tegegne GebreEgziabher. 2018. Urban Refugee Economies: Addis Ababa, Ethiopia. Working Paper. London: International Institute for Environment and Development.

Carver, Freddie, Ahmed Ali Gedi, and Dominic Naish. 2018. "Somali Regional Report: Refugee and Host Community and Context Analysis." Mimeo. ODI and Danish Refugee Council, London and Addis Ababa.

Carver, Freddie, Fana Gebresenbet, and Dominic Naish. 2018. "Gambella Regional Report: Refugee and Host Community and Context Analysis." Mimeo. London and Addis Ababa: ODI and DRC.
Carver, Freddie, James Chienien, Santino Atem Deng, Yotam Gidron, Duol Ruach Guok, Nicki Kindersley, Bichok Wan Kot, Sara Maher, Jedeit J. Riek and Gatwech Wal. 2020. 'No one can stay without someone': Transnational networks amongst the Nuer-speaking peoples of Gambella and South Sudan. London: Rift Valley Institute. http://riftvalley.net/sites/default/files/publication-documents/ No\%20one\%20can\%20stay\%20without\%20someone\%20-\%20 RVI\%20Report\%20\%282020\%29.pdf.

Central Statistical Agency, 2014. Analytical Report on the 2013 National Labour Force Survey, Statistical Bulletin. Addis Ababa: Central Statistical Agency, Federal Democratic Republic of Ethiopia.

Chambers, Robert. 1986. "Hidden Losers? The Impact of Rural Refugees and Refugee Programs on Poorer Hosts." International Migration Review 20 (2): 245-63.

Clapham, Christopher. 2002. "Controlling Space in Ethiopia." In Remapping Ethiopia: Socialism and After, edited by Wendy James, Donald Donham, Eisei Kurimoto, and Alessandro Triulzi, 9-32. James Currey: Oxford.

-_-. 2018. "The Ethiopian Developmental State." Third World Quarterly 39 (6): 1151-65.

--_. 2019. "The Political Economy of Ethiopia from the Imperial Period to the Present." In The Oxford Handbook of the Ethiopian Economy, edited by Fanta Cheru, Christopher Cramer and Arkebe Oqubay, 33-47. London: Oxford University Press.

Crisp, Jonathan. 1999. "Who Has Counted the Refugees?" UNHCR and the Politics of Numbers. New Issues in Refugee Research Working Paper 12, Geneva: UNHCR. https://www.refworld.org/ pdfid/4ff58e4b2.pdf.

da Rugna, Daniela. 2005. "Movement of Somali Refugees and Asylum Seekers and States' Responses Thereto." Mimeo. Addis Ababa: United Nations UNHCR. 
Davison, William, and Mistir Sew. 2018. "Turmoil Blocks Aid as Communal Conflict Rages in Gold-Seamed Benishangul Gumuz." Ethiopia Insight, November 18. https://www.ethiopia-insight. com/2018/11/16/turmoil-blocks-aid-as-communal-conflict-rages-in-gold-seamed-benishangul-gumuz/.

de Waal, Alex. 2015. The Real Politics of the Horn of Africa: Money, War and the Business of Power. Cambridge: Polity.

--- . 2018. Mass Starvation: The History and Future of Famine. Cambridge: Polity.

Deardorff Miller, Sarah. 2018. "Assessing the Impacts of Hosting Refugees." World Refugee Council Research Paper 4. Waterloo, ON: Centre for International Governance Innovation. https:// www.cigionline.org/sites/default/files/documents/WRC\%20 Research\%20Paper\%20no.4.pdf.

Donham, Donald, and Wendy James. 2002. The Southern Marches of Imperial Ethiopia: Essays in History and Social Anthropology. Oxford: James Currey; Athens, Ohio: Ohio University Press.

Fearon, James, and David Laitin. 2000. "Violence and the Social Construction of Social Identity." International Organization 54 (4): $845-77$.

Feyissa, Dereje. 2006. "The Experience of Gambella Regional State." In Ethnic Federalism: The Ethiopian Experience in Comparative Perspective, David Turton (eds.), 208-230. Oxford: James Currey; Athens, $\mathrm{OH}$ : Ohio University Press; Addis Ababa: Addis Ababa University Press.

---. 2010. "The Cultural Construction of State Borders: The View from Gambella." Journal of Eastern African Studies 4 (2): 314-30.

---. 2011. "The Political Economy of Salt in the Afar Regional State in Northeast Ethiopia." Review of African Political Economy 38 (127): $7-21$.
-_-. 2013. "Alternative Citizenship: The Nuer between Ethiopia and the Sudan." In The Borderlands of South Sudan: Authority and Identity in Contemporary and Historical Perspectives, edited by Christopher Vaughan, Mareike Schomerus, and Lotje de Vries, 109-31. London: Palgrave-Macmillan.

--_. 2015. "Power and Its Discontents: Anywaa's Reactions to the Expansion of the Ethiopian State, 1950-1991." The International Journal of African Studies 48 (1): 31-49.

Feyissa, Dereje, and Dawud Mohamed. 2018. "Afar Regional Report: Refugee and Host Community Context Analysis." Mimeo. London and Addis Ababa: ODI and DRC.

GoE (Government of Ethiopia). 1984. 1984 Population and Housing Census of Ethiopia. Addis Ababa: Office of the Population and Housing Census Commission, Government of Ethiopia. http:// www.csa.gov.et/census-report/complete-report/census-1984.

---. 2007. 2007 Population and Housing Census of Ethiopia. Addis Ababa: Central Statistical Agency, Government of Ethiopia. http://www.csa.gov.et/census-report/complete-report/ census-2007.

Guyatt, Helen, Jenny Spencer, Flavia Della Rosa, Sophie Turnbull, and Matthew Klick. 2018. Evaluation of the UNICEF Ethiopia BSRP: Baseline Study Report. Nairobi: Kimetrica and UNHCR.

Hagmann, Tobias. 2014a. Talking Peace in the Ogaden: The Search for an End to Conflict in the Somali Regional State in Ethiopia. London: Nairobi: Rift Valley Institute. https://riftvalley.net/ publication/talking-peace-ogaden.

Hagmann, Tobias. 2014b. "Punishing the Periphery: Legacies of State Repression in the Ethiopian Ogaden." Journal of Eastern African Studies 8 (4): 725-39.

Hagmann, Tobias. 2020. "Jigjiga's Autocratic Modernity." Conflict Research Programme (blog), February 6. https://blogs.Ise.ac.uk/ crp/2020/02/06/jigjigas-autocratic-modernity/. 
Hagmann, Tobias, and Alemmaya Mulugeta. 2008. "Pastoral Conflicts and State-Building in the Ethiopian Lowlands." Afrika Spectrum 43 (1): 19-38.

Hagmann, Tobias, and Finn Stepputat. 2016. Corridors of Trade and Power: Economy and State Formation in Somali East Africa. DIIS Working Paper 8. DIIS, Copenhagen. https://pure.diis.dk/ws/ files/624676/DIIS_WP_2016_8.pdf.

Hagmann, Tobias, and Mustafe Mohamed Abdi. 2020. "Interethnic Violence in Ethiopia's Somali Regional State, 2017-2018." Conflict Research Programme Research Memo. London School of Economics and Political Science. http://www.Ise.ac.uk/international-development/Assets/Documents/ccs-research-unit/ Conflict-Research-Programme/crp-memos/Inter-ethnic-conflictsSRS-Final-April-2020.pdf.

Hammond, Laura. 2004. This Place Will Become Home: Refugee Repatriation to Ethiopia. Ithaca and London: Cornell University Press.

---. 2008. "Strategies of Invisibilization: How Ethiopia's Resettlement Programme Hides the Poorest of the Poor." Journal of Refugee Studies 21 (4): 517-36.

---. 2014. History, Overview, Trends and Issues in Major Somali Refugee Displacements in the Near Region. New Issues in Refugee Research, Research Paper 268. Geneva: UNHCR. https://www. unhcr.org/en-us/research/working/5310b0159/history-overview-trends-issues-major-somali-refugee-displacements-near. html.

Hassen, Mohammed. 1990. The Oromo of Ethiopia: A History, 1570-1860. Cambridge, UK: Cambridge University Press.

Holcombe, Bonnie, and Sisai Ibssa. 1990. The Invention of Ethiopia: The Making of a Dependent Colonial State in Northeast Africa. Trenton, NJ: Red Sea Press. https://www.hrw.org/sites/default/ files/reports/ethiopia0112webwcover_0.pdf.
ICG (International Crisis Group). 2009. Ethiopia: Ethnic Federalism and its Discontents. Africa Report 153, September 4. Brussels: International Crisis Group.

Jacobsen, Karen. 2002. "Can Refugees Benefit the State? Refugee Resources and African Statebuilding." The Journal of Modern African Studies 40 (4): 577-96.

Jacobsen, Karen, and Loren B. Landau. 2003. "The Dual Imperative in Refugee Research: Some Methodological and Ethical Considerations in Social Science Research on Forced Migration." Disasters 27 (3): 185-06.

James, Wendy. 2013. "Whatever Happened to the "Safe Havens"? Imposing State Boundaries between the Sudanese Plains and the Ethiopian Highlands." In The Borderlands of South Sudan: Authority and Identity in Contemporary and Historical Perspectives, edited by Christopher Vaughan, Mareike Schomerus, and Lotje de Vries, 213-33. London: Palgrave-Macmillan.

JRS (Jesuit Refugee Service). 2005. "Ethiopia: Forced relocation to Sherkole Camp." JRS. https://reliefweb.int/report/ethiopia/ ethiopia-forced-relocation-sherkole-camp.

Kibreab, Gaim. 1991. The State of the Art Review of Refugee Studies in Africa. Uppsala Papers in Economic History 26. Uppsala: Uppsala University.

--_. 2009. Eritrea: A Dream Deferred. Oxford: James Currey.

Labzae, Mehdi. 2019. "Benishangul Conflict Spurred by Investment, Land Titling, Rumours." Ethiopia Insight, March 8. https://www.ethiopia-insight.com/2019/03/08/ benishangul-conflict-spurred-by-investment-land-titling-rumors/.

Landau, Loren. 2003. "Beyond the Losers: Transforming Governmental Practice in Refugee-Affected Tanzania." Journal of Refugee Studies 16 (1): 19-43. 
---. 2004. "Challenge without Transformation: Refugees, Aid and Trade in Western Tanzania." Journal of Modern African Studies 42 (1): 31-59.

--_. 2014. "Urban Refugees and IDPs." In The Oxford Handbook of Refugees and Forced Migration Studies, edited by Elena FiddianQasmiyeh, Gil Loescher, Katy Long, and Nando Sigona, 139-49. Oxford: Oxford University Press.

-_-. 2018. "Friendship Fears and Communities of Convenience in Africa's Urban Estuaries: Connection as Measure of Urban Condition." Urban Studies 55 (3): 505-21.

Lindley, Anna. 2010. "Leaving Mogadishu: Towards A Sociology of Conflict-related Mobility." Journal of Refugee Studies 23 (1): 2-22.

-_-. 2013. "Displacement in Contested Places: Governance, Movement and Settlement in the Somali Territories." Journal of Eastern African Studies 7 (2): 291-313.

Mallett, Richard, Jessica Hagen-Zanker, Nassim Majidi, and Clare Cummings, with Georgina Sturge, Kourtnie Schaefer, and Pauline Vidal. 2017. Journeys on Hold: How Policy Influences the Migration Decisions of Eritreans in Ethiopia. Working Paper 506. London: ODI. https://www.odi.org/publications/10728-journeys-hold-how-policy-influences-migration-decisions-eritreans-ethiopia.

Markakis, John. 2011. Ethiopia: The Last Two Frontiers.

Woodbridge, Suffolk; Rochester, N.Y.: James Currey.

Maxwell, Daniel G., and Majid, Nisar. 2016. Famine in Somalia: Competing Imperatives, Collective Failures, 2011-12. New York:

Oxford University Press.

Meckelburg, Alexander. 2014. "Large Scale Land Investments in Gambella, Western Ethiopia: The Politics and Policies of Land." In A Delicate Balance: Land Use, Minority Rights and Social Stability in the Horn of Africa. Addis Ababa: Institute of Peace and Security Studies, Addis Ababa University.
Milner, James. 2016. When Norms are Not Enough: Understanding the Principle and Practice of Burden and Responsibility Sharing for Refugees. Global Leadership and Cooperation for Refugees Series Paper 2. December. Waterloo, ON: Centre for International Governance Innovation. https://www.cigionline.org/sites/default/ files/documents/Refugee\%20Paper\%20no2web_3.pdf.

Moreda, Tsegaye. 2017. "Large-Scale Land Acquisitions, State Authority and Indigenous Local Communities: Insights from Ethiopia." Third World Quarterly 38 (3): 698-716.

Nigusie, Alemu Asfaw, and Freddie Carver. 2019. The Comprehensive Refugee Response Framework: Progress in Ethiopia. Humanitarian Policy Group Working Paper, September. London: Overseas Development Institute. https://www.odi.org/sites/odi. org.uk/files/resource-documents/12941.pdf.

Pape, Utz Johann, Benjamin Petrini, and Syedah Aroob lqbal. 2018. Informal Durable Solutions by Micro-Data: A Skills Survey for Refugees in Ethiopia. Washington DC: World Bank. http:// documents.worldbank.org/curated/en/996221531249711200/ Informing-durable-solutions-by-micro-data-a-skills-survey-forrefugees-in-Ethiopia.

Planel, Sabine, and Marie Bridonneau. 2017. "(Re) Making Politics in a New Urban Ethiopia: An Empirical Reading of the Right to the City in Addis Ababa's Condominiums." Journal of Eastern African Studies 11 (1): 24-45.

Polzer, Tara, and Laura Hammond. 2008. "Invisible Displacement." Journal of Refugee Studies 21 (4): 417-31.

Porter, Gina, Kate Hampshire, Peter Kyei, Michael Adjaloo, George Rapoo, and Kate Kilpatrick. 2008. "Linkages between Livelihood Opportunities and Refugee-Host Relations: Learning from the Experiences of Liberian Camp-Based Refugees in Ghana." Journal of Refugee Studies 21 (2): 230-52. 
ReDSS. 2018. Local Integration Focus: Refugees in Ethiopia. Nairobi. https://www.alnap.org/system/files/content/resource/files/main/ Local-Integration-Ethiopia-full-report-Jan-2018.pdf.

Ronnås, Per and Aditya Sarkar. 2019. An Incomplete Transformation: SDG 8, Structural Change, and Full and Productive Employment in Ethiopia. Geneva: International Labour Office.

Samatar, Ahmed. 1985. "Underdevelopment in Somalia:

Dictatorship without Hegemony." Africa Today 32 (3): 23-40.

Samuel Hall. 2014. Living Out of Camp: Alternatives to Camp-Based Assistance for Eritrean Refugees in Ethiopia. Commissioned by the Norwegian Refugee Council. https://static1.squarespace.com/ static/5cfe2c8927234e0001688343/t/5d5294e624fd2f0001 52d679/1565693209831/Living-Out-of-Camp-Alternative-toCamp-based-Assistance-in-Ethiopia.pdf.

Sanghi, Apurva, Harun Onder, and Varalakshmi Vemuru. 2016. Yes in My Backyard? The Economics of Refugees and their Social Dynamics in Kakuma, Kenya (English). Washington, DC: World Bank. http://documents.worldbank.org/curated/ en/308011482417763778/Yes-in-my-backyard-The-economicsof-refugees-and-their-social-dynamics-in-Kakuma-Kenya.

Segatti, Aurelia, and Loren Landau. 2011. Contemporary Migration to South Africa: A Regional Development Issue. Africa Development Forum. Washington, DC: World Bank Group. https://openknowledge.worldbank.org/handle/10986/2349.

Tadesse, Medhane. 2007. "Gambella: The Impact of Local Conflict on Regional Security." Occasional Paper. Addis Ababa; Pretoria: Institute for Security Studies. https://www.africaportal.org/publications/ gambella-the-impact-of-local-conflict-on-regional-security/.

Tesfagiorgis, Paulos. 2017. "Eritrea: Nationalism and SelfDetermination." Paper presented at a Workshop on Nationalism and Self-determination, University of Cambridge. Mimeo.
Thomas, Eddie. 2015. South Sudan: A Slow Liberation. London: Zed Books.

Turton, David. 2003. Conceptualising Forced Migration. RSC Working Paper 12, University of Oxford, October. https://www. rsc.ox.ac.uk/publications/conceptualising-forced-migration.

UN-Habitat and UNHCR (United Nations High Commissioner for Refugees). 2018. Housing, Land and Property Issues of Syrian Refugees in Lebanon from Homs City: Implications of the Protracted Refugee Crisis. Beirut: UN-Habitat Lebanon. https://www.un.org.lb/ library/assets/UNHABITAT-UNHCR_HLP\%2OISSUES\%200F\%20 SYRIAN\%2OREFUGEES\%2OIN\%2OLEBANON\%2OFROM\%20 HOMS_NOV\%202018_web-093805.pdf.

UN News. 2017. "Famine Declared in Region of South Sudan-UN." UN News, February 20. https://news.un.org/en/ story/2017/02/551812-famine-declared-region-south-sudan-un.

UNHCR (United Nations High Commissioner for Refugees). 2018. CRRF Ethiopia. August. UNHCR. https://data2.unhcr.org/en/ documents/download/65916.

---. 2020a. Ethiopia Fact Sheet. February 2020, https://data2. unhcr.org/en/documents/download/74648.

---. 2020b. Ethiopia Country Refugee Response Plan 2020-2021. Addis Ababa; Geneva: UNHCR. https://data2.unhcr.org/en/ documents/download/73572.

UNHCR (United Nations High Commissioner for Refugees) and ARRA. 2020a. Kule Refugee Camp. Camp Profile: Gambella. February. UNHCR Ethiopia and ARRA.

---. 2020b. Pugnido Refugee Camp. Camp Profile: Gambella. February. UNHCR Ethiopia and ARRA. https://data2.unhcr.org/en/ documents/download/74540. 
UNHCR Resettlement Service. 2011. "UNHCR-NGO Toolkit for Practical Cooperation on Resettlement. Community OutreachOutreach to Host Communities: Definitions and FAQs." United Nations High Commissioner for Refugees. https://www.unhcr.org/ protection/resettlement/4cd7d1509/unhcr-ngo-toolkit-practical-cooperation-resettlement-community-outreach.html.

Van Brabant, Koenraad. 1994. Bad Borders Make Bad Neighbours: The Political Economy of Relief and Rehabilitation in the Somali Region 5, Eastern Ethiopia. Relief and Rehabilitation Network Paper 4. London: Overseas Development Institute. https://odihpn.org/ wp-content/uploads/1994/09/networkpaperO4.pdf.

Van Hear, Nicholas, Oliver Bakewell, and Katy Long. 2017. "PushPull Plus: Reconsidering the Drivers of Migration." Journal of Ethnic and Migration Studies 44 (6) 1-18.

Vaughan, Sara, and Kjetil Tronvoll. 2003. The Culture of Power in Contemporary Ethiopian Political Life. Stockholm: SIDA.

Vemuru, Varalakshmi, Rahul Oka, Rieti Giovani Gengo, and Lee Gettler. 2016. Refugee Impacts on Turkana Hosts: A Social Impact Analysis for Kakuma Town and Refugee Camp Turkana County Kenya (English). Washington, DC: World Bank Group. http:// documents.worldbank.org/curated/en/359161482490953624/ Refugee-impacts-on-Turkana-hosts-a-social-impact-analysis-forKakuma-town-and-refugee-camp-Turkana-County-Kenya.

Ward, Patricia. 2014. "Refugee Cities: Reflections on the Development and Impact of UNHCR Urban Refugee Policy in the Middle East." Refugee Survey Quarterly 33 (1): 77-93.
Waters, Tony. 1999. "Assessing the Impact of the Rwandan Refugee Crisis on Development Planning in Rural Tanzania, 1994-1996." Human Organization 58 (2): 142-52.

Whitaker, Beth Elise. 1999. "Disjunctured Boundaries: Refugees, Hosts, and Politics in Western Tanzania." Ph.D. Diss., The University of North Carolina at Chapel Hill.

---. 2002. "Refugees in Western Tanzania: The Distribution of Burdens and Benefits Among Local Hosts." Journal of Refugee Studies 15 (4): 339-58.

World Bank. 2018. Mixed Migration, Forced Displacement and Job Outcomes in South Africa. Washington, DC: World Bank Group. https://openknowledge.worldbank.org/handle/10986/30158.

World Bank. 2019. "Towards Local Integration: Socio-Economic Integration of Refugees with Host Communities in Ethiopia." Mimeo. World Bank, Washington, DC.

Young, John. 1999. "Along Ethiopia's Western Frontier: Gambella and Benishangul in Transition." Journal of Modern African Studies 37 (2): $321-346$.

Zewde, Bahru. 2001. A History of Modern Ethiopia, 1855-1991. 2nd ed. Oxford: James Currey; Athens: Ohio University Press; Addis Ababa: Addis Ababa University Press. 


\section{Part II. Case Studies}
A Addis Ababa: Gofa Mebrat Hail and Bole Michael
B Benishangul-Gumuz: Sherkole refugee camp
C Gambella: Kule, Nguenyiel, Pinyudo refugee camps
D Somali Region: Aw Barre and Sheder refugee camps 


\section{A. Addis Ababa}

\section{Displacement in Addis Ababa}

Addis Ababa counts an estimated 15,000-30,000 refugees out of a national refugee population of 1 million. ${ }^{54}$ The Eritrean population, with an estimated 17,000 people, represents the majority. They are followed by Somalis (5,000), Yemenis (1,300), and Congolese (400) (Betts et al. 2019a). However, these numbers only reflect Somalis who are registered as refugees; in reality, Somalis represent the second largest group, but many are unregistered with the United Nations High Commissioner for Refugees (UNHCR).

Urban refugee figures are only indicative of actual numbers because the registration process is ongoing; official updated figures have not yet been released. A UNHCR representatives explains:

"The number of refugees in Addis increases every day because of referrals for medical reasons, protection-related concerns, and newcomers like Yemenis and Syrians who do not have camps, so they are here in Addis."

In the past, the government designated specific areas for refugees; as a result, Eritreans are located in Shire, Somalis in Melkadida, and the South Sudanese in Gambella.

There is a historical dimension to the refugee presence in the capital city of Addis Ababa, with the temporal nature of the presence of urban refugees highlighted in many of the collected stories and viewpoints, notably in the perceptions that hosts hold of refugees. Addis Ababa has been home to refugees for over 40 years: beginning with the collapse of Zaire (before it became known as the Democratic Republic of Congo) and continuing with the Somali influx from the 1960s to the 2000s. Since then, various nationalities have joined the refugee population-predominantly Eritreans and Somalis, but also South Sudanese; Yemenis; Syrians; Congolese; people from the Great Lakes, and even refugees from Cote d'Ivoire, Cuba, and Afghanistan. The Eritreans and Somalis comprise the majority and are the focus of this case study.

Beyond its temporality, another key feature of Addis Ababa is its transient nature: it is seen by some refugees as a transit point: a step out of the camp and a precursor to resettlement. Some refugees just pass through Addis Ababa, some have a medical condition and cannot pursue their journey further, and many-if not most-hope to resettle (Mallett et al 2017). The transient nature of Addis Ababa is highlighted in interviews by hosts, who link this to an ambivalence toward refugees who are not economically or socially committed to their host environment.

\footnotetext{
"Most of the refugees come here not to establish a livelihood. Rather, they consider Ethiopia as a transit country. They don't want to invest and maintain a life here. Refugees have no long-term plan to live here. They spend the money they get through remittances and aid for consumption. But you don't see a Somali refugee after a year." (FGD7.R5)
}

UNHCR staff have a different view regarding the presence of refugees in the urban landscape of Addis Ababa, explaining that they are still a minority, with limited impact:

54. All figures are preurban registration estimates based on a key informant interview with a UNHCR representative. 
"In Addis Ababa, there are around 6 million people, and there are 25,000 refugees, out of which half of them are working, so the number is insignificant compared with the host population. They are not going to have an impact on livelihoods." (KII with UNHCR Addis Ababa)

This case study report synthesizes the data collected across 17 semistructured interviews (SSIs), 10 focus group discussions (FGDs) and five key informant interviews (KIIs) in Addis Ababa to understand the social dynamics that bind refugees and hosts and to illustrate the types of impacts refugees have had on their host environments. Men, women, and youth from both groups-refugee and host-were interviewed at two locations: Bole Michael and Gofa Mebrat Haile. These locations are the largest Somali and Eritrean-hosting areas of the capital city, respectively. Key characteristics of the urban refugee population and of the study locations is provided below.

\section{Three "types" of refugees}

There are three legal/administrative categories for refugees living in Addis Ababa:

\section{Refugees registered under the out-of-camp policy.} Under this legal framework, developed by the government of Ethiopia in 2010 and aimed at building selfreliance among Eritrean refugees, each refugee must have a sponsor who guarantees that he or she will cover any living expenses the refugee might need in the chosen city. Sponsors are usually relatives; they must be Ethiopian citizens, and they must sign an agreement with the Agency for Refugee and Returnee Affairs (ARRA). ARRA then confirms that the sponsor can provide for the refugee and finally approves the city of residence. Refugees under the out-of-camp policy cannot access the formal wage labor or assistance services provided to urban refugees by UNHCR. They do maintain the option of returning to the camp (Samuel Hall 2014).
2. Refugees registered under the Urban Assistance Programme. Refugees under this scheme receive a monthly allowance from UNHCR but are not permitted to work. There are currently about 2,700 refugees under this program who are authorized to live in an urban area, generally Addis Ababa, for reasons related to security, medical, or family reunification purposes..55 Once the reason for the initial authorization has lapsed or has been resolved, refugees are then expected to return to living in one of the refugee camps.

3. Other refugees, including refugees from countries without designated camps, such as Yemen and Syria (Brown et al. 2018); refugees benefiting from an educational scholarship (e.g., UNHCR's DAFI program-a higher education scholarship program), although their numbers are restricted; unregistered refugees; and refugees who come to Addis Ababa to process visas with referrals from the camps.

"One of the reasons why we have so many refugees is because we have this out-of-camp policy, a measure taken by the government in 2010 benefitting only the Eritrean refugees; taking into account their cultural background, it is presumed that they can easily integrate with the host community. We also have refugees coming from the camps for various reasons: medical referral, security issues; they can be referred to the urban refugee program until the issue ceases to exist." (UNHCR)

55. See "Ethiopia Refugee Program Urban Health Sector Strategic Plan 2014 2018" at https://data2.unhcr.org/en/documents/download/62626. 
The first hope of many refugees in Addis Ababa is resettlement. Registered refugees receive a monthly stipend of $\mathrm{Br} 3,000-5,000$ (US\$102-172) from UNHCR to cover their rent and food, and additional support for return for those who possess refugee cards from UNHCR. In addition, refugees receive free health services through the Ethiopian Orthodox Church Development and InterChurch Aid Commission (DICAC), with specific care for pregnant women and their children.

"I joined the refugee camp in 2014 with two children, one of whom was sick with nerve paralysis. ARRA referred me to Addis Ababa to get better health care for my paralyzed kid. I left the other child with my mother."

(A Somali woman living in Bole Michael benefiting from the Urban Assistance Programme, SSI16)

\section{Two study areas, two groups}

Bole Michael and Gofa are home to poor and middle-class host community members (table A.1). Inflation and rapid population growth are common features of both locations, alongside a process of gentrification that is pushing some of the host members further out into the suburbs of Addis Ababa.

Both areas have become denser with central markets, and have become "heaven for the landlords," who reap the most benefits from the higher housing demand.

\footnotetext{
"Bole Michael is the most inconvenient place for poor host community members. Refugees have enough money to fulfill their basic needs, whereas most of the host communities have fundamental problems meeting their basic needs." (FGD8.R3)
}

While refugees are seen as having generated rapid economic growth at Bole Michael, benefiting landlords, shopkeepers, and restaurant owners, among others, some also see refugees as the reason for some of the challenges facing host communities.

\begin{abstract}
"People are moving to the suburbs and newly emerged neighborhoods like Bole Arabesa and more peripheral neighborhoods. An individual who earns a monthly salary of $\mathrm{Br}$ 4,000 must pay $\mathrm{Br} 3,000$ for rent and the remaining $\mathrm{Br} 1,000$ is not enough for food and transport. Thus, the only option to the individual is to leave Bole Michael and find relatively affordable rent in the suburb." (FGD6.R2)
\end{abstract}

While Gofa is considered a predominantly Eritrean refugee neighborhood, and Bole Michael a Somali refugee neighborhood referred to as "Little Mogadishu," there are also refugees from other African countries, such as the Democratic Republic of Congo and even as far as Yemen and Syria.

For almost 25 years, refugees from different parts of Somalia, fleeing the civil war, have settled in Bole Michael, located in Bole subcity, woreda 1. The area used to be mainly residential, with farmland and poor infrastructure. The presence of Somali refugees has turned Bole Michael into a dynamic commercial area, with many refugees opening guesthouses, shops, and restaurants as a means of livelihood. Most of the Somali refugees living in Addis Ababa are unregistered (Brown et al. 2018) and thus do not receive assistance from UNHCR. They rely on the Somali community-including hosts-and personal networks, remittances, or informal trade activities, and can be considered as being under a de facto out-ofcamp policy (Brown et al. 2018). Because Bole Michael is predominantly inhabited by Somalis-not just those from Somalia but also Ethiopian Somalis-the level of integration and social relationships differ by community. 
Table A.1. Economic Indicators for Addis Ababa: Comparison Across Groups

\begin{tabular}{|c|c|c|c|}
\hline & Somali Refugees & Eritrean Refugees & Host Community \\
\hline Monthly income (Br) & 1,400 & 1,500 & 4,000 \\
\hline Unemployment rate (\%) & 79 & 93 & 23.5 \\
\hline $\begin{array}{l}\text { Proportion of individuals who completed } \\
\text { vocational training (\%) }\end{array}$ & 13 & 51 & 22 \\
\hline Start-up capital for the self-employed (Br) & 2,000 & 16,500 & 70,000 \\
\hline House rent, including water and electricity (Br) & $1,500-3,000$ & $4,500-6,000$ & 3,000 \\
\hline Remittances, monthly average (Br) & 5,874 & 2735 & N/A. \\
\hline \multicolumn{4}{|l|}{ Source: Betts 2019a. } \\
\hline
\end{tabular}

"I think the relationship is challenging but overall a positive one. I say this because sometimes we do feel like we really are refugees the way some of the hosts talk to us. I am not speaking of the Somali hosts. I was talking about the other hosts. The Somalis have been very welcoming, that is why we like living in Bole Michel. They are our brothers and sisters who have supported us through giving us money." (FGD10.R6)

In fact, the presence of a large Ethiopian Somali community makes it difficult to distinguish refugees from nationals, which can be perceived as a form of protection, according to the refugees themselves.

Gofa Mebrat Hail is an area with a high concentration of Eritrean refugees, hosting some of the oldest condominiums in Addis Ababa; and it is a historical hub for Eritreans and Tigrinya-speaking Ethiopians. During the pre-Eritrean independence period, the main road leading to Gofa Mebrat Hail was lined with garages operated by Eritrean mechanics. Moreover, condominiums were initially cheaper than other housing options in Addis Ababa, and this, combined with the historical familiarity of the area, presented an ideal place for Eritrean refugees to settle.
Over time, Gofa Mebrat Hail has established itself as a relatively expensive middle-class area, and has seen an increase in Eritrean refugees since the peace deal between Eritrea and Ethiopia.

"We pay around $\mathrm{Br}$ 4,500 for a studio flat and $\mathrm{Br}$ 6,500 for a single room flat. If you want to live around here, you really need money." (SSI17)

Despite the rise in the cost of living across Addis Ababa, the increase in the price of rent in Gofa is often associated with the presence of Eritrean refugees.

\footnotetext{
"There are rumors we hear. I mean the locals accuse us of being the cause of the increase of house rent. They say everything increased when you came." (FGD1.R2)
}

The spatial-demographic structure of condominiums in Gofa exacerbates the increase in rent: rooms and apartments are shared by groups of young, single, male and female Eritrean refugees. This demographic group, while being the most dominant in the area, receives significant sums in remittances, allowing them to pool their resources and offset the cost of rent more easily than Ethiopian families living in the same condominiums. 
Integration is not cited as a source of conflict or security in Gofa. Due to the shared cultural, linguistic, and religious ties, Eritreans and Ethiopians are considered parts of a common group.

"To begin with, the Eritreans were part of Ethiopia before, not more than thirty years ago. Most of the refugees are part of Eritreans who were living here in Ethiopia before the 1998 border conflict." (FGD2.R5)

"The Eritreans I feel, do maintain their 'Eritrean-ness' in this situation and losing that is not something that is desirable." (KII3)

Both areas are marked by internal migration and population growth, with a positive sense of overall security. This is partly due to the capacity of the various groups to coexist.

"Everyone from each corner of the country and all the refugees are coming and living peacefully." (SSI9)

It is also partly due to efforts by the police in Bole Michael.

"Nowadays, the police are more effective than they used to be before, two years ago no one used to care about our security." (FGD2.R3)

But while positive police-led efforts are noted, so too are concerns regarding harassment in Gofa.

"[t]he police are supposed to ask you to produce some sort of identification instead of hastening to beat you up. There are Eritreans beaten up without being asked for any identification card." (FGD1.R3)

A key concern among both host and refugee respondents are the recent episodes of Ethiopian political instability. One refugee notes:
"The hardship is getting intense. We have growing worries of the current situation [the recent assassinations of military generals, a mayor, and his assistant]. We are second-class citizens, and we really don't know what will come of us if things keep worsening. When I converse with my husband, I tell him that if something goes wrong, those with two feet will skip town, all that remains will be us." (FGD 10)

In addition, Somali refugees living in Bole Michel felt the impact of the August 4, 2018, clashes between Oromos and Somalis in Ethiopia's Somali Region. They say they were profiled and that there were tensions in their interactions with non-Somali Ethiopians during this period.

"They [locals] view them [refugees] as Somalis and do not care that they [refugees] were Somalis from Somalia and not the Somali Region." (FGD10)

\section{Limitations and Constraints}

Selection of research location. Gofa Mebrat Hail was selected because of the history of settlement and the large population of Eritrean refugees. However, toward the end of the fieldwork, it was noted that Gofa Mebrat Hail is a predominantly middle-class neighborhood; other Eritrean refugees have settled in other, more affordable areas of the city, such as Lafto and Jomo Condominium. Shifting or expanding the research to other Eritrean settlements could have increased this study's propensity to capture a wider range of socioeconomic statuses and vulnerabilities.

"Types" of refugees and disparate access to services. Our research questions focus on the differences in access to services between refugees and host communities. While this difference exists; there is an even greater discrepancy between the services refugees under the "legal" out-of-camp policy or the Urban Assistance Programme can access compared with refugees living in Addis Ababa without proper documentation who therefore are 
considered "illegal" by authorities. However, refugees with "illegal" status prefer not to be identified, and delivering services to them remains a major challenge.

Neglect of other refugee groups. By focusing on the two largest refugee populations with the longest history of settlement and interaction with the host community; our sampling excluded other refugee populations of interest (Syrian, Congolese, South Sudanese, and Yemini refugees), which have different histories of displacement and different levels of interaction. Syrian and Yemeni refugees have a relatively recent history of settlement in Addis Ababa, yet Yemenis are far more integrated. South Sudanese and Congolese refugees have a longer history of settlement, but they are arguably highly discriminated against and tend to be less visible in both urban demographic and policy planning. There is room for further research on these other refugee populations.

Sensitivities of host community in Addis Ababa. Due to the security situation and political context in which the fieldwork was conducted, it was impossible to hold focus group discussions that included both refugee and host community members. Moreover, the team also experienced research fatigue and cultural barriers among prospective participants, both in Gofa Mebrat Hail and Bole Michael. Participants demanded greater compensation for their time; and Eritrean women were particularly reluctant to be interviewed, especially if they were married. The research team often had to seek the permission of a husband before conducting an interview.

\section{Identifying and understanding host communities in Bole}

Michel. Considering the main population groups, specifically in Bole Michel, the research team had to be particularly careful when identifying host communities because unregistered refugees self-identify as members of the host community. It was also difficult for the host community to clearly differentiate between their interactions with Somali Ethiopians and Somali refugees.
Understanding informal gatekeepers. Members of the Refugee Central Committee $(\mathrm{RCC})^{56}$ can easily mobilize refugee participants, and their past experiences with refugee studies in Addis Ababa, which may have offered compensation in response for such mobilization, created unrealistic expectations of the research team. Also, with RCC members being viewed as strong informal leaders, it was key for our research team to successfully manage this relationship.

\section{Context of Displacement}

While the government of Ethiopia is committed to transitioning from strict encampment policies to self-reliance among refugees, the reality for urban refugees in Addis Ababa is challenging. As rapid urbanization progresses unabated across African cities, and as policy discussions progress at global, regional, and national levels, understanding the local challenges that urban refugees face and how best to cater to their needs is extremely timely. Cities offer better livelihood opportunities, access to information, and transnational networks, but there are trade-offs, notably in terms of direct assistance provided by nongovernmental organizations (NGOs). The geographic spread of refugees, the fact that they are embedded within host communities, and the magnitude of needs across refugee and host communities makes it difficult for NGOs to assist or protect urban refugees (UNHCR 2012). A broader, areabased, and rights-based approach is needed to mitigate the situation. Studies show that in major African cities, urban refugees are vulnerable to exploitation, systemic discrimination, and detention (Campbell 2005).

The challenges faced by refugees are the same as those faced by the urban poor: insecure housing, limited access to services, and high levels of unemployment. This is especially the case in Addis Ababa, where the urban population is expected to triple by 2037 (UN-Habitat 2017) and

56. The RCC is a representative organization that is consulted on issues affecting refugees. 
where unemployment is the highest in the country-at around 23.5 percent (RSC 2019). The city is struggling to contain urbanization, collect revenue, and overcome resource constraints (EC 2016).

Urban refugees in Addis Ababa are a heterogeneous group with different socioeconomic profiles, histories of displacement and settlement, and social networks upon which they can draw (Buscher 2003). Eritrean and Somali refugees are the largest refugee group and have the longest history of settlement in the city. Social networks play a pivotal role as a source of information as well as emotional and material resources, determining where refugees decide to settle. For Eritrean and Somali refugees, their respective histories of displacement and settlement are an additional factor impacting their decision to settle predominantly in the two research locations for this study.

Ethiopian Somalis have been settling in Bole Michael for generations (Mena 2017). This made it an attractive place for Somali refugees to settle and tap into existing social networks for their survival. The majority of Eritrean refugees settled in Gofa Mebrat Hail prior to a series of deportations that occurred between 1998 and 2000 during the Eritrean-Ethiopian War (Mena 2017), making it an attractive place to settle for Eritreans returning home after the war and for new refugees fleeing indefinite military service and an oppressive political environment. This history and the presence of social networks continue to play a role today, evident in the reported influx of Somali refugees into Bole Michael during the conflict between Oromo and Somali Ethiopians in 2018 (RSC 2019). The same pattern applies to the time after the peace deal was struck between Ethiopia and Eritrea: there was a rise in the number of Eritrean refugees entering Ethiopia to settle in neighborhoods such as Gofa Mebrat Hail (The New Humanitarian 2018). Most Eritrean refugees live under the out-of-camp status; most Somali refugees are unregistered asylum seekers (The New Humanitarian 2018). Under article 13 (6) of the (older) Refugee Proclamation, the
Ethiopian government grants refugees without appropriate documentation freedom from arbitrary arrest (Webster 2011). Freedom of movement is still strictly controlled by the Ethiopian government.

Most of the literature concerning urban refugees in Addis Ababa focuses on refugee economies because the ability to work is a crucial feature of refugee selfreliance (Crisp 2004). Refugees are currently not permitted to work, yet there exist no punitive legal restrictions on refugees engaging in informal work (Brown et al. 2018). The Ethiopian government does not grant work permits or issue business licenses, making it extremely difficult for refugees to start and own enterprises (Zetter and Ruaudel 2016). However, such restrictions have not dampened the economic contributions of refugees in neighborhoods such as Bole Michael, where they are cited as identifying niche markets, spurring innovation, and establishing transnational value and supply chains.

Beyond economic engagement, local integration is a process that includes legal and social dimensions. Socioeconomic conditions among the host community can hinder or enhance the integration of African refugees in urban settings (Salem 2013). Therefore, understanding the social dynamics between refugees and host communities is paramount to the aims of increasing selfreliance among refugees and integration with the host community in Addis Ababa.

\section{Governance and programming}

What do inhabitants of the area know of and how do they perceive the various policy measures regarding and actors involved in refugee integration? What are the expectations of the hosts and refugees regarding development interventions?

Nationality is considered a key marker of integration and differentiation among refugee groups. Stakeholders recognize that host-refugee relationships depend on countries of origin. There is a difference in how Eritreans 
and Somalis are treated and their relationships with the hosts; within each of those groups there is also variation between old and new refugees. These dimensions-of nationality and time-are reflected in the nine pledges of the Ethiopian government, as well as in existing legal frameworks targeted at Eritrean refugees living in Ethiopia for 20 years or longer, such as the out-of-camp policy. Interviews with refugee practitioners reiterate a common assumption.

\begin{abstract}
"Eritreans are more integrated because they were Ethiopians, they know the culture, they speak the language and so it is easy for them to integrate. ... The Congolese and Yemenis claim that they are discriminated because they come from specific nationalities. For instance, the Eritreans, they used to be Ethiopian so it is a lot easier for them to live with Ethiopians, some of them moved to their original neighborhood in Addis Ababa so it is easier for them to integrate." (KII5)
\end{abstract}

The potential for future conflict will rise if effective awareness raising is not in place to accompany legal changes. Key informants raised concerns over potential conflict or an increase in social tensions in the aftermath of the new refugee proclamation. UNHCR staff members share the concerns that once the revised refugee proclamation comes into force, it will give refugees more rights and bring about more competition over jobs, while unemployment remains high in Addis Ababa. This cycle of rights and competition could lead to insecurity in the host community.

\footnotetext{
"So far since the number of refugees living in Addis is very small compared with the host population, (tensions) are not visible, but in the future, the urban refugee population is expected to rise with the out of camp policy which is one of the pledges, and if we have more refugees competing for jobs, it will
}

definitely create competition with the host community." (KII5)

The conclusion for practitioners is that, in the process of implementing the new proclamation, programs will need to increase their efforts at effective communication about the inclusion of the host community, ensure awareness, and remain informed of the benefits that will also reach them (Abebe 2018).

$$
\begin{aligned}
& \text { "I don't think the majority of the people know the } \\
& \text { new proclamation" (KII5). }
\end{aligned}
$$

The focus groups and semistructured interviews with refugees and hosts echo this sentiment.

Organizations note that problems have arisen due to the gap between implementation and refugee expectations [KIls with the Norwegian Refugee Council (NRC) and UNDP], illustrated by the Syrian refugee populations' attempts at accessing driver's licenses. In theory, a Syrian refugee should be able to obtain a license but, in practice, they are unable to, which curbs their capacity to conduct business. Eritrean refugees interviewed in Gofa express ed that government officials are not sufficiently informed about the content of legal decisions made at the national level.

\footnotetext{
"After the peace deal, when you go to various offices to have your paper done, upon examining your refugee ID card they tell you ... "oh you are no longer a refugee!" (FGD1.R5)
}

To what extent is the new framework being implemented? Respondents claim that local authorities and the community at large have a minimal understanding of the new framework (KII4). One respondent explains that, while mass media has spread the word,

"While I heard that refugees will be allowed to sell and buy property, have their very own bank book 
account, and the right to have business license among other things, in reality, nothing has changed ... It will make a big difference for those refugees who are already in the business world and who already are successful. But I don't think everyone will benefit from such schemes-some will lose and some will gain. Some will employ this scheme to a greater advantage, mostly those who have a half-brother or sister through an Ethiopian mother or father. Since these people tend to be more integrated and know the ins and out of business bureaucracy, their businesses will flourish." (SSI7)

A refugee in Gofa explains:

"You come and get information, then what?" (FGD4.R5).

Refugees mention hearing about the new proclamation from organizations such as the NRC, but they have not seen any tangible progress.

"I have observed many organizations doing similar research, maybe they can make financial support for starting a business. But, they don't follow up on it." (FGD4.R5)

Can ARRA bring about change? Refugees express some apprehension about ARRA's capacity to bring about needed change. When refugees try to access vital documents, such as birth certificates, they are faced with governmental staff already under pressure to respond to a climate of changing laws. This, in turn, makes them less welcoming than the general host community, and makes it difficult for refugees to obtain the services they need.

The host community is largely unaware of the changing governance on refugee issues in Ethiopia. Of the minority who are aware, some hosts are ready to back the new proclamation, others are concerned about opportunities for hosts. At one focus group discussion, respondents shared mixed views, some supportive of a government that can create a conducive situation for refugees, seeing it as an indirect benefit to hosts as well, and others concerned about the future for the country's youth.

"When the government gives more opportunity to the refugees, what is going to happen to the youth of the country?" (FGD3.R3)

Refugees recognize this tension and are sensitive to what host community members will think and how they will react. Beyond the implementation gap, refugees are concerned about the possible backlash of such a proclamation.

"I even heard some people talking on mass media, asking the question: 'How come refugees will be given opportunities to work while there are so many locals who can't find jobs?' I guess the government's policies might have changed but the changes the new administration is trying to implement hasn't sunk in the psyche of the general population. I hear there is a lot of opposition from within the host community regarding such plan." (FGD5.R3)

The new government in Ethiopia and the peace deal between Ethiopia and Eritrea are seen as opportunities but also as a potential source of problems. During focus group discussions, Eritrean refugees highlighted that "Eritreans are flocking in and, obviously, tensions will increase," noting that those arriving after the peace deal will not be able to benefit from the same sort of schemes that prior groups of refugees have (FGD1.R5). They highlight, for instance, that they will not benefit from the coupon scheme, get access to public services such as medical care, or have the same bonds on an individual level with neighbors that would allow them to access water or sugar in times of need. 
"Overall, there are not the types of social provisions for them in Gofa." (FGD2.R4)

Eritrean refugees who have been living for years in Ethiopia speak of the changes they have seen since the coming to power of Prime Minister Abiy Ahmed and the peace agreement that followed. Changes toward Eritreans, in their view, are noticeable.

\begin{abstract}
"Before we weren't even allowed to rent a house under our name. So, we used to rely on Ethiopians for their ID card. It had even reached a point that some hosts refused to rent us their house and told us that we had no right to do so because we were refugees. But, now refugees can rent a house. Things have changed for the better. In previous years, we didn't even have a meeting among ourselves, let alone with Ethiopians. There were really very few gatherings I could remember." (FGD2.R4)
\end{abstract}

Another respondent from Gofa details the changes seen in the transition from the previous government to Abiy Ahmed's accession to power:

"The previous government had not brought much change in regard to condominium developments. The new government has already initiated programs. Each condominium has been given the go-ahead to build fences. There are greening initiatives, sanitary programs, and other developmental initiatives. If a tenant lives for more than six months he is obliged to participate in these initiatives. Though we have the support of the leadership in the district and subcity administrations, in previous years, all efforts to bring those initiatives to fruition failed. The compound is still full of garbage. The compound is still used by people to relieve themselves. Now, there is no reason why this type of condominium couldn't be better than Bole [an upscale neighborhood]." (SSI2)
NGOs are seen as a crucial but inaccessible, and at times misinformed, actors (SSI7). The formal mode of communication is facilitated through ARRA and NGOs. But most NGOs are seen as being unapproachable or inaccessible to most refugees because they are physically removed from where refugees reside. In Gofa, the teams observed that participants lack information on the services provided to refugees in general and youth and women in particular. Refugees mentioned services provided by one or two NGOs known to them (e.g., the Jesuit Refugee Service). Even in those cases, however, they lack knowledge of where the NGO offices are and are only receiving assistance passively.

NGOs also do not seem to well understand the changing policies. One respondent described attending a five-day seminar in 2019 on business and integration for 20 Somali refugees and 50 Eritrean refugees, led by PLAN international and the European Union. At the seminar, they were told that refugees would be given $\mathrm{Br} 25,000$ (US\$855) to run a business.

"After a while, without response, we contacted the seminar team, and they told us that the plans changed. They told us to organize ourselves in groups, open one bank account, rent a house, and bring a valid business license. When we finished all these steps, the business license office refused to give us a license in the absence of a national ID card. We want NGOs to give the support they promised, and if it doesn't work, we need feedback." (SSI7)

A key question in refugees' discourse relates to the impact of the proclamation on resettlement.

"The only thing that I am very much concerned with is if the new opportunities are going to affect the plans and processes of resettlement of refugees to a third country." (SSI6) 
Refugees are concerned about how proposed plans of increased integration by the Ethiopian government might affect plans and processes for refugees to travel abroad for family reunification or third-country resettlement.

\section{Ecosystem}

What does the microsystem/mesosystem/macrosystem look like around communities? Who are the most relevant stakeholders? What is the dominant discourse about refugees?

Unlike refugees living in camps, NGOs do not feature as prominent actors for urban refugees.

"Most NGOs are unapproachable or inaccessible to most refugees as they tend to base themselves far from where most refugees reside." (SSAE)
This speaks to the challenges related to service provision to refugees in an urban context. As a key informant interviewee from UNDP explains:

\section{"Service delivery and policy and program interven- tion toward refugees in an urban setting is much more difficult than would be the case-or if not much more expensive-if one was to do it in a rural set up." (KII with UNDP representative)}

This can be attributed to the geographic spread of recipients; the invisibility of vulnerable groups, such as unregistered refugees; and the need to address structural rather than isolated problems. The six main actors influencing refugees' lives in Addis Ababa are described below (see also figure A.1).

\section{Figure A.1. Refugee Ecosystem Model, Addis Ababa}

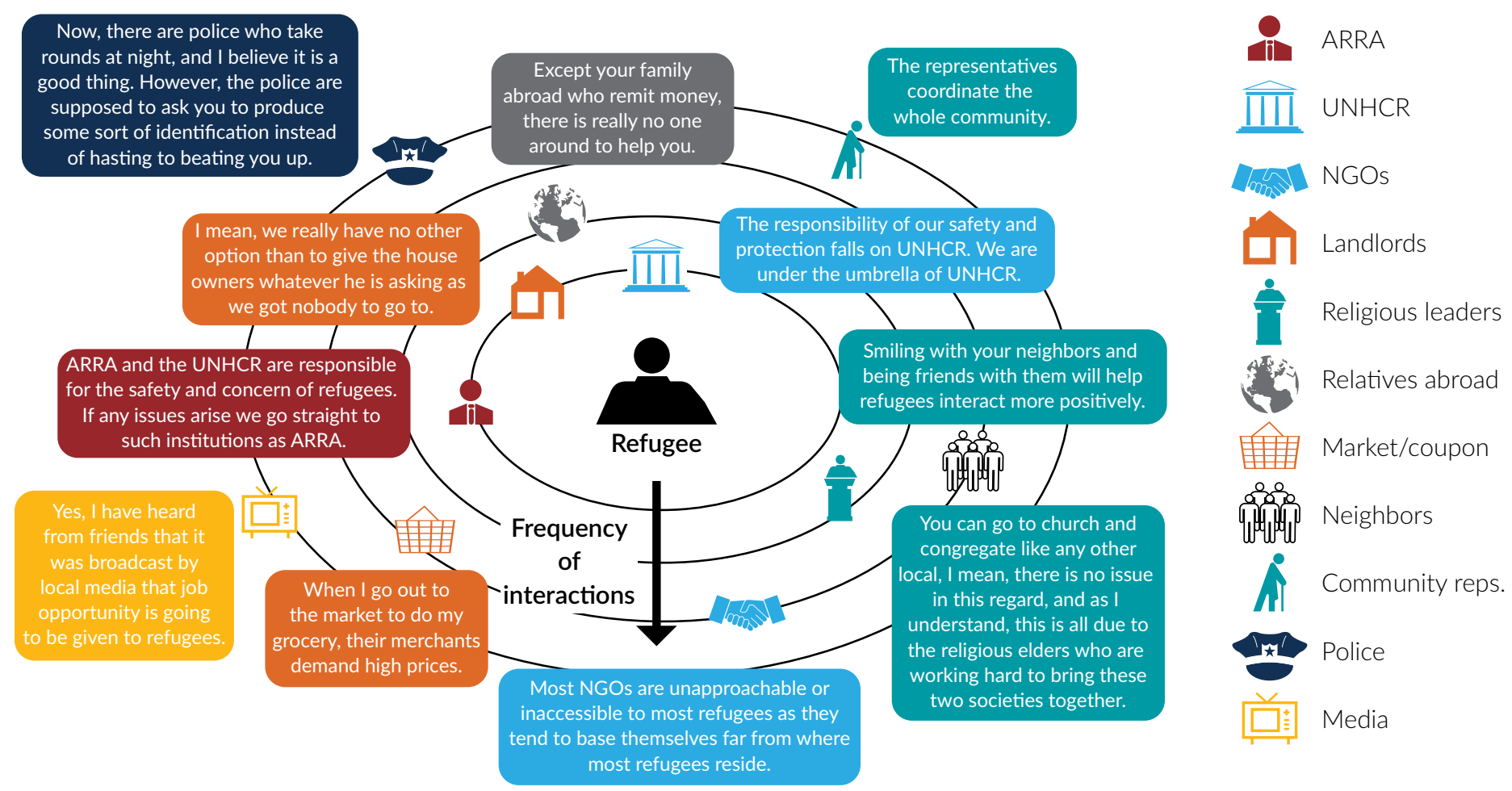

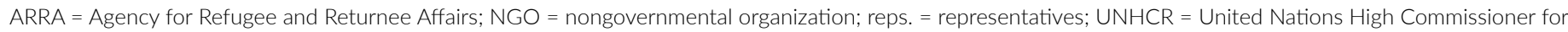
Refugees. 
1. ARRA. Refugees have no link to the local administration, and ARRA remains the sole authority in charge of refugee affairs. Refugees view ARRA as responsible for their needs and safety.

"If any issues arise, we go straight to ARRA." (SSI8)

ARRA is responsible for administering identification cards to refugees and provides access to essential services, such as health care. ARRA is the institution to which all of the refugee respondents petition for their needs and to resolve any disputes with the host community. However, despite the omnipresence of ARRA in the life of refugees in Addis Ababa, many doubt its capacity to administer to all of their needs.

2. UNHCR. Refugees view UNHCR as the international counterpart to ARRA that is responsible for the protection of refugees.

"The responsibility of our safety and protection falls on UNHCR, we are under the umbrella of UNHCR." (FGD5.R3)

There are two main reasons why UNHCR is such an important stakeholder in the lives of refugees in Addis Ababa:

- It determines the eligibility of refugees for the Urban Assistance Programme. Refugees registered under this program are granted permission to stay in Addis Ababa for a limited amount of time for security, medical, or family reunification purposes; they also receive a monthly allowance of $\mathrm{Br}$ 3,000-5,000 (US\$102-172).

- The vast majority of refugees aspire to relocate to Europe or North America, and UNHCR is the stakeholder in charge of third-country resettlement applications.
"I have already started the process to go to Canada on the family reunification scheme. Here I cannot have a stable life." (SSI6)

3. Landlords. Housing rentals are cited as the main challenge for refugees participating in this study. On average, refugees pay more in rent than hosts, especially those who have fled Eritrea. Landlords dictate both the amount of rent and the services available to refugees. Respondents provided examples of landlords barring them from using electricity to cook or from using the washing machine and clothesline, despite their paying utility bills (SSI16). The high cost of rent has resulted in refugees living in groups to offset the financial burden. This is particularly the case in Gofa Mebrat Hail, where the dominant demographic group are young, single, male, and female Eritrean refugees. The host community claims that this coping mechanism increases the cost of living by making it easier for landlords to set higher rents, therefore, increasing tensions with refugees both in Bole Michael and Gofa Mebrat Hail.

"What I feel aggrieved about is livelihood has become very expensive after the arrival of the refugees. Poor people are suffering beyond what I can explain." (FGD3.R1)

4. Relatives abroad support refugees in Addis Ababa in several ways, most notably with financial support. As most refugees are unable to work, and only a limited number are registered under the Urban Assistance Programme, the majority of refugees in Addis Ababa rely on remittances as a lifeline.

"Except your relatives [family abroad who remit money], there is really no one around to help you. I mean how can they [host friends] give you monetary assistance when they can't even secure you a job!" (FGD5.R3) 
Remittances are cited as a source of inflation because they enable refugees to accept-willingly or unwillingly-the artificially raised rents and prices of other goods set by landlords and business owners. This results in the perception among host community members that refugees are a gentrifying force.

\footnotetext{
"Generally speaking, life for a refugee revolves around remittance, pubs, and residential homes." (FGD5.R5)
}

5. The market is an important site for refugee-host interactions. However, the two refugee groups engage in the market in different ways. In Bole Michael, Somali refugees are heavily involved in the informal market and are seen as drivers of the local economy through their engagement in various forms of trade. In Gofa Mebrat Hail, Eritrean refugees contribute to the market with their spending power rather than their business acumen-they often represent the largest customer base for Ethiopian businesspeople in the area.

6. Religious leaders play a pivotal role in the integration of refugees into the host community. Refugee respondents for this study consistently rank churches and mosques as the primary spaces of interaction with host communities.

"There is a strong interaction between host and refugees in religious settings regardless of nationality differences." (FGD6.R3)

For some refugees, religious spaces offer the only meaningful interaction they have with hosts, although most of these interactions do not extend beyond such spaces.

Turning now to the host community ecosystem, there five main actors for the host community, described in turn (see also figure A.2).

\section{Figure A.2. Host Community Ecosystem Model, Addis Ababa}

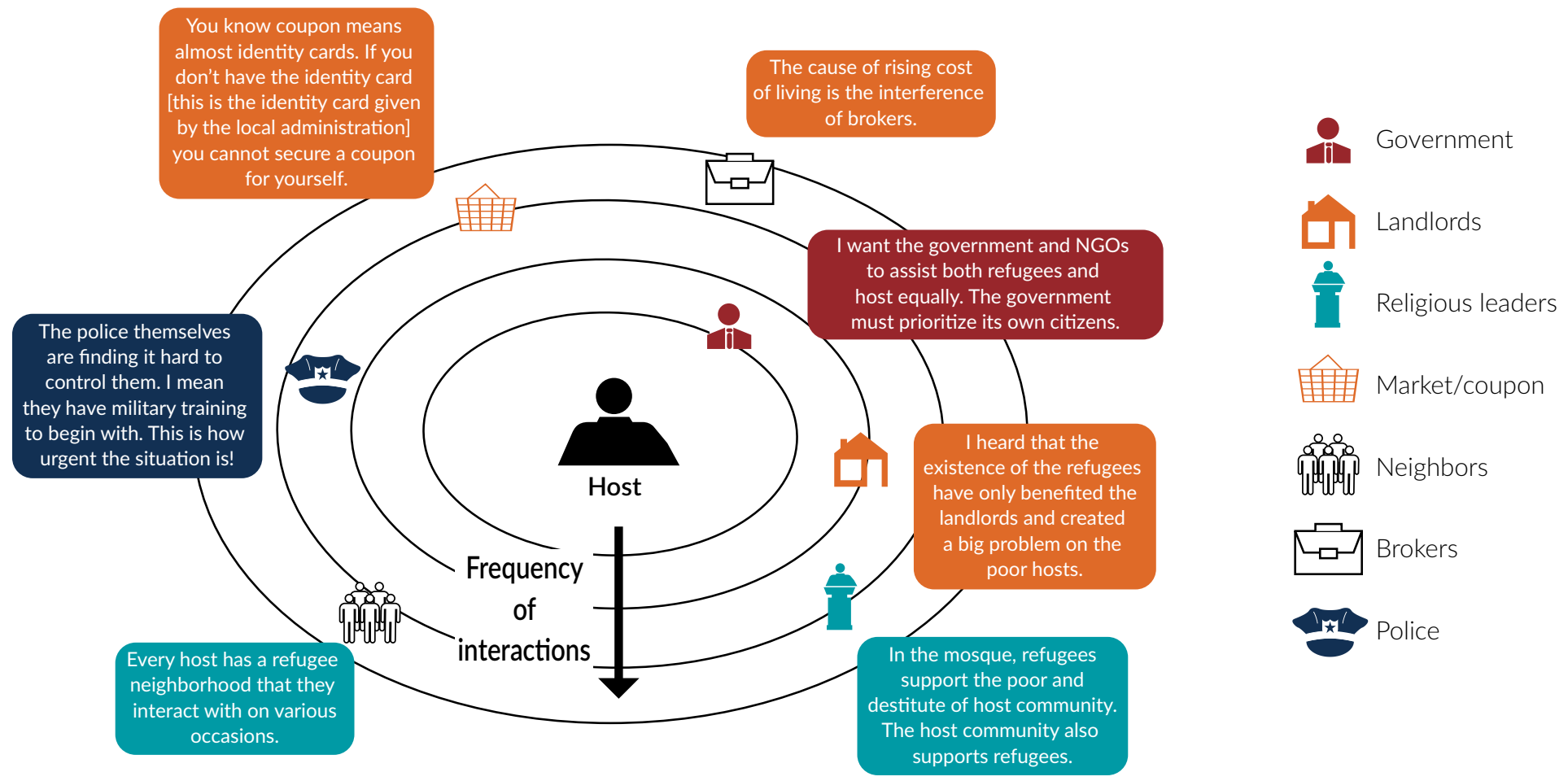

NGO = nongovernmental organization . 
1. The government. Host community members perceive the government as the sole institution responsible for service provision covering their needs and those of refugees.

2. Landlords and brokers are cited for the increase in the cost of living and rent.

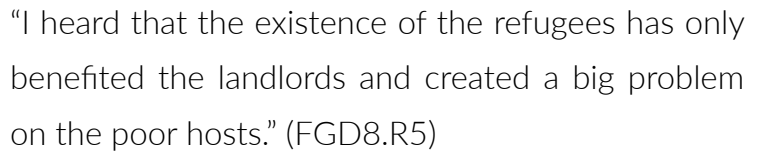

In fact, brokers are a unique feature of the host community ecosystem, and they are viewed as interfering in the market and raising the cost of living.

\footnotetext{
"Here comes the role of the brokers. The Ethiopians cannot afford to pay the house rent they are asked to pay by the brokers." (SSI4)
}

3. Religious leaders contribute to improved relations between hosts and refugees. Participants cite churches and mosques as the most important sites of interaction. One of the main reasons is the use of mixed languages within these religious spaces to accommodate both the host and refugee communities.

\footnotetext{
"You can go to church and congregate like any other local. I mean there is no issue in this regard and, as I understand this, is all due to the religious elders who are working hard to bring these two societies together." (FGD5.R3)
}

4. Market actors from the host community play the dual role of price setter and employer. Both refugees and host community members often refer to shrewd businessmen and women who take advantage of refugees by exploiting their limited access to information and the language barrier to arbitrarily set higher prices for goods. This has the knock-on effect of increasing the cost of living for the host community.

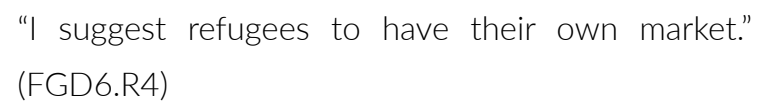

Refugees are denied the right to work and are barred from accessing business licenses. This means that refugees have to partner with Ethiopians to open their own enterprises. Local entrepreneurs can capitalize on cross-border value and supply chains that refugees offer, and set up partnerships with more favorable terms for themselves. Moreover, refugees willing to be informally employed are a cheaper source of labor, therefore increasing tensions between refugees and unemployed locals.

5. Traditional Ethiopian social organizations for loans and financial assistance-Okub and Edir-are pivotal safety nets for the host community. They do not restrict refugees, but most do not engage with them, possibly due to the shortterm nature of most refugees' stay in Addis Ababa, which inhibits the formation of the deep social bonds necessary to practice Okub or Edir.

\section{"Personally, Edir is a long-time commitment: it takes time and energy. And you need to stay put for long, but I move from house to house looking for a cheaper rent." (FGD5.R5)}

The police are relatively benign actors toward both refugee and host communities. Respondents feel police are relatively inactive, or that refugees perceive political instability as the greatest threat to their overall safety.

\footnotetext{
"Yes, I feel unsafe. I mean their [Ethiopians] political situation is in disorder. You really don't know what tomorrow will bring-especially if you have young ones. I always live in worry. Life might be going on as normal, but we have worries." (FGD5.R2)
} 
A dominant discourse? Host perceptions of refugees range from those suggesting that "refugees should not be living amidst society" but rather should remain only in designated refugee camps (SSI2), to those suggesting that Eritrean refugees are family and that Somalis are changemakers in their communities. There is no dominant urban discourse but rather a range of discourses on refugees. Common features, however, include the fact that most Ethiopians and refugees seem to agree that Ethiopia is a refugee-welcoming nation and that Addis Ababa-and specific neighborhoods such as Gofa Mebrat Hail and Bole Michael-have significantly changed in recent years thanks to the activities and presence of refugees in these areas. Benefits include market and economic activities; trade; and the availability of clothing, cosmetics, and other imported products (Mena 2017). Hosts also note changes in rent and inflation that have adverse effects, notably on the poorest; the link between the economy and the presence of the refugees needs to be clarified.

Some hosts believe they should learn to speak Somali to better communicate and improve their interactions with refugees.

"They stay here for a short time and have no interest to speak Amharic. I don't know why they lack [knowledge] in our language and culture. This needs research. Until they adapt to the environment, service providers should serve them in Somali. I put this forward because of their significance for the local economy. Government offices of this area should also have Somali-speaking employees who can facilitate and serve refugees. Somebody should listen to them. In the next five years, either the government or NGOs or individuals or in collaboration should consider the above points in order to improve the relationship between hosts and refugees. They are part of us; you cannot ignore them. Thus, inclusivity is very important to improve the relationship between hosts and refugees." (FGD7.R3)
Some host participants spoke of the need to extend care and integration to all refugees-not only Eritreans and Somalis.

\begin{abstract}
"Somali and Eritrean refugees are living a good life compared with Congolese and Syrian refugees. Congolese and South Sudanese refugees have no source of income. So, we must assist them too. I suspect no one helps Congolese and South Sudanese refugees either from abroad or inside. I doubt their refugee status and rights are protected. I give money and buy them tea-specifically for Congolese refugees." (FGD7.R1)
\end{abstract}

Some hosts are concerned that refugees want to keep to themselves and do not want to integrate.

"First of all, the refugees prefer to interact with their own people. But the Ethiopians don't hate them. We meet at work, in the market, in recreation centers, in churches, and we have friends. But, usually, the refugees prefer to live together in some places. As a result, their interaction becomes within their own community." (SSI13)

Public figures-such as police representatives in Bole Michael-consider refugees as "family." Tensions are often seen around the lack of language skills.

"At first, there might be some language problems and hesitation among each other. But, after the refugees and the hosts do start communicating and know each other, they have very good interactions. They consider each other as a family. We invite each other during wedding ceremonies, ritual ceremonies, coffee ceremonies and at the religious places etc. The refugees start to support you much better than what your real brothers and sisters can do for you." (SSI9) 
Ethnicity is an important marker in relationships in these areas. Discussions around tensions between Tigrayans and others illustrate internal ethnic tensions. One Eritrean refugee explained how the animosity she experienced was over her perceived ethnicity, not her refugee status.

"You see we speak Tigrinya, and they [Amharas, Oromos] really can't differentiate who is the local and who is the refugee. So, they confuse us with the local Tigrinya speakers. And they don't see us in good terms [racial tension is brewing between local Tigrinya speakers and Amhara or Oromo]. There is the tendency for the locals to confuse us with Tigrayans." (SSI8; further examples: A2.FGD4.hosts. q7 and FGD1.bole.female-hosts.R1)

Ethnic similarities also play out in the relationships between hosts and Somali refugees.

"The Harare Oromos and the Ethiopian Somalis are very similar to the Somali refugees. Even you cannot identify them. They speak the same language. Besides, they have similar religion, dressing styles, marriage ceremony ... They share the same mosques. That is why they do have similar needs. We are also adapting and sharing our cultures, feeding styles, and other experiences." (SSI11)

Tensions that occurred last year in Ethiopia's Somali Region affected Somali refugees in Bole, with similar reports of animosity claimed by a Somali refugee whose greatest concern is that refugees are all seen as Somalis and not Somali refugees. Refugees see Ethiopians as being hospitable and subject to their own hardships.

"Ethiopians are really hospitable, and we really don't have an issue living with them. The main problem for refugees is securing livelihood. I find young and old Ethiopians friendly. But I am aware of the upheavals and the hardships they are going through and I don't think it is appropriate to expect more for refugees." (SSI7)

Refugees even feel protected by the hosts during volatile times such as the insecurity experienced in 2019.

"The majority of the people we interact here are good people, they are even better than the UN agencies who claim to support refugees. For example, last year during the time of clashes between the SomaliEthiopians and the other Ethiopians, a committee in our village protected us, they said contact us if anyone harassed you in any way, we felt so special. No one was harmed." (SSI15)

\section{The ecosystem of each location.}

Respondents often turn around the question of refugee integration, to speak instead of hosts learning to integrate with refugees in the Somali community.

"We live among them in Bole Michael" (SSI11).

The question no longer becomes whether refugees have integrated, but whether hosts are able to integrate in a changing environment.

"I feel like I belong to the Somali community. I have lived here for 13 years with the Somali people, all my customers are Somali, I speak the Somali language perfectly, and I have very close relationships with them. They come to my home and I usually go to their home. We do share and eat everything except meat. They do not eat meat in my home because I am orthodox Christian by religion. I do not eat meat in their home because they are Muslims. Some of my previous customers who are now living abroad are sending me gifts. Now we became like family. That is why I feel as if I am Somali." (SSI11) 
At the same time, refugee youth still speak of traumatizing exchanges with hosts, specifically in schools.

"There was a time me and other Somali kids were staying in school and discussing a religious ceremony and the school principal just came and yelled at us for doing nothing and told us 'you Somali boys are plotting something and you are not good people' so he stopped us from interacting with each other. Another example: me and my other classmate did a project together. When I stood up to answer a question from the group, the teacher told me to sit down and said, 'you are Somali so you don't know anything, don't bother.' So that was a very heart-wrenching moment for me. I was demoralized by my teacher's speech." (SSI13)

The complex ecosystem of each location has to be understood before delving into the relationship between hosts and refugees or on the impact of refugees on hosts. As explained by a Danish Refugee Council staff member when speaking of the make-up of Bole Michael:

"The informal economies in Bole Michael go way beyond their relationship to refugees. It is a place where you can get a passport for all of the Somalihosting nations. It is a place where remittances from Australia are sent and you can pick it up before banks were very popular. The informal underground aspect of it is significant; it is a place now where Yemenis are starting to trade. So, it's no longer a Somali refugee hotspot, it's where nationalities and statuses all meet. It is not a place where being a refugee makes you distinct from a poor Ethiopian Somali; because they have their own networks and systems of doing things, they issue their own IDs, have their own schools, own travel agents. It's a mini state." (KII1)
In Bole Michael, the lens of refugee versus host is not the most important one. The distinction between host and refugee does not lead to better analysis there.

"If the person has three passports; like there are people that have Djiboutian, Kenyan, Somali, and Ethiopian-four passports in their pocket because they are all arbitrary once you have a certain amount of money, you can obtain those things. So, the distinction breaks down and their usefulness of analysis goes with it." (KII1)

A host representative in Bole Michael agrees, explaining that residents of Bole Michael have learned to live in a diverse community made up of Somalis, Arabs, Oromos, and other ethnic groups.

"I worked with diverse identities on various occasions. I don't like the perspective that narrows a person to a certain group or identity. I respect their identity. I have many friends, born from Gurage mother and father in Addis Ababa. I have also Oromo grandparents. My son is from Gurage and Oromo family. Where do you locate me? It is very difficult to have one identity and be part of it." (SSI10)

On the other hand, the distinction is relevant in Gofa Mebrat Hail. Although on the surface contradictory, as Ethiopians and Eritreans share a stronger past, the distinction between them is more visible. This is because in Bole Michael, integration is mediated by clan-ethnic-linguistic markers, rather than nation-state status. In Bole Michael,

"if you are Somali you are Somali right?" (KII3)

This notion does not carry the same weight in Gofa Mebrat Hail, because there is a perceived reluctance by Eritreans to fully integrate with the host community. 
"We [host and refugees] live together like brothers. But, they [Eritreans] have this unique manner which seems out of place." (FGD2.R5)

"The Eritreans, I feel, do maintain their 'Eritreanness' in this situation, and losing that is not something that is desirable." (KII3)

In Bole Michael, refugees are seen as running the central market and as having a monopoly over certain trades or certain areas of that neighborhood. The consensus is that Bole Michael has developed because of the presence of the Somali refugees. It has become a business center where landlords are benefiting and where shopkeepers and restaurants have more customers.

"Somali refugees own cosmetics and sweets shops. There is a place called Somale Tera (synonym with beat) that only Somali-speaking people sell commodities." (FGD7.R4)

However, they are also engaged in selling commodities that the hosts consume, like halwa and sweets.

"They occupied Bole Michael. Now Bole Michael is like Mercato (the largest open marketplace), however, the majority of buyers and sellers are refugees. They own most of the butcheries where only halal meat is available." (FGD7.R1)

The research team observed that differentiating and identifying Somali refugees and hosts (Ethiopian Somalis) was challenging. Shop owners are therefore assumed to be Somali refugees.

In Gofa, Eritreans have given names to streets in the area, such as "Godena Harnet" (SSI6), which is emblematic of the close cultural ties between the two groups and the history of Gofa serving as a hub for Eritreans and Tigrinya speakers. The formal economy is less established in Gofa Mebrat Hail; therefore, refugees play a different role in the local economy. Rather than engaging in trade or business ownership, their impact is their spending power. As a local business owner in Gofa Mebrat Hail commented,

"We have many Eritrean customers. More than 85 percent of our customers are Eritreans. If you can give satisfactory service, there are good opportunities ... The positive side of the change is the fact that there is good economic activity in this area. The Eritreans, contrary to the economic slowdown in our country, get remittances. For instance, I know an Eritrean who used to eat his breakfast, lunch, and dinner in our restaurant. You can imagine how difficult it is to frequently eat in a hotel." (SSI1)

The dominant demographic group in Gofa is young, single, male, and female refugees. Remittances therefore play a dual role. First, local business owners (especially landlords) can capitalize on a group with a high degree of purchasing power; and second, host community members often feel gentrified, associating the increased cost of living with the presence of refugees in the area.

Rural to urban migration, particularly among youth, can partly explain the poverty and criminality in some areas.

"Recently, there has been an influx of youth and children [from the adjacent countryside] into Addis Ababa, and it is beyond the government means to take care of all the needs of these children with regard to education, shelter, and employment. People with means should pitch in to accommodate the youth's needs. It gives me great distress watching those youngsters doing menial jobs, chewing khat, smoking shisha, drinking, and ultimately growing up without education. People ultimately resort to theft and other vices if they are needy or lack education to get employed. So, effort must be exerted by the government and other stakeholders to get them to school and finding them employment." (SSI2) 
The missing actors of the ecosystems are aid organizations. This perspective is shared among youth as well as the elderly. An older sick Somali man explains:

"There is no visible intervention from the NGOs because they are the ones who are ruining my life. I have lived here in Ethiopia for nine years, they are wasting my time, because every time I ask them to help me they say to wait and that they will help but they are not." (SSI14)

Some refugees even claim that most of their problems stem from miscommunication by aid organizations that are not "honest about the support issue." (SSI15) One refugee participant explains:

"[UN agencies] say that they will support the refugees in the area of skill building; they promised to give the refugees trainings on business management and entrepreneurship, financial support for the new business, and help the refugees to get licenses for their business, but until now there is no action taken, it is just word of mouth. They want to entertain the refugees on such activities, but the reality is that they don't want to do anything for the refugees." (SSI17)

One Eritrean refugee expressed concerns over the lack of information provided to them,

"Where do you get the information? You go to the ARRA office to have your identity card renewed or for marriage issues and things like this. The same is with the UNHCR office but, who gives you the information about job opportunities, educational opportunities ... ? Basically, organizations such as UNHCR don't give you information. How can the refugee know the existence of opportunity? Four-five years ago meetings were organized and notices were posted where we live. You need to have a person or an organization to inform you about the existence of employment and educational opportunities. Most of the refugees have no information." (FGD4.R5)

Frustrations over the lack of relevance of the UNHCR refugee card compared with a citizenship card brings to the fore the lack of progress and change.

Gender and youth issues transpire in both locations. Women feel unsafe at night.

"Currently in Bole Michael, a girl or a woman can't freely move after 9:00 pm. This is because many youths are sexually harassing them." (FGD6.R4)

"I am a nurse by profession. Sometimes drunkards might sexually harass the nurses while they are providing them professional support. One night, I was treating a drunkard guy [patient] who had an accident. He holds my hand and he tried to force me to have sexual intercourse with him. Fortunately, because of my friends I escaped. Besides, some of the patients came to our bedrooms and try to abuse us. So, in general, the environment is not safe at all for girls and women." (FGD6.R5)

\section{Key themes}

\section{Identity and aspirations}

Where are the refugees from, when/why did they arrive? What are their future intentions? Where are the hosts from? How long have they been living in this community/region? What does it mean to be a "host community"?

"In early years, there was more affinity between Eritreans and Ethiopians." (FGD1.R3)

Generally speaking, the memory of unity and camaraderie toward Eritreans remains but is stronger with older generations. 
"Let alone Eritreans with whom we share cultural, language and religious commonalities we consider Somali to be part of us." (FGD2.R5)

\section{Refugees as temporary guests}

The transient nature of refugees' stay reveals a critical feature of their intentions: refugees are seen as temporary residents (FGD4.R1). The aspiration to leave the country might lead some refugees not to invest in their lives in Ethiopia, whether in business, education, or relationship-building (Betts et al. 2019a).

"This creates bad feelings in the hosts. I mean, I may go back home or continue to another country as I wish. This understanding doesn't create good feelings in the hosts. They feel as if you are misusing them."

According to a recent study, over 90 percent of refugees aspire to move onward, mainly to Europe and North America (Betts et al. 2019a). Resettlement remains the key aspiration for Eritrean and Somali refugees in Ethiopia (Samuel Hall 2014). One interviewee speaks of resettlement, even at the age of 62 :

"My plan is to move to Canada through UNHCR's resettlement program. When I came to this country, my plan was to leave this country, and now I have the chance." (SS12)

Hosts speak of the temporariness of refugees' stay and the coming and going of refugees, a sentiment often heard in Bole Michael:

"Most of the businesses that are owned by the Somalis are Ethiopian Somalis. Most of the refugees have left, only few are remaining, and those remaining are here to go to other countries."

A key informant speaks of Addis Ababa and Ethiopia being part of refugees' exit strategy.
"They use Addis for transitory purpose, their interest is not to live in Addis, but to spend some time in Addis, in Ethiopia and to go abroad. I think for the Somalis, they use Ethiopia as an exit strategy, not as a final destination." (KII5)

Time is prevalent in the host discourse, pointing to different integration pathways between

"those who stayed here for a long time [and who] have become familiarized. I have even forgotten that they are from another country. Though we don't have interaction, they are agreeable in what we tell them. The new ones, maybe because of their short stay, they tend to isolate themselves. They don't give you a chance to interact. Moreover, due to their huge numbers, they want to limit their interaction to their own society. I haven't seen them participating with the locals. I think they need time." (FGD3.R5)

Although Ethiopians often consider "refugees as members of society" (FGD3.R1), they speak of differences in behavior and cultural differences between hosts and refugees: hosts often speak of Somalis and Eritreans speaking loudly, shouting in a way that disturbs Ethiopians. Refugees explain that although Ethiopians are welcoming, "a refugee is always aware of his status as a refugee" (FGD4.R5), with the continuous feeling that they will remain as "guests" in Ethiopian society (FGD2.R3) and that they will struggle more in terms of accessing financial services, land, and work. (FGD2.R3)

The tension between these aspects-the hope for resettlement and transient nature in Ethiopia, as well as the self-perception that the refugee label is permanentare related to the psychological impact of protracted situations.

"Well I can say two things. One is, if the stay here [Ethiopia] is protracted and you really can't secure a job and pursue your education, then in effect it 
becomes mental torture. It makes you dull and numb. Secondly, considering the place where we came from; where expression of thought is curtailed, we [refugees] feel relieved as we have found heaven on a temporary basis. As your children and wife are around you; you start to spend your days being quite hopeful, awaiting resettlement schemes to a third country. But if your stay protracts, it makes you mentally numb." (FGD.R3)

\section{Ethiopian identity}

Refugee presence influences the identity and aspirations of hosts. One 45-year-old Ethiopian respondent and his wife are contemplating becoming refugees themselves in the United States. Have they been influenced by living among refugees in Gofa?

"In the earlier days, I had no intention to go abroad. But the instability we are witnessing these days in this country doesn't make you feel comfortable, especially when you have children. It is horrifying. Even our small children are worried. If the situation had not been so threatening, our country, Ethiopiawhere we were born and brought up-is unparalleled. To go abroad means to become a refugee."

Hosts also note the impact of refugees on practices, notably on Ethiopian women and girls. In Bole Michael, the arrival of Somali refugees has been accompanied by new commodities, such as cosmetics. The hosts explain that most Ethiopians were not heavy users of cosmetics, but now they are, even though the quality of the imported cosmetics is low (SSI11).

The presence of refugees has also led to instances of mobilization among the host population.

"Somali and Eritrean refugees are better off, they buy groceries and pay high rents. Eritrean refugees drink and get in trouble with the host. People in Addis Sefer [a neighborhood adjacent to Bole Michael] have now decided not to rent their houses to Eritrean refugees. Host communities there held a demonstration to ask the government to expel Eritrean refugees from their neighborhood. Eritrean refugees have political sentiments, and when they get drunk, they bring out their country politics. They blame Ethiopia for their problems." (FGD7.R2)

Eritrean refugees feel they may be misunderstood, noting that the urban landscape of condominium living limits their interactions with the host community.

"You don't interact with Ethiopians if you are living in a condominium ... The reality is different when you are living in compounds. In condominiums, you don't have much to share. For instance, you have your own toilet. On the contrary, if you are living in a compound, you share a lot of things such as common oven, common toilet, common working area in the compound, and the like. Hence, your interaction increases significantly. So, as a resident in a condominium, I can only identify myself with the Eritreans."

\section{Self-reliance and access to services}

What are the characteristics of vulnerable households? Which refugees are better and worse off? What access to services (e.g., education, health, water, and energy) do refugees have? Which are integrated services? Are services spaces/sources of interaction or conflict between refugees and hosts?

\section{The internalization of status and legal procedures} Access to services is determined by status. Refugee status determines the type and level of access one has to services, as well as the expected level of self-reliance. While the urban refugees under the Urban Assistance Programme are resettled in Addis Ababa on the basis of particular needs, where they are granted access to services, especially health care, but others, such as urban 
refugees under the out-of-camp policy, are expected to be self-reliant, forgoing any type of support so they can live in Addis Ababa. Since they are permitted to live in Addis Ababa, they can access municipal services, but they must pay their own medical bills. They must declare themselves self-reliant-whether or not it is true. Additionally, there are refugees who are directly registered in Addis Ababa, such as Yemenis and Syrians, part of an eclectic collection of refugees of 21 nationalities (KII1). Unregistered refugees have no access to services.

Access levels to health care are widely disparate across groups, while access to education is fairly equal: anyone except undocumented refugees, can access schools. UNHCR used to pay for the education of the registered and special populations in private schools, but this ended in 2017. The support provided has been homogenized into assistance to public schools.

Refugees note differences in treatment between them based on nationality.

\footnotetext{
"When it is time for a holiday, we are given $\mathrm{Br} 500$ by

DICAC, but Syrian and Eritrean refugee community receive $\mathrm{Br}$ 800. I don't understand how we can be different from one another." (FGD2.R3)
}

Syrians are rarely viewed positively, compared with beggars who ask for money from the host community, thought of as not being officially registered, and under suspicion for potentially carrying out terrorist activities (SSI11).

Refugees depend on hosts for access to coupon stores (which allow Ethiopian citizens to buy essential goods at subsidized prices). The coupon scheme is seen by many as a normal feature of refugee life, but others say it limits self-reliance among refugees. By law, refugees cannot access the coupon store without a coupon card given only to Ethiopian nationals.
"It is hard to get sugar and other basic commodities as we are not allowed to access the coupon store without having the coupon card; and to have the coupon card you need identification cards, which obviously we lack. It would go a long way to mend relations and alleviate the sense of tension if we were allowed to access the coupon store with our own refugee cards. There is also the case where some Ethiopian landlords don't want to rent their homes to Eritreans; and we have to go back and find an Ethiopian who can sign the contracts as a guarantor on our behalf with the house owner. This issue would be resolved if refugees were allowed to rent a house with their own ID cards. Now, I believe this would give me a sense of balance when compared with the local community.

A coupon is like documentation. Some refugees say that coupons have become a crucial legal and economic card.

"If you don't have the identification given by the local administration, you cannot secure a coupon for yourself. Refugees don't have any problem with water and the like, which is connected to the house they rent. But if they go to the consumer's association without the coupon, they simply don't get services. They buy sugar at double the price outside the consumer association. Here, lies the difference between refugees and hosts." (FGD3.R1)

Landlord and coupons. Other refugees have internalized the fact that, as refugees, they must have intermediaries through whom they can-indirectly-have access.

\footnotetext{
"There is equal access of services provided both to host and local community. For example, my landlord lends me his coupon card, and I simply have to go to the kebele ${ }^{57}$ to take out the subsidized goods. Whatever I need be it sugar, oil, I stand in queue like the rest of the people and get what I want." (SSI7)
}

57. A kebele is a local administration unit. 
Legal procedures set refugees and hosts apart. ARRA handles all aspects of refugee issues and documentation, with no linkage to the local administration. It not only prevents further interactions, it also prevents the local administration from being able to plan or include refugees in public service delivery and resource allocation for the municipality and its neighborhoods. Identification is a local issue: ID cards are given based on the location of residency. A new ID card is issued to nationals who change their residence. However, that is not the system for refugees who receive their IDs from ARRA; regardless of where they live, ARRA determines their access to services.

\section{Equity and access to basic services}

Hosts speak of improved access to services resulting from the presence of refugees:

\begin{abstract}
"Because of refugees, there are now a lot of new services like hospitals, schools, and formal jobs for the host community." (SSI1)
\end{abstract}

Many refugees have come to Addis Ababa to access health care, directly impacting health service provision but also creating a general demand for shops. One interviewee explains that

"host women can get work opportunities near to the refugees places." (SSI1)

Services mentioned include health care, education, security (police), water, loans, and Internet/communications. Access to these services is the same for refugees and hosts in Bole and Gofa in Addis Ababa, these remain public services administered by the government. The privately run services are also accessible but dependent on the financial capacity of the particular group. While equal access is recognized, refugees question the quality of services.
"The government services are not well integrated. Hospitals, for instance, I took my young sick daughter to a government hospital; the Tukur Hambasa hospital. The issue is that the doctors we were meeting at the hospital are interns or students from public universities who are still in the learning phase. I have seen eight doctors already for my sick daughter. It has discouraged me: I wanted to meet specialist doctors." (SSI7)

Those who can afford it will rely on private services, which are administered equally to refugees and hosts alike.

The housing lottery system. The "condo lottery" is part of the Ethiopian Integrated Housing Development Program's response to the uncontrolled growth of urban centers and lack of decent housing. The government constructed thousands of condominium houses in multiple towns across the country with the aim of transferring houses to citizens at affordable prices. Nearly one million people registered during the 2005 and 2013 campaigns, and an estimated 150,000-200,000 houses were constructed. Due to financial problems and lack of construction management skills, the program has been deemed a disaster, with soaring prices and considerable delays. Some of the host members interviewed for this study explain how they won a housing lottery-the Ethiopian government draws names to determine who receives the condominiums with a very low mortgage rate paid over a long period of time. This lottery is not available to refugees.

Electricity has improved in Bole Michael. Alongside the rise in other services, one of the most visible changes noted by host members is access to electricity.

"In the past, the government used to cut the power from the Bole Michael section, where the refugees and the majority of Somalis people live. After the power cuts, the police would start arresting people in Bole Michael. These actions used to make us feel unsafe. These issues thankfully don't exist any longer today, there is permanent electricity in Bole 
and it's peaceful with different communities living here peacefully." (SSI17)

On the other hand, access to water is still uneven for all, with reported water shortages at both locations because water is still supplied in shifts to refugees and hosts alike. Both hosts and refugee raised the issue of insufficient water wells.

Access to justice remains a significant-and often overlooked-challenge to refugees. In principle, refugees are entitled to access the same protections and rights afforded citizens under the justice system. In practice, however, this is an area that is difficult for a refugee to navigate. As a staff member of NRC explains:

"We know so many refugees with issues of criminal cases, they cannot access lawyers, therefore with the language barriers and not knowing how the court systems work and the court structures ... they cannot access it. Yes, access to justice is available for refugees, but how they access it is not supported by any of the implementations. (KII1)

The question of quality and access to services is closely tied to one of identification and contributions. "Refugees should contribute to services" and "NGOs should disburse services equally across the host community" are sentiments that were echoed during focus group discussions with host community members in Bole Michael.

"Refugees should benefit the host community. They should help in setting up schools and hospitals. In order to get services equally, they should also contribute. The government should provide them with identification cards, which allow them to work and live anywhere. In support of the government, NGOs should also support the establishment of schools and hospitals that both refugees and hosts can use equally. With their presence, the host community must also get benefit. NGOs should also engage in availing groceries both for refugees and host communities."
A 45-year-old Ethiopian restaurateur in Bole Michael explained the existing committee-led community work, whereby everyone contributes money to the local committee. Through the community funds, improvements have been made to security, infrastructure, and roads, including the building of cobblestone roads, fencing, and other activities run by the committees. However, these committees require more support.

When it comes to education, one constraint is the lack of report cards or equivalent documents for refugee children. While refugees do have access to public schools, some Eritrean families are unable to enroll their children or have been denied access because they were unable to produce report cards for their children's schooling. A respondent notes that "most refugees get here without their educational credentials and certificates of their vital events" (FGD1.R5). This is confirmed by hosts who are concerned about the lack of schooling for some Eritrean refugee children.

"While our children are learning, there are Eritrean kids who waste their time by playing in the vicinity. This is the time when they have to attend school. Sometimes, I try to approach them and they tell me that some of them are waiting to go abroad, they have come here dropping their education ... I feel sad because I have children at their age. This is the age that they should attend school. Missing this opportunity could result in moral failure later on." (SSI1)

Despite these difficulties, hosts noted that refugee children are among the best ranked students in the local schools. One interviewee explains that in Bole Michael, his child attends a school where the majority of students are from Somali-speaking families.

"Most high scorers in the school are children of refugees and Ethiopian Somalis." (SSI10) 
In terms of vocational training and skills building, on the other hand, NGOs are seen as giving refugees preferential treatment.

\begin{abstract}
"[The centers] are following the 70/30 principle. This means the NGO is providing 70 percent of skill training for the refugees and 30 percent for the host communities. I recommend the NGOs should give equal opportunities, particularly skill training for the unemployed youths of the host communities. This would help the refugees and hosts to live together peacefully." (FGD6.R2)
\end{abstract}

Constraints surrounding financial services. Access is harder for refugees at formal markets and to financial services. Ethiopians' mobility is seen as an advantage in this regard.

"The Ethiopians can buy from other places because they know the language and the places so they can buy cheaply, but the refugees can't go to far places." (FGD2.R4)

Another participant at the same focus group disucussion confirms this.

"The hosts can access banks, they have access to the market, they can sell anything, but the refugees are not allowed to have those. The refugees buy from the cheap corner of Bole Michael for groceries." (FGD2.R3)

The most uneven access issue surrounds banks and financial services. Refugees do not have access to financial institutions and cannot open savings accounts. They speak of applications for savings accounts being rejected by banks after seeing their refugee IDs. For banks in Ethiopia, the refugee ID is insufficient, equal to a travel document, not an identification document (FGD1.R5). During some interviews and focus group discussions, the
NRC was mentioned as an NGO that has worked with refugees to help them open bank accounts (FGD6.R2). NRC acknowledges the issues they have met in their work, confirming that

"some banks recognize IDs, and some don't. They do not allow refugees to open bank accounts." (KII3)

Extensive work is needed to sensitize local stakeholders, such as service providers and banks, to the pledge and the new proclamation in terms of recognizing and providing legal identification to refugees, and to inform these providers about the types of entitlements, rights, and obligations that come with these new identity documents. In parallel, refugees need to be made aware of the rights and services that they can demand of these actors.

"We don't borrow from each other. Even the identity paper we have doesn't enable us to get bank services. Now things are improving. We can have a savings account at Wegagen Bank. We have a bank account with the commercial bank that we secured with the identity paper we have. We were able to do this at one area, known as Atlas. But we can't withdraw money from any branch of the commercial bank. We are supposed to use only the branch at Atlas. How can I go there every time I want their service? The only thing that I could do is just to leave my money where it is in the bank. We aren't allowed to borrow money from the bank anyway." (SSI5) 
New initiatives are also mentioned, such as a revolving fund for unemployed youth that resembles a microfinance initiative by the government. However, the services of this fund are not availed to refugees, only to local youth. Overall, refugees are barred from joining community-led or social saving schemes. To be granted access to the Edir or Okub, they need to show title deeds of cars and houses or their permanent residency (FGD2.R3). As a result, refugees are often unable to access community groups. Host community members can use their IDs as collateral to borrow money. Host community youth are now able to access loan services or group-based loan systems to set up small businesses. Refugees do not have such access but may receive in-kind loans from shops owned by Ethiopian Somalis or seed money, or in-kind support from NGOs. Most importantly, they rely on remittances from their friends and families living abroad (Mena 2017). Remittances are a key coping mechanism for refugees and fuel the local economies of Bole Michael and Gofa (FGD6; FGD10).

\section{Coping Mechanisms}

What are needs of the refugees and hosts? What positive and negative coping strategies have been adopted?

\section{Language and learning}

Language learning is happening among both groups: hosts in Bole Michael are learning to speak Somali, and in Gofa, refugees are learning to speak Amharic. Some hosts work as translators (locally called toorjuman) to help newly arrived refugees interact with the Amharic-speaking host community (Mena 2017).

\footnotetext{
"Learning the language of the host has opened a way to improve my relationship with them." (FGD2.R5).
}

Hosts and refugees agree that the language barrier is the first source of conflict. As one of the host participants of a focus group explains,
"The language barrier is the source of conflict. Refugees interpret our speech as an insult or as an intention on our part to marginalize them. They are hot-tempered. They carry knives. If they interpret our speech negatively, they point the knife at us. Thus, the language barrier is the cause of tension." (FGD7.R5)

Mixing children of refugee and host communities in schools is seen as bringing in many benefits. Somali schools in Bole Michael are considered, even by the host community, to provide a high-quality education. As a result, host parents are sending their children to these schools. One of the first barriers their children face is one of language.

"I sent my daughter to a school dominated by Somali-speaking students. My daughter only speaks Amharic. My daughter and other Somali-speaking students fought in the school. How would she be able to communicate with other students? They accused my daughter as if she insulted the student. But she asked the student to leave her alone. The school is purposely set up for Somali-speaking students. We do send our kids to this school because they provide quality education." (FGD7.R6)

Language and the lack of social interaction are obstacles to scaling up trade between the groups. It is recognized as a barrier to economic participation.

"I am a trader by profession, and I usually encounter situations where they [Eritreans] come to me; but as it gets difficult for all of us to communicate, they leave my shop to a nearby establishment where the shop keeper happens to be a Tigrinya speaker." (FGD2.R2)

To improve trade and economic interactions, hosts suggest using social management committees to strengthen social cohesion and economic interactions among groups to ensure that both communities adapt to each other and 
learn each other's languages and preferences at events organized by a social management committee.

"Refugees don't have any social life with the locals. They feel that the country they are living in isn't theirs and the host community considers them as refugees, and they don't interact with us. But in marketplaces, they interact normally." (FGD4.R5)

The hosts are learning to adapt to the refugees. As seen previously in the testimony of the 45-year-old restaurateur and seen again in the testimony of a shop owner in Bole Michael:

"I am a shopkeeper. The Somali refugees do business with me. I have a good relationship with them. I provide services much better to the refugees than I do to the hosts because I do very good business with them. They do buy commodities with higher prices. They pay without creating any complexity. In general, they get priority of getting services in my shop. However, some Somali refugees have aggressive behaviors. They easily get upset. So, I am taking care of them because I need to make my own business." (FGD8.R1)

Refugees also report that business owners can take advantage of them by charging them more. Hosts and refugees alike report that landlords and businesses often increase the price of commodities when approached by refugees. They charge different prices to refugees and hosts for the same goods. Language is a limiting factor preventing refugees from bargaining; and this is often used against them. At the same time, some business owners feel threatened by a growing refugee customer base. During a semistructured interview for this study, one refugee described how he has had to develop his soft skills and adapt the way he handles his customers when interacting with refugees.
"If one Somali refugee hates you, all the others will similarly hate you and stop buying from your shop. That is why I usually treat all the Somali refugees with care. Even sometimes, some of the Somali girls try to steal from me. When I see them, I keep quiet because I do not want to lose the other customers." (SSI11)

\section{Social mobilization and support}

Host community members, supported by the police, have been calling local meetings to resolve sources of conflict. A focus group discussion in Gofa revealed meetings held with police staff at a local police station to address concerns over Eritrean youth defined as being "deviant" or having "manners that are out of place," such as smoking shisha (FGD2.R2). One proposed solution is to put refugee youth in special camps to preserve the general public. Other solutions include setting a closing time of 10:00 p.m. for the shisha sheds and pubs and limiting the number of tenants per house on a lease.

Living in groups is one of the primary coping mechanisms used by refugees in Addis Ababa. "Clustering is viewed as a way of avoiding isolation" (Betts 2019a). However, hosts do not take a positive view of this; they link the high numbers of refugees in housing arrangements as a source of both inflation and chaos.

\footnotetext{
"Refugees living in groups are more likely to make unnecessary noises that can cause tension. They don't want us to bring together large groups over three to four persons." (FGD4.R5)
}

Some hosts living in the poorer neighborhoods of Gofa and Bole Michael see refugees as a potential source of money, which can distort their relationships with them. As one participant reports, the monetary value of refugeehost interactions is an obstacle to further interactions. 
"In Eritrea, if you ask someone for help, he does it very willingly. But here, for every help you ask, you have to pay money. So, it is difficult to interact with them [the hosts]." (FGD4.R1)

Landlords are seen as a source of access to services but also of restrictions. A refugee explains that her landlord does not allow her to use the electricity for cooking, forcing her to use a petrol-based cooking machine, which causes her respiratory problems. Similarly, he will not let her use the water to wash her clothes with a washing machine; she is only permitted to wash clothes by hand. So, although she pays rent, which includes electricity and water, she is not given full access to these resources (SSI16). A focus group in Gofa confirms similar mistreatment by landlords. One young refugee explains that he was not allowed to dry his clothes on the yard rope, being told to "dry it over your body," which made him feel "like an animal" (FGD9.R5). Refugees think that most of the conflict between themselves and hosts arise from issues around the home, such as rental fees, broken materials, and the use of water and electricity.

\section{Refugees' relations with host communities} and other stakeholders

The overall outcome of discussions shows that while refugees and hosts meet in marketplaces, restaurants, on the street, and in building blocks, they do not have strong social relationships (FGD3.R5). They know and understand one another, but the different groups keep to themselves socially.

\section{Impact on local actors}

What are the implications for local actors-public and private, formal and informal-of the refugee presence? How have the social organization and structures changed in the host community? In what ways has the arrival and protracted stay of refugees impacted this evolution? What changes have been triggered by the arrival and ongoing presence of refugees?

\section{Local urban and economic development}

Local urban development since the arrival of refugees is widely noted and, for the most part, has been positive. Hosts who have been living in Bole Michael for decades explain that with the coming of Somali refugees into their neighborhood, the locals began building houses to rent, setting up hotels, and contributing to a cleaner and more pleasant neighborhood setting.

\begin{abstract}
"This area was once a place for urination and waste disposal. With the influx of Somali refugees, big buildings, hotels, and malls have been built. The number of hotels in this neighborhood is countless. People who have appointment with Embassy use rooms in hotels." (SSI10)
\end{abstract}

The changes happened across the last two decades, benefiting hosts in terms of their living environment (cleaner and better kept) as well as economically.

"I worked as a taxi driver and then set up a boutique. Of the 10 people I served, nine of them were Somali refugees. In my progress, the contribution of Somali refugees is enormous. The change is mostly positive."

The local economic development of "Small Mogadishu" has accompanied such urban development. The demand for services created by the hosts is closely linked to improved infrastructure and services.

"Before any refugees came to this area; all members of the community had a low income. All the hosts had almost similar living standards. But, when the refugees came to this area, things completely changed. This area became more civilized and advanced. It became a market center in which many job opportunities have been created. Similarly, the living condition of the landlords improves. They build many, nicer houses. As a result, their income has increased." (SSI9) 
Box A.1. Community Consultation Highlights Misunderstandings About Inflation

During the community consultation, hosts agreed that refugees are blamed for inflation. Such scapegoating is often based on a misunderstanding.

"Ethiopians think that Eritreans have money. That they can afford to pay expensive house rents, they can eat and drink as much as they like. Because of this, the host community says the Eritreans caused the inflation. But the Eritreans actually don't work, and they don't have any source of income. Most are educated and highly skilled people who can deliver services but are denied the opportunity. Eritreans only interact with their own people when they have social gatherings because they don't have the opportunity to work together with the Ethiopians." (27-year-old host)

The presence of refugees also plays a role in internationalizing the local economy through diaspora links, as refugees engage in transnational networks (Brown et al. 2018). This is reflected in the presence of many imported products, such as clothes, cosmetics, electronic items, food, and beverages (Mena 2017).

Host members have benefited from these developments at disparate paces. Discrepancies within the host population highlight how landlords become richer while the urban poor become marginalized. While part of the host population has become "very rich, ... poor host communities become the poor among the poorest" (SSI9).
It has become more difficult for the poorest to meet their basic needs as prices of commodities increase, with a notably negative impact of population growth on inflation and on the purchasing power of the poor. While Bole Michael has become a convenient place for the refugees; landlords; and those running shops, restaurants, and hotels, some are finding themselves pushed out of the area due to the rising cost of living. However, changes are overwhelmingly seen as positive and benefiting a broad group. Economic benefits have led to peaceful coexistence.

\section{Housing market and inflation}

Host communities mainly complain about the rise of rental prices and the shortage of housing. The main issueacknowledged by refugees and hosts alike-is that refugees rent houses at higher prices-prices that Ethiopians cannot afford. Ethiopians are then unable to rent houses, while refugees can.

\section{"The worst impact of the refugees on the lives of the host community is related to the problem of house rent. Otherwise, the refugees don't have a negative impact as they are self-sufficient." (SSI3)}

Refugees are known to pay more, as a broker in Bole Michael explains:

\footnotetext{
"The Eritreans and Syrians, they can pay, whatever the amount they are given, it is ok because if they rent one house they share it with so many people ... The Somalis are also like that, especially the Argesa Somalis, they don't use beds, only mattresses, so they have all mattresses in the house and have so many of them in one room." (SSI4)
}

While this increases business for landlords and for service providers in the area, creating jobs, it is also changing the urban fabric in places such as Bole Michael, creating tensions. Both groups call for policy changes to regulate rental prices in refugee-hosting areas. 
"If you could intervene in the increasing cost of living and house rent, I would be very glad. Why are we being asked to pay more as compared with the Ethiopians? If the locals are asked to pay say Br 4,000-I am talking about the earlier days, now it has reached up to $\mathrm{Br} 8,000$-they will not agree to pay. On our side, we rent it in groups of five or six. This has also negative impact on the locals. They are being pushed away to the outskirts of the city where rent is cheaper as compared with the central part. They are going to areas known as Gelan, Summit." (SSI5)

The reason refugees pay higher rents-and sometimes higher commodity prices as well-is threefold:

\section{They can afford to pay more because they receive} remittances in foreign currencies, such as the U.S. dollar. A female host shop owner explains that the Ethiopian government benefits from receiving foreign currency:

"With the lack of foreign currency in earlier days, we were not receiving proper medication" (FGD3.R3).

At another focus group, hosts explained that Somali refugees receive remittances from abroad, which means that they are targeted with higher rent because they are seen as having more money than the Habesha (host) community (FGD6.R6). The purchasing power of the Somali refugees in Bole is seen as being higher than that of the hosts.

"If the Habesha is able to pay $\mathrm{Br} 1,000$, the Somali refugee will pay $\mathrm{Br} 2,000$ or more." (FGD6.R6)

\section{They cannot bargain rental prices due to the language} barrier and the lack of local knowledge. They end up agreeing to whatever price the landlords request of them. They are often also pressured and threatened by landlords, with forced eviction being a common threat if rents are not paid on time (FGD9.R3).

\section{Box A.2. A Focus Group Discussion on the Tensions Around Rental Prices}

"The locals accuse us of being the cause for the increase of house rent. They say everything increased when we came." (FGD1.R2).

"It is they [Ethiopians] who are the root cause of the rising house rent and stuff. I mean the first time I arrived here I didn't know a word of Amharic. When I went out to the market to do my grocery, their merchants demanded high prices and as I really did not know the price and could not haggle, I just gave them whatever they asked for. I mean the merchants are Ethiopians, they should have called the right price to begin with." (FGD1.R3)

"In regards to house rent-we are not paying willingly ... We have no other option than to give the house owner whatever he is asking as we got nobody to go to." (FGD1.R4).

\section{They live in groups and share rent, allowing them to pool} funds, each individual paying a part. It puts less pressure on a single family or individual. The "group living" among refugees has an economic impact (on house rentals), but it is also seen as a practice that has negative social impacts. In Gofa Mebrat Hail, Eritreans rent accommodations in groups of four or five. They jointly rent studios, partitioned areas of businesses and stores, and apartments. Studios rent for about $\mathrm{Br}$ 1,000 and condominiums for about $\mathrm{Br} 4,500$, while locals used to rent the latter for about $\mathrm{Br}$ 1,800 (FGD4.R3).

"I am the auditor of the social committee here in Mebrat Hail, and when we call for a meeting, the house rent is listed as a major problem for the locals. The other issue is that, day is night and night is day for refugees. They are loud and roam the streets at night." (FGD2.R4) 


\section{Box A.3. A Semistructured Interview}

"The price of injera has risen to $\mathrm{Br} 7$ or $\mathrm{Br}$. The poor who live here are finding it hard to survive. Imagine! An injera worth $\mathrm{Br} 7$ or $\mathrm{Br} 8$ is not enough for a 10-year-old kid. The cost of 1 kilo of shiro has increased to $\mathrm{Br} 50$. The cost of living has become unbearable. I have three children, and we all have stomachs to fill. As it is summer and the school year is over, I got my 15 -year-old son a job so he could pitch in. We, the poor, can't bear the situation. I hear people in other blocks discontent about those Eritreans who rent a house in group of seven and eight. They say they are the reason why house rent is increasing. I don't know how this particular issue is seen by the government. But I don't think this is appropriate [renting a house in groups]. There is also the disturbance issue: you can't get to sleep even if you are sick." (SSI3)
Hosts say they bear the greater financial burden because they live in nuclear family structures rather than in groups (FGD2.R3).

The shortage of housing has worsened since the recent peace agreement was signed between Eritrea and Ethiopia; landlords have been raising rents and asking tenants to vacate. Demand is rising, and costs are increasing. Poor host members complain of the unaffordability of rent in their own country.

\footnotetext{
"The ever-hiking rent price, which is only affordable to refugees, is causing tension. Our people can't afford to pay equally like the Somali refugees. Due to this, there is a tension. People raise a concern and get irritated that in their own country, they fail to get affordable rent while refugees are taking those houses. They feel as if their right is stripped off. I haven't seen any other source of tension in my neighborhood than housing issues" (FGD2.R2).
}

The poor are pushed further out to the city's outskirts.

"There is tension among the hosts and the refugees. This is mainly because of inflation created because of refugees' presence. The poor ... are leaving Bole Michael and renting houses in Bole Bulbula, where rates are lower." (FGD8)
Another respondent confirms this.

$$
\begin{aligned}
& \text { "As a solution the hosts are leaving Bole Michael and } \\
& \text { renting houses in other periphery part of the city." } \\
& \text { (FGD8.R3) }
\end{aligned}
$$

For some, the competition over access to housing is an opportunity. The research team conducted a life history with a broker in Bole Michael that is illustrative. $T_{--}$, a 36-year-old industrious man, moved to Addis Ababa from Gondar when he was 13 years old to escape "dememeless"-the Amharic word for revenge.

\footnotetext{
"My uncle killed someone, so he left to Welega, and the only family member left was my father, but he died, and I am the only son. After my father died, my mother had children with someone else. So, I was the only one left from this family. This is why I had to leave."
}

In Addis Ababa, $T_{---}$held numerous jobs while continuing with his education.

\footnotetext{
"I started working in welding, they paid me $\mathrm{Br} 200$, it was still very difficult but I needed the money so I took this job. I worked there for two years until I finished my studies."
} 


\section{Figure A.3. Lifeline of a Host Community Member, Addis Ababa}

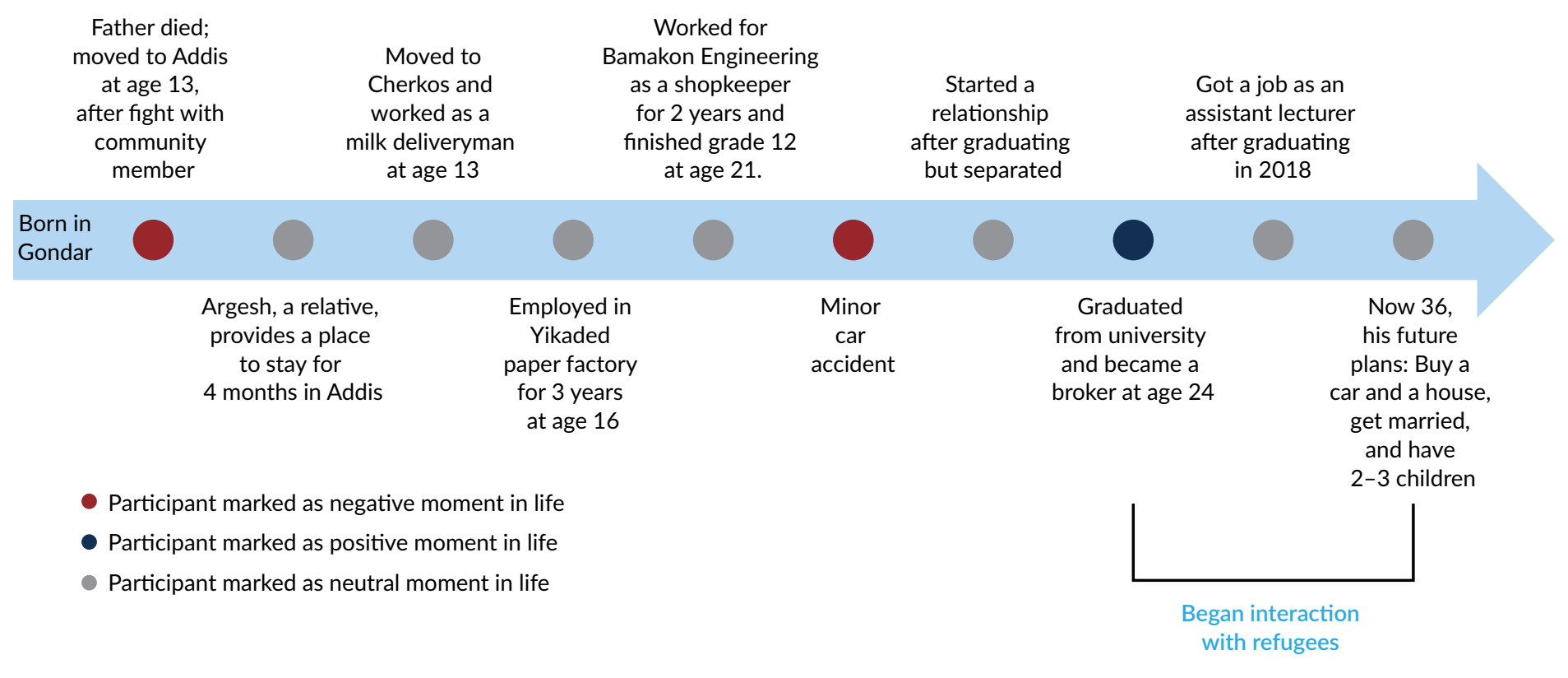

His fortune began to change when he graduated from university and became a broker working to sell or rent houses. His profession is lucrative amid the housing crisis in Addis, and refugees are his primary customers.

"I know if there are Ethiopians or refugees because normally when they come, the refugees don't speak Amharic, so they come with a translator, for example, if they only speak Somali. ... Yes, with the refugees, especially the Eritreans and Syrians, they can pay, whatever the amount they are asked."

Brokers occupy a niche position in the social environment of Addis Ababa and are important actors for both the refugees and the host community. For refugees, brokers offer a crucial solution to poor access to information and lack of social networks, two resources necessary to secure housing in a city struggling to accommodate its residents. But brokers are also seen as agents of gentrification, pushing out locals who cannot afford to match the prices refugees are willing to pay.
"They [the hosts] even tell brokers that after the refugees came to this area, it became more expensive, some left the area and went somewhere else."

In a city where youth unemployment is high, the presence of refugees has opened up opportunities for young graduates who are unable to rely on their degrees to obtain jobs or ensure their social mobility.

"After I started working as a broker, I started making good money so financially it was a positive change in my life."

\section{Changing social dynamics and social norms}

Changes in social dynamics and norms concern the host populations in Bole Michael and Gofa. Much of the tension seems centered around the preference of many Eritreans to be active at night. Hosts see refugees as living differently than they, and provide several specific examples, discussed below. 
"Refugees live at night." Due to the lack of daytime employment and livelihood activities, refugees tend to go to bars, pubs, and clubs while Ethiopians would prefer a more peaceful and quieter environment in which to rest and sleep after a day's work. Urban development in such areas has been accompanied by more pubs than had previously existed in the middle of residential areas. Hosts worry about the impact on their children and on women.

\section{"Refugees are louder than Ethiopians" and "refugee} youth drink alcohol and use khat." Hosts see refugees as being more susceptible to becoming addicted to drugs or alcohol. In Gofa, for instance, members of the condominium administration committee explain that residents complain of loud disturbances, drinking, and fighting.

\footnotetext{
"Youth are unemployed. The status quo is not sustainable. The government must assist refugees and expedite their resettlement program. Joblessness makes youth vulnerable to addictions, such as chewing khat, drinking, smoking shisha ... These vices lead to fights and killings." (SSI2)
}

"Refugees do not respect the local order." Refugees acknowledge that idleness among youth is clashing with the local way of life. During a focus group, a young refugee explains:

"Ethiopians have jobs and go to bed early. Their children go to school and get home early as their parents are waiting for them at home. But we [Eritreans] hover around like stray dogs and get home loud, drunk, and late. This situation tends to get us in trouble with our neighbors." (FGD1.R5)

The addiction rate among youth, the presence of night clubs, shisha houses, and khat users have increased the frequency of negative interactions between refugee and host youths (FGD6.R6).
These elements are seen as "disturbing Ethiopian society," with practices that "do not go with the Ethiopian culture" (FGD3.R4). Hosts do not consider the refugees who have been living among Ethiopians for years to be the problem; they are instead focused on recent arrivals. Some refugees feel that whatever they do, they will be negatively perceived and blamed as the source of all economic and social problems in their areas.

\section{"They blame us for the rising cost of living. It is diffi- cult to understand their feelings; as a result, we don't feel good." \\ "Everything has become expensive since the arrival of the Eritreans," (FGD4.R4),}

Refugees often hear sentiments that diminish their sense of self and confidence.

"You cannot be equal."

Some hosts defend the refugees, claiming "we are not added" (FGD4.R3), referring to an expression that has become common in Ethiopia since Prime Minister Abiy has come to power. It translates to the willingness among some to integrate refugees in the public discourse of unity.

"The recent influx has made a negative impact, especially in relation to sanitation. The problem that comes with the increase of population is obvious. There is an impact on tranquility and sanitation. They are not accustomed to our waste disposal system. They drop waste materials on the road. They don't put it in the garbage tin. Moreover, they don't participate in communal cleaning initiative. Most of them consider it as if it doesn't concern them." (FGD3.R5)

Population growth and group living are seen by hosts as putting a strain on the availability of water and is linked to sanitation-related concerns (FGD4.R2). 
Waste and waste management are seen as a rising source of conflict. Hosts have organized themselves to elect local representatives for each building. Refugees are not necessarily a part of this effort, but they are thankful that the host population is trying to coordinate with the entire community. Eritrean refugee interviewees explain that they do not feel that they will be listened to if they ask neighbors (members of the host community) to be mindful of waste. There is a business area on the ground floor of almost every building, which refugees and hosts care about, but waste products are sometimes found in such bases. While Eritreans cannot speak up to the locals, Ethiopians can do so easily.

\footnotetext{
"When I see an Ethiopian spilling dirty water in my vicinity and I ask him why he does that, the response is not respectful. Such attitudes from the host community can generate bad feelings in the mind of a refugee." (SS16)
}

\section{Conflict-sensitive analysis}

Who sees the refugees as essential? What/who stands out as the main obstacle to refugees? What are the existing frustrations and tensions that require mitigation? What conflictresolution and peace-building mechanisms and institutions currently exist? How effective are they? What recent changes have been implemented in the prevalent rules, incentives, and social norms that govern interactions?

Individual-not community-wide-conflicts

Misunderstandings are frequent, with tensions rising between individuals more than groups (SSI6; SSI7). Common issues include the choice of played music in a bar. Such disputes do not rise to the community level, nor do they pit groups of refugees and hosts against each other. Frictions tend to be restricted to individuals, some of whom seem to pose specific threats. According to one host member in Bole Michael:
"Somali refugees are holding knives. So, if there happens to be conflicts, they attack the host community in groups using the knives." (FGD6.R1)

Another respondent explained that he does not fight with Somali refugees because he knows the potential consequences, as they are known for carrying knives and moving in groups (FGD6.R4).

Violence by hosts was also anecdotally mentioned by refugees. One focus group participant explained that, on the eve of a holiday, Somali women had returned to a shop to change the size of a dress bought for one of their children. The shop owner not only refused to serve them, but he beat them so badly that the ARRA ambulance had to be called, which took them to the hospital (FGD2.R3).

Spillover violence and threats from various sides have been noted, mainly due to the political developments in Ethiopia over the last 18 months. The peace deal between Eritrea and Ethiopia has led to new refugee arrivals, creating new tensions. Young Eritrean youth, often between the ages of 13 and 20 are coming to Ethiopia on their own:

"... without their family or moral compass, such as their fathers and mothers back home. These youth get hooked on khat, alcohol and other vices." (SSI7)

Similarly, there are concerns that the volatile political situation in Ethiopia could "flare up" and that police would then target refugees. More structural safety concerns relate to political instability and fear of recent upheavals and events, notably in the Amhara regional state where the head was killed.

"I feel safe where I live. The time when I was afraid was last week with the killing of the Army chief and the regional government officials." 
Regional conflicts in the Oromo and Somali Region have reportedly created a sense insecurity among the Somali refugees.

"Yes, I feel safe here now. But there was a lot of insecurity last year. Somalis, especially the SomaliEthiopians, were brutally targeted by the Oromo people, since we are all Somalis, these conflicts affected us, and we felt unsafe, but nothing happened here in Bole Michael." (FGD9.R1)

Finally, conflicts within the host community are rising, linked to the presence of refugees, rising rents, and inflation. While some landlords are seen as benefiting economically, others, particularly the urban poor, are growing increasingly tense.

"Conflicts among the host communities have increased because of the refugees' presence. As I observed in Bole Michael, the landlords are enforcing the host renters to leave their home to rent to refugees. That is why conflicts are happening among each other." (FGD8.R4)

\section{Remittances and language as sources of conflict}

Some refugees speak of a criminal practice, referred to as "hang," which consists of beating people up and then robbing them. It is a common crime in Ethiopia and now also targets refugees in Addis Ababa.

"Recently a crime known as 'hang' is being committed on Eritreans. This is done on the assumption that Eritreans are getting remittance. We Eritreans are seen differently. Even house rent increases differently on Eritreans. If you rent a house for $\mathrm{Br}$ 4,000 per month, you are asked to pay more in the following month or to leave the house." (SSI5)

"The tensions will remain until they speak our language or we learn their language." (FGD7.R5)
The mention of language as fundamental to refugee-host interactions was raised in all interviews, across groups and demographic profiles. Not only is language a common form of verbal exchange, but it is also important when handling disagreements. The role of mediators and interpreters is seen as positive.

"The problem between my daughter and the boy at school was solved with an interpreter." (FGD7.R6)

Others consider the problem to be more profound than only language. They speak of lower tolerance thresholds in places like Bole Michael today compared with the past.

"These days conflict easily develops due to failure to understand each other. The emerging problem is the lack of tolerance. Previously, people listened to each other. We lost that patience, with trivial disagreements between individuals; from there, you will see later a group conflict developing. People are now flaming minor disputes. The other day, a violent conflict happened in this neighborhood. During those days, our revenue declined. The source of the conflict was a lack of tolerance, not other factors. One person was assaulted by a certain youth from a certain ethnic group, the next day the ethnic group of the assaulted person waged a group conflict on the ethnic group of the perpetrator." (SSI10)

Another focus group raised a similar issue, linking intolerance with hosts' lack of patience with refugees.

"They really are growing impatient with us. One sister was telling me that they [Ethiopians] are getting used to saying that we are a constant figure wherever they go: in bars, coffee shops ... and that they couldn't go outside as they can't stand watching us anymore. This wasn't the case a couple of years ago. Back then, they used to tell us of wonderful memories they shared with our older brothers and sisters." (FGD1.R5) 
Unresolved tensions facing all groups

No effective solutions seem to be offered to address these tensions. The police are known to get involved in cases of theft and break-ins, some of which are caused by refugees, others by hosts. However, focus group discussions reveal concerns over the activities of and indiscriminate use of violence by the police.

"Now, there are police who take rounds at night, and I believe it is a good thing. However, the police are supposed to ask you to produce some sort of identification instead of hastening to beating you up. There are Eritreans beaten up without being asked for any form of identification. ... Some policemen threaten that they will take you if you don't pay them bribes. This sort of thing is happening. I know a friend who, while on his way home, he came across these policemen who beat him up with a butt of a rifle, and they threatened to take him to prison if he did not pay them a bribe, so he did. I also know some friends just four days ago were beaten up and later sent home." (FGD1.R3)

Police inaction is another concern. The police are seen as being insufficiently reactive to fights and alerts.

"They show up after you are beaten. ... These days, you can't walk at 10:00 to 11:00 p.m. We ask: 'What are the police doing?' People are dying during the day and nighttime. Recently, four men were beaten at 10:00 p.m. There are thieves from both the Eritreans and Ethiopians." (SSI4)

Insecurity is not attributed to one specific group but rather to a local problem of rising theft and beatings taking place day and night. At night, a lack of lighting and limitations on movement make neighborhoods particularly vulnerable to crime.
"There are places that are known to the community where these problems take place. At times, they beat you, but the aim is to just take your belongings. People are seriously injured in the process. No one exactly knows who the robbers are." (SSI6)

Respondents believe that communities should be able to solve problems, either with mediation through the elderly or a greater tolerance within and among groups.

"NGOs can create the platform for dialogue among groups; they can work to strengthen interactions. They can do this by opening schools, health centers, and youth centers that all can get services equally. Host communities and refugees should participate in planting trees, cleaning their environment, and playing sports. This will strengthen our interaction and can serve as a good platform to solve problems. This will also minimize the likelihood of conflict. Largely, our relationship is restricted to trade. But life is not only about trade, there should be platforms that help to achieve better interaction." (SSI10)

There are also reports of gender-based violence occurring.

"I know of an incident where an Eritrean girl hailed a taxi. He molested her. We took her to ARRA, and ARRA sent us to the hospital for check-ups. At that point, she was physically fine. But, five months later she came to know she was pregnant. There are incidents like these." (FGD1.R4)

\section{Social organization}

How and where do refugees and hosts interact? What are the "places of connection" for refugees and hosts? How are refugees and hosts spread out and organized? What are the formal and informal leadership structures? What are the roles and functions of community organizations? What is the level of interaction among groups and with key stakeholders (e.g., kebele development committees)? 
Civil society engagement constrains and limits local mobilization

A semistructured interviewee in Bole Michael echoes comments that refugee-host interactions are limited to trade and the economic sphere. He encourages the research team not to assume that there is a specific mode of social organization between groups.

"Honestly speaking, the interaction between the host and refugees is not so big, apart from some transactions in daily life, we cannot say these are socially interactive people, and there is no kind of community-based organization here." (SSI15)

One of the additional limiting factors is structural. Under the previous government, civil society engagement was constrained.

"It will take many years to get that culture going again. There had been a cultural, social, and economic decimation of civil society organizations so there isn't much of a culture for it as a form of mobilization. People keep to religious institutions and church groups, informal savings groups, and mosques. Community mobilization is very weak to nonexistent."

This explains why there is a complete absence of community-based organizations in Bole Michael and Gofa Mebrat Hail.

When respondents were questioned about social organization and mobilization in Gofa, their responses were the same. They are unaware of community-based organizations, only referring to condominium administration committees that hold regular residents' meetings across a number of building blocks. While refugees are not barred from joining these meetings, the content is geared toward host community problems (not refugee problems) and communal activities, such as cleaning up campaigns that can benefit everyone (SSI6). Block representatives are seen as powerful sources of communication between refugees and hosts and within specific groups.

Events around clean-up campaigns that address concerns over sanitation are welcomed by all and are a good opportunity to strengthen interactions and relationships. Eritrean refugees also join these efforts.

\begin{abstract}
"The social sanitary campaigns we do around our block [picking and clearing garages] together with them [Ethiopians] strengthen relationships. We even contribute money so our neighborhood stays clean. Unfortunately, it seems these are the only events which the locals approach us as they need our help and money. I mean why shouldn't they approach us other days to hear our concerns too?" (FGD1.R3)
\end{abstract}

The issue of language is raised again in relation to social organization. The lack of language skills leads to insecurities and a lack of self confidence among refugees, which in turn limits social interactions.

\begin{abstract}
"I feel a bit insecure and not sure of myself when talking to a local person as I feel I am less eloquent when it comes to language, so I withdraw from expressing ideas in a conversation." (FGD1.R3)
\end{abstract}

"You tend to belittle yourself in the presence of locals, you are less sure of yourself, you feel less confident when talking to them [Ethiopians]." (FGD1.R2)

"There is also the case where the locals assuming that you don't speak the local language [Amharic] tend to gossip about you-this again puts you off. This is why we don't build good relations with them." (FGD1.R3)

One opportunity to address the language gaps and create a safe space involves relying on the positive role of religious institutions as places of connection. Mosques use mixed languages-Amharic, Somali, and 
Arabic-preaching and delivering messages in multiple languages (FGD7.R3).

\section{Places of connection}

Due in part to the lack of other civil society organizations and community-based organizations, churches, mosques, and religious institutions play an important role in bringing together refugees and hosts. Meetings between groups happen in markets; at hospitals when receiving medical services at the same time; and in recreational spaces, particularly when playing soccer. Refugees and hosts also convene during specific times, such as holidays, births, and funerals.

"They accept our cultural routines as their own and accompany us during our funeral and when a woman gives birth. We do the same when they encounter those vital events." (FGD6.R5)

Some Somali refugees report that, in recent years, the soccer field has become a place where refugees can be kicked, robbed, and have the shirt stolen off their back, but such instances are rare.

The main locations and events for interactions are listed in order of importance:

\section{- Bole Michael}

"We interact at the mosque, the market place and meet at the UNHCR office. We mostly meet at the churches or mosques when there are community meetings in the kebele."

"I think the refugees and the people interact more at the market but also when the youngsters play football [soccer] at the football field." (A2.FGD2)

\section{- Religious institutions}

"In religious institutions there is no discrimination." (SSI13)
"Be they Protestants, orthodox Christian or Muslim, refugees maintain good relationship with host communities. There is a strong interaction between host and refugees in religious settings regardless of nationality differences." (FGD6.R3)

"I think it is good if churches, mosques and the like can help in educating refugees. Religious institutions such as churches and mosques can help in making them believe that there is no one who hates them: they have to know their rights and obligations and behave accordingly." (FGD3.R5)

"You can go to church and congregate like any other local. Religious elders are working to bring the two societies together." (FGD5.R3)

- School and sports (e.g., soccer), social events (e.g., weddings, funerals, and births), and holidays

"There is an annual religious holiday such as Mariam Ginbot $^{58}$ where the whole block pitches in financially and we all gather at the grounds of the block and chat while having tea, coffee and bread. This is really exciting to me! I just love it! The money to celebrate such holidays is collected by knocking door to door." (FGD1.R3)

\section{- Coupon store; pubs, cafés, restaurants}

- Transportation services, taxis

\section{- Local administrative structure (kebele)}

- Okub. A local savings association where each person contributes money and takes turns to take the whole sum at the end of a certain period of time. Okub runs at the household level. People save with people they trust. NRC explains:

58. "Mariam Ginbot" is a religious celebration which falls on May 9. It is widely celebrated by followers of the Ethiopian Orthodox Church. 
"It is not possible to see who is entering to these venture as it depends on social ties. Refugees who have good social ties with their Ethiopian neighbors can loan money until their next remittance comes or until the next round of assistance comes from the UN, in the meantime, they have this supporting mechanism." (NRC)

"We have an Okub that consists of five membersthree of which are Eritreans. We contribute money once a week." (SSI3)

- Edir-a traditional form of social organization whose members assist one another specifically during times of mourning. Monthly financial contributions are made to the Edir fund, and members are entitled to receive a certain sum. The rates vary based on the level of proximity of the Edir member to the deceased. The support can be used to cover financial expenses associated with funerals and deaths. A refugee can be a member of an Edir alongside the host, however, none of the interviews from this study revealed the existence of mixed Edir groups. While refugees and hosts do participate in joint Okub, they are usually not part of each other's Edir (SSI10).

Knowledge of these two forms of association-Okub and Edir-is not always present. Most refugees know of them but do not participate.

"I haven't come across refugee members. As far as I know, there is no rule that segregates refugees. Personally, I haven't seen refugees asking for membership in the associations I mentioned." (FGD3.R5)

Furthermore, the transient nature and temporary stay of refugees helps account for the limited refugee participation in Okub and Edir. Refugees confirm that their preference is for short- over long-term plans, such as savings agreements.
"Refugees live here temporarily and expect to leave as soon as possible. This attitude doesn't favor longterm involvements. Okub is all about saving, and they can make savings starting from $\mathrm{Br} 50$ in banks. In the case of Okub, I prefer to put my money in the bank." (FGD3.R3)

Another refugee respondent explains,
"Because we don't settle in one place, we are the least bothered in joining such associations. Personally, Edir is a long-time commitment: it takes time and energy. And you need to stay put for long, but I move from house to house looking for a cheaper rent." (FGD5.R5)

The occasions where refugees participate in these groups are still rare. Limited social interactions and legal obstacles continue to constrain the economic well-being and further economic interactions of refugees. Their lack of access to financial institutions and loan mechanisms remains a barrier both in terms of social and economic participation (A2.FGD4.hosts).

Mixed interactions (mixed marriages, mixed schools) Some report that mixed marriages are common among Somalis, Eritreans, and Ethiopians. While interactions began in the marketplace and continued at school and through educational opportunities and further skills training, such links have also been consolidated through marriage.

\begin{abstract}
"Somali refugees open Internet centers, shops, restaurants and other shops like butcher shops by marrying with the hosts. Golis Hotel is one example. The owner is Somali. Currently, they are running a big business. Most refugees do eat and sleep at that
\end{abstract} Hotel." (SSI9)

Another respondent explains that Ethiopians are increasingly getting married to Somali refugees, affecting changes in the community. This market transition is seen as one 
trend linked to mixed marriages between refugees and hosts.

"Their dress, food, and living styles have changed. The numbers of mosques and butcher shops have increased. Currently, there are many cosmetic shops, shisha shops and club nights in Bole Michael. Previously, these shops were not available in this area." (SSI11)

As for the younger groups, youths who attend mixed schools are better integrated.

"The youth of the refugee and host have a good relationship with one another. They play football [soccer] with one another or use the Internet at the school cafeteria." (FGD2.R2)

Cultural differences are still strong, and while youths may attend school and play soccer together, the hosts are still wary of mixing their children with refugee children.

"This is because, as I have mentioned, they have deviant behavior when compared with our children. If you offer to any of our children khat to chew, they would refuse; and if you want to take our children to shisha houses, they wouldn't go. They just make groups among themselves and mingle around. They don't want to join the social gathering of our youths. It is not that our youth are segregating them but they [Eritreans] don't want it." (FGD2.R2)

Hosts who participated in a focus group discussion echoed this sentiment.

"Children who are brought up here and the children who come from there [Eritrea] are different. If a child from the host community interacts with the child from the refugee community, he is more likely to learn unethical behaviors. So, we prefer to keep away our children from the refugee children." (FGD3.R1)
A lack of youth centers that can embrace host and refugee groups in Gofa and Bole Michael is among of the gaps raised during this study. In Bole Michael, an Ethiopian youth explains that he meets Somali youth at game centers, where they play electronic games and ride motorcycle simulations, or on the soccer field. The opening of game zones happened with the influx of refugees:

"Before their arrival, we had no access to game zones. It is after the refugees' arrival that many game zones and Internet cafés opened. This created [recreational and employment] opportunities for Habesha youth." (FGD1R4)

The host community assumes refugee youth need support because many of them lack family structure. Discussions with the Danish Refugee Council confirm this.

"There are youths without the family structure to support them or even a community structure that replicates a family structure" (DRC)

This is especially the case in Gofa Mebrat Hail, where the dominant demographic group consists of young female and male refugees. This group often has its eyes set on resettlement to a third country and is unable to work. Idle and without family structure, many engage in what the host community deems deviant behavior-often cited as the main source of community tension. Providing jobs to young refugees has been touted as a solution by several host community members, according to a member of the neighborhood committee.

"The refugees should be assisted by NGOs, the government, and the rich. This will delight me. How can they be beneficial to us when they can't even earn a living! If they had employment and somehow were deviants, that would have been another matter, but these people don't have any employment to begin with." (SSI2) 
Box A.4. A Community Consultation: "There is no place where people do not interact"

One community consultation conducted for this study revealed that places for interaction abound. Language is the main constraint. According to one older refugee representative:

"Christians meet at the church. Muslims meet at the mosque. We meet inside transportation services. We can say there is no place where people don't interact. If there were work opportunities, there would be even more interactions. Another reason why there is less interaction is because of the language barrier. If I can only speak Tigrinya, I can only interact with people who can speak Tigrinya. If I only speak Amharic, I can only interact with people who can speak Amharic. If I can only speak Arabic, I can only interact with people who can speak Arabic. Even if a person goes to a bar, he can still only interact with the people that can speak his language. A person can't walk around with a translator." (54-year-old Eritrean man)

Finally, there are concerns over the lack of diversity on women's committees. The research reveals the existence of women's development teams organized on the basis of ethnicity, including the Amhara team and the Tigray team. The teams hold monthly discussions that do not include refugees.

\section{Economic interactions}

What trade systems and organizations are in place between hosts and refugees? What formal and informal livelihood activities do refugee and host communities pursue? Are they complementary or competing? What are the constraints to economic participation? How do refugees and hosts access financial services and resources? How do refugees and hosts save; how do they borrow?

\section{Mutual benefits over competition}

Refugees and hosts speak of their economic interactions as the strongest link they share. The hosts have homes they rent to refugees and businesses where they hire and serve refugees. Some hosts act as intermediaries for refugees to access goods at the coupon store. When trust binds the relationship, a host may lend money or other assets to a refugee. Many speak of a relationship that is noncompetitive and based on mutual interests (SSI17). One host restaurateur explains that he has adapted his business to better respond to the Eritrean population's demands and tastes. As a service provider, he has to give

\begin{abstract}
"due consideration to the Eritrean culture. We work hard to make them satisfied. When we study the nature of our customers we came to know that they were Eritreans. Then, we tried to study what their preferences are. For instance, they like pasta. Some others prefer injera. ${ }^{59}$ So, by serving them according to their preference, we have managed to build good relationships with them. The other thing is that they like football [soccer] very much, so we show them football games on the television. They like the premier league very much. I don't think that they relax even in Asmara as they do here."
\end{abstract}

Not all nationalities have an equal chance to engage in informal employment. Very few refugees from South Sudan or the Great Lakes are employed; and those from Eritrea, Somalia, and Yemen have greater access to Ethiopian-owned and refugee-owned businesses (Brown et al. 2018).

59. Injera is a sourdough flatbread with a slightly spongy texture. 
Informal agreements bind Ethiopians and Eritreans in economic activities. They open businesses together, such as Internet centers, restaurants, and butcher shops. Partnerships are generally privileged over competition (SSI6). Refuges are engaged in many small-business activities, such as roadside businesses, beauty salons, petty trade, and the selling of shoes and other small items; but they also work as laborers in urban construction, as nurses in clinics, and as translators assisting others in overcoming language barriers (Mena 2017). In Bole Michael, hosts recognize that refugees bring in cheap materials and equipment from Somalia that they can purchase, such as Somali cultural clothes, cosmetics, perfume, and shoes. At the same time, Somali refugees buy Ethiopian cultural clothes, foods, and meals, among other items, from hosts. There is mutual benefit from this interaction, which increases at wedding ceremonies, ritual ceremonies, and places of worship (SSI11).

A representative sample of common questions that arose during this study include:

\footnotetext{
"Why are we forced to pay money to Ethiopians in order to get a job opportunity?" (FGD1.R3; FGD1.R4).
}

\begin{abstract}
"How many times can you present your demands to the Ethiopians? They have sponsored us to come here from the camp. No, we can't ask them to start business on our behalf too." (A1.SSI2.Yohana)
\end{abstract}

\begin{abstract}
"We are working just to relieve our minds from stress. Otherwise we are not benefiting from it. ... It is joblessness that creates friction with our neighbors, and it is the reason why we live in [groups of] four so as to cope with the financial expenses." (FGD8.R3)
\end{abstract}

"I have been working as a housemaid with the Somali
refugees for the last 10 years. They have good manners. They do not like to lie or take somebody's property ... If they like you, they like you forever. If they hate you, they hate you forever. I am bringing up my child based on the income I get from these refugees."

"What she has been saying is correct. There should be some solution especially with respect to driving and business license. We should not have to lease business licenses from locals."

The forced cooperation between refugees and hosts is real, as there is no other choice for refugees until the new proclamation is implemented.

"As Eritreans aren't allowed to work, most of the small-scale jobs are done through cooperation: a business license on lease from an Eritrean, handling of paper works ..." (FGD2.R5)

In other cases, businesses are owned by Ethiopians but employ Eritreans.

"We have a job and they have a job but I don't feel there is competitive tendency among us." (FGD2.R1)

Hosts also work for refugees, notably taking on positions as domestic workers, washing clothes, or cleaning the houses of refugees (FGD7.R6). Host women explain that the presence of refugees has created job opportunities for women to work as domestic workers and for youth to work as taxi drivers (SSI10).

\section{Isolation in the job market}

Women interviewees describe feeling insecure at their workplace due to their refugee status. One woman explains that when she used to work as a hairstylist in an Ethiopian-owned hair salon, she felt isolated. The first opportunity she heard of to set up her own independent salon, she was faced with barriers to entry. 
"I don't think most of them are forthcoming in helping you out with your situation as a refugee. Later, I tried to open my own hair salon following new guidelines issued by ARRA for refugees to work. Even though I obtained the proper supporting letter from ARRA, when I got halfway through my application, it was denied. Imagine! I wasted time and energy navigating through these bureaucratic offices and got to a dead end. Apparently, the law isn't that clear cut. The laws passed by a certain agency are completely alien to another office. So, when that didn't work out, I had to lease a license from an Ethiopian and that costs a lot of money-you have to bribe your way to get it. That's why most Eritreans stay home all day long because of this problem, not because they hate work. I spent a couple of months without a job the first time I got here." (FGD1.R3)

Refugees also complain that they are not authorized to form cooperatives or to establish a business. To form a cooperative, a person must be a legal resident and have a resident identification card. To have that, they must rely on the support of Ethiopians. Otherwise, they cannot participate in economic activities, which often results in a sense of boredom and despair (Betts 2019a). Hosts see things differently. They do not believe that avenues are closed to those "who really want to work."

"Eritreans who open hair salons, barber shops, and snack bars, or work as a shoe shiner. For those who intend to stay on a permanent basis; an awareness campaign should be given on the importance of holding down a job, job ethics and social norms." (FGD.R2)

Discussions confirm that refugee women are marginalized from economic activities.

"There is nothing to help incorporate women in business ventures or otherwise." (FGD2.R4)
"There is an attitudinal problem among our own people too. If a Somali refugee woman engages in a coffee business-like operating coffee shop-no one drinks her coffee. They consider her as unclean and culturally inappropriate. I believe this attitudinal problem has constrained them from participating in economic activities." (FGD7.R4)

The importance of remittances and aid money to the local economy

A recent study by the Oxford Refugee Studies Center found that 31.89 percent of Somali refugees and 69.12 percent of Eritrean refugees receive remittances (Betts et al. 2019a), a key source of income to cope with the cost of living in Addis Ababa. Refugees and hosts acknowledge that the remittances sent from abroad nurture the local economy. As one respondent explains,

"When we [refugees] send money to Somalia through local money transfer we use their service; when we buy groceries, we buy it from them; when we use transport service, the ones that provide this service are the persons from the local host community." (A2.FGD2.R3)

While remittances obtained in U.S. dollars are seen by some as the source of inflation and inequity between refugees and the poorest of the urban hosts, others explain the positive impact of remittances on hosts. The same applies for money obtained by refugees through UNHCR.

"The refugees use transport, they buy food items from the community, they rent from the local host community. We are useful to the hosts and to the government thanks to the money we bring." (A2.FGD2.R5)

The host community recognizes this. Some hosts point out that the acceptance by the community has increased because refugees are seen as having "good money" (FGD6.R6). 
Part of the money, however, goes to drug and khat use. Frustrations arise as refugees are seen as being dependent on aid and remittances, while

"the host wakes up early at 5:00 a.m., waits for the public bus, spends the day making a living. In Bole Michael, the majority of khat and drug users are refugees, not the host. This is because the money they have is not hard-won. Refugees sleep the whole day and go out for clubs and pubs. The hosts cannot do this. If you sleep the whole day you will die with hunger." (FGD7.R3)

Money also goes into trade between refugees and hosts. Hosts note that refugees do not haggle or negotiate. This is among the real causes of inflation, according to participants of one focus group discussion (FGD2). While some blame remittances, aid money, and the growing refugee population, respondents in that group stressed that these factors are only partly to blame.

"If we assume the whole population of Addis Ababa to be $10,000,000$, they wouldn't even account to 100,000; so, I guess the effect of their stay here in regards to increasing living condition is really a drop in the ocean." (FGD2)

Instead, they focus on the inflated prices that merchants give to refugees, who do not know the context and do not negotiate.

"They do not know how to haggle with prices at the market-they simply hand over whatever is asked by the merchant-but again, money is remitted to them from abroad but we haggle with prices at the marketplace. This usually affects prices during the holiday season and the effect isn't exactly the same for both of us." (FGD2.R3)
This is confirmed by a trader who explains that refugees

"just pay whatever price is being asked by the merchant. They lack the basic skills on how to use money wisely and when you come to think of it-as they live in groups-they just share whatever is the cost. The money they spend is not hard earned, it is remitted to them. They spent it all and wait for the next batch to arrive." (FGD2.R2)

One of the risks of these economic interactions is that the poorer hosts are discriminated against. Even when employed, their salaries are lower than the remittances and aid money that refugees receive. With their small salaries, they cannot afford the commodities and products that merchants sell at higher prices to refugees.

"I was with my friend looking to buy clothes from a boutique. In the meantime, a refugee came and the merchant left us immediately. Since we are poor, merchants prefer them. The other thing is that they should learn to work and make a living on their own. This way, they understand how we make a living. If they use the remittance and aid to set up businesses we will also have the opportunity to work with them." (FGD7.R5)

Refugees understand the hardships that the urban poor hosts face and recognize the low wages given to them. One refugee explained that even if she wanted to work,

"the payment they offer to us is very small due to the fact that we have no alternative. I can't benefit from this kind of employment. It is futile. I tried to work in an Internet café. They offered me a monthly salary of $\mathrm{Br} 600$ only. This can't cover my expenses of house rent, clothing, etc. it is useless and tiresome." (SSI2) 
One of the hopes for host youth is the rotating fund set up by the government, which allocates money to job opportunities for youth and women. Respondents report that they have not yet seen this being implemented.

"Most of us, including myself, have a shortage of capital. There are ways of getting loans. But it would be fine had it been done without asking for collateral security to motivate businesses in due consideration of their performance only. There was a loan that my wife received. It was funded by the World Bank to assist women at a very low interest rate. But the government incorporated it with the microfinancing program, and the loan was given at a higher interest rate, so it would be good if NGOs could play a role in providing capital and giving professional training that is in building capacity. In the earlier days, when loans were given to the youth, they were not accompanied by training and consulting. Thus, they were using the money to go to South Africa. It is not only for lack of job opportunity that the youth is resorting to go abroad through illegal means. Mainly, we are lacking proper management of problems. If they are not trained to change their lives by working in their country, if they are not [taught] to love their country, the provision of loans is not sufficient." (SSI1)

\section{Conclusions}

While policy implications are critical and evolving, host and refugees alike lack preparation, information, and awareness regarding policy changes and activities of the government, United Nations, and NGO activities. Common statements made across the board include not seeing any development or any change in practice and not hearing of opportunities being offered by the government. Beyond resettlement, refugees' interactions with NGOs are limited, and their expectations from those interactions are mainly focused on their hopes for resettlement. Others have raised the need for local support in getting business and driver's licenses. The volatile security and political context is a concern for refugees and hosts alike. Both groups highlight the fact that the next few years will be challenging for them and a test of the government's ability to include refugees in its safety net programs while also controlling their impact on the country's economy.

It is widely agreed that key programming elements are needed to support the ongoing processes of integration. Among these, both groups highlight how essential youth-based programming that goes beyond refugee/ host dichotomies and targets demographic groups is to the future of the relationship between their communities and local integration. A key demand from hosts is to find work and a sense of purpose for refugee youth to prevent jobless youth from roaming the streets at night.

The need for more sources of information and more accessible sources of information is highlighted. Refugees would like to be able to get information from a physical place situated in an area that they can access easily, with information on employment, education, and registration. Finally, hosts and refugees speak of the need to build health, education, and clean-up campaigns to get groups to work together more closely and to interact through their children and in their neighborhoods. The need to nurture feelings of togetherness by teaching children on another's language is key to the future of integration. One crucial feature raised during multiple conversations is the importance of language as an obstacle to integration. Livelihoods and language are the two factors that all respondents agree on, and that the community consultation concludes are the two main obstacles to integration between groups.

While social dynamics have been generally positive, respondents are worried that patterns of exclusion are being formed. While some host community members consider refugees to be a threat, they may also suffer from a sense of injustice. Hosts benefit from the refugees' presence but 
also suffer from it as they are being pushed to the outskirts of urban areas, unable to afford higher rents. Refugees also feel a sense of injustice due to cases of forced evictions. Both groups feel that the government is not hearing them, and both face challenges in accessing justice, which requires one to have information about one's rights, where to go, and how to access remedies. There are additional barriers for refugees, including cultural and linguistic, that further constrains their access to justice.

Host members suggest arranging monthly, biannual, or annual meetings with the government or concerned organizations to explain to hosts and refugees the benefits of interaction and integration. This space for dialogue is needed as part of integration programs As one woman explains:

"The fact that we have a common social life has to be inculcated in the minds of both groups-the refugees and the hosts. We don't know each other. We have different perceptions. We could be afraid of approaching one another." (FGD4.R2)

\section{References}

Abebe, T. 2018. Promises and Challenges of Ethiopia's Refugee Policy Reform. Institute for Security Studies.

Betts, A., L. Fryszer, N. Omata, and O. Sterck. 2019a. Refugee Economies in Addis Ababa: Towards Sustainable Opportunities for Urban Communities? Oxford: Refugee Studies Center, University of Oxford. https://www.rsc.ox.ac.uk/publications/refugee-economies-in-addis-ababa-towards-sustainable-opportunities-for-urban-communities.

Brown, Alison, Peter Mackie, Kate Dickenson, and Tegegne GebreEgziabher. 2018. Urban Refugee Economies: Addis Ababa, Ethiopia. Working Paper. London: International Institute for Environment and Development.
Buscher, D. 2003. Case Identification: Challenges Posed by Urban Refugees. Geneva: Annual Tripartite Consultations on Resettlement.

Campbell, E. 2006. "Urban Refugees in Nairobi: Problems of Protection, Mechanisms of Survival and Possibilities for Integration." Journal of Refugee Studies 19 (3): 396-413.

Crisp, J. 2004. Local Integration and Local Settlement of Refugees: A Conceptual and Historical Analysis. New Issues in Refugee Research, Working Paper No. 102. Geneva: UNHCR. https://www. unhcr.org/en-us/research/working/407d3b762/local-integration-local-settlement-refugees-conceptual-historical-analysis.html.

EC (European Commission). 2016. The European Union

Emergency Trust Fund for Stability and Addressing the Root Causes of Irregular Migration and Displaced Persons in Africa: Action Fiche for the Implementation of the Horn of Africa Window. European Commission.

Mallett, R., J. Hagen-Zanker, N. Majidi, and C. Cummings, with G. Sturge, K. Schaefer, and P. Vidal. 2017. Journeys on Hold: How Policy Influences the Migration Decisions of Eritreans in Ethiopia. Working Paper 506. London: ODI. https://www.odi.org/publications/10728-journeys-hold-how-policy-influences-migration-decisions-eritreans-ethiopia.

RSC (Refugee Studies Centre). 2019. Refugee Economies in Addis Ababa: Towards Sustainable Opportunities for Urban Communities. London: Refugee Studies Centre.

Salem, R. 2013. Understanding African Refugees Integration in Cairo through the Eyes of Underprivileged Host Communities. Cairo: American University in Cairo.

Samuel Hall. 2014. Living Out of Camp: Alternatives to Camp-Based Assistance for Eritrean Refugees in Ethiopia. Commissioned by the Norwegian Refugee Council. https://static1.squarespace.com/ static/5cfe2c8927234e0001688343/t/5d5294e624fd2f0001 52d679/1565693209831/Living-Out-of-Camp-Alternative-toCamp-based-Assistance-in-Ethiopia.pdf. 
The New Humanitarian. 2018. "Eritrea-Ethiopia Peace Leads to a Refugee Surge." The New Humanitarian.

UNHCR (United Nations High Commissioner for Refugee). 2012.

Finding Durable Solutions: UNHCR Global Report 2012. UNHCR.

UN-Habitat. 2017. The State of Addis: The Addis We Want.

UN-Habitat.
Webster, S. 2011. "Getting Beyond Politics and Bad Blood: The Protection of Eritrean Refugees in Ethiopia." Unpublished MA Thesis, American University in Cairo.

Mena, W.B. 2017. "Assessing the Local Integration of Urban Refugees: A Comparative Study of Eritrean and Somali Refugees in Addis Ababa."

Zetter, R., and H. Ruaudel. 2016. Refugees Right to Work: A Labour Market Assessment. KNOMAD. 


\section{B. Benishangul-Gumuz}

\section{Study Areas, Groups, and Types of Refugees}

Sherkole camp is located in Benishangul-Gumuz, a 40-minute drive from Assosa. The camp opened in 1997 to accommodate Sudanese refugees fleeing conflict in the Blue Nile and Upper Nile states of Sudan. At that stage, the camp was mainly inhabited by three Sudanese ethnic groups: (1) the Maban; (2) the Uduk; and (3) the Funj (Watol and Assefa 2019).

In 2005, refugees arrived from the Great Lakes region and Eritrea due to the anticipated available space at the camp following the Comprehensive Peace Agreement that ended 21 years of war in Sudan and paved the way for the United Nations High Commissioner for Refugees (UNHCR) to lead the repatriation effort of Sudanese refugees (UNHCR 2006). From 2006 to 2008, the number of refugees in Sherkole fell from about 16,000 to 4,000 after the voluntary repatriation (UNHCR 2006).

Conflict in North Kivu and South Kivu in the Democratic Republic of Congo in 2004 displaced many Congolese refugees, who fled into neighboring countries. A fraction of them made their way to Ethiopia.

\section{"Congolese arrived in this camp 15 years ago." (KII25)}

Conflict between rebel groups in Kivu displaced more people in 2012; a new wave of Congolese refugees therefore arrived in Sherkole Camp.

In 2011, following fighting between the Sudan People's Liberation Movement North and Sudanese government forces, Sudanese refugees fled into Ethiopia.
Reports speak of 34,500 Sudanese refugees entering the Benishangul-Gumuz region, which added to the estimated 4,000 Sudanese refugees already living in Sherkole camp since before the 2011 conflict (KII25). The South Sudanese civil war, which broke out in December 2013, also drove some South Sudanese refugees to settle in Sherkole.

"For most of the refugees from Sudan and South Sudan, the history of displacement of refugees is war." (KII27)

Thus, the refugees in Sherkole camp predominantly come from three countries. From the most recent figures that we could find from 2016, there are 6,083 refugees from Sudan; 4,723 from South Sudan; 607 from the Congo; and a handful from Burundi, Tanzania, and Uganda (ARRA 2016). There are an additional 14,123 refugees in Tsore refugee camp (ARRA 2018).

The three groups have markedly different levels of interaction with the host community. Sudanese refugees have the most positive relationships with hosts due to historical cross-border, linguistic, and cultural connections. Even though Congolese are the third-largest refugee group, they have quite low levels of interaction with the host community. This is because Arabic-their dominant language-along with with a culture that is foreign to Congolese refugees, makes it difficult for them to form bonds with the host community.

To get to Ethiopia, Congolese refugees must travel through Uganda and Kenya. There are two main factors that influence the decision of Congolese refugees to settle in Ethiopia. The first is information about Ethiopia's refugee policy. 
"When we interview the Congolese refugees, they know the Ethiopian government. They have information. They settle in Kenya or some country but they choose Ethiopia because they have some information on how Ethiopia treats refugees. So now they cross Kenya, Uganda, and come to Ethiopia." (KII27)

The second is that there were elements present in the transit countries closer to the Democratic Republic of Congo that were similar to those that forced the Congolese refugees to flee in the first place.

"Ethiopia is far from our country. And we fled our country because there are some people who would kill us. So that is why we fled. When we reached Rwanda, the same people are in Rwanda, if you cross to Burundi, the same people are there. If you cross to Uganda, even to Kenya, many Rwandese who made the genocide, they crossed to Kenya. that is why some who cross the Ethiopian border say, 'this is a country far from our country, maybe those people who we fled from cannot reach us here.' That is the main reason why we came to Ethiopia." (FGD42)

In Sherkole, refugees are divided into zones based on their country of origin. Ethnicities mix within the zones-and the Administration for Refugees and Returnees Affairs (ARRA) claims that this form of organization is more organic than premeditated. In cases of intraethnic conflict, groups may be separated into different zones.

A novel feature of Sherkole camp is the fact that it is not enclosed, and management of the camp is more decentralized than camps in the Gambella region. In each zone, there is a zonal leader who is annually elected by the refugees. Zonal leaders coordinate with ARRA to manage the affairs of their respective zones.

"The camp is not fenced. The reason being, we are nine zones, we are all structures, zone A, B, C, D. ...
All the structures administer themselves. We have leaders from every zone. They administer themselves, their protection, all activities, so the camp is not fenced." (FGD42)

The main road runs through the camp, and the host community is situated in close proximity to the refugees. The absence of any fence creates the perception that there is no formal boundary between the host community and the refugee camps. The positive relations with the initial arrival of Sudanese refugees played a role in that. In addition, the construction of infrastructure by UNHCR and the ability to trade with refugees means that increasingly more host community members began settling closer to the camp (Watol and Assefa 2019).

\section{Limitations and Constraints}

The Samuel Hall team hired two local enumerators from Assosa after a vetting process that included conducting test key informant interviews. Once hired, the two enumerators were trained, and a one-day pilot was conducted two days before the fieldwork was scheduled to begin. The pilot went well, and the team was scheduled to start the following day. However, on the first day of fieldwork, both enumerators failed to show up for work and were unreachable by telephone or text. The Samuel Hall team used their contacts and found two translators to work with: one from the refugee community and the other from the hosts. A brief training was held with both individuals. To ensure quality, a Samuel Hall staff member conducted all of the interviews with the help of live translation. This ensured that the interviews were conducted properly and that all pertinent follow-up questions were asked. A limitation of live translation is that not all answers could be fully conveyed or translated, as the translator would summarize or edit parts during live translation. However, adequate measures were taken during the transcription period to ensure that no meaning was lost, including listening to the original audio files to complete the transcripts. 


\section{Context of Displacement}

Established in 1997, Sherkole is among the oldest refugee camps in the country. It was created to accommodate Sudanese refugees fleeing the civil war. In 2005, as a result of the influx of refugees from the Democratic Republic of Congo, the Ethiopian government decided to relocate all asylum seekers and refugees from the Great Lakes to Sherkole camp (JRS 2005). In 2005 and 2006, a significant portion of the refugees returned to Sudan and South Sudan with the support of UNHCR and International Organization for Migration after the signing of the 2005 Comprehensive Peace Agreement (IOM 2013). But following South Sudan's secession in 2011, new arrivals of Sudanese and South Sudanese refugees were recorded entering Ethiopia in search of protection. In addition to Sherkole camp, two additional camps were established in Benishangul-Gumuz: Bambasi and Tongo. The inward movement of South Sudanese refugees continued in December 2013, when violence broke out between factions aligned to President Salva Kiir and his former vice-president Riek Machar (Akwei 2017). Since 2017, large numbers of South Sudanese refugees from overcrowded Gambella camps have been relocated to Benishangul-Gumuz. A new camp-Gure-Shembola-was established in May 2017 for this purpose.

Today, Sherkole camp accommodates almost 12,000 refugees from Sudan, South Sudan, the Democratic Republic of Congo, Burundi, Uganda, and other African countries. ${ }^{60}$ The majority of the population consists of Sudanese refugees originating from the Blue Nile and South Kordofan State of Sudan, who belong to the Funj, Uduk, and Nuba tribes (KII28, UNHCR). Most of them arrived in Ethiopia after 2011, fleeing the fighting between the Sudanese Armed Forces and the Sudan People's Liberation Movement-North (SPLA-N). South Sudanese refugees, however, are protracted: originating from Jonglei and

60. The figure as of January 31, 2018, was 11,826; see UNHCR, "Sherkole Refugee Camp, Camp Profile," March 2018, https://data2.unhcr.org/en/ documents/details/62699.
Upper Nile States, they have stayed in Ethiopia since 1997 (KII28 UNHCR).

In Benishangul-Gumuz, displacement is also internal. While there is a history of clashes between the Bertha and the Gumuz and between these two groups and their Oromo and Amhara neighbors, the multiplication of intercommunal conflicts over the past two years has reached new heights and has led to massive displacement, especially along regional borders. In 2018, tens of thousands of people had to leave the Kamashi zone in Benishangul-Gumuz-situated at the Oromia borderfollowing the killing of several officials in Oromia in retaliation for alleged attacks on the Gumuz people (Protection Cluster 2019). The capital of the region Assosa was also affected by civil unrest and episodes of violence. In 2019, clashes erupted in Metekel zone (along the Amhara border) and caused the death of dozens. According to the International Organization for Migration, ${ }^{61}$ those conflicts have displaced an estimated 19,752 individuals since September 2018. Due to ongoing conflicts and insecurity, humanitarian actors had difficulties accessing several parts of the region at the end of 2018 and in 2019. In May 2019, the Ethiopian government started rolling out its Response Plan to Internal Displacement and declared that 72,593 internally displaced persons had been returned to the Kamashi and Assosa zones (OCHA 2019).

\section{Governance and programming}

Governance and programming at the camp is split between the government (ARRA), international organizations (mainly UNHCR) and nongovernmental organizations (NGOs). ARRA is the primary actor responsible for camp management, providing protection, food, water, and basic services; it also directly manages educational and health facilities. The agency ensures the camp's security, including the resolution of conflicts among refugees or between refugees and hosts. However, when it comes to

61. IOM Displacement Tracking Matrix, March 2019, available at https://displacement.iom.int/route? requestType=country\&id $=E T H$. 
interactions between refugees and hosts, ARRA's role is not limited to conflict management. It also plays an important role in enhancing social cohesion: by giving locals access to education and health facilities, ARRA contributes to fostering interactions between the two communities. While refugees do not speak much about ARRA, hosts express discontent with its recruitment policy, wondering why they are not given leading positions but are instead relegated to low-skilled jobs:

\begin{abstract}
"An example is ARRA, who only hire us as guards; guards are not important. We have an education, we are educated people, and we have youth that can work. Why are we not benefiting from these opportunities so that we can be given job vacancies and opportunities to work since we are educated people and well experienced people?" (FGD39)
\end{abstract}

UNHCR is the government's main partner on refugee protection and service provision. Involved in all aspects of camp management, UNHCR plays a key role in refugee status determination. Under its refugee protection mandate, UNHCR also manages the resettlement program, which represents the greatest hope for most of the refugees, although their chances of being resettled are extremely limited. As detailed later, the program is a major cause of frustration for refugees waiting for their opportunity to resettle, especially for the Congolese, who feel they are discriminated against.

"We wonder, because every day the Sudanese are getting support for resettlement, but us, Congolese, we are forgotten. But I think if we were Sudanese, they would come to pick us up in our houses, they would enter, even they would beg us to get this chance of resettlement. But for Congolese, this does not happen. There are people who have completed 15 years here in Sherkole camp, including myself, I have stayed about 8 years here: nothing!" (FGD41)
NGOs operating in the camp are key players in the everyday lives of refugees. Locals also benefit from activities such as trainings, although respondents from the host community often complain about being left behind. NGO interventions range from basic service provision to livelihood and environmental protection. Respondents also positively mention projects implemented by the International Rescue Committee (IRC) targeting women and children. While the positive impact of NGOs on the area is widely acknowledged, there is strong resentment over the lack of opportunities for local residents, who often speak of highlanders being preferred:

\begin{abstract}
"From my understanding, the NGOs maybe are not from abroad, maybe they are just from around Ethiopia, one when you look at ARRA, it is led by Oromo people, when you go to Norwegian Refugee Council [NRC], it is led by Tigray people, when you look at UNHCR, it is led by Amhara people, and we the Benishangul with black color, we have no job and the camps and the organizations are in our land." (FGD39)
\end{abstract}

In the host community, the kebele gets little support to implement projects that improve the lives of the host community. The only program targeting the host community in the Assosa area is the World Bank-supported Development Response to Displacement Impacts Project (DRDIP). DRDIP comprises three investment components: social and economic services and infrastructure; (2) sustainable environmental management, and (3) livelihoods. It follows a community-driven approach with a fourth component on project management.

\section{Security}

Relations between the host community and refugees is predominately peaceful. Incidents of community-wide violent conflict between the two communities are rare to nonexistent. In fact, the majority of refugees and host community members are proud of the peaceful reputation 
that Sherkole camp has compared with the neighboring region of Gambella. The Ethiopian government has begun to implement a policy of transferring South Sudanese refugees who arrive in Gambella to Benishangul-Gumuz as a mitigation strategy for alleviating the ethnic tension between the Nuer and the Anywaa. In this context, it is worth noting that South Sudanese refugees are far better integrated with the host community in BenishangulGumuz than in Gambella (ODI 2019).

However, this does not mean that tensions do not exist between the host community and refugees. Theft is a major point of tension because refugees are often perceived as the culprits.

\begin{abstract}
"They are always stealing our property. Stealing our goats, stealing our chicken, stealing everything that we have. Even sometimes they steal our clothes. But who can we blame? We can't blame them; we blame our government that brought them here." (FGD38)
\end{abstract}

Even though theft is a burden on the host community, there is an acknowledgement that refugees steal because rations have decreased and are often delayed.

"We are having a good relationship with the refugees, but even though we have a good relationship, most of them are disturbing us with theft. They steal our maize, goats, and all the property that we have. The reason is because the ration is not given to them on time." (FGD38)

Furthermore, the size of the rations is not enough for refugees to sustain themselves, as one host community member explains:

\footnotetext{
"For example, the food that is given to them is only 7 kilograms. That is not enough for a whole month, and sometimes it is not brought on time. So that is why sometimes they steal things so that they can find something to eat to save their lives." (SSI66)
}

Not all host community members are understanding. For some, theft has become a point of contention that forms the basis of resentment against refugees.

"From my side, I am not seeing any benefit because
the arrival of refugees here has caused destruction
because nowadays you cannot farm. Whenever you
farm, they will come and steal everything that you
farm. So, I don't see any benefit that comes from
staying of refugees here." (FGD38)

Incidences of theft are so common that some members of the host community have been discouraged from rearing livestock-an expensive investment-as an alternative means of livelihood.

"Long ago, before the arrival of refugees, we were
keeping our property safe, but nowadays when they
come, we cannot keep those things. If we keep, we
know that we will lose them in the future or in a
short period of time. That is why we are no longer
keeping those animals again." (FGD39)

If theft occurs, it is reported to ARRA and the kebele. However, both institutions have been unable to stop theft in the area. Some host community members blame the lenient punitive measures imposed on refugees who steal, which do not serve as a sufficient deterrent.

\footnotetext{
"For example, we can give them to ARRA so that they can talk to them. But if you give them, they will only be arrested for two days, instead of giving them some punishment in two days' time, they will be released and tomorrow they will come back again and steal our things." (SSI63)
}

Such lenient punishments have also instilled fear in some members of the host community, particularly women, about going into the forest due to incidences of rape by refugees. 
"Yes, as women, we have unique safety concerns. I feel like I am not safe. Sometimes we walk in a group; if I am alone, I have to be careful and always turn my back when someone is coming. To the forest, we go in groups or I will go with my husband. I don't go alone because I am afraid. I am afraid because some of us have experienced rape from refugees. That is why I am afraid." (FGD38)

Refugees are also victims of attacks by the host community. Most refugees cite incidents of violent attacks by the host community when they find refugees cutting down wood in the forest. Moreover, some refugees often go gold mining in the nearby woreda, only to be robbed of their earnings as they return.

"In 2014, I encountered violence, at that time I was out of the camp, I was going to the host community to buy charcoal, and I experienced violence there in the host community outside the camp. Not even that, those who go to the mines, they face violence there, that is why they came without anything." (FGD41)

Refugees also allege that they have sometimes faced abuse from officials.

\section{Ecosystem}

In Sherkole, the three main actors for refugees are ARRA, UNHCR, and the National Resource Development and Environmental Protection Department (NRDEP). ARRA protects refugees, coordinates with NGOs for service delivery, and issues permit passes. ARRA is also responsible for the distribution and storage of rations along with UNHCR, and it is the main body responsible for the settlement of disputes.

"When a conflict occurs, there is a committee from ARRA, the police, host, and refugee elders. We all sit down and we agree." (KII27)
UNHCR is in charge of rations and holds a crucial position in the ecosystem of refugees. This is particularly the case because the size of rations has decreased and due to significant delays in delivery. This has forced some refugees to steal from the host community, increasing tensions between the two groups.

"Before, they were giving them 16 kilograms for a month, but gradually they cut it down until they reached 8 kilograms. With 8 kilograms, you cannot survive unless you have an extra income, and refugees do not have an extra income." (LLI 6)

The National Resource Development and Environmental Protection Department is a government agency mandated to protect the forests around refugee-hosting areas by taking punitive action against perpetrators found in the forests. Due to limited livelihood opportunities, energy deficiencies, and a lack of alternative means of selfreliance, refugees often go into the forest and cut down wood to use as fuel and as a source of income.

"For example, NRDEP and those people from the local police, they don't want anyone to cut wood so they will catch people in the forest. Some are good, but some will beat them and take their goods." (FGD40.R3)

The market is an important place of interaction between refugees and the host community. In Sherkole, the most important day of the week is Monday because host community members bring in goods from Assosa and trade with refugees. Refugees can also place orders with hosts to acquire goods from Assosa, which are also delivered on Mondays.

"The host community will come to our market, the refugee market side, and the refugees will also go to their side, so they mix this together with refugees. They will bring their property, and the 
refugees' property will be there in the market. We will exchange with each other; we will buy from the host community, and the host community will come and buy from the refugees." (SSI59)

Refugees are placed in different zones, usually based on the different tribes or ethnicity of different refugee groups. Zonal leaders are refugees themselves and are elected. They liaise with ARRA, UNHCR, and other NGOS in the settling of disputes and to represent the needs of refugees in their respective zones.

"If conflicts happen in our zone with the host communities, our leaders may send a letter to the leaders of the host, then they come. If it is a big issue, ARRA will be involved, if it is not a big issue, it will be solved by leaders of zones." (SSI59)
Refugees cite education as one of the services with the most positive impact. They note the changes in education resulting from NGOs building schools that accommodate higher grade levels. In the past, refugees walked several kilometers to attend secondary school.

"The area has changed for the better, because I was a student at the time when we succeed from grade 8 to 9 , at that time grade 9 was not yet here, it was in Komacha. We used to go on foot, for two years. We always used to request UNHCR and ARRA to bring grade $9,10,11$, and 12 to Sherkole, but now it has already been around for three years. This is a good thing." (SSI59)

Remittances do not play as important a role in Sherkole as they do in Addis Ababa. However, some refugees have

\section{Figure B.1. Refugee Ecosystem Model, Sherkole}

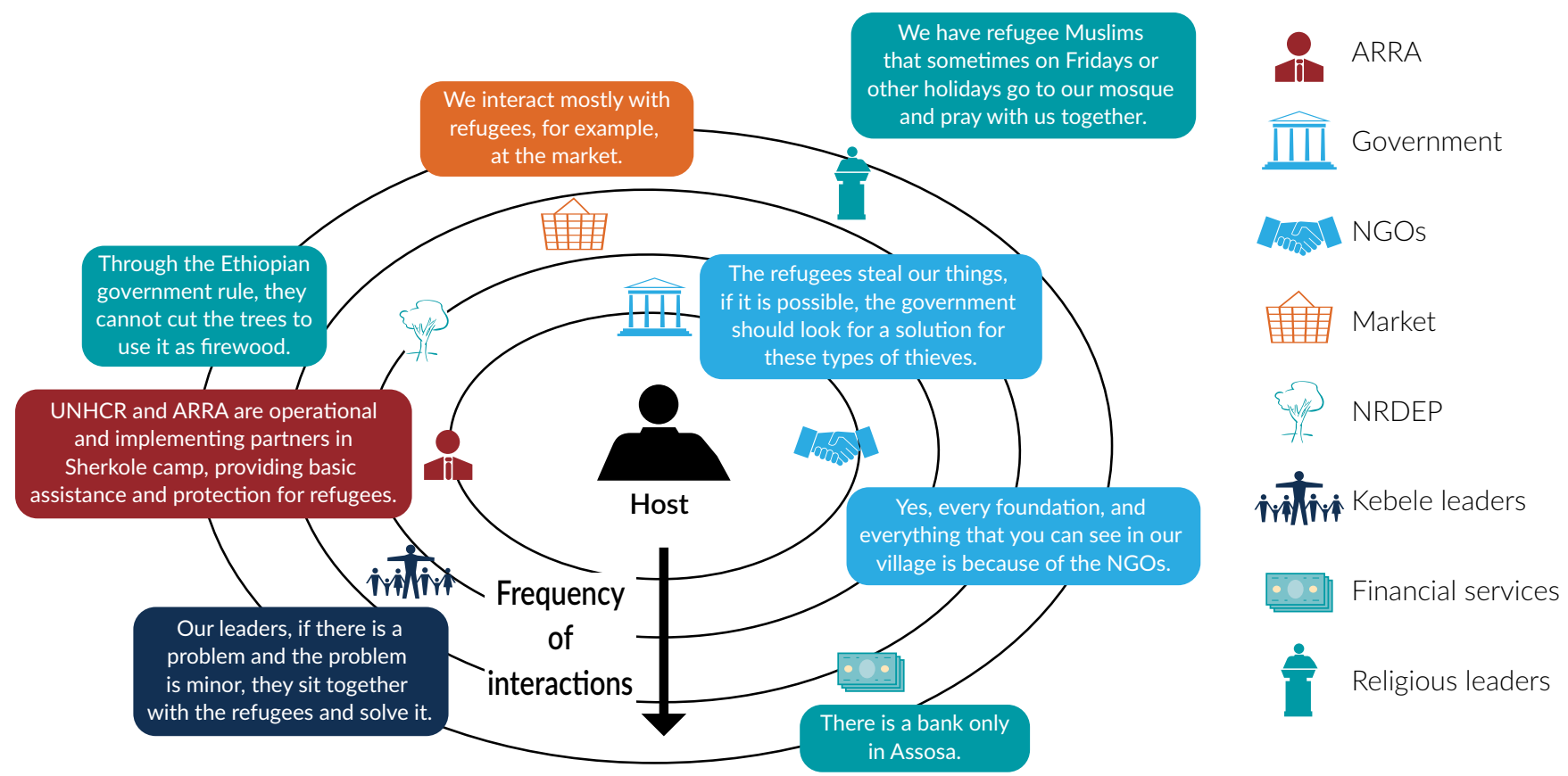

ARRA = Agency for Refugee and Returnee Affairs; NGO = nongovernmental organization; NRDEP = National Resource Development and Environmental Protection Department; UNHCR = United Nations High Commissioner for Refugees. 
had family members who have been resettled to a third country and receive remittances from them.

\begin{abstract}
"Some of my family members are abroad, in America and Canada. One called J___ is in Canada, he is my brother in law, and also my sister from my mother's sister is in Canada. Her name is $\mathrm{A}_{---}$. Sometimes, I receive money from them, but it has been a long time, also it has been three or two months before receiving from America." (KII25)
\end{abstract}

The host community reports benefiting from the presence of NGOs even if they are not their primary beneficiaries. Further, most members of the host community are aware of the 70/30 percent split between the services provided to refugees and those provided to hosts; and although most believe that they do indeed receive around 30 percent, some still find this inadequate.

"There is not much relationship between us and the NGOs except when they want assistance, so they will come to us and ask for us but there is not much relationship, even the service delivery we are not getting any service from them." (SSI64)

There is only one program that targets the host community as the main beneficiaries: the World Bank's Development Response to Displacements Impacts Project (DRDIP).

"The other new building was built by DRDIP, this project is run by the World Bank, and both of them are schools. Not only schools, the other building here is a clinic, health center." (SSI64)

Although ARRA is a state agency dedicated to refugee affairs, it is a prominent stakeholder for the host community because of the many incidences of theft in the area caused by high levels of food insecurity among refugees.
Host community members report perpetrators to ARRA before they consult the police.

"If refugees commit a crime, we take them to ARRA, and ARRA will take them to the court, and they will be disciplined." (FGD39.R4)

Most host community members credit the area's development to the presence of NGOs, However, the government is still a key actor. Most of the interviewed host community members are aware of the government's intentions regarding the integration of refugees in line with the nine pledges, and were generally positive about the set of policies.

"What the government is thinking about is good because when refugees are given opportunities and their lifestyle changes, we as the host community will also see change." (FGD39.R1)

Many host community members also blame the government for the prevalence of theft in the area and look to it for solutions.

\footnotetext{
"The biggest challenge that we are facing is theft, the refugees steal our things, if it is possible, the government should look for a solution for these types of thieves." (FGD39.R1)
}

Unlike refugees, the host community has access to financial services from which they benefit.
"Yes, we are practicing all these things, like banking and microservices, microservices are done in Hamasha, you may take your money there and keep it and protect it from being stolen by thieves or being destroyed, and also you will get profit on your money." (FGD39.R1) 


\section{Figure B.2. Host Community Ecosystem Model, Sherkole}

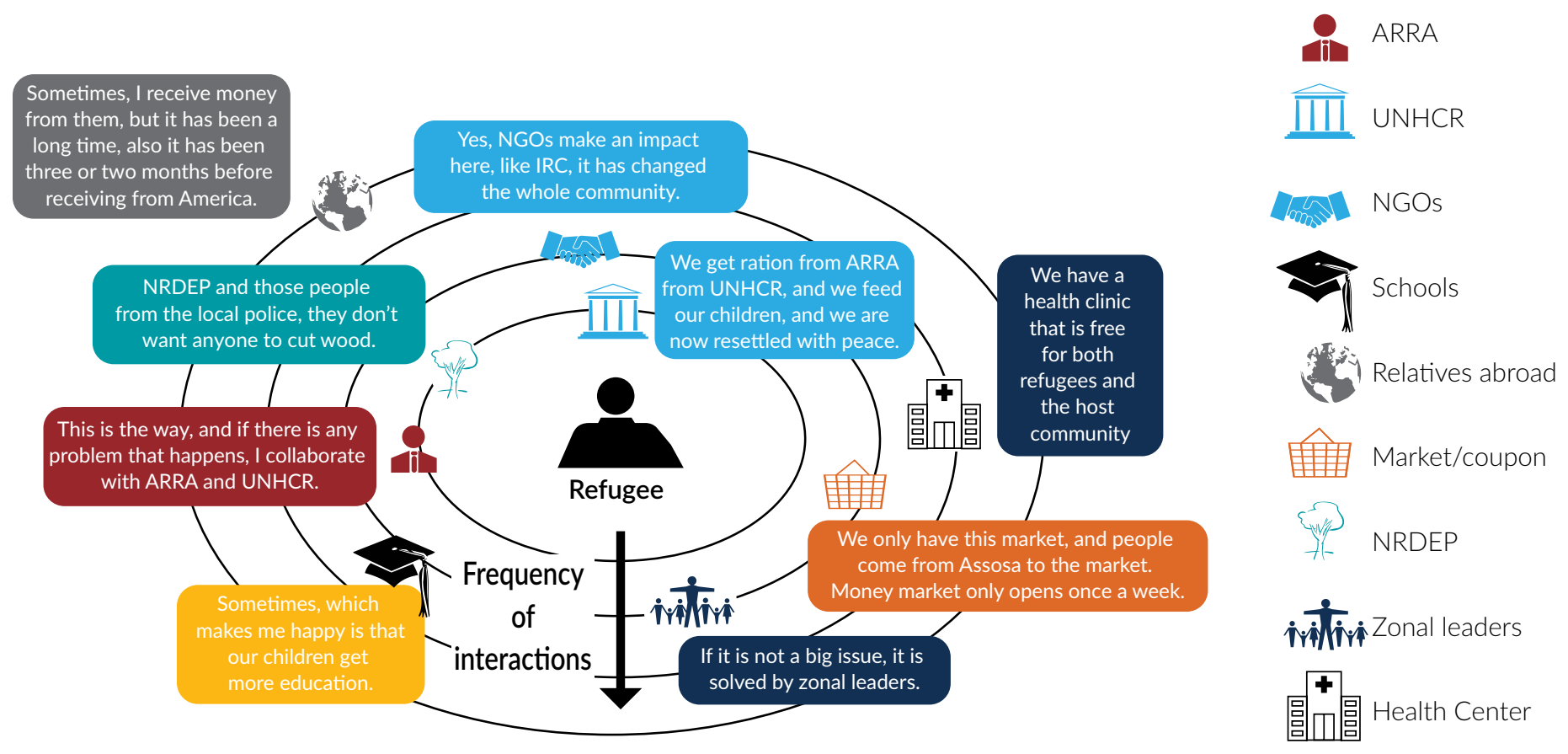

ARRA = Agency for Refugee and Returnee Affairs; NGO = nongovernmental organization; NRDEP = National Resource Development and Environmental Protection Department; UNHCR = United Nations High Commissioner for Refugees.

\section{Key Themes}

\section{Identities and aspirations}

Who are the refugees?

Refugees in Sherkole refugee camp are predominantly from three countries: Sudan, South Sudan, and the Democratic Republic of Congo. The common denominator between all three groups is that war has been the primary driver of displacement and all have had a protracted stay in Sherkole camp. Of particular note is that Sherkole camp is home to refugees who were once repatriated from the camp and since returned. This group consists primarily of Sudanese refugees due to the oscillation of peace and conflict in Sudan since the early 2000s. A refugee from Sudan explains their migration history:

"We stayed in Ethiopia from 1987 to 2003. In 2003, we went back to Sudan. We left Sudan in 2011, and we entered the border in Ethiopia, and our life here is good. In 2003, we returned back to Sudan, we stayed up to 2011, and in 2011 we ran away again and came back to Ethiopia. In 2011, we arrive here again. Since 2011, we stay here in Sherkole, it's been 8 years now in Ethiopia." (LLI 17)

This is not a unique case among Sudanese refugees due to the close proximity of the border. Most Sudanese refugees therefore know the area and the host community well. This close link is fostered by a common culture and language.

Congolese refugees have experienced a protracted stay at Sherkole camp, with most having lived in the camp for over 10 years, yet their level of integration is low compared with South Sudanese refugees who are the latest to arrive at the camp. The main barriers to integration for Congolese refugees are language, cultural practices, and religious practices. Arabic is the main language spoken by 
Sudanese refugees and the host community, which makes it difficult for Congolese refugees to communicate with them or feel as if they are well integrated.

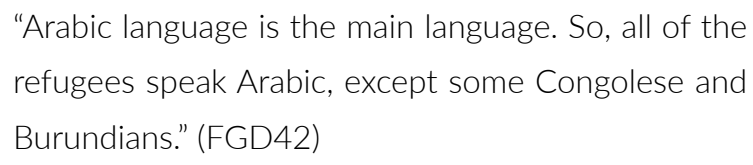

The language barrier has material consequences for Congolese refugees, limiting their ability to effectively engage in trade with the host community. Their ability to fetch a fair price as a consumer or as a supplier is undermined by their inability to negotiate. What is striking is the limited availability of language programs provided by NGOs and the host community to help Congolese refugees learn the common language. Further, most Congolese refugees do not want their children to learn Arabic in school, preferring for them to be taught in English.

"Our children are taught in English. We wouldn't like them to be taught in the local language." (FGD42)

As a result of these barriers to integration, Congolese refugees do not feel as if they are or could be integrated. This perception fosters a sense of rejection of government plans to integrate refugees and the host community.
A common sentiment among Congolese refugees is to either be relocated to another camp or be repatriated back to their country.

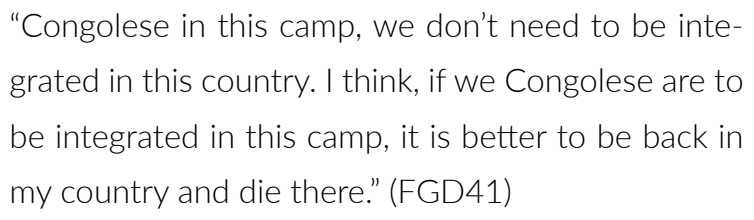

Low integration levels among Congolese refugees stems from cultural and religious differences. First, most Congolese refugees are Christian, but Islam is the religion practiced by the vast majority of the population in Sherkole woreda (EUTF 2016). While there have been no incidents of religious altercations, Congolese refugees are unable to use religion as a catalyst for positive social integration as other refugees have in the other study areas. Furthermore, Congolese refugees have different diets, which are incompatible with the rations they receive. Sorghum is the main grain included in the rations delivered to refugees. Sorghum is completely foreign to the diet of Congolese refugees. Despite their requests for a substitute, Sorghum continues to feature in refugee rations because it is the staple food of Sudanese refugees-the predominant group.

\section{Figure B.3. Lifeline of a Host Community Member, Benishangul-Gumuz}

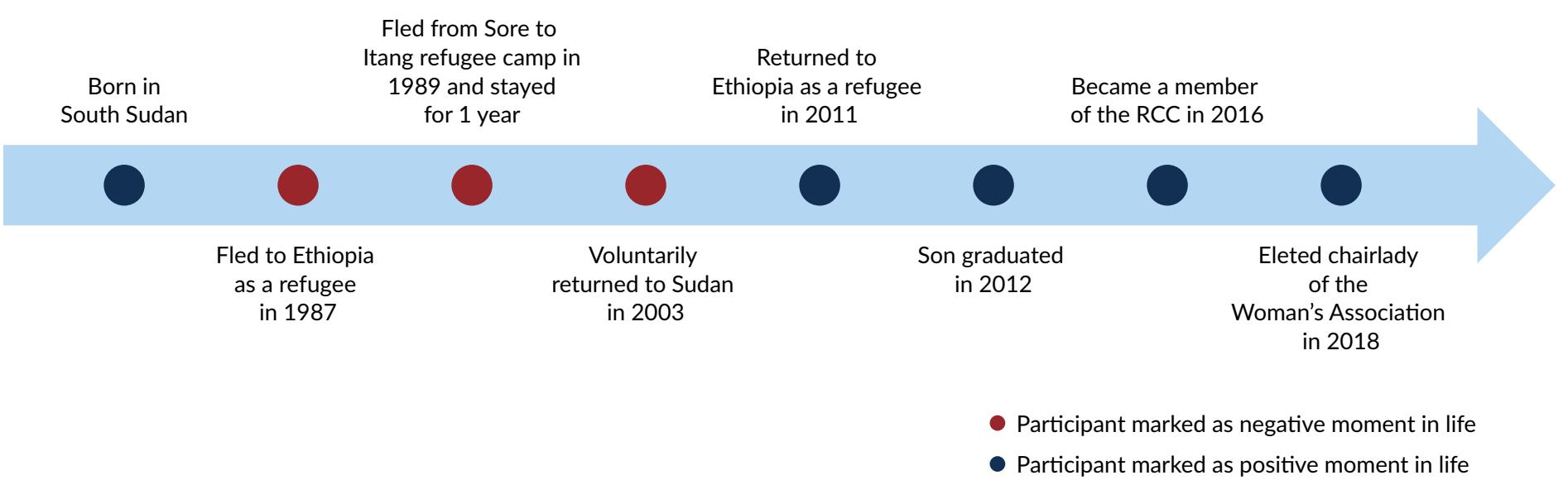




\section{Box B.1. The Trajectory of Double Refugees in Sherkole}

Sherkole is unique because it has individuals who arrived from Sudan as refugees in the late 1980s, who returned back to Sudan in the early 2000 s only to return to return again as refugees to Ethiopia in 2011. B__-_ age 47 is one such example, recounting her path of circular migration:

"We ran away to Ethiopia in 1987 from Sudan. We stayed in Ethiopia from 1997 to 2003. In 2003, we went back to Sudan and stayed, we stayed up to 2011, and in 2011, we ran away again and came back to Ethiopia."

Sudanese refugees with similar paths of circular migration are interesting because they have lived in

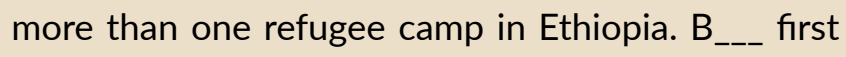
settled in Sore camp before fleeing to Itang, and finally settling in Sherkole in 2011. The movement of Sudanese refugees to Itang reflects how unstable the country was after the fall of the Derg regime.

"[In] 1989-that was the time we ran from Sore to a place called Itang. This is because in 1987, 1988 , and 1989, Ethiopians began to be displaced therefore we ran away searching for a place to hide. We went up to the place called Itang, and we stayed there for one year."

This group of Sudanese who have twice been refugees in Ethiopia have positive relationships with the host community. $B_{---}$recounts how the host community were their means of support at different stages of her trajectory as a refugee and as a returnee. The Ethiopian army provided the initial support when they first arrived in Ethiopia.

"They said: 'don't run, don't run, we are from Ethiopia, we are not from the North.' In our mind we are thinking that our government is following us, but when we met them, they would tell us to 'sit down put the children under the shade, and we will get some biscuits to feed them."'
The host community provided for their basic needs in Sore.

"The Ethiopian people tried to bring us maize; after maize they would bring powder; after that they would bring lanterns-different things to help us, and ARRA facilitated their repatriation through the radio and Ethiopian people who take care of us and they take us back by car back to our own home."

B_-_'s story shows how essential education is in attracting refugees to Ethiopia. She recounts how, upon returning to Sudan, the limited education opportunities prompted her desire to return to Ethiopia.

"When we returned back to Sudan, our children were not getting an education, also the country was politically unstable, our government would make an agreement today only to change it tomorrow."

$B_{\text {--- }}$ herself has benefitted from the education provided at the camp, enrolling in school as an adult, which allowed her to work for NGOs and feel as if she is giving back to her community. Her story illustrates the material and psychological importance of increasing employment opportunities for refugees in the NGO sector.

"Something which makes me happy is that our children get more education, and if they get their education, the NGOs here can also give you the work for training for HIV/AIDS, training to work in the health center, to work at IRC and UNHCR, to be a social worker, for anyone to be put in a different place, like myself, I am working with Plan International. These things make me happy. If you are finished with training, you can help your community." 
"Due to our culture, different language, different food, we really are discriminated against. Before, they gave us rice, but due to complaints from Sudanese, they took it back because Sudanese said they don't need rice. Now we have sorghum, but if you try to complain, they will say that we are living here because of Sudanese. (FGD41)

Such incidents contribute to the perception among Congolese refugees that they are a marginalized group. Congolese refugees feel as if they do not receive equal treatment to Sudanese refugees in terms of opportunities in trainings conducted by NGOs and even in cases involving the UNHCR resettlement program.

"What we need to complain about is the issue of resettlement cases concerning the Congolese, for around six or seven years, no one is opening the cases of the Congolese, only last year did the cases open. Other tribes were receptive because we came from far to this country. But it has been difficult for us. We spent six years, no one went abroad, and this is what we used to complain about." (FGD42)

As a result, most of the Congolese refugees that we interviewed advocated for their relocation, either to another area in Ethiopia, especially Addis Ababa, or back to their own country. Many Congolese refugees are disillusioned by the experience in Sherkole.

"For sure, it is very difficult for us as refugees, especially the Congolese. It is very difficult. As I came here, I was expecting maybe that I was going to get enough peace. But for sure, I totally regret this myself." (FGD42)

Despite feelings of marginalization among Congolese refugees, most report positive relations with other refugees in the camp. Sudanese and South Sudanese refugees disagree with the notion that Congolese or any other refugee group are marginalized. In general, all the refugees interviewed for this study report positive relationships between refugee groups, with only minor incidents of reported conflict.

"Here in this camp, we are having no differences between us, no discrimination between the refugees. We are having a relation with other people of other countries. We are respectful together, no difference between us, we respect all of them and all of them respect us, other tribes of other countries like Burundians, Congolese, we don't have any problems with them. They are our brothers and sisters and they respect us. So here, we don't have anything like problems or issues, we don't have any." (FGD42)

Several participants have highlighted the fact that Congolese refugees have passed on knowledge or changed behavioral traits among Sudanese refugees and the host community.

"Before, when they saw some Congolese walking around here because some Congolese women used to wear trousers-because this area is a Muslim area-if they see a Congolese lady walking with a boy, it was a shame to them, but now they have changed, they start to do what they were seeing before." (SSI62)

Smartphone usage also increased with the arrival of refugees.

"Even smartphones, most of the people were not using them by the time we came here. (SSI62)

Most host community members think that refugees have more advanced skill sets and report having learned from them. 
"Yes, refugees and host community might have similar experiences, but maybe refugees might be more talented than us because if we put it in percentage, maybe it can be 75 versus 25." (FGD39)

Who is the host community?

The main ethnic groups in the host community of the Benishangul-Gumuz region are the Berta (25.4 percent), the Amhara (21.69 percent), the Gumuz (20.88 percent), the Oromo (13.55 percent), and the Shinasha (7.73 percent). Of these, the Berta, the Gumuz, and the Shinasha are considered indigenous (EUTF 2016). Due to the protracted stay of refugees in the area and the fact that Sherkole camp is open, the host community is well integrated with most of the refugees. Host community members report positive relationships with all refugee groups despite the prevalence of theft in the area.

The host community is sympathetic to the plight of refugees. They often lament the decreased size and delivery delays of rations. Host community members implore NGOs to provide better food security for refugees.

"So, let the organizations that are responsible for refugees provide them enough food so that they do not steal because even if you want to take action, you cannot take action against a hungry person because he is stealing for a reason. He is lacking." (FGD39)

The host community also cites the lack of movement available to refugees as a limiting factor. Refugees cannot move freely to areas beyond Sherkole refugee camp without a pass permitting them to do so.

"According to the law, refugees are not supposed to move more than 8 kilometers away from the camp. (SSI63)
For example, refugees need a pass to travel to Assosa and can only stay for a maximum of three days.

"The situations or challenges that the refugees face are difficult. One, we as the local people can move, if we have a problem, we can move to find something that we can solve our problem with. Once we have freedom of movement, we can go find work. But for refugees, movement is not free, and they are only depending on the rations; that is how their situation differs from the situation of the local people." (FGD39)

A history of cross-border movement and trade with Sudan means that the host community and Sudanese refugees share a common culture and language. For example, in 2002, the Ethiopian and Sudanese governments issued permits and licenses to formalize and promote crossborder trade with border communities, such as Sherkole (FGD39). Moreover, the Berta, the largest ethnic group in Benishangul-Gumuz, can also be found across the border under the name Funj in Sudan. A history of seasonal migration and intermarriage has engendered positive relations with Sudanese refugees. For instance, there are various accounts of Ethiopian citizens crossing the border to work in Sudan before returning. As one participant recounts:

"When I went to Sudan, I started working and sending money back to my family. My job in Sudan was a laborer worker for one year. After two years, I became an assistant for a construction company. After three years, I decided to become self-employed. I opened a salon at the age of 19. At that time, when I was working at the salon, I was going to a private school. While I was working, I was having classes in Arabic. Also in Sudan, I worked as an electrician for one year, connecting electric wires, I was 21 years old. First, I was working as a volunteer with them, then they later on gave me trainings for one year, then it became a full-time job, they gave me a certificate." (LLI16) 


\section{Self-reliance}

Refugees have limited livelihood opportunities to attain self-reliance. They cut down wood in the forest to use as fuel and to sell in the marketplace to earn a living. Similar to other refugee-hosting areas, the forest is protected by the local community and NRDEP, and there are therefore punitive measures in place for refugees caught cutting down wood in the forest. However, firewood is critical to the survival of refugees, and many have no choice but to navigate the risks involved.

"When I bring firewood from the forest, it may last three days, after that if it is finished, I will go to it the forest again. Even if I am not allowed, I still have to go." (SSI60)

Deforestation is a point of contention for the host community and refugees. The host community feels as if refugees are destroying the environment. Refugees perceive hypocrisy from the host community, often citing cases when the host community has either engaged in deforestation themselves or taken advantage of refugees by stealing their charcoal.

"They don't give us charcoal to cook this food. If you go to the host community to buy charcoal, it is not allowed. If we go at night to arrange how you can get it, if you come from the host community, you will meet other people hiding on the way then they will take that charcoal. You will be in loss; you will lose your money and charcoal. Look at the life we are living in this country." (FGD41)

Refugees also engage in gold mining as a source of income. Most of the gold mined in Benishangul-Gumuz is artisanal. Indigenous hosts often use gold mining to supplement their agricultural activities (EUTF 2016). However, there are currently no large-scale mines operating in Assosa or neighboring regions (Bullock 2018). In
2018, the Ethiopian government suspended the operations of the Lega Dembi mine (Meleskachew 2018). For refugees, gold mining is an activity fraught with danger. Participants report incidents of refugees leaving the camp to mine gold and returning empty handed. Refugees are not legally permitted to participate in gold mining, but the host community allows it informally, taking advantage of the refugees' skill set.

"For the gold mining, we don't have any problem because mostly we as the host community, we don't know how to dig, so the refugees are the ones that are experienced to know where the gold is, even now you can see that the camp is empty, most of them are in the gold mines." (SSI63)

This is not always a benevolent act by host community members, as participants report refugees being robbed of their earnings by a network of mine owners and local authorities.

"For example, we have our people who go to mine gold so they can assist their families here at the camp. But it is a serious and terrible issue, if they went there and used their energy, but after, they will come back and the Ethiopian citizens with the police and military will intimidate you. We have many people here who lose their gold, they left without anything so that they can leave alive." (FGD41)

Refugees cite the inability to utilize their skills as a major obstacle to their self-reliance. Many offer valuable skills and qualifications from previously held jobs. However, limited livelihood opportunities and freedom of movement to larger economic hubs such as Assosa mean that refugees are unable to engage in the economic activities with which they are proficient. Moreover, their status as a refugee precludes certain occupations because of legal restrictions attached to the employment of refugees in certain positions and for certain wages. The incentivized 
worker scheme caps the salary of refugees who work with $\mathrm{NGOs}$ at $\mathrm{Br}$ 700, an amount insufficient to earn a living. Furthermore, occupations outside of the NGO sector are closed to refugees due to their status; and even with the jobs available to refugees, participants cite their inability to gain employment at high-level capacities.

\begin{abstract}
"There are some who came from their countries as doctors, some are drivers, they have different experiences, but because you are a refugee, we have limitations. Some are drivers but we are not allowed to drive a car. You will find a doctor who is not allowed to open a private pharmacy. So, it is difficult, even here working as a teacher in primary schools, any refugee is not allowed to teach above grade 6 because they normally tell us that we are not qualified-even if we have a university degree." (FGD42)
\end{abstract}

\section{Access to Services}

In an area where infrastructure is poor to nonexistent, the presence of refugees is perceived as having a positive impact on service provision.

"The essentials are provided, children are going to school, electricity is there, and also there is water, so in terms of development, everything is going well." (SSI65)

Respondents were particularly vocal about education and health facilities but did not elaborate much on water and electricity. Yet one significant difference between refugees and hosts in terms of services is the absence of electricity in the refugee camp: only the host community is connected to the power grid, forcing refugees-especially women-to collect firewood for lighting and cooking. Refugees have been given solar panels, but these do not seem function for most people. One refugee woman (SSI59) mentioned stoves using ethanol as a primary need for women living in the camp. Regarding access to water, refugees and hosts use separate water points, but infrastructure and supply appear to be of similar quality. There were no education or health facilities prior to the establishment of the camp.

\begin{abstract}
"The benefit that we have got from the stay of refugees is that before, our children would walk kilometers to go to school but, when the refugees came here, a school was built for them and one was built for the host community. This is one thing that we have benefited from. The second thing is the health center. The health center here was constructed because of refugees. The third is we were told that if there is a woman that wants to deliver, or a child with a nutritional problem, we have to take them to the refugee health center." (SSI66)
\end{abstract}

The camp has more schools than the host community, which gives rise to complaints from locals. While the camp accommodates all levels, from preschool to high school, only primary school is available to hosts living around the camp: local children must walk eight kilometers to access secondary school. As a result, schools established for refugees also cater to some of the host community children. The host community benefits from the materials and equipment provided, such as school uniforms and textbooks.

"The positive part that organizations have brought here is that they have built schools for our children and provided exercise books for them." (SSI66)

Therefore, locals acknowledge that the situation has improved as a result of refugee presence, especially as education infrastructure was nonexistent before the camp was established:

"And even schools that were started for refugees, our children come from different corners of the area, and they go to refugee children schools, and they learn, so these things we are benefiting from because of refugees." (SSI65) 
Respondents also highlight the role played by shared schools to strengthen social integration:

"That means in school, when local students and refugees are learning in one school, they may develop a friendship. This high school that is built for refugees, it is also open for local students. They are integrated and are learning together." (FGD40)

Education providers are numerous around Sherkole camp: NGOs, ARRA, and the Development and Inter-Church Aid Commission (DICAC) split the work by focusing on different age cohorts, from preschool to the adult program. The latter, provided by NRC, targets adults who have never attended school and who lack basic knowledge, such as literacy and numeracy skills. The objective is to help beneficiaries fill gaps and gain skills that they may need in their everyday life and for their livelihoods, as an NRC staff member explains:

"The purpose of this adult education is not to pass good to great, but is to have basic knowledge like literacy that is key when they are supporting their livelihood, you know, the shortage of budget is what can make us fail. For instance, while we teach, we have agriculture, parental education, and social bridges, it is to make them functional. While we are having this, it is better to change them into practical. It is very interesting." (KII26)

However, residents lament the quality of education compared with the neighboring Gambella region. Refugees speak negatively about the schools around the camp:

"If you visit you cannot say that this is a good school." (SSI62)

Local informants express concerns regarding the availability and quality of teachers, poor infrastructure, and lack of essential materials-such as textbooks. Education lacks funding, and the budget is a constant challenge, jeopardizing the quality of education services.

"We have one project called adult education, delivered by NRC, and education also for the small child. There is a plan for international delivery of a preschool, with ARRA from grade 1 to grade 8 , and from grade 9 to grade 12 by DICAC. All of our teachers are crying because of quality of education. There is a shortage, like textbooks, and generally the school infrastructure is poor." (SSI62)

Some hosts complain of unequal treatment, pointing out that the quality of services is better in refugee schools. Specifically, locals voice their dissatisfaction over the fact that refugee schools have a feeding center while schools in the host community do not. This differential treatment is regarded with incomprehension and indignation by the host community.

"They provide exercise books while the host community have no exercise books. So, even sometimes during break time, because they all break at the same time, our children may decide to go through a fence and watch while the refugee children are being fed. We requested several times from the organizations that because we are near the refugees and our children are always watching refugee children feeding ... we also want to be fed, why not also give our children a chance to be fed like the refugee children? We get no reply from the organization because they said this is only for refugee children and the budget is only for the refugees not the host community." (FGD39)

However, refugee students also face specific challenges that can lead to frustration. They mention difficulties they encounter compared with host community students if 
they want to continue their education if they do not pass the grade 8 exam: 62

\begin{abstract}
"Refugees, they are facing a big challenge because if you complete grade 8 there and you do the exam and fail, there is no other chance, you will stay in the camp, there is no other way to continue your education. But if you see a member of the host community who failed, he has a chance to do another exam again, but for refugees it's not like that. Even if he doesn't pass the exam, he has the right to have private school but for refugees how can you pay for this private school? No way." (SSI62)
\end{abstract}

Regarding health, most respondents describe the quality of services as mediocre. Here also, the host community benefits from health services provided for refugees, and locals can access treatment for free:

"We are using this health center for free because of the refugees. If you are sick, you go to the health center and get treated and get medicine and then you come back." (SSI65)

However, many participants-from both communitiescomplain about not receiving appropriate care:

"Even for refugees, they don't have good hospitals. We don't know the problem. Because they are under the government, sometimes you go there, you are sick, they say 'no you are not sick.' Immediately, when you come back at home, you die. So that is why I talk about the treatment for refugees here, we don't get treatment." (SSI61)

Although medical staff tend to use the fact that hosts should go to the local health center as an excuse, hosts

62. The grade 8 exam is a regional examination at the end of primary education, which consists of two cycles (grades 1-4 to grades 5-8). Ethiopia primary school education consists of two cycles, from grades 1-4 and grades 5-8. Successful candidates are admitted into secondary schools. and refugees are equally denied treatment, according to a community leader:

"Forget about the refugees, even us-the host community-we were given the opportunity to go and get medicine and treatment at the health center; but now if we go, they will tell us to go back to your place, that we have our own health center and this is only for refugees, but even the refugees are complaining about not getting the services." (KII25)

Nonetheless, Congolese refugees accuse ARRA of discriminating against them and report differential treatment at the health center:

"If you go to the Sherkole health center, they will ask: 'Is it a Congolese who is sick or where did that patient come from? Is it a Congolese or a Sudanese?' They used to say that if he is a Congolese, he is not sick. The way they treat Congolese is not the same way they treat other refugees here." (FGD41)

The inability to provide adequate care might be the result of understaffed units failing to deal with the influx of patients:

"Sometimes, we might be sick or our children are sick and we go to the hospital, people who are working there might tell us to go back and come back in the afternoon. If you come back in the afternoon, they tell us that now there is no space for you, go back and come tomorrow." (FGD39)

The number of doctors is far below what is needed.

"For example, you may find 100 patients in the hospital, but when the doctor comes, they will say they can only receive 10 patients because the doctor has another meeting and other jobs to do." (KII25) 
In such a context, the way the health center prioritizes patients is unclear. Referrals do not sufficiently meet their needs either, leaving patients with no medical care whatsoever.

"In 2012, I got this referral abroad to get enough treatment, up to now I am here in the camp. If I go and ask, they tell me wait, wait-I waited for seven years. I think you understand this referral system. It is only in the document, in writing, but beneficiaries they are not receiving." (SSI62)

As a result, refugees must find alternative options to access health care: some of them sell their belongings or borrow money from the community to access private health centers surrounding the camp.

\begin{abstract}
"If a refugee is sick and goes to the health center, they will not be given a good treatment. Sometimes they decide to work or sell the belongings that they have, and they decide to go for private health centers like Kurihamsa or they come to Homesha or they come here to Jimma kebele health center so that they can get a good treatment for their diseases." (KII25)
\end{abstract}

Pregnant women cannot find satisfactory prenatal care in Sherkole and have to travel to Assosa for pregnancy follow-up care.

"Every woman who is pregnant here uses her own mechanism to go to ultrasound to Assosa to check if the child is in good condition inside the body. Many who used their own way to check themselves used to find that they have cancer, because here there is no progress at all. Even for a pregnant woman to get a mosquito net is not easy here in this camp. Sometimes, they refuse to treat us there." (FGD41)

Others travel all the way to Addis Ababa to receive adequate health care after attempting without success to receive treatment in Sherkole or Assosa.
"For example, in 2016 I was sick. I tried to pursue for around one year, they refused to give me a letter to Assosa. We sat in our community, to contribute some money, they sent me to Addis Ababa, then in Addis Ababa I carried on myself because I don't have a relative or a brother to send me money. I was depending on my community, to ask everyone to give $\mathrm{Br} 20$, $\mathrm{Br}$ 50, Br 100, they sent me to Addis Ababa. I stayed in Addis Ababa for six months, when I came back, I became strong. But I know there are others who are sick here in Sherkole, we don't have treatment, that's why I stayed in Addis Ababa." (SSI61)

Another acute problem related to health services in Sherkole that most respondents mention is the lack of medicine. Refugees speak of medicine misuse, accusing the health center of selling medicine to pharmacies in Assosa.

\begin{abstract}
"There, they have their own car, which used to come and take the medicine inside the store. They took all medicine that had value, they take them to Assosa and sell them. For refugees, they will only give them medicine that is expired and available around, but the best medicine will be taken out of the health center. They will give the refugees medicine which they will see that won't help them." (FGD41)
\end{abstract}

According to refugees, medicines are provided but all end up in Assosa:

"I used my own way, and I got money and went to Assosa to buy medicine. They gave me quality medicine in Assosa because they knew that I am using my own money. As I said before, they used to take good medicine to the pharmacy and sell them. There in Assosa, you may find medicine from refugee camps." (FGD41)

The lack of medicine may have serious consequences when refugees are not able to find their prescribed medication, which is common in Sherkole. 
"In the time I was delivering my child, they operated on me, I lost blood and had blood deficiency problem. It was in Assosa, they told me to go back home, they wrote a paper of medicine that I will use at home. By the time I came here to the health center, I looked for the medicine, they didn't have it, they sent me here to the camp, they checked for the medicine here but they didn't have it. They only gave me a simple tablet to show me that they did something while they didn't give me medicine." (FGD41)

Some report inappropriate distribution of medicine, regardless of the condition of the patient.

"The refugees are just given amoxapine and paracetamol. This is the tablet we are familiar with in the health center. If you have common cold, cough, pneumonia, anything they will give you amoxapine and paracetamol." (FGD41)

Finally, testimony from women indicates the existence of practices that constitute acts of gender-based violence. The infrastructure is inadequate for providing medical care to pregnant women, who must deliver in a public room.

"If you enter the delivery room, you will not find a door, it is like a public room. This is a serious issue, and if we talk about it always, we used to tell them but there is no change. No one wants to hear us." (FGD41)

The situation is no better in the host community, where the local health center has no delivery room or appropriate equipment. Several female respondents also complain about being denied sanitary pads, even though they are available at the health center.

"There are pads for women, it is kept in a store. They keep it and it expires. If you go beg them, "please give me one," they refuse, they will not give it to you. They will keep it until they burn it because it expired in the store. They will burn it in the dustbin because it expired ... For example, they used to give us women three pads and say use these three pads in seven months." (FGD41)

Overall, respondents from the host community express resentment over the imbalance in the support refugees get and what is provided to locals. Youth centers are mentioned as an example of services available for refugees that do not exist in the host community. One host explains:

"The services that cater to women and youth is not much, but it is better than nothing. For example, here there is a recreation center for youths; in the kebele, there is no recreation center. Here in the refugee camp, there are seven zones, in each zone there is a recreational center for youths. In the kebele, there is not even one recreational center. That is the difference." (SSI64)

While mentioning the informal measure of $70 / 30$ split of services delivered by relief organizations to refugees and hosts, some suggest that hosts do not actually receive their share.

"The refugees get 75 percent of the service, and the host community gets 25 percent. But that 25 percent is not fully implemented. For example, here they give solar energy power, they distribute more to the refugees, but they distributed only one to the host. This distribution is not fair." (SSI64)

Hosts not only complain about the amount of support refugees get, they also indicate that refugees receive better quality services.

"Always put priority to refugees of course. The best quality of things and services are for refugees, and some few of them will be for the host community. The refugees get the best quality." (SSI65) 
The poor quality of the local health center is a recurring complaint, although the refugee health center does not give satisfaction either, as previously noted. Here again, the common demands concern education (preschool, primary, and secondary school) and health (better quality of care and ambulances). They are addressed to the organizations active in the area as well as to the government.

\footnotetext{
"They have to build schools for our children. They have to bring an ambulance for the health center because when someone is sick at night and needs to be transferred to the hospital or other health center, we need the ambulance. That is what we want the government to do for us." (FGD38)
}

In this regard, the World Bank-supported DRDIP provides an appropriate response. As part of the project, a new health center is being built, and a school has been established in the host community. Host community members mention both facilities.

\section{Coping Mechanisms}

Marriage is a unifying force between refugees and the host community. Similar to other refugee-hosting areas, intermarriage is a powerful method for bringing together two communities. In Sherkole, marriage between a Sudanese refugee and a host community member is the most common and easiest to facilitate because of the common culture and cross-border kinships. However, intermarriage with host community members is not common among all refugees. For example, there are no reported accounts during this research of refugees from the Democratic Republic of Congo or Great Lakes marrying someone from the host community. Proposals of marriage between refugees and the host community members are one-sided. There are many more refugee men proposing to host community women than there are host community men proposing to refugee women. One member of the host community explains:
"The other thing that can strengthen the relationship between the refugees and host community is intermarriage, for example, we have marriages into each other, we have given them our women, they are married to us, but we cannot marry their women." (FGD39)

Refugees provide numerous accounts of acts of solidarity by the host community when refugees first arrived. When Sudanese refugees first arrived in Sherkole, there was not a single NGO operating in the area. The host community was the refugees' first line of support.

"I will start from the beginning that the refugees arrived, when they come, we give them a warm welcome, we give them shelter, some of us provide them with food, clothes, we treat them as brothers." (SSI63)

It helped that the first group of refugees arriving were predominantly Funj-the same ethnic group as the Berta, who are indigenous to Benishangul-Gumuz. Similar acts of solidarity were also displayed for other refugee groups despite their being of a different ethnicity.

Because the size and delay of rations negatively affects relationships between the host community and the refugees, some members of the host community have taken it upon themselves to provide food to refugees on credit.

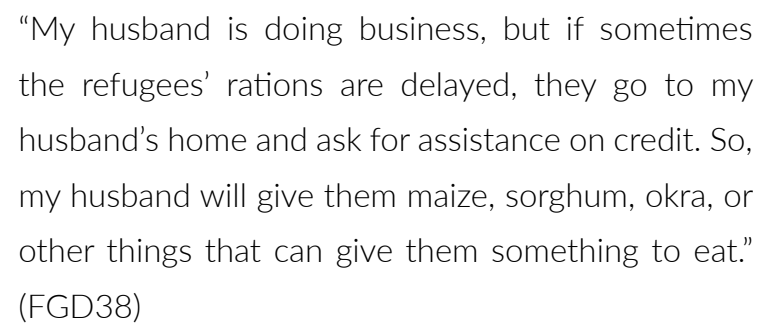

Host community members also allow refugees to work on their farms or to perform odd jobs for money or food. Most feel empathy toward refugees, taking a reflective attitude that drives their assistance. 
"As human beings, life is not always permanent. Today, he may be a refugee, but tomorrow he may go back to his home and something might happen to me. So, we stay with them as brothers. Even though not all of them are doing these negative things, it is some of them. A few of them that are doing this." (SSI63)

The host community also finds it in their self-interest to assist refugees, as a way of lowering the incidences of theft and potential violence.

"Yes, when refugees are benefiting, we as the host community are also benefiting from them. Let's say, for example, if the refugees are being given food, and they are safe and they eat, we also feel safe. Why? For example, theft will stop. They will not come for us and ask us or beg us for other things. Those are the benefits. If the refugees are benefiting, we as the host community also benefit." (SSI63)

Other members of the host community have carved out a profession by only catering to specific needs that refugees might have and capitalizing on the legal restrictions placed on refugees, such as limited mobility. As one host community participant explains:

"Yes, I support them, especially when they ask for assistance with painting, construction, and other things. One example is, sometimes I work as a cameraman, and they need the passport photos, they will come and ask for assistance from me to take their photos, and I will take them and they pay me back. So, every time I take their photos, I take them to Assosa, print them, and bring them back to the owners." (LLI16)

The segregation of refugees into zones has the effect of managing relations among ethnic groups. Zones act as a way of ensuring that when refugees first arrive, they have the support systems they need. However, the composition of the zones is not permanent. Different refugee groups can be moved to other zones if conflict arises. Zones can include refugee groups from multiple countries living together, which supplements cross-cultural understanding. As one Congolese refugee explains:

"My tribe, we are living in zone F. We are living with another tribe from Dinka, Fung, we are living in peace. Before, we were living there in zone G, every day we had fighting, but now we are living by peace." (SSI61)

NGOs have engaged in awareness-raising and livelihood workshops as a way of increasing self-reliance and easing tensions. When refugees initially arrived, NGOs collaborated with the host community to assimilate refugees into the community and introduce measures for positive socialization.

"Things have changed through awareness raising, some done by the organization and some by the host community to support the refugees to stop what they are doing and to change their lives into better lives. (SSI66)

To combat theft, refugees engage in livelihood programs initiated by NGOs. These programs are also open to the host community.

"What NRC was doing was giving me a chance to become a tailor. For example, there were a lot of projects like bee keeping, chicken-keeping, tailors, carpenters, constructors, and other things." (SSI66)

\section{Impact on local actors}

The arrival of refugees has drastically changed the overall economy of the area. The establishment of the camp has fostered local development and led to the creation of new infrastructure that benefits locals, such as roads and education and health facilities used by both communities. 
"I remember since mid-1997, even this road was not like that. The school where we learned in Homesha, UNHCR is the one that built those classes." (SSI59)

The circulation of basic commodities resulting from the refugee presence gives the host community access to products they could not otherwise find in the area, for which they had previously travelled to Assosa to obtain.

"For example, during the distribution of rations, we as the host community we can go and buy things like cereal from them, we buy oil from them, that we can use for our own family. Even highlanders buy some things that are useful for them, so their staying here is benefiting the whole country." (SSI65)

Trade triggered by food distributions allow locals to buy food and basic products at low prices that they could not get from regular merchants:

"Also, what we receive for our food, like oil, beans, we used to sell them, but it is not expensive, it is cheap, not like in Assosa. They used to go to buy there but it is very expensive. Some of them used to come to buy especially during distribution." (SSI59)

One of the main consequences of the establishment of the camp is the influx of NGOs and international organizations, which has two main effects on the local population. First, the development of services and implementation of projects can also bring benefits the host community. Although the priority given to refugees is a source of frustration for hosts, locals usually benefit from 25 percent of aid. This means that for activities such as trainings, a minimum number of beneficiaries must be from the host community.

"Some NGOs have spent 18 years, for example, ZOA, IRC, UNHCR, and ARRA.] The organizations have benefited the host community a lot, for example, when there are things made for refugees also the host community would benefit. For example, when
ZOA was here, they would give livelihood trainings, such as carpenter training, mason training, and those are the 25 percent that we were having." (KII25)

Job creation has been triggered by the arrival of new organizations and has resulted from the increased demand driven by the refugee presence.

The arrival of refugees also has a social impact. First, it increases social and cultural diversity. Interactions and repeated exchanges among different communities encourage the development of new social practices, each community influencing the others.

"Also, if there are celebrations, for example, if there are any weddings, we will go and celebrate those weddings with the refugees together. So, these are the things that we copy from the refugees and also the things that refugees have copied from us." (SSI66)

In addition, both refugees and hosts have learned new languages so they can communicate with each other. Being able to speak the same language is key to integration because it allows social interactions to happen and prevents disputes from arising.

"If you speak their language [that of hosts], it is very easy and very nice for them and for us. Even if there is a big problem happening between them, they may not share with us something big because we don't speak their language. They also learn Arabic from refugees. Now they are studying with refugees together." (SSI59)

Secondly, the refugee presence has led to changing gender roles. Seeing refugees from different cultures fosters tolerance toward social practices that the local population once thought unacceptable, particularly regarding the way Congolese refugee women dress and interact with men. 
"Some Congolese women used to wear trousers; because this area is for Muslims ... (pause) if you see a Congolese lady moving with a boy, it was a shame to them but now they change, they start to do what they saw them doing." (SSI62)

Local women speak with great enthusiasm about improvements they have noticed in women's education.

"The change that we are seeing now is that, for example, women, long time ago, we were not allowed to learn, but nowadays, there are opportunities for women to go to school. For example, taking my example, even though I am old, I am learning three days a week. Which means in a month I may learn for 12 days." (SSI65)

In addition, the arrival of NGOs and international organizations was accompanied by the development of awareness-raising activities about women's rights, child marriage, and early pregnancy. Furthermore, local women have been inspired by the skills brought by refugee women, especially in tailoring.

"They know how to make hand clothes, they know how to do something by hand, but they don't have some of the things that they need here. They would ask 'why don't they [NGOs] want to bring us tailoring, we want to sew a handkerchief, we want to sew a sheet using colorful thread.'" (LLI17)

However, refugee women emphasize that women remain marginalized and relegated to domestic roles.

"Women's needs are not satisfied. Women need good health and, secondly, they need some work to be busy because you will see some girls, they are married early because they are jobless and they don't have work to do. Then some don't get the opportunity to do anything because they are ladies ... Maybe at the primary school where I teach, they find some four ladies, not men. They give opportunities to men, not ladies, so you will find many ladies at home just pregnant. They have to create many jobs for ladies, like they have to do like handwork, so that they get many jobs to do." (FGD42)

Hosts also speak of negative effects associated with the presence of refugees, particularly environmental degradation. Deprived of electricity and gas, refugee women have no choice but to cut wood for cooking, which contributes to the destruction of the forest and causes tensions between refugees and hosts-who perceive this as a threat to their own livelihoods.

"Refugees are giving us a hard time because as you can see, all our forest is destroyed. They have destroyed our income because they come and take our animals, and nowadays we cannot release our animals freely to go and eat." (LLI18)

\section{Conflict-sensitive analysis}

Relationships between hosts and refugees in Sherkole are mostly peaceful. According to ARRA, this peaceful coexistence is due to cultural similarities between the populations living there.

"There is no more tension in refugee camps, as describing the area, because of the similar culture, there is no more tension." (KII27)

However, the reality is more complex, as Sherkole camp accommodates refugees of different nationalities, some of them with better relationships to the host community than others, while interactions among refugees are mostly peaceful. The peaceful coexistence among refugees is supported by the organization of the camp. Refugees are placed in different zones depending on the language they speak and their ethnic origin, which facilitates interaction. A Sudanese Funj refugee explains: 
"The interaction is good between refugees. We are Funj, we are living in zone ___, in zone ___there are different groups, there is Funj, Jumjum, and Nuba, we communicate in Arabic." (SSI59)

However, despite this social arrangement, tribal conflict can happen, encouraged by the political situation in the refugees' country of origin. An ARRA representative explains:

"Conflict occurs sometimes tribe against tribe. It does not happen often. The political situation in South Sudan influences the conflict. If in South Sudan there is conflict of clan against clan, sometimes it happens here because in some clans there are some accidents that they hide." (KII27)

Refugees living in the camp confirm this and single out specific communities as being involved in fights.

Asked about their interactions with refugees, hosts describe harmonious relationships sustained by regular interactions.

"We live in an equal system, the host and refugees together. We cultivate with them together, we eat together with them, and anything that we have in life we share together with them. Like if we have two things, we share with them, one goes to the refugees and another to the host." (SSI65)

This is particularly the case for Sudanese refugees' relationships with local communities, as they share common cultural features. As these groups comprise the majority, interactions remain positive overall. However, relationships can be rough between refugees of other nationalities and Ethiopians with different ethnic backgrounds: Ethiopian highlanders consider cultural differences to be a challenge in their relationships with refugees.

"The refugees moving from one place to another area is a problem. For example, the refugee culture is different from the national culture. The refugees don't know the culture of the Amhara or other nationals so how they can manage? This is a problem." (SSI64)

Among refugees, Congolese tend to have the most difficult relationships with locals. This is reflected in the way Congolese refugees describe hosts.

"Sometimes, you meet with locals, they ask you why you are here, it is difficult. There is no relationship with the locals. Five years ago, it was always like this. My relationship with the host has not gotten better." (SSI61)

Hosts also acknowledge that interactions with Congolese are less frequent because of the language barrier:

"Yes, the Congolese refugees are present here. They do not interact as well with the host community as the Sudanese. Because they cannot speak the language, Congolese communicate in English." (SSI64)

Hosts do not, however, cite any problematic interactions with Congolese refugees, but they do speak of difficult relationships with populations from the Blue Nile.

"Yes, they [refugees] are treated differently. Because we have never experienced problems from Congolese, or from Darfur, or from Dinka. Those who are disturbing us are especially from Blue Nile. They are the ones who are disturbing us, but as with other refugees, we are living peacefully with them. We all agree." (FGD38)

Despite overall peaceful relationships, conflict does sometimes occur between refugees and host community members, often over natural resources. Deforestation, the practice of cutting wood due to the absence of an alternative energy source, is a source of tension and conflict at the camp, consistently highlighted by hosts, although 
some of them acknowledge that locals also participate in this activity.

"The negative impact that they have had is on the resources, especially the forest. They have cut down the trees that should be kept for wildlife and other things. Not only refugees are doing this, but even the host community themselves." (SSI63)

Refugees also go in the forest to collect fruit, which is a source of income for locals.

"They also destroy our forest, for example, they cut down our mangos, they cut down the bush. Even the mangos that we are supposed to get income from, like lemon and other things, before they are ready, they come and destroy it. So, this is another problem. We allow them only to cut down the dry ones, not the ones that have life." (FGD38)

Refugees speak of the tensions created by this practice, which puts women at risk because they are in charge of cutting firewood and can therefore be targeted by disgruntled locals.

"If we go to collect firewood from the woods, they will capture us, and some of them will fight us, some of them will tell us to stop. Also, they will rape the women or the girls." (SSI59)

Competition over land can also result in conflict. Although refugees do not have the right to own land, arrangements with locals allow them to cultivate it so they can provide for their own needs and so they can earn additional income. This can lead to disputes, especially if a host decides to withdraw permission and deny a refugee access to the land.

"There is the problem of, for example, if you ask them for a piece of land to cultivate, they may give you only one year to cultivate. But when they see that you are getting a good harvest, they may stop you. Also, they may take what you get from the land. Sometimes, some of them may say that you will divide the harvest. If you try to say no, it will cause problems." (SSI59)

Competition over gold can cause disputes as well. Conflict can erupt when refugees find gold while working in mines and locals force them to sell it at a low price.

"Some of the refugees work in the gold mine here, when you find gold, they cannot let you go with it. They will take it from you, and they will give you just some small money. Because you are a refugee, how can you take the gold for yourself?" (FGD42)

Repeated delays of food distribution causes refugees to steal from hosts so they can feed their families. An NRC staff member describes:

"They even come and break the door of the host community and steal materials; this is what they tell us. They steal because of the delay; they don't have something to eat. When we become hungry, we human beings become like that." (KII26)

This practice creates tensions between the host community and refugees, but locals hold the government and NGOs responsible because the theft occurs due to the lack of food:

"What will strengthen the relationship between the host and the refugees is help. The government and NGOs must bring their food on time so that they cannot come into our farms and our homes and steal our property. If they stop doing this kind of thing, we will live with them in a peaceful way, if their food comes on time. So, this will strengthen the relationship between the refugees and host community." (FGD38) 


\section{Box B.2. Formal and Informal Conflict-Resolution Mechanisms}

"If conflicts happen in our zone with the host communities, our leaders may send a letter to the leaders of the host, then they come. If it is a big issue, it will be in ARRA; if not a big issue, it is solved by leaders of zones like zone $C$. If it happens in their area, their leaders go and solve the problem. ... Because every zone has zone leaders, if it is not a big issue, the zone leaders will go and solve that problem. If it is a big, they may call the leaders of the zone and they will go together with ARRA; then they will solve the problem."

Source: SSI59.

In addition, the lack of support from NGOs and international organizations, coupled with the feeling that refugees are exhausting natural resources, could increase tensions. As one host explains:

"What the organizations are doing here will cause other problems among the refugees and the host community because if the services that refugees are getting and the host community are not getting, then they come to our locality and destroy our forest, farm, and steal our things while we keep quiet and the organization cannot provide the simple services that are being provided to refugees or their children and, as human beings, sometimes you may feel upset and take all these thing in your heart and say: "Why am I bothering myself or suffering because of refugees while their people don't want to support me?' This is also the thing that causes the hatred between refugees and host community." (FGD39)

Local resentment is exacerbated by the lack of job opportunities, which tends to make hosts skeptical about strengthening the economic integration of refugees:
"There will be some problems because, even right now, there are Ethiopians that are lacking jobs, so if the government provides land to refugees while the hosts lack jobs, it will bring problems. If this policy is implemented, there will be a problem because there are Ethiopians that are educated but don't have jobs. Five years, six years since graduating, there is no job, they don't have an opportunity to work." (SSI64)

Mediation mechanisms are in place to deal with potential conflicts. While ARRA is the formal body for addressing disputes involving refugees, refugee leaders resolve many conflicts. Refugees from each camp zone select their own representatives for a zone-specific peace committee. The committees are tasked with solving all disputes, except for serious matters such as crimes, which ARRA handles. If conflicts arise between individual refugees, the relevant zone leaders gather and organize a meeting with the involved parties. When conflicts arise between refugees and hosts, refugee leaders meet with representatives of the hosts, otherwise following the same process.

\section{Social organization}

In addition to regular meeting places, women and youth have their own ways of interacting, most commonly of an economic nature in the marketplace. Sherkole camp has its own weekly market, but refugees also rely on the local market for their daily needs. Coping mechanisms such as borrowing and buying on credit builds linkages to local merchants. Interactions also occur at businesses run by refugees, such as restaurants and cafés.

"Right now, I do have my restaurant in the market. They will come and buy things like seeds and they will eat. We have five restaurants which are very small restaurants, the host communities come there." (SSI60)

Repeated economic interactions can lead to strong relationships. 
"I feel like I belong to both sides, both the host community and the refugees because sometimes I go to the refugees and also, I used to stay with my family in the village in the host community. What makes me a part of the refugees is because sometimes when they run short of food, they come to us and borrow something, so it makes us interact with the refugees." (SSI66)

Distance to the camp affects the strength of ties between the two communities, as interactions are more frequent between refugees and hosts when the latter lives in very close proximity to the camp. These hosts are the primary providers of essential goods to the refugees; in return, they rely heavily on refugees for their own livelihoods.

\footnotetext{
"Some of them are also near us, they used to come to visit us or we used to go to visit them, and we used to buy some charcoal or firewood." (SSI59)
}

Places of worship allow for a different kind of interaction based on a shared faith. In that sense, mosques and churches play an important role in social cohesion. Most refugees and hosts are Muslims; they gather on Fridays at mosques located inside the refugee camp or in the host community.

"The religions are important because, for example, we have refugee Muslims that sometimes on Fridays or other holidays go to our mosque and pray with us together. And, also, we have some Muslims that are from the local area that also go to refugee complex for prayers. So, the relationship between the host community and the refugees in terms of religion is okay." (FGD38)

In addition, celebrations trigger social interactions between refugees and hosts. As put by a host, refugees and hosts share moments of happiness and sadness, revealing a

\section{Box B.3. Building a Relationship of Mutual Trust Through Refugee-Host Exchanges}

"If you want to buy beans, you will ask her if she has more, maybe you will buy only from her. If she has more than that, because you don't have money, if she can, you will discuss with her if she has more at home. You will introduce yourself to her, and she will also introduce herself. If she is good, maybe one day you will tell her that 'I will come to visit you,' and if you want to visit her maybe you will take something to her, maybe what we receive like oil, beans, and if you go to her house, she will also give you some beans. After that, you will start your relationship with her. Whenever you have needs, you will go to her house and discuss with her, and when you need something, you also give. They are used to coming to our houses and zones."

Source: SSI59.

strong sense of solidarity between the two communities despite their differences.

"What we have learned from the refugees is the way of brotherhood or sisterhood because when there is someone who is in happiness or sadness, we will go together and stay for those days together with the refugees." (SSI66)

These shared moments are celebrated with traditional dances performed by host community members.

"We have the Zumbara team, this is like a traditional team for dancing. If there is any occasion, they will organize and come and celebrate with the refugees." (FGD38) 
Activities organized by NGOs for the United Nations' World Refugee Day also bring refugees and hosts together. This has become an annual ritual.

"For example, on World Refugee Day, we come with our own traditional ways and we dance with them on refugee day; and also on women day, we celebrate with them [during events] organized by NGOs like IRC." (SSI65)

This highlights the ability of NGOs to mobilize community members and the important role they play in fostering social cohesion.

Critical life events, such as weddings and funerals, are also occasions for social gatherings supported by shared identity.

\begin{abstract}
"We are sharing together as we are coming from Africa, we have different tribes like Congo, Darforia, Mabaan, Fung, and Nuba, so if there is any ceremony like a wedding, they will invite us, and we will go there to sit together with them and eat food together." (SSI60)
\end{abstract}

As previously noted, a shared faith is a powerful driver for social cohesion. Connections between Muslim refugees and Muslim locals are reinforced by multiple religious celebrations throughout the year.

\footnotetext{
"For example, because most of the host community members here are Muslims and part of refugees are also Muslims, during fasting of Ramadan, they fast together with the refugees, and during dinner time, they dine together, and at the end of the fasting period is Eid, they celebrate Eid together." (SSI63)
}

Ties between refugees and hosts have been strengthened by the multitude of mixed marriages, blurring the line between the two communities:
"The hosts and refugees intermarry. I even have a sister who is married in the host community and has seven children." (SSI59)

Youths have their own places of interaction, offering opportunities for them to develop strong relationships. Students from both communities meet in class because refugee schools also cater to local children. This leads to daily interactions that are sustained over several years. The parents also meet each other on "parent days."

"And also, during parent days at school, we also
come and celebrate our children at the end of the
year with them. The refugee and host community
children are in school together in all grades." (SSI65)

Although the host community does not have its own youth centers, they can use the ones in the refugee camp. Although these recreation centers have limited equipment, they remain a gathering place for youth, a place where they can play sports. As a result, youth from both communities spend extensive time together and develop common interests. One host explains:

\footnotetext{
"Because the youth are mostly interacting with the refugees, the benefit that the refugee youth get, the host youth also get because they are always in competitions, they are playing together, sharing things together." (SSI65)
}

Soccer (football), which is widely practiced and popular, provides an extremely powerful way to foster interactions. Games take place at the refugee camp or in the host community, gathering young children and teenagers. Playing soccer is not restricted to boys and male youths. Encouraged by the success of soccer competitions at helping youths meet, organizations have started organizing similar games for girls. 
"The same things to girls, our girls and refugee girls, being organized by the help of ARRA and other NGOs, sometimes they play football [soccer] together or do other activities for women together, so it is a form of interaction." (SSI65)

Finally, women have their own sociability, bringing together refugee and local women. Whether they are locals or refugees, women face similar challenges and share common interests. The women's rights association has involved the refugee women's association in its activities, which helps raise awareness of child marriage and early pregnancy.

"We have achieved a lot in changing the lives of refugees in terms of ending early marriage or other things, for example. We always have meetings with other refugee women, including the refugee leaders. If there is any problem, we try to solve the problem with the host community and the locals, so these are our achievements." (SSI65)

\section{Economic interactions and impacts}

The protracted presence of refugees has reshaped and boosted the local economy, stimulating both demand and supply, bringing in new skills, and creating job opportunities. Many interactions happen in the marketplace, where refugees are buyers and sellers. For the host community, the demand triggered by refugees has created new business opportunities. Hosts express positive views regarding this impact.

"Yes, the presence of refugees here has changed a lot of things. For example, business was very poor before, but nowadays, the presence of refugees here has improved the businesses. For example, the refugees have experience in business and the host community have less experience in business, so some businesses we copied from the refugees, then we adapted them into our own culture." (SSI66)
Hosts and refugees trade in two different spaces: a refugee marketplace and the local marketplace. On Mondays, sellers from the host community go to the refugee market in Sherkole to sell basic commodities and goods from Assosa. Locals are an indispensable intermediary for refugees to access products from town.

"Yesterday was market day. There is only one day when goods come from Assosa, so you order goods from Assosa and then you come and collect them at the market. You order from the host community." (SSI59)

Locals, for whom trade has not been a primary livelihood, do not see the development of shops run by refugees as competition by locals.

"It is complementary because most of the local community depend on farming, they are not traders. Some refugees are traders. The local community buy from refugees things like shop materials, like salt, macaroni." (SSI64)

In fact, hosts have become dependent on the demand created by refugees.

"Yes, there are benefits. For example, in income-generation time, I go and bring firewood from the forest and sell them to the refugee. This is part of the benefit because I get money so that I can put something on the table for my children." (FGD38)

Local merchants also benefit from refugee presence in their pricing. The extra demand has increased prices, increasing the profitability of their businesses.

"The change that I experienced in these 40 years is the economy, a long time ago, things were cheap, they sold things in coins starting from 10 cents and 
5 cents up to 25 cents, and sometimes we begged the buyers to buy things from us. ... But now, the coming of refugees here has brought development for us because what we were selling at 5 cents and 10 cents, we can sell at $\mathrm{Br} 5, \mathrm{Br} 6, \mathrm{Br} 10$, so this is a positive change." (SSI66)

Refugees can also access the local market where many run businesses, such as small shops, butcheries, restaurants, and cafés.

"All of them, especially Sudanese, they access the market, they support themselves, they have small shops and even the host community comes to buy from here." (KII25)

The products received by refugees during food distributions are the basis for trade. Refugees keep part of the rations and sell the rest to get cash for buying basic essential products.

"When the refugees get the food, the ration, they share out. For example, if you are size 4, [you keep 2] and you take money for size 2, it goes to the host community. Size 4 means four people, because we receive the ration according to size. When I say size 1 , it is one person. So, you take that and sell it out. If you take, for example, 2 liters of oil, in your house maybe you don't have soap, you can sell 1 liter of oil and use only one. That's how you can get money to go and buy soap." (SSI66)

This practice is highly appreciated by locals, who benefit from products that are hard to find in local markets at a good price, such as sugar. However, locals living around Sherkole are poor and have limited purchasing power. While some of the goods offered by refugees are too expensive for the host community, they also attract highlanders, who can afford the higher prices.
"We buy sugar, for example, because the refugees are provided with sugar, salt, oil. We the host community we are interested in buying those things that refugees receive for example blankets, cooking materials, or solar lamps, but we have a shortage of cash in our hands. We have others coming from highlands with that money and they can come and buy at expensive prices, most goods of refugees go to the highlands, not to the host community." (SSI65)

Such form of trade is a win-win for refugee and host communities, especially because resources are scarce for both. As agricultural production is weak, local farmers lack sufficient volume to sell in Assosa. Refugee demand is therefore their only possible outlet.

"The reason we don't take these things to Assosa is that we are only getting farm products and the farm products that we get are not much. It is not something that can be taken by sacks or cartons. It is only something that can be taken by bikes. It can only benefit refugees. So, because what refugees get from ration is small, so we decide to cultivate other thing like onions and sell in their markets so that they can also benefit from us and we can also benefit from them." (FGD39)

Receiving very small sums of cash, refugees are in the habit of borrowing money, which they pay back once food is distributed. This practice is common among refugees but also occurs between refugees and hosts.

"They borrow from each other. For example, when the rations of refugees are delayed and they have seeds or crops in their home, refugees will come and borrow from them." (SSI65)

Borrowing is the primary coping mechanism when food distribution is delayed, making refugees heavily dependent on their solidarity with hosts. 
"Even yesterday, refugees said that when there are delays in food distribution, the host community is the one that takes care of them more than the organizations. ... The only challenge is theft, but we are supporting each other. They come and borrow maize, sorghum, or other basics." (KII26)

Some hosts speak of the challenges that result from this practice, which puts their businesses at risk. A commonly mentioned challenge facing shop owners is theft committed by refugees.

"The reason our business is not going forward is because, for example, if you open a shop today, some refugees will come and rob it. If it is not robbed, they will come and take things on credit. So, when they borrow, what is borrowed might not be brought back forever or at the right time. That is why we are always going back. So, if you start a business, you will decide to close, and it is the same circle." (FGD39)

On the economic front, another important effect of the refugee presence is the creation of job opportunities. Organizations supporting refugees hire highlanders as well as locals.

"There are people from the host community who are employed by NGOs. For example, the manager of NRC is from the host community from Berta; the ARRA protection officer is also from the host community from Manji. He is called Abdul Kadi. So those are examples." (SSI66)

Emerging issues, such as environmental protection, can also lead to the creation of jobs.

"Even job opportunities, even if it is not us ourselves, some of our relatives or family members are working as forest keepers; there is an organization to keep the forest, so these are opportunities for jobs." (SSI65)
Although locals mainly engage in farming, some hosts have opened businesses, attracted by the opportunities triggered by the increased demand. However, the limited purchasing power of potential buyers, the scarcity of resources, and the lack of financial services are not conducive to developing larger-scale businesses.

Financial services are limited. Basic services exist but are not extensively used by the population. Although microfinancing is available, products are incompatible with Islamic principles, and most hosts are Muslim.

"Yes, we are practicing all these things like banking and microfinance services. Microfinance services are done in Homesha, you may take your money there and keep it and protect it from being stolen by thieves or being destroyed, and also you will get profit on your money. If you put like $\mathrm{Br} 50$, you may get like 50 cents on each $\mathrm{Br}$ 50. So, later on, when you want to withdraw the money, you will have some profit that you get from the money. But for us as Muslims, that is Haram, it is not allowed by the sharia that when you keep something you can get profit from it. So that is why sometimes it is difficult for us to use microfinance services. But saving the money in micro is very good." (FGD39)

For hosts as well as refugees, the most popular financial system remains saving groups, which allow people to contribute small amounts and to take out loans.

\footnotetext{
"There are some groups where we contribute money, then after the contribution, we assign someone to put the money in a project. But not everyone is in these groups." (FGD40)
}

The arrival of refugees has enabled the development of new skills among hosts in two ways: 
First, the presence of refugees from different nationalities and ethnic groups has encouraged locals to learn new languages, especially English.

\begin{abstract}
"But now, the locals have more benefit, they start to speak English. I think the Maaban are the ones that started this camp. They came and started to teach the locals English, even now the locals have become open." (SSI61)
\end{abstract}

Although refugees living in Sherkole have different backgrounds, hosts consider them to be skilled and knowledgeable. Locals benefit from the refugees' knowledge of agriculture, crafts, and business.

\begin{abstract}
"Most of the refugees are very experienced people. I may have the money and the land, but I don't have the knowledge, while the refugees have the knowledge. So, I may call the refugee because they have experience maybe in agriculture and on other things that I want them to do for me. So, they will do for me in good quality and I will pay them." (SSI63)
\end{abstract}

Finally, refugees engage in informal economic activities because they do not receive enough aid to survive. Many refugees run small businesses, as previously noted, catering to their fellow refugees as well as to hosts. Locals, who do not traditionally engage in business and trade, do not perceive such activity as a threat. However, regulatory constraints are preventing refugees from developing businesses outside of the camp's immediate surroundings.

"Even if you have money, you cannot buy a motorbike or a car; because you are a refugee, that is a restriction. Another thing is freedom ... you cannot go to any other village. You can only work here, you cannot go to Homesha or Assosa to open a shop to sell things, no. Only in Sherkole. You cannot move to any other village or city to open a shop to sell things. You can only use your money here." (FGD42)
Many refugees work as daily laborers on farms or in gold mines. Sometimes, rather than being paid for their work, they receive in-kind payment.

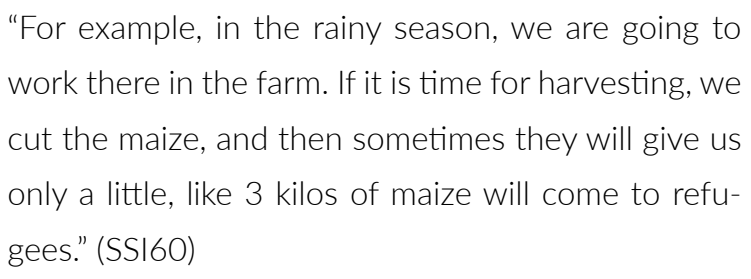
work there in the farm. If it is time for harvesting, we cut the maize, and then sometimes they will give us only a little, like 3 kilos of maize will come to refugees." (SSI60)

Although refugees are not formally allowed to engage in such activities, locals have decided to let them work, recognizing that they receive an insufficient amount of food.
"Because we have made good relationship with them ... they will go up there for mining and get their gold and change it into cash and come back and feed their children because what is provided by UNHCR and ARRA is not enough. Before, they would be captured and brought back to the camp, but we have sat down with the government and we told them about the challenges that refugees face and now they allow refugees to go and work and at least get something for their children." (KII25)

However, refugees only receive small incomes; they are not allowed to receive proper salaries. The so-called "incentive" used to be $\mathrm{Br} 700$; it was increased to $\mathrm{Br} 805$. Even in Homesha, where the cost of living is low, this amount of money is just enough to buy food and does not allow refugees to purchase clothes or domestic items.

\footnotetext{
"We are getting $\mathrm{Br} 805$, this money, I start work in 2015 up to now I can't buy clothes with that money. I use that money to feed myself only. I think you understand how people are suffering, we are able, I can work but the payment I'm getting cannot support me with anything." (SSI62)
} 
In addition, this treatment is causing frustration among refugees, who see locals getting much higher salaries for the same work.

\begin{abstract}
"They say that ARRA decides. For example, I may work with you today as an interpreter. They will pay me only $\mathrm{Br} 70$ per day and say this is because of the government. We see our brothers who ... are getting US\$45 per day." (SSI62)
\end{abstract}

\section{Conclusions}

A review of the group-based dynamics between refugees and the host community, the factors that aggravate tensions, and those that promote social cohesion, are presented below. These elements are key to understanding the social dynamics between refugees and the host community, as well as the best areas for implementing interventions. Recommendations are then proposed for policy planners, followed by an examination of the effect of the Comprehensive Refugee Response Framework (CRRF).

\section{Relations between the host community and refugees is} generally positive. There are two factors behind this. One is the protracted stay of the refugees, with most having been in Sherkole more than 10 years. Moreover, Sherkole camp is unique in that it includes refugees who initially settled, then repatriated, and then years later returned to the camp. The long duration of stays has meant that both hosts and refugees have learned to adapt to one another. The second factor is the common culture and language that the hosts share with Sudanese refugees-the largest refugee group. However, this has the knock-on effect of leaving refugee groups from the Great Lakes region feeling marginalized.

\section{Congolese refugees constitute the third-largest refugee} group but feel the most marginalized. Language and cultural differences have been difficult to overcome even though some Congolese refugees have lived in the camp for over 15 years. Congolese refugees claim they are being marginalized by NGOs in terms of the type of food available in the rations and the rejection of their claims for resettlement. What is striking is their perceived reluctance to improve integration. For instance, most Congolese refugees cite the language barrier as the greatest obstacle to their integration, but most parents do not want their children to learn in Arabic, preferring that they learn in English. This points to a common sentiment among Congolese: the desire to be relocated-either to Addis Ababa or in some cases back to the Democratic Republic of Congo.

\section{Deforestation and the delay and decrease of rations are} the main contributors to tensions in the region. Refugees are not connected to the national electricity grid, nor are they provided with clean cooking fuel or appliances. Refugees therefore have no choice but to cut down wood, which they use as fuel and as to sell in the marketplace as an income source. Deforestation is a flashpoint between the two communities. Some host community members take punitive measures against refugees to prevent them from cutting down trees, but absent alternatives, many refugees will take the risk, which can spark conflict. The size of rations has decreased, and deliveries are frequently delayed, placing refugees in a desperate situation. Many refugees therefore steal from the host community to survive. Some choose to leave the camp to engage in gold mining in nearby woredas. Several reports from refugees indicate that this is a perilous journey, with most returning empty-handed after being robbed of their earnings on their way back to the camp. Limited livelihood opportunities force refugees to take risks to sustain themselves.

\section{Refugees and the host community collaborate with each other during tough times. The host community is recep-} tive to the struggles that refugees face, especially the decreased rations and delivery delays-which can last up to two months. In response, members of the host community often hire refugees as day laborers in exchange for food, or they allow refugees to take a small portion of land for cultivation. This improves relations between the host 
community and refugees tremendously, and it also acts as a mitigation strategy to prevent incidents of theft-a primary aggravating factor for tensions between the two groups.

The host community perceives the presence of refugees as beneficial due to the services provided by NGOs. Education and health services are cited as the most impactful change in the lives of hosts. Although most schools are located inside the refugee camp, children from the host community are allowed to access those services. The host community also credit the availability of basic commodities that used to be difficult to find on the market to the arrival of refugees. In Sherkole, every Monday is market day. This is when members of the host community come to the camp and trade with refugees.

The arrival of refugees has positively impacted gender roles in several ways. The host community has adapted to the ways in which Congolese women dress, and the general restrictions placed on the way women dress have been relaxed. Host community women find that they have expanded opportunities to receive an education. NGOs are also cited as improving gender roles by educating both refugees and the host community on women's rights, child marriage, and early pregnancy.

\section{Implications for the Comprehensive Refugee Response} Framework. The CRRF has a good chance of success in Sherkole due to the positive relationships between the host community and refugees, as well as the patterns of existing integration and exchanges between the groups. Integrating the two largest refugee groups from Sudan and South Sudan would not be difficult due to their common culture, language, and history of cross-border movement and kinship. Moreover, due to the open structure of the camp, refugees and the host community already interact on a daily basis. Therefore, further integration would not be a collective shock to either group. The only obstacle would be tailoring integration programs to address the challenges of Congolese refugees. This would mean ensuring that they, as well as refugees from the Great Lakes, are included in conversations about the rollout of the framework.

Providing work permits and allowing refugees to work and own land would not create tensions between the two communities because they already share a history of economic collaboration. Moreover, several host community members believe that refugees possess high-level skills. Therefore, allowing refugees to work together with the host community can enhance the transfer of knowledge. There have been accounts of host community members leasing out small tracts of their land to refugees, suggesting that land ownership is less of a security issue than it is in Gambella.

However, the potential gains offered by the CRRF could be offset unless:

- Refugees are provided adequate energy provision. The rollout of the CRRF should explore options for connecting refugees to the national grid or for using renewable energy to prevent further deforestation.

- Improvements are made to social and basic serviceswhich also impact the host community. This is especially crucial in the education and health sectors to maintain the current positive relationships between the communities. 


\section{References}

ARRA (Agency for Refugee and Returnee Affairs, Ethiopia). 2016. Administration for Refugees Returnee Affairs). ARRA.

---. 2018. Camp Profile Assosa: Tsore Refugee Camp. ARRA.

Akwei, Ismail. 2017. "Ethiopia Opens New South Sudanese

Refugee Camp to Ease Congestion." Africa News, July 27. https:// www.africanews.com/2017/07/27/ethiopia-opens-new-southsudanese-refugee-camp-to-ease-congestion/.

Bullock, L. 2018. "Ethiopia Could Be Sitting on One of the World's Great Untapped Gold Deposits." Quartz. https://qz.com/ africa/1189246/ethiopia-gold-mining-asosa-region-has-one-ofworlds-great-untapped-gold-deposits/.

EUTF (EU Trust Fund). 2016. "European Union Emergency Trust Fund for Stability and Addressing the Root Causes of Irregular Migration and Displaced Persons in Africa." Cross Border Analysis Mapping. Cluster 3: Western Ethiopia and Eastern Sudan.

IOM (International Organization for Migration). 2013. Displaced Youth's Role in Sustainable Return: Lessons from South Sudan. IOM. https://publications.iom.int/system/files/pdf/mrs_47_6nov.pdf.
JRS (Jesuit Refugee Service). 2005. "Ethiopia: Forced Relocation to Sherkole Camp." JRS, October 13. https://reliefweb.int/report/ ethiopia/ethiopia-forced-relocation-sherkole-camp.

Meleskachew, A. 2018. "Ethiopia Agrees to Suspend MIDROC Gold Mining After Protests." VOA News.

OCHA (UN Office for the Coordination of Humanitarian Affairs). 2019. "Ethiopia: East and West Wellega, Benishangul-Gumuz Access Snapshot as of 15 May 2019." OCHA. https://reliefweb. int/report/ethiopia/ethiopia-east-and-west-wellega-benishangul-gumuz-access-snapshot-15-may-2019.

ODI (Overseas Development Institute). 2019. The Comprehensive Refugee Response Framework: Progress in Ethiopia. Humanitarian Policy Group Working Paper. London: ODI.

Protection Cluster. 2019. Protection Cluster Monthly Report. July 2019.

Watol, B., and D. Assefa. 2019. Ethiopia and the Refugees: History, Current Situations and Legal Framework. International Affairs and Global Strategy.

UNHCR. 2006. Agreement in Ethiopia Paves Way for Sudanese Refugees to Return Home. UNHCR. 


\section{Gambella}

\section{Displacement in Gambella}

Gambella hosts the largest population of refugees in Ethiopia: in 2018, it was home to 401,594 refugees, accounting for 44 percent of the total population of the country's registered refugees and asylum seekers (Abebe 2018). Displacement has played a crucial role in shaping the social, political, and economic life of the region. The protracted stay of refugees has not only occupied the center of Gambella's political economy but has fueled conflict and insecurity in the area, involving different ethnic groups, environmental pressures, and historical grievances. As the patterns of conflict are long-standing, this section begins by providing a historical background before moving to the link between displacement, present day conflict, and economic and political configurations in Gambella.

Gambella, situated in the southwestern lowlands of Ethiopia, is roughly the size of Rwanda (HRW 2005). It covers one of Ethiopia's longest international borders with neighboring South Sudan (Lie and Borchgrevink 2012). Cross-border kinships and economic ties have greatly influenced the region, with Gambella hosting the largest portion of South Sudanese refugees in the country. For instance, of the two regions in Ethiopia that predominantly host South Sudanese refugees, Gambella hosts 98.5 percent $(313,975)$ while the Southern Nations, Nationalities and People's Region hosts the remaining 1.5 percent (4,934). (UNHCR 2019b) (33 $^{6}$ At the center of the regional ties and the border between South Sudan and Ethiopia are two ethnic groups in Gambella: the Anywaa (also referred to as the Anuak/Anyuak) and the Nuer. Understanding the relationship between these

63. Some have also been relocated to camps in Benishangul-Gumuz due to overcrowding. groups-and their relationship with other populations in Ethiopia-is central to understanding the context of displacement and conflict seen today.

The Anywaa's claim to dominance. The 1902 Boundary Agreement between colonial Britain and Imperial Ethiopia demarcated the international boundary between Sudan and Ethiopia and defined the national identities of the Anywaa and the Nuer (Feyissa 2010). The majority of the Anywaa were placed within the borders of Ethiopia, and the majority of the Nuer were placed within the borders of Sudan (Feyissa 2010). This colonial outcome plays a role today in Anywaa's perceptions of Ethiopian Nuer as "foreigners," and supplements their claim for dominance in regional politics. The border between the two countries not only influenced the formation of group identities between the Anywaa and the Nuer but also represents the transnational dimension of the conflict between the two groups. Historically, Nuer men married Anywaa women, and the two tribes engaged in economic exchange of cattle, grain, and-later-ivory (Tadesse 2007). Gradually, the Nuer began to move eastward due to conflict with the Dinka in the west and during the colonial period to escape British taxation (Young 1999). This cross-border movement of people and goods (particularly weapons) has complicated the conflict between the two communities by introducing a regional dimension.

In the 1980s, the Anywaa were Gambella's dominant tribe in terms of population (Young 1999). This began to rapidly change with the onset of the civil war in Sudan and the political policy of the Derg regime. Beginning in 1984, the Derg regime's resettlement program resulted in the migration of 60,000 highlander farmers, who took over land to capitalize on the region's agricultural potential and as a 
way of mitigating the effects of famine that ravaged the highlands of northern Ethiopia. The Sudanese Civil War extended the violence across the border and deteriorated the security and stability of Gambella. The war resulted in a large inflow of South Sudanese refugees. In the 1980s, the Itang refugee camp in Gambella was the largest in the world (Tadesse 2007).

The massive displacement of South Sudanese refugees into Gambella altered the region's demographic and power balance. Due to the large number of refugees in Gambella-300,000 by the mid-1980s (Tadesse 2007)_Nuer became the numerically dominant tribe. With the Derg regime's support of the Sudan People's Liberation Army (SPLA), which included a large portion of Sudanese Nuer, thousands of Nuer refugees settled and acquired citizenship in the 1990s (Erda 2017). The union between the Derg regime and the SPLA created discontent among the Anywaa. Resentment formed against the SPLA for the sporadic acts of violence in Anywaa villages. For instance, in September 1989, the SPLA forces attacked a village in Pinyudo, burning it down and killing 120 people (Erda 2017). The massacre was the apex of a series of violent acts committed against the Anywaa. The Derg regime took little to no action against the SPLA, exacerbating anti-Derg sentiment among the Anywaa community.

The movement of Sudanese Nuer refugees impacted the region's stability. Most refugee camps have been built in Anywaa areas, such as Dimma, Bonga, and Pinyudo, with only one camp built in Nuer territory in Itang woreda (Erda 2017). The large presence of refugees disrupted the local economy as imported grain to feed the refugees depressed the local market. Violent encounters ensued between refugees and the Anywaa, with the Anywaa attacking and killing Sudanese Nuer, sparking retaliatory attacks by Ethiopian Nuer (Young 1999), a pattern that remains manifest today. Deep distrust and animosity for the Derg regime culminated in the formation of the Gambella People's Liberation Movement.
Once the Sudan People's Liberation Movement and Army (SPLM/A) could no longer access economic and military support offered by the Derg regime, they were expelled from the area. Anticipating the fall of the Derg regime, the SPLA administration organized evacuations for South Sudanese refugees across the border (Young 1999). The ascension of the Ethiopian People's Revolutionary Democratic Front in 1991 enabled the Anywaa to regain regional dominance as a reward for their loyalty and support for the ruling regime. Once in power, the Anywaa political elite denounced Nuer claims to land and political participation, often citing the 1902 Boundary Agreement as historical proof of the distinction of the Nuer as foreigners in Gambella. However, the 1994 housing census revealed that the Nuer were the most populous tribe (40 percent); followed by the Anywaa (27 percent) and highlanders (25 percent) (Feyissa 2010). This led to two changes: (2) the Nuer elite pressed for greater political representation; and (2) the highlanders became the most economically dominant group, providing over 50 percent of skilled labor to the new regional administration (Feyissa 2010). As a result, the Anywaa felt squeezed by both sides. They perceived the Nuer as a threat to their land and the highlanders as weakening their economic and political position. Conflict over political power took on a more violent dimension as the stakes were perceived to be higher, setting off a wave of violent massacres and ambushes between the Anywaa, the highlanders, and the Nuer between 1994 and 2003.

The conflict in South Sudan has created a new influx of South Sudanese refugees that threatens to once again tip the balance in an already volatile area. In 2017, the refugee population outnumbered the host population, and this threatens to disturb the demographic balance as the overwhelming majority of refugees are ethnic Nuer (Adabe 2018). Despite the regional president being Anywaa, previous fears of being under siege from both the Nuer and highlanders have not abated. 
This calls for caution in the rollout of integration policies targeting Nuer refugees that could aggravate regional tensions. Allocating irrigable land to refugees and integrating them into the local community may increase environmental and economic pressures as well as ethnic conflict. Social dynamics must be well understood to align policy measures to the realities on the ground.

\section{Geographic Overview}

This section reviews the territorial configuration of the region. Such a geographic overview is central to any discussion of solutions, as territoriality is a basic principle of social organization among the Anywaa (Feyissa 2015). Although the Nuer are the most populous tribe in the region, its members live predominantly in two woredas covering a quarter of its land mass. The Anywaa are settled in a majority of Gambella's woredas and lay claim to 70 percent of the total land area (Lie and Borchgrevink 2012).
Gambella has four major rivers running through it-Baro, Akobo, Alwero, and Gillo-with tributaries providing enough water to support the population and its irrigation activities. In fact, Gambella is among the most fertile regions in Ethiopia. with both average rainfall and temperature creating a conducive environment for agricultural activities. Despite its agricultural potential, Gambella remains one of the poorest regions of Ethiopia. Subsistence agriculture remains the primary economic activity, and 75 percent of the population live in rural areas. The Ethiopian government has classified Gambella as an underutilized area, a justification used to lease out large tracts of land to private investors (Gebresenbet 2016). Population density in Gambella is also low, making it costly to implement social services. As a remedy, the Ethiopia government initiated a policy of villagization to "voluntarily displace" people and move them into administered areas so government services can be more easily provided. The Ethiopian government has come under severe criticism for this practice.

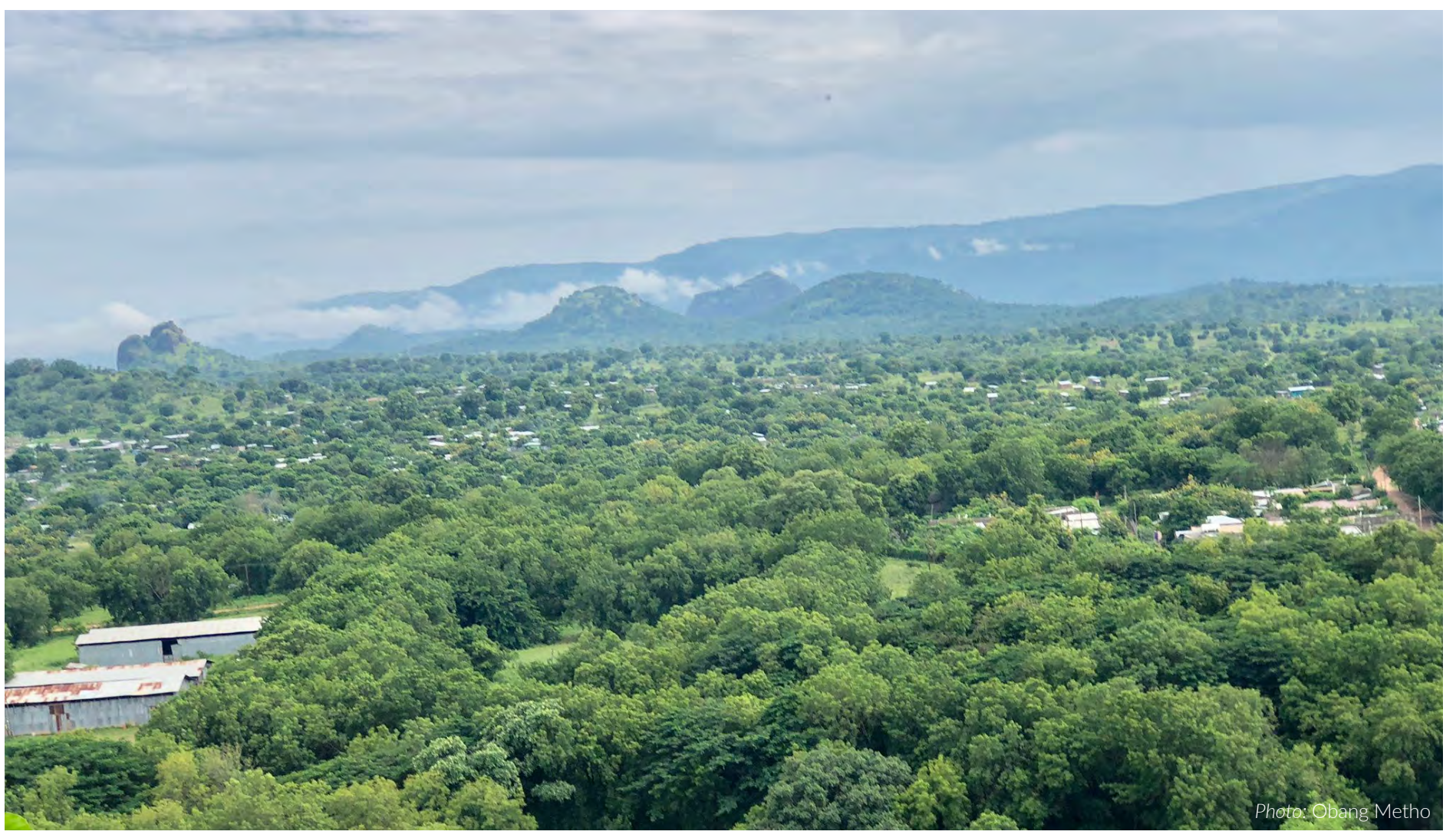

Gambella landscape 
Gambella is divided into three administrative zones, 11 woredas, and one special woreda. The three zones are: (1) the Anywaa zone, comprising the five woredas of Gambella Zuria (Abol), Abobo, Gog, Jor, and Dimma; (2) the Nuer zone, comprising the four woredas of Lare, Jikawo, Wantewa, and Akobo; and (3) the Majang zone, comprising the two woredas of Godere and Mengeshi. Gambella is regarded as a city administration and has historically been the driver of economic and political developments in the region.

\section{Gambella}

As a part of the 1902 Anglo-Ethiopian agreement, the British were able to establish a port on the Baro River (Feyissa 2010). Gambella became the economic center for the first three decades of the 20th century, handling 70 percent of Ethiopian foreign trade through Sudan (Bahru 1987). The port was used to import salt, cloth, and ivory from Sudan in exchange for coffee, hides, and beeswax from the Ethiopian highlands (Bahru 1987). The town's role as the region's economic and political hub has been a constant in an area that is persistently changing. The outbreak of civil war in 2013 put an end to the once-lucrative trade between Juba and Gambella through the waterways that connect them (Jeffery 2019). The refugee economy has offset the repercussions of the halt of trade with Juba. In 2018, the budget allocated for Ethiopia's refugee population was $\$ 618$ million (Jeffery 2019). Gambella hosts the largest number of refugees in Ethiopia, and a large percentage of donor money flows through the town.

\section{Itang special woreda and the refugee camps}

In 2010, the Gambella administration gave Itang the status of a special woreda that belongs to none of the three zones (Seide 2017). Itang is home to three refugee camps that predominantly host Nuer refugees: Kule, Tierkedi, and Ngeunyyiel. According to local discourse, refugees refer to the three respective camps as Kule 1, Kule 2 (Tierkidi),

\section{Map C.1. Gambella Detailed Operational Overview" (as of January 2018)}

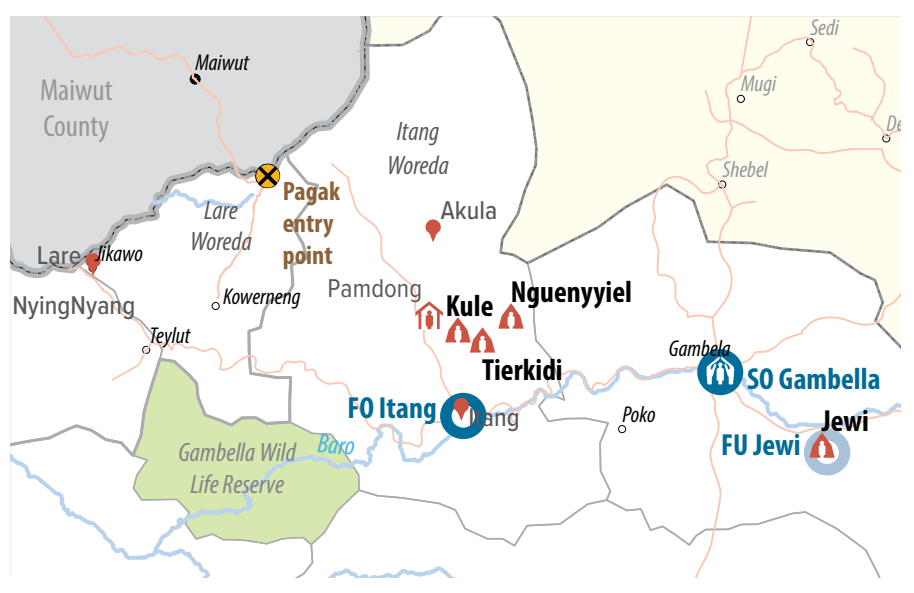

Source: UNHCR 2018.

and Kule 3 (Nguenyyiel), reflecting the order they were opened to handle the influx of South Sudanese refugees.

\footnotetext{
"Nguenyyiel was established in 2017. Here we have Kule 1 established in 2014, while we also have Kule 2 which was established in 2014." (SSI40)
}

In times of peace, movement between the camps is common among refugees, as most refugees have relatives living in one of the other camps.

The arrival date of refugees is important in local discourse. For instance, in Kule camp, refugees designate the various zones of the camp with the months of the year that specific groups of refugees arrived.

\footnotetext{
"The areas in the camp are divided based on the month in which buses arrived, and now I am living in area of June near the village of July." (SSI36)
}

Each camp is located under the jurisdiction of the Itang special woreda, however the Agency for Refugees and Returnees Affairs (ARRA) is responsible for the 
management of the camp. Each refugee camp has a camp chairperson, usually elected by fellow refugees, who serves as intermediary between refugees and ARRA.

"Camps are divided according to my information, each having their own camp chairman. While all those three camps (Nguenyyiel, Kule 1, and Kule 2) are under Itang special woreda." (SSI36)

\section{Mazoria}

Mazoria, located in a predominantly Nuer area, is an important center of trade for both refugees and hosts in Itang. Highlanders, who dominate the economy, have a strong presence in Mazoria; they engage in trade with refugees and indigenous locals.

"Those who live around Mazoria are Nuer. They are Nuer around Mazoria, together with highlanders, that means they mix themselves." (SSI39)

Refugees travel to Mazoria to buy goods that are not included in their rations. However, the trip to Mazoria is cited as being quite dangerous, especially in times of insecurity, as it requires passing through Anywaa and Nuer villages.

"The shopping place is at Mazoria. We go from here to Mazuria on foot. We pass through their area." (FGD21.R4)

\section{Itang Town}

Itang town is the capital of Itang special woreda and the furthest town from the refugee camps. Due to its distance from the refugee camps, Itang town has not benefited from the positive economic and development spillover associated with proximity to refugee camps. Host community participants cite underdevelopment of
Itang town as a point of contention, often referencing the lack of financial, educational, and health services available despite its status as the capital of the woreda. As one participant describes:

"In Itang, conditions are poor. It has a shortage in the area of health, also there are not enough banking services; there is only one bank that is one Wegagen, and it is a woreda." (SSI46, Simon)

One telling sign of underdevelopment is the lack of private schools in Itang.

"There are no private schools, only government school in Itang town here. Private schools are available at the kebeles. There is a school called Lutheran [um (paused)] and something called Trinity colleges they came to Pulkot kebele. These two colleges are in Pulkot kebele." (SSI46 Simon)

There is an interesting distinction made between Itang woreda (further away from the camps) and Pulkot kebele (closer to the refugee camps), with the latter experiencing more benefit from the presence of refugees and hence being more developed despite the fact that it is a lower administrative unit.

\section{Pulkot (Tharpam) kebele}

The close proximity of Pulkot (Tharpam) kebele to the refugee camps has enabled it to absorb the positive economic and development spillover to a greater degree than Itang town.

"Without refugees here, Tharpam can never become a town. It became a big town now because of them." (FGD27.R5) 
Refugees travel a short distance to Pulkot kebele from the refugee camp to engage in trade in Mazoria.

"They come here to Tharpam/Mazoria and meet us here. They regularly come here because the distance between us cannot even take one hour." (FGD28.R2)

As a result of this economic activity, Pulkot has significantly developed and outgrown its status as a kebele but without a shift in the allocation of state resources to reflect this growth. As a result, Pulkot kebele suffers from a deficit of needed resources to provide social services to its burgeoning population.

"The issue with the kebele is that we are too many people, and one kebele is not enough, and the resources are not enough." (FGD29.R2)

Insufficient resource allocation is creating conflict within the kebele.

"They have only one kebele, which is not enough for them, so conflicts in that area are because resources are not enough." (FGD28.R3)

The host community in Pulkot, mostly comprising Ethiopian Nuer, was displaced from their land to accommodate refugees. One key informants explains:

"Well, refugees first arrived here in 2014, and their arrival resulted in huge displacement of the host communities, particularly Ciereng subclan of Gaatjaak in Ethiopia who owned Pulkot kebele. In fact, there was a displacement and many people were displaced because of the arrival of the refugees." (KII12, Thachar)
Another participant also recounts the same incident.

"Local government and the [United Nations] told us that refugees would come here and live together with us. The government ordered us to demolish our huts and houses that we built on the other side of the main road and we did that. We were displaced and our farmland was given to refugees. We moved from that side of the road to this side." (FGD27.R1)

The host community was willing to give up their land to accommodate refugees because of shared ethnic ties. Numerous Ethiopian Nuer recounted giving up their land voluntarily without conflict, albeit not without expectation of compensation.

\section{Pinyudo}

Pinyudo 1, built in 1993, is the oldest refugee camp in Gambella. Its two sections host South Sudanese Nuer and Anywaa refugees. Anywaa refugees are located in the section closest to Pinyudo town-a 10- to 15-minute drive (i.e., walking distance).

"The camp is close to Pinyudo town. Hosts and refugees are connected as one because the hosts expand the construction of their homes till it is borderless with the refugees' camp." (SSI52)

The second section hosts Nuer refugees. This section is about a 30- to 40-minute drive from Pinyudo town and is separated from Pinyudo town by forest. Beyond the Nuer section of Pinyudo 1 begins Pinyudo 2. When refugees first arrived in Pinyudo, both groups could access Pinyudo town and travel to Gambella. However, movement to both locations is now restricted due to the deterioration of security. Violent attacks between the Anywaa and the Nuer have escalated since 2016. Moreover, both refugees and the host community are prone to attacks from the Murle-an ethnic group from South Sudan. 


\section{Two Major Ethnic Groups/ Types of Refugees and Hosts}

There are five ethnic groups that consider themselves indigenous to Gambella: the Anywaa, the Nuer, the Majangir, the Opo, and the Komo. The Nuer and the Anywaa are the two largest ethnic groups, the third largest is the "highlanders," a term used to refer to Ethiopians originating in the country's northern regions who first migrated en masse to Gambella during the Derg regime. Highlanders dominate the local economy but are considered nonindigenous. In fact, the Anywaa see themselves as hosting two sets of foreigners: (1) South Sudanese Nuer refugees (and the Nuer in a broader sense); (2) and highlanders.

\section{The Anywaa}

The Anywaa have a special relationship to land and territory. The village is their principle marker of social identification. They are deeply attached to the land of their ancestors and to the borders surrounding them (Feyissa 2015). Each village is delineated by a boundary referred to as a kew, which is known and respected by both inhabitants and other villages (Feyissa 2015). This conception of land, territory, and border is crucial to the formation of Anywaa identity and political organization. The Anywaa believe that you are a "guest" if you reside outside your natal village, and that this status is permanent unless one returns to it. This is why the Anywaa have repeatedly used the 1902 boundary agreement to mobilize politically and reinforce their cultural identity (Feyissa 2010). The international border resulting from the 1902 agreement established Gambella as the territory of the Anywaa and labelled the Nuer as permanent guests. Kew is an essential element of social cohesion for the Anywaa, because it enables communities to avoid conflict and keeps societies "pure." As an Anywaa member of the host community in Pinyudo explains:
"In this town, we are about four or five ethnic groups. Our home becomes impure. Lives become difficult in our home. We do not protect our hometown, and since we did not protect our hometown and leave the doors open, then it becomes impure. If a home is secured and stabilized then it remains clean. Now our home is open, and many ethnic groups came, and everyone is undisciplined, and this is mainly due to the indigenous' lack of self-discipline." (SSI54)

\section{The Nuer}

The Nuer, a pastoralist ethnic group dependent on livestock, are found mostly in Akobo, Jikawo, and parts of Itang woreda. The Nuer migrate with their cattle annually. This migration pattern has led to a decentralized form of political organization and a less stringent form of cultural identification. For instance, unlike the Anywaa, Nuer identity is not territorialized (Erda 2017). The Nuer have a different conception of land: land ownership involves the active use of the land-"if no one uses it, no one owns it." This is markedly different to the Anywaa conception of land ownership, which is regulated by ancestral ties regardless of whether or not the land is in use (Lie and Borchgrevink 2012). The different conception of land use creates tensions during the migratory patterns of the Nuer pastoralists, particularly when cattle are moved down to Anywaa territory by the riverbank during the dry season.

The majority of South Sudanese refugees are members of the Nuer, which include four subclans: (1) the Eastern Jikany Nuer; (2) Lou Nuer; (3) Fangak (Central Nuer); and (4) and Bentiu (Western Nuer). A common ethnic link creates cohesion within the camp.

"Nuer are locally known as 'Nuer ka Nguaan': we are one family even though we are category of four subclans." (FGD24.R1) 
However, this does not exclude moments of intraclan fighting. Participants cite conflict between two subclans that disrupt both refugees and the host community living close to the camp.

"In this camp, there are different subcommunities or clans, including people from Nasir, people from Akobo, and people from Maiwut or Gaatjaak subcommunity and for that they sometimes have conflict." (SSI41)

\section{Deterioration of Security}

The advent of the Sudanese Civil War during the 1980s deteriorated security in Gambella. The Sudan People's Liberation Movement/Army (SPLM/A) was given license by the Derg regime to set up bases in Gambella from 1983 to 1991 (Tadesse 2007). Their presence is associated with theft, cattle raiding, the rape of women, and destruction of the environment (Tadesse 2007). The Anywaa were on the receiving end of the majority of these attacks, the most notable being the alleged massacre of 120 people in Pinyudo in 1989 (Tadesse 2007).

The saliency of regional politics and the perception of the Anywa that they were under siege from both the Nuer and highlanders resulted in an escalation of violence between 1994 and 2003. Gambella was gripped by a series of attacks and counterattacks between the Anywaa and the highlanders, culminating in the region's worst incidence of violence. On December 13, 2003, five highlander contractors were ambushed by Anywaa bandits, and their amputated bodies were displayed in the center of Gambella (Tadesse 2007). This sparked a three-day campaign when Anywaa villages and neighborhoods were destroyed, reportedly resulting in the death of 400 Anywaa (Erda 2017).
Weak security systems resulting from multiple wars in Sudan and South Sudan have worsened security in the region. Arms left over from the Derg army and the SPLA have resulted in a proliferation of weapons within Gambella. Cross-border cattle raids have complicated security in the region. For example, in 2006, large-scale cattle raids led to ethnic conflict that spread all over the south of the region (Tadesse 2007). As a result, most villages close to the Ethiopian-Sudan border are unwilling to give up arms as they anticipate future cattle raids.

A turning point in 2016. Incidences of violence in pockets of the region between refugees and the host community have escalated, especially in Pinyudo and Itang, due to tensions over scarce resources and the uneven distribution of services to refugees versus the host community. Conflict between the Nuer and the Anywaa was particularly rife in 2016. An official in Itang district blamed the inflow of weapons from the South Sudanese border for the 2016 spike in violence (Davidson 2016). In Pinyudo, participants mark 2016 as the year when the relationship between the Anywaa and the Nuer began to decline.

Escalating tensions in 2019. On April 29, 2018, the United Nations High Commissioner for Refugees (UNHCR) suspended operations at all refugee camps following weeks of violence (UNHCR Ethiopia 2019). Four senior security officials were removed from the regional government on July 15, 2018 (Borkena 2019) in response to the escalating violence. Roads between certain villages were closed and public transport suspended at various times between 2016 and 2019. United Nations (UN) agencies and nongovernmental organizations (NGOs) travelled by convoy to Itang to deliver services. On September 5, 2019, two Action Against Hunger staff members were killed near Nguenyyiel refugee camp in Itang, resulting in the suspension of operations of all aid groups working in the area. Six days later, a member of the Anywaa militia was killed in Pinyudo town. 
Ethnic conflict is the greatest security challenge

In Itang, both refugee and the host communities claim that the Anywaa community is a security threat.

"Actually, we still feel unsafe because of the Anywaa, not refugees. Refugees have adjusted the way they live." (FGD27.R3)

Diverging conceptions of land and conflict over natural resources-particularly firewood-are the main catalysts for the attacks committed by the Anywaa. Deforestation is seen as a major environmental consequence of hosting refugees. As a result, most attacks committed by the Anywaa are done in the forests. Women are particularly vulnerable because they are primarily responsible for collecting firewood to use an energy source, for cooking, or to sell at the market.

\begin{abstract}
"When our women go searching for firewood, they [the Anywaa] attack our women in the bush because they said the bush is their land too." (SSI40)
\end{abstract}

The risk of rape is reportedly high when women go and collect firewood.

\begin{abstract}
"We [women] face many challenges in this camp. We are facing these challenges because we are the ones who raise the children that need great efforts. We go to the bush to collect firewood and sell it on the market and when we go to the bush to collect the wood, there are groups who follow us to either kill us or rape us." (FGD24.R3)
\end{abstract}

The attacks committed by the Anywaa have deepened the ties between the Nuer host community and Nuer refugees in Itang. The two groups feel responsible for guaranteeing each other's safety from the nondiscriminatory attacks committed by the Anywaa.
"The refugees are in our hands." (FGD28.R3)

"We fight the Anywaa ethnic group together because they [the Anywaa] do not differentiate between Nuer who are refugees and Nuer who are citizens. They kill any Nuer they get." (FGD27.R1)

Insecurity has eroded trust between both ethnic groups and has created a deep sense of fear at night due to the unpredictability of the attacks.

"It is like that on both sides. Anywaa themselves do not sleep at their homes at night. They sleep in the bush because we do not trust each other. At night, you can't be sure you are safe unless you see the daybreak." (FGD28.R1)

Deforestation is a symptom of a confluence of challenges: Kule, Tierkidi, and Nguenyyiel have all reached full capacity-adequate housing is in short supply. Moreover, refugees are not connected to the national energy grid and do not have alternative methods of cooking other than charcoal. Lastly, institutions responsible for security in the area are struggling to contain the attacks and mitigate the sources of insecurity.

\footnotetext{
"The Anywaa have finished refugees, they kill them every day. Even humanitarian workers who serve the refugees with food, Anywaa kill them, too. Something like that becomes a mystery for people of Gambella, nobody understands it. Nobody knows how to end this conflict." (FGD21.R1)
}

Nuer refugees in Pinyudo perceive the government and UNHCR as responsible for their safety but, at the same time, they do not feel that these two institutions are doing enough to protect them. As a result, Nuer refugee men patrol and guard the forest that surrounds Pinyudo 1 during the day and night. While the federal police are supposed to assist in the protection of refugees, ARRA 
protection officers informally admitted that there are not enough police to adequately protect refugees. The area that would need to be secured is large, and the federal police do not have the resources to run such an operation. Therefore, Nuer refugees are encouraged to form their own militias to patrol the forest and warn ARRA and the federal police of any suspicious activity in the areas surrounding the camp.

For their part, Anywaa refugees and the host community report suffering from frequent attacks committed by Nuer refugees. To mitigate this, the Anywaa host community has pressed for restrictions on the movement of Nuer refugees, who are now barred from accessing Pinyudo town and the surrounding forest. These measures have not been successful in quelling the violence. Certain zones in the Anywaa section of Pinyudo, close to the main road and forest, have been abandoned due to the recent attacks on refugees. When the study team conducted interviews in Pinyudo 1, these three zones were desolate because the refugees had moved closer to on another at the center of the camp to increase their security.

"This life is hard. As I speak right now, part of the camp is abandoned, particularly the part where I live in; zone 11, 10, 12 is empty at this time and even zone 8 too is empty right now because people are frightened by the recent attack on us where two persons were killed [by Nuer refugees]." (SSI52)

Participants from all three interviewed groups (Nuer and Anywaa refugees and Anywaa hosts) have suggested relocating to escape the violence. Incidences of violence have put such a strain on members of the host community that some are willing to move away despite the fundamental cultural attachment to their land.

"In these past five years, aren't we finished already? If you can't go to the farm, you can't collect firewood, and you can't sleep without worry for your kids. If the government removes us from our land and lets us move like nomads, then let it be." (FGD33.R5)

Ethnic conflict is not always contained within the borders of Ethiopia, making it more difficult for the government to gain control over the region's security. In 2015, the Murle, a group from South Sudan, allegedly engaged in cattle raiding in Pinyudo (Tadesse 2007 ).

"In 2015, close to 2016, there was a crisis caused by Murle who were seen frequently in the bushes around the surrounding area, especially on the refugee site." (SSI52)

This was the precursor to the start of a period of conflict between Nuer refugees, the host community, and Anywaa refugees. Participants recount how some refugees attempted to return to South Sudan on foot to escape the violence.

"Life became really hard, and we have tried to go back but some people reached Pochalla (a county in South Sudan near the border) as this safe haven became a place of death. Many people went back to Pochalla on foot until they were termed as returnees; they were supported by the Ethiopian government." (SSI52)

Conflict is not only between refugees and the host community. Conflict among refugees is also a security challenge. Participants reported that intraethnic tension between factions of Nuer refugees in 2018 resulted in violent conflict that spread to the host community.

"Last year, refugees fought among themselves, they came here to our community and hit some of our people and killed one person." (FDG27.R1)

The conflict between refugees in Kule camp was so severe that it caused the displacement of both the host 
and refugee communities, with some host community members moving to Gambella and some refugees moving across the border back into South Sudan.

"There were individuals who did not want to be here, they went to Gambella; there are individuals who went to South Sudan." (SSI36)

\section{Theft and deforestation aggravate instability}

In a region where resources are scarce and livelihood opportunities limited, theft has become a recurrent security risk for both refugees and the host community.

"Secondly, you must know that many people have come to this area, and so resources become scarce. (FGD29.R2)

"Stealing is not a nature of human beings. It is an environmental influence." (FGD21.R5)

Theft is centered around money, goods obtained from refugee rations, and livestock. Host community members in Itang are the primary targets for livestock theft because of the location of refugee camps within traditional grazing areas.

"The cattle that have remained in our hands, the grass that they feed on are the ones located there, in the area in which refugees are settled. If a cow happens to spend a night there, it would be killed, it would never return. These things became difficult for us." (SSI44)

This is among the main sources of intraethnic tension in Itang woreda. Cattle are extremely important to the Nuer community for their livelihood but also for cultural processes, such as marriage. With a large demographic of young men in the area seeking to get married, the demand for cattle to be used for dowry is likely to increase, further exacerbating livestock theft within Itang.
Theft has increased insecurity in refugee-hosting areas and disrupted the movement of refugees. Refugees often move between camps to visit relatives, search for food, or trade their rationed goods at the market. Mobility, as this study shows, is highly predicated on perceptions of security.

"The situation is challenging our movement for food from one camp to another. Robbers are snatching refugees along the road by force, and if you refuse to give, it may lead to murder, especially at night." (SSI36)

Participants in both Itang and Pinyudo believe that a network of thieves from both refugee and host communities are responsible for the region's insecurity, taking advantage of the anonymity they gain from working together.

"They steal goods here in the camp and sell them out to the hosts and in the same manner; they steal from the host community and sell the stolen goods here in the camp. Thus, there is a link or connection between these thieves, and they are creating so many problems in the relationship between hosts and the refugees." (FGD24.R1)

Deforestation is a flashpoint in the conflict between refugees and the host community. The government has banned the cutting down of wood and has issued a mandate for the National Resource Development and Environmental Protection Department to protect the forests. The forest is a perilous but necessary place for refugees. Participants cite insufficient food or delay in rations as a primary reason for foraging in the forest. The selling of firewood is perhaps the only livelihood opportunity available for women to obtain goods not included in their rations, such as clothes. Therefore, despite the dangers posed by both Anywaa and highlanders, the forest is a place they cannot avoid. 
"Here, highlanders have farms around their farms where our women go and collect firewood, there when they spot our women they will beat them, they will also torture women. Anywaa also attack our women around their farms, last year four people were killed." (SSI38)

\section{Insecurity has socioeconomic impacts}

Refugee participants in Itang note that security is mediated by purchasing power. If you can afford to use a bajaj (a tuk tuk), then travelling between camps is relatively risk-free because the main road is considered safe. However, if you cannot afford transportation, then your options are limited.

"The safe road to other camps is to go to the main road, and use bajaj if you have the money. If you try to use the short-cut road through the forest, you may get robbed or beaten." (FGD21.R3)

Due to the limited purchasing power of refugees, a solution raised by participants is the construction of roads that connect all three refugee camps to ensure safety in numbers and increased visibility.

"If the government constructed open roads between camps, it could minimize our problems. This is because the person can walk on the open road with many other people." (FGD.21.R3)

"Previously, we paid $\mathrm{Br}$ 5, but now they increase the fare to $\mathrm{Br}$ 10. We do not have extra sources of income. They do not accept to reduce the fare. Why do they rob us while we are the refugees? We do not have places to get money. If you do not go to collect firewood to sell, you do not have a chance to get the money unless you get a job. The host community makes it difficult for us."

A participant explained how insecurity hinders development in Itang. Despite Itang town being the capital of the woreda, it has far fewer services and a less vibrant economy than Pulkot kebele, which is closer to the refugee camps. As noted earlier, close proximity to the camp and the presence of the main market (Mazoria) could explain the disparities in development. Yet, it is also important to consider how cyclical patterns of insecurity and displacement can explain the area's underdevelopment. As the participant laments:

"There are times in which some stability can be achieved, and people can resolve their differences, and it may look like peace has come, and people live together but after that, it will resume again. For the first time, there was development because people live together and there could be business activities in the market. At this time, development flourished again; but after that, the development that was about to flourish stopped after most of the population left. The Anywaa left and crossed to the other side of the river, part of the population also left from the Nuer, and they moved to this side (pointed) because of the conflict, that is what reduced the development in the area. In the recent past, although attempts were made to develop the area, but basically development comes because of the community." (SSI46, Simon)

Security dictates the nature and frequency of interactions between the host community and refugees. Refugees and the host community are not in a perpetual state of conflict. Positive interactions between the Anywaa, the Nuer and refugees are noted by participants and highlighted in the subsequent sections of this report.

"The nature of our relationship with refugees is fluctuating. It changes depending on incidence of occurrence of the conflict. When conflict occurs, the frequent contact we usually have may change because we confront each other as refugees and citizens. Therefore, supporting each other with refugees depends on peaceful coexistence." (FGD27.R3) 


\section{Governance and Programming}

Gambella is among the poorest and most marginalized regions of Ethiopia despite its endowment of natural resources, and it has been historically marginalized. "Resolving the conflict between the Anywaa and the Nuer was not a priority of the Ethiopian government" (Tadesse 2007). Previous interventions have largely been about finding a security solution rather than a political one (Tadesse 2007), relying on a military approach to contain conflict rather than targeting the root causes of insecurity.

Solutions to the conflict cannot be derived unless special attention is paid to the specificities of the region. For instance, the issue has a regional dimension, and conflict resolution in Gambella relies on the economic-securitydevelopment architecture of the subregion. The advent of ethnic federalism in 1991 created new political space for local empowerment and the inclusion of the country's previously marginalized regions-such as Gambella-into the state apparatus (Tadesse 2007). However, it also had the effect of complicating tensions by politicizing the conflict between the two communities. This is because the new system of ethnic federalism created a new local bureaucratic class, and ethnic identity became the sole logic of political competition. Moreover, political control of regional administrative units, especially woredas, means access to food aid in some cases, jobs, and other state resources. Power over these administrations was distributed based on the size of the respective ethnic groups, giving demographics new saliency in local politics.

The question of which ethnic groups have legitimate claim for supremacy in the regional government and how power is shared among the indigenous groups of Gambella remains fiercely contested by the Anywaa and the Nuer.

"The Anywaa have been leaders since the Derg regime. We get the presidency once since then. It was only Gatluak Tut very recently. Why not us,
Nuer should lead. We are the majority based on the statistic." (FGD28.R1)

\section{The role of the government}

The Ethiopian government's Comprehensive Refugee Response Framework (CRRF) seeks to gradually shift the country's refugee operation from one of encampment toward one of hosting refugees in village-style, development-oriented settlements and other alternatives similar to the out-of-camp policy (ODI 2019). Two key factors to achieving the CRRF goals is increasing local integration and livelihood opportunities. In Gambella, this is particularly pertinent, as South Sudanese refugees are the poorest group of refugees along several indicators, including food security, housing, and labor market participation (World Bank 2018). The 2019-20 Country Refugee Response Plan (UNHCR 2019a) sets out the government's objectives to increase the livelihoods and integration of refugees through multiple actions:

- Increase access to education at the primary, secondary, and tertiary levels by integrating refugees into the national education system, including technical vocational education and training.

- Integrate refugees who have lived in Ethiopia for more than 20 years. In the context of Gambella, this would primarily be refugees in Pinyudo, some of whom have been settled in the camp since it opened in 1993.

- Expand environmental protection and the pursuit of renewable energy.

- Increase skills development and job matching by including the private sector.

Implementation of these policy objectives relies on the government's coordination of a large group of donors and local and international organizations, which have only recently begun rolling out programs. It is difficult to identify 
specific government policy directed toward refugees in Gambella due to the tension surrounding the involvement of the federal government. However, the recent increase of refugees as an outcome of the South Sudanese civil war and the pressure it has placed on the security in the region has prompted the national government to relocate new arrivals to Benishangul-Gumuz (ODI 2019). There are 35,000 unaccompanied minors in Gambella region, most suffering from trauma; in response, the government has prioritized child protection and the delivery of psychosocial care in the refugee camps (ODI 2019).

\footnotetext{
"There is a mental health center where mental health patients are treated, they get medicine there; there is a place where disabled people are assisted with bicycles, and there is a place where orphans are assisted with clothes." (SSI39)
}

According to a recent estimate, 80 percent of South Sudanese refugees are women (UNHCR 2018). As a result, the government's National Strategy on Prevention and Response to Sexual and Gender Based Violence is focused on implementing programs and livelihood approaches that are gender-sensitive, including workshops and strategies to mitigate gender-based violence in the camp. In practice, ARRA, with the support of UNHCR, is responsible for achieving CRRF objectives.

\section{The Role of ARRA}

ARRA has been responsible for the management of the refugee operations since the 1990s, and it is part of the federal government's security infrastructure (ODI 2019). However, ARRA does not take a blanket approach to the running of each camp. Implementation is context-specific, with different ad hoc agreements made with donors and implementing partners based on the conditions of the camp (ODI 2019). ARRA is primarily responsible for the safety of refugees in the camp, oversight of services delivered to refugees, and coordination of the implementation of the nine pledges and the CRRF (ODI 2019). This has had the knock-on effect of decreasing the role of local government in refugee affairs.

ARRA involves refugees in the social organization of the camp, particularly working with the Refugee Central Committee (RCC), zonal leaders, and elders from both communities.

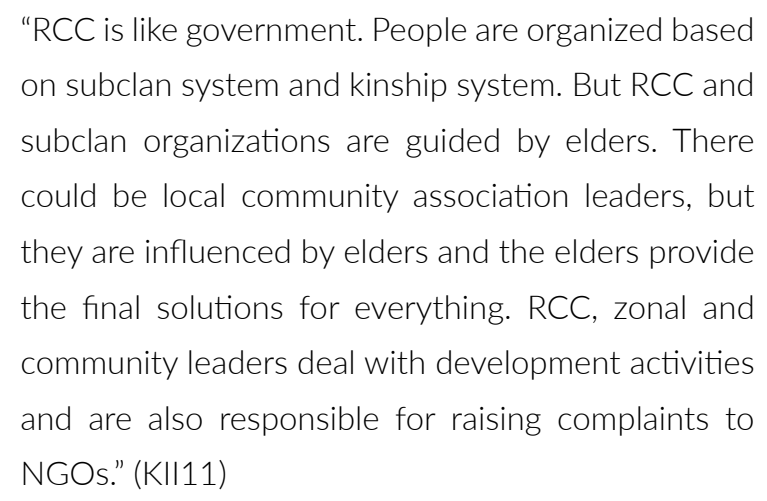

ARRA utilizes all three groups when it engages in peacebuilding efforts and conflict resolution, often facilitating formal meetings among the groups that are present.

\footnotetext{
"In case, we need something from the refugees, what we always do is we write a letter to ARRA, that we want to meet with your people, then ARRA will call us together with them (refugees) and we will meet. Now, it can be decided that the venue of the meeting can be either ARRA offices around Mazoria, then all of us can attend the meeting-refugees and host community." (SSI45)
}

However, refugees in Pinyudo, Kule, and Nguennyiel feel that ARRA could have been more proactive in implementing security measures. As a means of mitigation, refugees have deployed their own system of security. Shurtas are young refugees who take on the responsibility of maintaining the safety of refugees within and around the camp. In Itang, they patrol the area to prevent refugees from bringing alcohol into the camp and committing other petty crimes. 
"What we used to do is deploy these youths, that you see there now who have dressed in yellow uniforms those are the shurtas, they are the one who will be sent to the forest to find the criminals." (SSI39)

In Pinyudo, Nuer refugee men settle in the forests surrounding the camp as a first line of defense against attack.

\section{Perception of the Comprehensive}

Refugee Response Framework

Awareness levels of the nine pledges and the CRRF among both refugee and host communities, neither having basic, if any, knowledge of the latter. Even among those participants with have a general idea of the intention to increase the integration of refugees, very few can outline what this concretely means in terms of policy interventions.

However, members of the host community in Pinyudo, unlike the host community in Itang, feel that greater integration would increase insecurity. But some host members are skeptical about how successful the implementation of the CRRF and the nine pledges would be to improving relations with the host community.

"In my opinion, I don't want refugees to have all these opportunities and be equal with the hosts. I want them to be repatriated. Earlier, I talked about the problems that refugees cause for the hosts. So, if they are going to be integrated, these problems will increase and worsen, thereby completely sabotaging the security of this place." (SSI53)

\section{Perception of $\mathrm{NGOs}$}

Refugees generally have a positive view of NGOs working in the camps. A majority of refugees identified education, health care, and water as the services that most impact their lives. Gender-sensitive programs centered on tackling gender-based violence exist, but there is a deficit of income-generating programs for women. Refugees cite livelihood programs as an area of service provision weakness.

Moreover, refugees feel neglected by NGOs in terms of employment opportunities. It is a common sentiment among refugees and the host community that NGOs do not use local human resources, choosing instead to hire people outside the region.

"If certain NGOs come and they specify the number of people that they may need: a specific number of people who are traders, a specific number of people from the community, and a specific number of people from the government, then there can be no complaints." (SSI37, Jak Kong)

Incentivized worker schemes between refugees and NGOs is an issue that creates negative perceptions of NGOs among refugees.

"People who were displaced, they are vulnerable, that is why they are displaced. But now NGOs use refugees (as incentive workers) but pay them less, what is that?" (SSI36)

\section{Ecosystem}

The most prominent actors for refugees in Gambella are ARRA, RCC, zonal leaders, and elders. ARRA is in charge of refugee affairs. It provides security for refugees, coordinates with NGOs to ensure service delivery, and is the main arbitrator in the settlement of disputes. RCC, zonal leaders, and elders form the governance structure of refugees. In Gambella, a subclan system is used to ensure that power is equally shared as a means of avoiding conflict.

"RCC is like government. People are organized based on subclan system and kinship system. But RCC and subclan organizations are guided by elders." (KII11) 
While the RCC is in charge of liaising with ARRA and NGOs and advocating for the needs of refugees, when it comes to the settlement of disputes, the RCC is guided by elders.

Actors that are highly relevant to both groups include the government, NGOs, church leaders, and schools. The government must consult with both host communities in Itang and Pinyudo for the settlement of refugees.

"By the time refugees came, it was the people of this area with the government of the region, which permitted them. As a result, they came to this place. From there we began to treat them as the people who are part of the community in this area." (SSI44)

Moreover, insecurity in Gambella also depends on local and regional politics.
"Here in Itang, more and more, the town causes most of the Gambella problems. The main cause of the Gambella problem is that resources in Itang are not equally distributed." (FGD22)

NGOs feature prominently in the lives of both refugees and the host community. Both groups have credited NGOs with the development and economic expansion of refugee-hosting areas. However, both host communities in Itang and Pinyudo feel that services could be better integrated and more equally distributed.

"The relations with the host community can be strengthened if and only if there is equal access to the services provided by NGOs to the refugees and host community alike." (SSI40)

\section{Figure C.1. Refugee Ecosystem Model, Gambella}

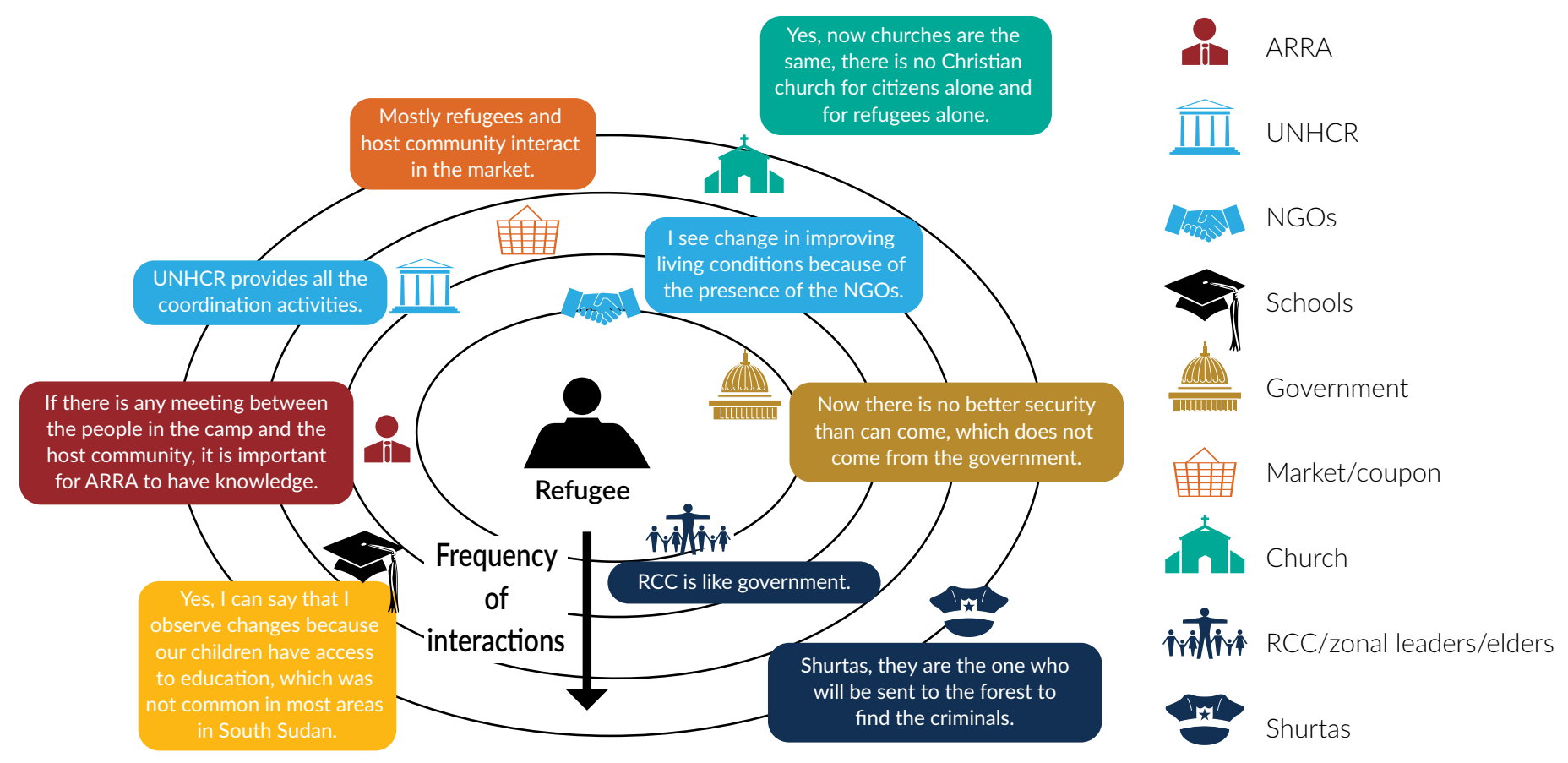

ARRA = Agency for Refugee and Returnee Affairs; NGO = nongovernmental organization; RCC = Refugee Central Committee; UNHCR = United Nations High Commissioner for Refugees. 


\section{Figure C.2. Host Community Ecosystem Model, Gambella}

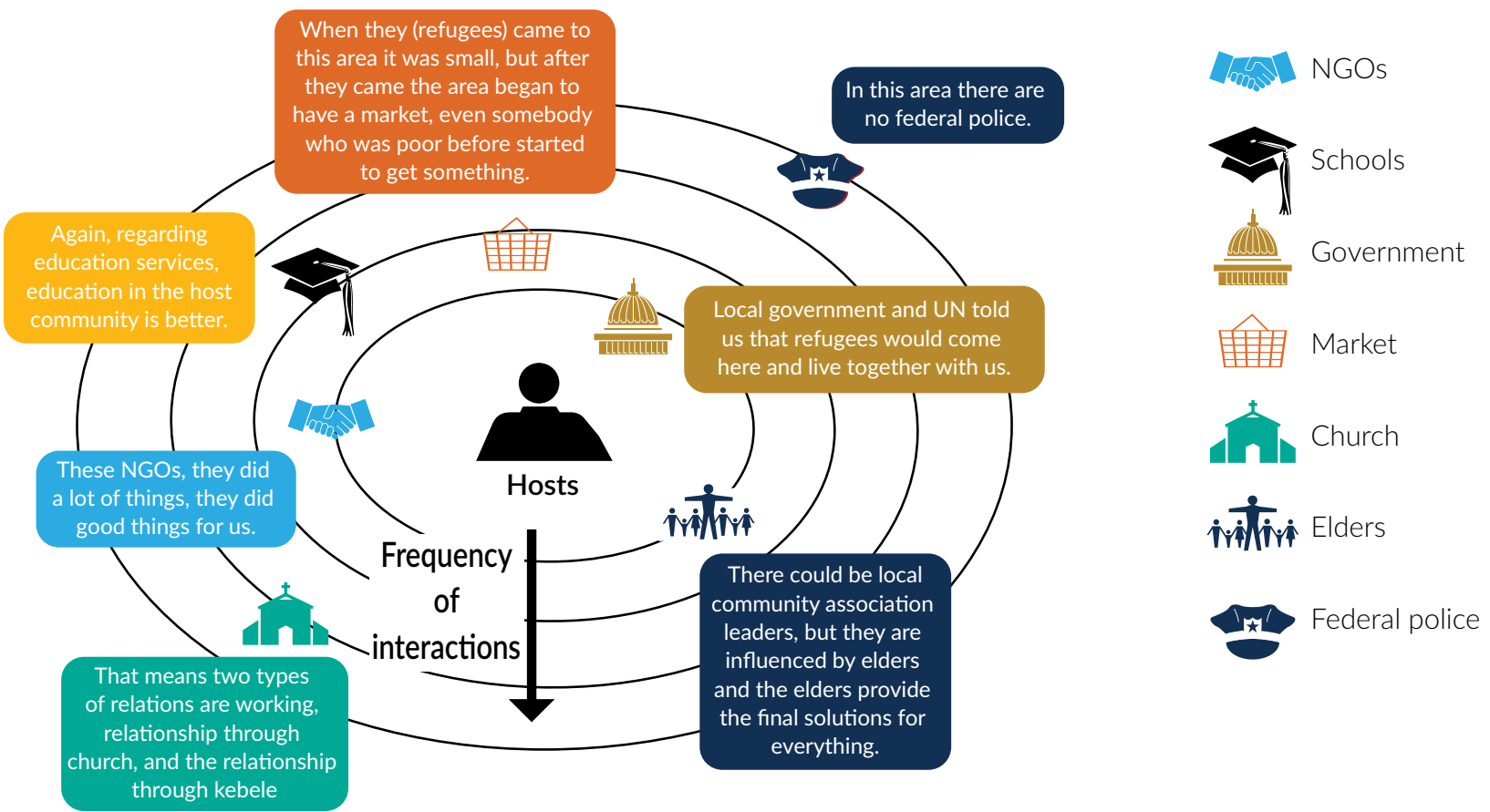

$\mathrm{NGO}$ = nongovernmental organization; UN = United Nations.

Church leaders are powerful brokers for peace in the region. This is because religion is one of few unifying factors between refugees and the host community.

"Yes, from a religious perspective, we interact with the host community because it is the same God that we all believe in. The majority of the refugees believe in Christianity." (SSI38)

Refugees highlight that education is the service with the greatest impact.

"If schools are opened in my country in South Sudan, yes I can go there I can take my children there, however, there are no school which are opened, so I educate my children in this place." (SSI39)

Schools connect the refugee children and the host community. In both Pinyudo and Itang host communities, youth attend schools meant for refugees, and refugees attend schools in the host community.

"Education connects us with the host community. Some of us go to Pulkot to learn there at the hosts' school." (FGD210)

Federal police are not a prominent feature in the ecosystem of the host community. Despite long periods of insecurity, the host community feels neither the presence nor the impact of the police. Both communities feel that the federal police are best placed to stem the violence between the two communities but lament their inactivity.

"When people are killed around here, or in the forest where they look for wood and wild vegetables, the federal police who should come. However, in this area, there are no federal police." (FGD21) 
Shurtas are the refugee response to insecurity and the perceived neglect of security forces. They patrol the forests surrounding the refugee camps.

"What we used to do is deploy these youths that you see there now who have dressed in yellow uniforms, those are the shurtas, they are the ones who will be sent to the forest to find the criminals." (SSI39)

\section{Key themes}

\section{Identity and Aspirations}

Who are the refugees?

Gambella only hosts refugees from South Sudan. In the three refugee camps in Itang, refugees primarily come from Nasir, Akobo, and Maiwut, and are predominantly Nuer. Cross-border movement among the Nuer at the Ethiopian-Sudan border has created transnational kinships. Ethiopian Nuer and South Sudanese Nuer are related to each other. Nuer refugees therefore have deep and positive connections with the Nuer host community in Itang and are able to easily integrate and assimilate into Ethiopian society. In the past, transnational kinships have muddied the distinction between refugee and citizen. For instance, a large number of South Sudanese refugees were allowed to gain Ethiopian citizenship in the 1990s, only to later relinquish their newly acquired citizenship when the situation in Sudan had improved enough for them to return (Erda 2017).

Anywaa refugees in Pinyudo 1 are from two regions in South Sudan: Pochalla and Akobo. The two groups have a good relationship with each other. To avoid intraethnic conflict, refugees make sure power is evenly distributed between the two groups in the organizational structure of the camp.

"There are mainly two groups of refugees here: the Pochalla and Akobo groups. If you are from Akobo and you marry someone in Pochalla group, everyone comes together to celebrate. Even the chairmanship of the camp is based on rotation. If the chairperson of the camp is from Akobo, the deputy will be from Pochalla. When the term is over, the next chairperson will be from the other group. It has always been like this." (SSI51)

Refugees from the same ethnic group are highly integrated. In Itang, members of the Nuer host community reportedly visit their relatives at the camp.

\section{"If there is somebody (from the host community) who has come (to the camp) this can only be some- body who came to visit their relative who had been displaced." (SSI35, Nyabiey)}

The same applies to Anywaa host community members, who visit and sometimes live with their relatives in Pinyudo 1. Refugees and the host community can often not tell each other apart absent obvious markers of distinction, such as the possession of ration cards, although such formal processes of identification are not so clear cut.

Refugees assimilate easily with the host community in Itang. During clashes among refugees in Kule camp last year, some went to live with the host community.

"All people are the same, both the host community and refugees cannot identify each other and some of our refugees escaped from camp to host community village during our clash last year and they live there." (SSI36 Nyakong)

Sharing a common ethnicity and cross-border kinships have played vital roles in the positive relationship between refugees and sections of the host community in Pinyudo and Itang. For most participants from the same ethnic group, the term refugee is merely a legal term. For example, the Nuer host community does distinguish between citizen and refugee; instead, they perceive refugees to be part of the wider Nuer family. 
"The name refugee is a world name. Because they become our people, we do not call any of them as refugees because they are people like us. They are Nuer like us." (FGD28.R1)

"Refugees are Nuer and we are Nuer. Some of us have blood relatives from refugees. I can see refugees as brothers and sisters." (FGD27.R1)

Cross-border movement and kinships between the two Nuer communities is illustrated by the following example:

"Mostly, when we come to Ethiopia, we come individually from Lungichuk, maybe some can come to seek medical services, but the whole family remains there. We also share resources, for instance, if a relative gets married from Lungichuk, you can go to Lungichuk and collect cows from dowry and bring them to Ethiopia. The same if a girl gets married in Ethiopia, brothers from Lungichuk may come and collect their cows as their right and take them back to Lungichuk, in line with our cultural norms." (SSI45).

Even though refugees and the Nuer host community have positive relationships, refugee integration with the host community was not always a given due to the slight differences in culture between Ethiopian and Sudanese Nuer. In the initial stages of settlement, refugees had to adapt to Ethiopian society. They cite learning aspects of Ethiopian laws as instrumental to improving their relationship with the host community.

"We were taught about some legal law of Ethiopia in order to improve our relationship with host community. And, nowadays, the relationship is not like before. We are not living like strangers or foreigners; we are living like a family with the host community." (FGD24.R1)
Despite the shared ethnic identity, refugees are considered "guests" by the host community, giving way to more lenient treatment of refugees, with transgressions viewed as mistakes borne out of ignorance rather than malice.

"Then we see even if they do bad things to us, we cannot consider them bad because they are guests to this area, they are not original people of this country they are people of South Sudan." (SSI44)

An example of this is the 2018 intraethnic conflict among refugees at Kule camp, which spread to surrounding villages, killing and displacing some members of the host community. Several participants cite a meeting held by the host community where they decided not to retaliate against the refugees but instead to forgive.

"We came here and had a meeting concerning the killing. We told ourselves not to do anything about what had happened. We forgot it." (FGD27.R1)

This is significant because retaliatory attacks are a strong feature of Nuer and Anywaa culture, especially if a relative or loved one has been killed. It is important to note that during periods of peace, Nuer refugees in Itang and Pinyudo have had positive relations with other members of the host community, such as the Anywaa.

"During the time of stability, it is possible they could have friends from other ethnic groups who are not Nuer, mostly Anywaa." (SSI46 Simon)

This reinforces one of the main points of this study: that conflict between the Anywaa and the Nuer does not stem from an intrinsic animosity toward each other but is instead driven and mediated by structural factors that intersect, such as the environment, the economy, and local and regional politics.

Refugees are still suffering from trauma. Psychosocial services are prevalent in Kule, Nguenyyiel, and Pinyudo, 
but participants note that recurring periods of insecurity have left some unable to recover.

"People have not settled like we thought we would ... they have not stabilized mentally." (SSI36)

Who is the host community?

In Itang, refugees consider the host community to be the Anywaa, the Nuer, the Opo, and the highlanders. In Pinyudo, both groups of refugees identify the Anywaa, and to a lesser extent the highlanders, as the host community. The identification of the host community is intrinsically tied to land ownership.

"I think, the host community are the owners of this area." (SSI35)

Refugees also identify members of the host community by where they reside and whether or not they receive rations. For example, refugees in Itang know that the Nuer who live in towns such as Lare and Gambella or by the Mazoria in Pulkot kebele are citizens.

"Lare it is not a refugee area and Gambella, those places, I think they are places for citizens. Because people who are in those places cannot receive rations. That is how we could know they are not people who belong to us." (SSI35)

However, there have been accounts of both Nuer and Anywaa members of the host community posing as refugees. This is not uncommon, as vulnerable and poor members of the host community do so to obtain rations and other services.

"Well, identifying citizens from refugees is something difficult because there are citizens who have ration cards like the refugees. There are different types of hosts or citizens, including Buny [highlanders], Nuer, and Anywaa." (SSI38)
Some host communities were formed recently, during the Derg regime. Such is the case in Pulkot kebele, where participants report that members of the Nuer host community who originally originated from South Sudan were given the land by the Ethiopian government to establish the kebele.

\begin{abstract}
"The land that we do not buy is this kebele land which the government gives us because we originated from South Sudan historically. In Pulkot kebele, I have lived there for 24 years, and other people from Cie-reng have lived for more than 30 years in this kebele." (SSI46)
\end{abstract}

This corresponds with reports of South Sudanese Nuer settling in pockets of Gambella during the Derg regime (SSI38). It also underscores the importance and prevalence of cross-border movement among the Nuer community.

There is a distinction between hosts who are indigenous to Gambella and those who are not. In Pinyudo, the Anywaa host community members conceptualize highlanders as permanent guests.

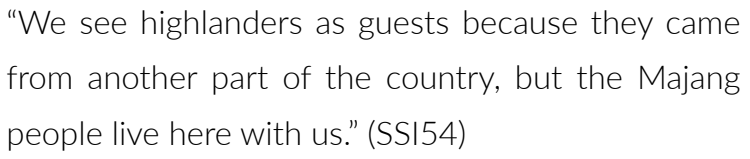

However, highlanders have heavily influenced the culture of both the Anywaa and Nuer host communities. This is apparent in the proliferation of coffee shops and restaurants serving food associated with the Abyssinian highlands, and the effect it is having in changing the eating and social habits of the indigenous host community.

"The highlander culture has completely changed our culture, and we have their culture now, and ours is totally changed. These light-skinned Ethiopians' culture is what Anywaa are practicing and behave accordingly now. (SSI54) 
Highlanders have a strong interaction with refugees due to their economic dominance. For instance, highlanders and refugees trade regularly at Mazoria, the main market in Pulkot kebele. Highlanders also dominate the market in Pinyudo. Refugees sell parts of their rations to highlanders and, in turn, buy goods from them that are not found in their rations, such as clothes.

"We don't have direct relationships with Opo, but we relate with highlanders because of the economic relationships based on refugee rations including maize, oil, pawpaw, and other types of refugee rations in Nguenyyiel are bought by them." (SSI40)

Highlanders also play a neutral role in the conflict between the Anywaa and the Nuer, choosing not to side with either ethnic group. Some participants have lamented the indifference of highlanders.

"No, they never unite together against us, but when Anywaa attack us, the highlanders will remain silent, they do not tell them that they are doing bad things." (SSI38)

However, it is strategically important for highlanders to maintain neutrality: it is key to maintaining their economic dominance in the region.

A common sentiment expressed by the Nuer and the Anywaa from the host community is a sense of unity with refugees from their respective ethnic group due to cross-border kinships, common language, and common culture. The host community feels that they have a duty to protect refugees. In Itang, multiple participants recount the Ethiopian government, especially the former Regional President Gatluak Tut, speaking to the host community when refugees started to arrive in Itang in 2014, urging them to care and protect refugees.
"The government tells us that refugees were accepted to be hosted here in Gambella Region by the Ethiopia government and the government of Gambella Regional State, so you should allow and treat them like your brothers. So, we as the Ceireng community were instructed by the government of Ethiopia and Gambella Region to take care for the refugees, and we accepted the responsibility, and from then on, we have lived peacefully with refugees." (KII12)

Ten leaders from the host community were selected with a mandate to protect refugees.

"We were appointed at that time by Gatluak Tut [Former President of Gambella Regional State] and there was a time he came to this place and he appointed 10 people to be in charge of the refugees."( SSI44, Both)

Even though some members of the host community were displaced from their homes to accommodate refugees, there is not a collective sense of resentment toward refugees.

\begin{abstract}
"The people of Pulkot, we were informed that these refugees are settled here under your responsibility, then all people on that side of the road were displaced from their land, animal huts were demolished." (FGD29.R1)
\end{abstract}

This sense of unity between Nuer refugees and the Nuer host community runs deep, and collective reluctance to abandon refugees exists, even if major transgressions are committed by them. As one participant explains:

"This area belongs to us, and if anyone of us is being killed by the refugees-and we were the one who said that in front of the regional administration officials-that these people, let them stay with us. They are our people." (SSI44) 
Similar forms of solidarity are expressed between Anywaa refugees and the Anywaa host community.

"They gave us land to live on. If we run out of food and have nothing to eat, they allow us to use the bush to collect something that can be sold to support ourselves. They have also allowed us to use their market, which has made a significant impact on our lives." (SSI50)

Anywaa refugees seek refuge in Pinyudo town during times of insecurity-a privilege that Nuer refugees do not have. This is synonymous with the sense of duty and protection the Nuer host community has with Nuer refugees. In the same vein, Anywaa host community members take it upon themselves to protect refugees from attacks.

"Whenever something happens, we come and join other people living in the center or bring children to them while we stay back to watch over our things." (SSI50)
Moreover, vulnerable Anywaa from the host community are allowed to live with Anywaa refugees.

\begin{abstract}
"Anyone from the hosts can live with refugees if they want. There are a lot of poor widows from the hosts who have ration cards and are living together with us here." (SSI50)
\end{abstract}

Seasonal weather patterns have historically influenced interactions between the Nuer and the Anywaa from the host community. The interaction between Nuer and Anywaa Ethiopians is infrequent but peaks during the dry season, when Nuer pastoralists move their cattle down to the river in Anywaa territory for grazing. One participant described incidences of the Anywaa leasing out land by the river to the Nuer for one year in exchange for cattle. While this practice is not common, it does speak to some of the positive interactions that exist between the two ethnic groups and how traditional practices of both communities can be mutually beneficial.

"It happens that if you have a friend who is Anywaa, they can give you small tracts of land to farm for a year for Br 500 and cattle." (SSI45, Nhial)

\section{Figure C.3. Lifeline of a Host Community Member, Gambella}

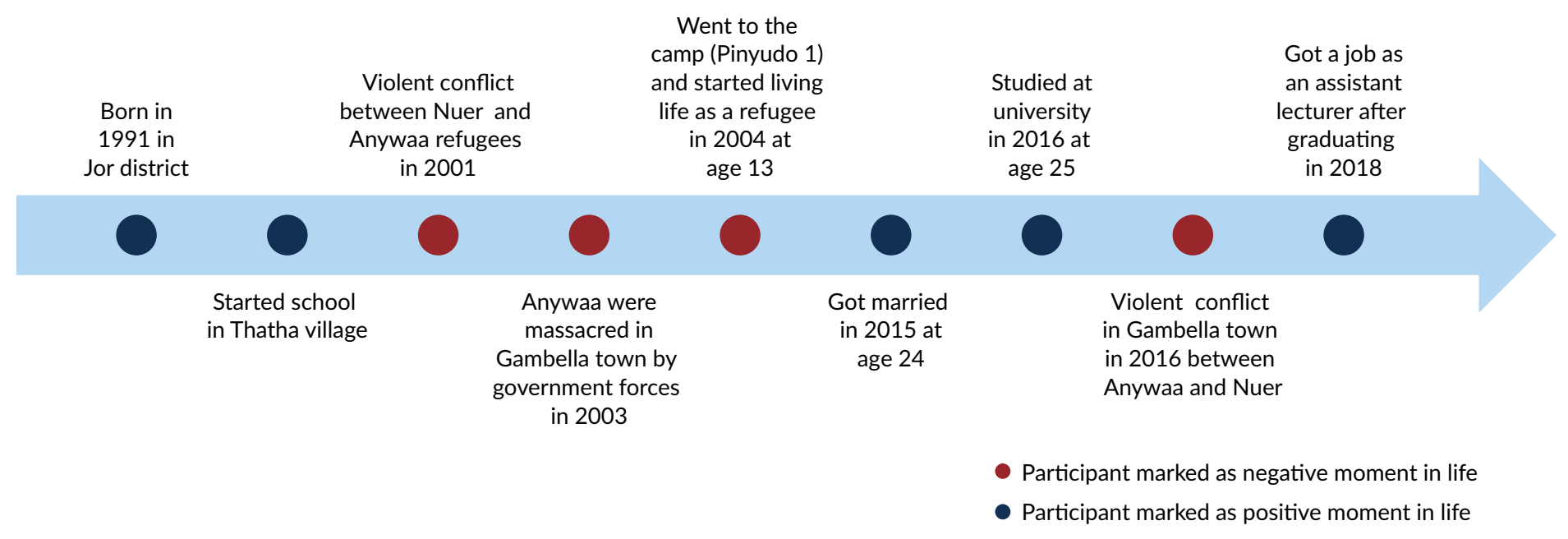

Source: LLI 15. 


\section{Self-reliance}

Refugee self-reliance is limited, as refugees engage in only three primary livelihood activities: cutting down wood, brewing local alcohol, and selling items that they receive in their rations. Deforestation is a major point of contention for the host community, and refugees are accused of destroying the environment. As a result, the forests have been protected by law. While refugees understand the need to protect the forest, the forest presents a major source of revenue, and without any alternatives in terms of livelihoods and resources, refugees will continue to exploit it. Firewood is both a source of fuel and a source of income that enables refugees to cook and buy goods not found in their rations.

"As a refugee, if your child has no shoes, you can go to the forest to collect wood so that you can sell them and buy shoes for your child." (FGD28.R1)

Surprisingly, Anywaa refugees are allowed to cut down trees in Pinyudo. This is unusual as most refugees are prohibited from doing so, such as those in Kule and Nguennyiel. Anywaa refugees cite limited resources and livelihoods as leaving them no choice but to exploit the forest.

"I can say that this area is good because the hosts have allowed us to chop wood and mow grass. In other refugee camps, a refugee is not allowed to cut trees or mow grass. We thank the government of this region for allowing us to do what is not allowed in other places." (SSI50)

Incompatible modes of production and land use between the Anywaa and the Nuer are challenges that need to be confronted to increase livelihood opportunities for refugees. The Nuer are predominantly pastoralists, whereas the Anywaa are farmers who also engage in fishing and hunting. Historically, "incompatible modes of production and clashing livelihoods has caused conflict between the
Nuer and the Anywaa" (Tadesse 2007). This is because during the dry season, the Nuer migrate with their cattle toward the banks of the Baro River and encroach onto Anywaa territory. Nuer pastoralists continuously encroach or trespass on Anywaa land to maintain their main livelihood. In fact, the initial migration of the Nuer to the east into Ethiopia was driven by the conflict with the Dinka in the west and shrinking pastoral areas (Young 1999). It is not easy for the Nuer to switch livelihood practices because pastoralism is deeply ingrained in their culture.

Most Nuer refugees (apart from those in Pinyudo) do not engage in pastoralism due to the lack of livestock, but the majority of Nuer refugees would do so if they had the resources. Cattle theft is rife among refugees because cattle is a means of income, with few alternative forms of employment. If Nuer refugees engage in pastoralism as a means of being self-reliant, then the competition for already scarce land in Anywaa territory increases. When refugees are given irrigable land to farm, they settle in areas claimed by the Anywaa. Furthermore, due to the allocation of land to large agribusinesses, land that could be allocated is becoming even scarcer. Other forms of livelihood that are less land-intensive are needed to avoid exacerbating an already sensitive issue.

Alcohol production is a popular source of livelihood for female refugees at all three camps, despite their having to pay a tax.

"On the other hand, our camp administration, we pay $\mathrm{Br} 10$ as tax and if you did not pay this money, they will not allow you to take to host community." (SSI35)

Livelihood opportunities are scarce for female refugees; brewing alcohol offers them, particularly mothers, the opportunity to buy items not found in their rations. It also helps them avoid confrontation with the host community over allegations of deforestation. 


\section{Box C.1. Blurred Lines: Citizens and Refugees and the Acquisition of Services}

Some vulnerable members of the host community pose as refugees to benefit from services provided to refugees. They are able to do this because it is difficult to distinguish between a refugee and a citizen who share a common ethnicity. $A_{---}$, 28-year-old, recounts how he spent most of his life as a refugee in Pinyudo due to the insurmountable economic challenges faced by his family.

"In 2004, we moved to the refugee camp to stay there permanently. It was my parents, especially my father, who decided that we should move to the refugee camp. He thought since he couldn't provide us with school materials, it was better if we went to stay in the refugee camp where food and other items are available for free."

It is difficult to ascertain how common this practice is because it is very rare for participants to reveal their double status, but we can conclude that this practice is not widespread. "People don't just enter the camp." Family networks are important for the initial support individuals who decide to give up their citizenship and become refugees. Because hosts and refugees know each other well and are closely related, those from the host community who want to join the camp do so by going to stay with people they already know. The fact that vulnerable members of the host community willfully give up their citizenship to acquire services that they otherwise lack points to both the quality of services provided to refugees and the failure of the government to provide basic services to the most vulnerable.

$A_{---}$benefited greatly from the provision of free food, education, and school materials, allowing him to pursue an education and become an assistant lecturer at the university.

"The teaching in refugee schools helped us tremendously because their curriculum was good, and English was the medium of instruction."

However, there were psychological tradeoffs that highlight the difficulty associated with giving up one's own citizenship.

"The weird thing about this was the fact that I gave up my Ethiopian citizenship status to be a refugee in my own country, which is not good and also affects your mind."

There is limited discrimination among hosts who decide to become refugees, except when it comes to positions of power in the governance structures of the camp.

"However, when it comes to job opportunities and appointment of camp chairpersons, real refugees discriminate against those from within the host community. They think they are the only ones who deserve to be appointed in those administrative positions."

It is still unclear how host community members who live as refugees regain their citizenship, this is because $A_{---}$no longer lives in the refugee camp and considers himself to be a host community member.

"Yes of course. I identify with the host community because that is where I belong. No feeling of exclusion at all. I only chose to live like a refugee in the camp because of economic hardship but I am still a host though." 
"The only thing that we are able to do here is a very small thing, maybe what you can do is make wine or alcohol that you use to buy onion and other supplementary food item." (SSI35)

Refugee women go to Mazoria in Itang or Pinyudo town to sell alcohol to the host community, typically selling 1 liter of alcohol for $\mathrm{Br}$ 20. In Itang, the host community profits off the limited mobility of refugees by reselling the local alcohol in other woredas, such as Lare. Because female Nuer refugees have been barred from accessing Pinyudo town for the past three years, this form of livelihood is practiced by female Anywaa refugees.

Refugees perceive the host community as much better off because they do not have any livelihood restrictions.

\footnotetext{
"They have everything here that we do not. They have livestock such as cattle, sheep, goats, and other things, and we came here with nothing. They [host community members] have farms for harvest, they have more money, and they have legal rights to operate business, and we lack of all these things as compared with them." (FGD24.R2)
}

Refugees face several barriers to being self-reliant, such as limited job opportunities, identification, and access to finances. For Nuer refugees in Pinyudo, limited mobility is the principle barrier to being self-reliant. Refugees cannot access the town or the forest, and they are prohibited from selling their cows in the market in Pinyudo town.

\section{Access to services}

Education and health services have the greatest impact on refugees and hosts

In Itang, refugees cite education as a significant positive change in their lives.
"These NGOs, they did a lot of things, they did good things for us that make us happy, and they provide school for our children; even if there is no place where they will work, that child gets school." (SSI35)

Plan International and the Development and Inter-church Aid Commission (DICAC) collaborate in the provision of education. Plan provides pre- and primary school education, and DICAC provides secondary school education. Interviewed refugees at the Kule and Nguenyyiel refugee camps constantly mention education as a crucial service that persuades refugees to remain in Ethiopia.

\begin{abstract}
"I have no plans to go anywhere. Now, living here in the camp is good, and I cannot plan to separate or take back children to South Sudan where there is no school, and the country is still at war. During our clash, I did not even plan to go somewhere because refugee camps have schools. I plan to educate my children, and they can be helpful in the future." (SSI36)
\end{abstract}

Access to education is not only a privilege for childrenadult refugees also take advantage of the educational opportunities.

Education has become a driver of migration for young South Sudanese children who cross the border and stay with relatives in Itang to access it.

\section{"Other children from Cie-reng come from Lungichuk, South Sudan, and they come to learn here from their relatives until they graduate and go back to South Sudan and hold a big position, which is a good change compared with the past." (SSI45)}

The host community in Itang also benefits from improved education services. The presence of refugees has expanded educational opportunities. In the past, Pulkot kebele only had schools for grades 1-5; now schools offer education for grades 1-10, and soon will offer it through grade 12 . 
UNDP and the World Bank Development Response to Displacement Impacts Project (DRDIP) are credited with the improvement of education services in Pulkot kebele.

\begin{abstract}
"UNDP constructed a school from grade 1 to 10 for Pulkot kebele. Additionally, there is a school called Koangdiew School constructed by DRDIP to Pulkot kebele, and it is up to grade 9. DRDIP recently constructed a preparatory school from grade 11 to 12 and it is not yet finished, and it will be joint school of host and refugee students." (SSI45)
\end{abstract}

Refugees travel to Pulkot kebele to access host community schools, particularly the new business college. This has had a positive effect on the relationship between the host community and refugees.

"Education connects us with host community. Some of us go to Pulkot to learn there at the hosts' school. They do not reject the refugees. They simply admit them. However, hosts do not come here to our schools because we get admission with our ration cards." (FGD21.R4)

Movement is heavily restricted for Nuer refugees in Pinyudo, so they cannot access the high school in the host community the way their counterparts can in Itang. To respond to their youth's idleness, refugees suggest building a high school in the refugee camp so that Nuer refugees are not denied an education.

"So UNHCR can bring this school to the camp, because no students can go to town to get education, this is the only thing. If there is a school here in the camp, there is no need of moving there to the town." (FGD36.R4)

The Anywaa host community benefits from the presence of refugees by enrolling in refugee schools.
"They have benefited hosts on health services and education because now hosts are attending schools in the refugee camp because they lack the finances to afford buying exercise books and school uniform." (SSI52)

Schools on the Anywaa side of Pinyudo 1 only go up to grade 10. After this, refugee students have to enroll in host community schools to further their education to grade 12. This is much more difficult for Nuer refugees.

"When a child from the refugee camp completes grade 10 , s/he has no option to further their education. Currently refugee students join host community schools to get a chance beyond grade 10 to advance their education." (SSI52)

Some claim refugees have access to better quality schools because they are free, the language of instruction is in English, and they have better facilities.

"Refugees' schools are better than our schools. They have libraries and recreation centers. Our school does not even have a fence. It becomes a grazing field for cattle and a playing ground for all people." (FGD28.R1)

Others claim that the host community has better educational services with schools that goes up to grade 12 and pathways to higher education, such as the business college in Itang. The construction of schools in Pulkot kebele has specifically benefited women. Host community girls are claiming their right to education and are taking advantage of the close proximity of the schools.

"It has helped women in many ways. Women now begin to go to school because they are given their rights. They do not have challenges as in the past when women did not have right to go to school because they can work for families, no, now they can learn, they are given right to go to school." (SSI46) 
In Itang, refugees can go to the host community for health care with referrals, but they cannot easily access the Anywaa side of town unless they are escorted by the federal government.

"Yeah, you can go to Itang, you can go and get health service there. You can also go, you can also go to Akule of the Opo and you can go and get medical service there. Sick people can be taken there, but they cannot go the Anywaa side." (SSI39)

The host community in Itang can access the health care facilities in the Kule and Nguenyyiel camps. Both refugees and the host community in Itang complain about the shortage of drugs in their health centers. This means that patients from the host community are still referred to Gambella for treatment.

"Concerning the health facility, it is an inadequate health center, it has a shortage of drugs. What we always do is to refer patients to Gambella, always." (SSI46 Simon)

Some refugees question how accessible the health services are in the camp and accuse ARRA of discriminating between patients.

"ARRA is not serious about our health and our lives. It allows and treats only patients who are in critical condition and rejects the rest." (FGD24.R1)

Refugees have credited Tierkidi (Kule 2) as having the best health care services due to Médecins Sans Frontières (MSF) clinic.

"We need standard clinic which provides similar services like the MSF health center at Kule 2, because the MSF health center at Kule 2, there is a standard health center, which offers a wide range of service." (SSI39)
In Pinyudo Nuer, refugees can only access the health center in their camp. Anywaa host community members often go to the Anywaa side of the camp to utilize the health services that are provided free of charge. However, for cases that require more advanced medicine, both Anywaa refugees and host community members prefer to use the health center located in Pinyudo town.

\section{The Impact of the UN and other NGOs on service delivery}

The size of rations provided by the $\mathrm{UN}$ is a major point of contention for refugees, who feel that they do not receive enough food.

"I feel tired of talking about improvement or help provided by NGOs, there is no improvement. In my opinion, improve our grinding mill, improve the care of orphans because they are living a poor life, and improve the kilogram of food in order to solve refugees' problems." (SSI36)

The delivery of rations depends on the security of the area. If conflicts occur, rations are delayed, and refugees have no other safety net but to rely on the host community for food.

"When something happens like this conflict, it causes ration distribution delay. For example, last month most of the refugees came here begging us for food because they spent 30 days without ration." (FGD28.R1)

Since 2016, Nuer refugees have been unable to access the host community in Pinyudo town. Highlanders therefore travel to the refugee camp and sell their goods. The UN built houses for the host community living nearby Kule camp, which has increased the hosts' perception of the benefits refugees bring. 
"The UN organizations that are operating in Kule refugees' camp has launched a project that built houses for the host community. We realized that the presence of refugees here in our land has some benefits." (FGD27.R1)

Women have services tailored to them through various NGOs. However not all women have the same access to these services.

"Not the needs of all women that are being put into consideration. Women who have children or who raise orphans have more access to services than other women." (FGD24.R5)

Two NGOs are cited as being heavily involved in catering to the needs of female refugees. Plan International is credited with providing sanitary pads to women at their Women's Affairs Office, and International Medical Corps provides workshops on gender-based violence in Kule, Nguenyyiel, and Pinyudo 1. However, providing clean cooking appliances for women is still a major challenge.

"It would be better if the UN could provide charcoal to every household as women face a lot of challenges whenever they go or move outside the camp to collect firewood. Providing the charcoal for cooking would reduce the problems that we face whenever we go outside the camp." (FGD24.R3)

Refugees do not feel that services are integrated with the host community nor do they think services are on par because the host community has to pay for all the services they access, whereas refugees get their services for free.

"We do not buy water, and also we do not pay for grains. Our services are given for free." (SSI39)

However, in Pinyudo, the Anywaa host community is allowed to access both the health service and the schools in the Anywaa section of Pinyudo 1. The same liberties do not apply for the host community in Itang, who are restricted from accessing schools in refugee camps without a ration card.

In Pinyudo, despite Anywaa refugees having additional privileges such as the freedom to travel to the market and cut down trees, Nuer refugees feel that the quality of services provided to both groups are equal.

"The way they treat the refugees, the Nuer and the Anywaa, is the same. The services that are provided by the NGOs are the same, they are equal, for the Anywaa refugees as well as the Nuer refugees." (FGD37.R4)

\section{Coping Mechanisms}

Sharing of food and water as a form of integration between refugees and hosts

Interactions between the host and refugees in Itang were initially centered around food. The host community showed refugees the location of the grinding mill and brought vegetables to the refugee camp to sell. This began a complementary economic relationship. Refugees sell products from their rations that the host community cannot get, such as lentils and chickpeas, and the host community sells fresh vegetables to the refugees. However, grinding mills have now been privatized, a point of contention among refugees.

"Our grinding mills are owned by traders in the refugee camp when I thought that the grinding mill was given to us by NGOs; they increase the price of the grinding mill so we are not able to pay. When the grinding mill was brought here, refugees could use it for free." (SSI36)

When rations are delayed in Kule, Nguenyyiel, and Pinyudo, refugees buy or beg for food from the host community. 
"Also, when there are shortages of food, especially when our ration is delayed, we buy food or grain such as maize and other food items, including oil, for survival from the host community." (SSI40)

Participants in Itang have also noted that some refugees with good relationships with the Anywaa community can acquire seeds that they can use to cultivate crops.

Refugees also play their part in supporting the host community. Water is abundant in the refugee camps, and the host community often comes to fetch water from refugees, which serves as a crucial and positive point of interaction.

"We used to get water freely, we did not pay them any money to get water, and it became clear to us that they [refugees] know we have a relationship with them." (FGD29.R2)

This is because the host community in Pulkot kebele have a recurring water shortage, and accessing the refugee camp to get water keeps them from having to walk long distances in search of water.

"The second thing that we face is a shortage of water, especially coming March; all pipelines will stop working." (FGD28.R5)

In Itang, the Anywaa have considerable control over the water supply. Some participants consider the fact that they keep the supply of water open to the camp to be a sign of positive relations despite incidences of conflict.

"For the Anywaa, water comes from them, if they closed the generator, water cannot come. That is what connects us, which enables us to believe that we are the same people because they are at the source of the water. If they hate us, they could not open water to us." (SSI39)
During periods of peace, the Anywaa allow Nuer refugees access to the river for fishing.

"The river belongs to them because they are the ones who live on the riverbank; if they did not permit it, they can quarrel with us. Yes, if there is nothing which has happened that divides people, you can be fishing together and so there is no problem between you." (SSI39)

Marriage is both symbolically and materially important

Marriage acts as a unifying force between refugees and the host community.

"Yes, it happens, there are marriages between hosts and refugees; if you like to marry someone from the host community, and because our culture is one, we share the same Nuer culture of marriage; it is only the border that divides Ethiopian Nuer and South Sudanese Nuer." (SSI41)

Intermarriage between the Anywaa and the Nuer exists but is uneven. There are more cases of Nuer men marrying Anywaa women than Anywaa men marrying Nuer women.

"People also intermarry a lot, people [Nuer] marry many Anywaa ladies but for Anywaa it is less, they can be counted, the way I see it, there could be a handful of people. We [Nuer], we marry many ladies from them [Anywaa]. This imbalanced intermarriage is related to the issue of cattle." (SSI41)

The unequal marriage patterns may be due to Anywaa men lacking cattle to pay dowries. Another explanation is the fact that children born through intermarriage are almost always considered Nuer (Feyissa 2010) due to the Anywaa's purist sense of lineage. A child would not be considered Anywaa unless both the mother and the father are from the group (Feyissa 2010). It has been argued that 
the Nuer have used intermarriage strategically, knowing that the children would be considered Nuer (Feyissa 2010).

Anywaa refugees can easily marry Anywaa from the host community and do not seem to lose their refugee status by doing so.

\begin{abstract}
"When I first came from my country to Ethiopia, I was 13 years old. When the first refugees arrived here, I was a young girl. Later, I got married to a host who took care of me and no longer lived in the camp. But when my husband died, I went back to live in the camp as a refugee, and it's been 13 years now since I lived in this camp." (SSI51)
\end{abstract}

Marriage between Anywaa refugees and Anywaa host community members have strong economic benefits for refugees, particularly refugee men.

"If you are a husband of a daughter of one of the hosts and have completed your diploma or degree then you can possibly get a job from the host community since refugees are not offered any job after their graduation even if they have those credentials. And this is not about changing your citizenship rather you are giving back the service to the host community and at the same time improving your life. These are the types of interactions we are noticing, and it is very important." (SSI52)

However, with increasing tensions between the Anywaa and Nuer communities, intermarriages have become more secret.

\footnotetext{
"Unlike in the past, marriages were open and the community could hear, the marriage ceremony have been celebrated by people in Anywaa area; but now you simply go alone, and you will do your marriage alone secretly." (SSI39)
}

The dowry that refugees pay has been adjusted to reflect their limited resources and livelihood opportunities. Study participants cite this gesture as a measure that creates positive relations between refugees and the host community. For instance, refugees pay only $\mathrm{Br} 700$ in "stick money," ${ }^{\prime 4}$ where as a host community member would pay $\mathrm{Br}$ 2,000-2,200. Decreasing the amount of dowry is not always enough to ensure a successful marriage; and the lack of cattle can be an insurmountable challenge.

"We have intermarriage with the hosts but, in most cases, many of these marriages get divorced because of lack of dowries, particularly cattle from the refugee's community." (SSI38)

\section{Restricting movement and alcohol as a means of mitigating conflict} In Itang and Pinyudo, the movement of refugees and the host community is predicated on the area's security status.

\section{"The only thing that affects people's movement is only what I said before, that means when some- thing happens, then people would stop movements." (SSI39)}

Mobility is essential for social cohesion, as most of the Nuer and the Anywaa have relatives in the refugee camp or in the host community. Moreover, refugees travel to Mazoria or Pinyudo town to trade or to access schools in the host community. Therefore, restrictions on movement can be destabilizing to both groups.

\footnotetext{
"The government must grant free movement between refugees and hosts because as long as we are moving freely, we shall develop trust among ourselves." (FGD27.R3)
}

To prevent incidences of violence, alcohol has been banned in the refugee camps in Itang.

64. Stick money refers to cash paid to the parents of a daughter who elopes. 
"Our leaders stopped selling alcohol in the area at Nguenyyiel, in the camp, they said it is alcohol that kills people, it is what leads people to kill themselves." (SSI39)

The sale of alcohol has not been banned from the host community in Itang, however, so refugee women are still able to earn a meager profit from their smaller customer base.

\section{Impact on local actors}

The presence of refugees has resulted in significant economic benefits and development for the host community

The arrival of refugees led to cheaper prices of goods and services because the host community will buy items included in the rations that refugees receive. Refugees sell their rations for prices below market value, with the cumulative effect of lowering the price of once-expensive goods, such as oil, maize, and wheat.

\footnotetext{
"But I have seen some changes here in Itang because when I heard their situation was different before Nguenyyiel camp in 2017 was established. Since then our relationship with hosts has improved due to them benefiting from refugee rations for cheap prices such as 1 liter of oil for $\mathrm{Br} 20$. A quintal may vary from maize to sorghum such as from $\mathrm{Br} 150$ to 120 , or $\mathrm{Br} 300$ to $\mathrm{Br} 200$. I only know of them buying here from the refugee camps." (SSI40)
}

This positively impacts the relationship between refugees and the host community.

\footnotetext{
"So, aid commodities regulate the market. For example, public employees of Itang come here to eat their lunch. Here food is less expensive than in other places" (SSI43).
}

However, the presence of refugees has led to increased transportation costs.

"Before refugees, we travel from Tharpam (Pulkot) to Itang town, which is a distance of 7 kilometers with $\mathrm{Br} 5$ by Bajaj, but now it has increased to $\mathrm{Br} 10$. Hence, the presence of the refugees has resulted in the increase of the price of services, especially services that are owned by the host community." (SSI42)

Anywaa host community members benefit from the presence of refugees by having access to the ration center. One accusation made by refugees is that the ready availability of food has affected the productivity of farmers in Pinyudo.

"Since there are a lot of local people who have ration cards, which allow them to freely get food, most of them stopped the work they used to do, including farming, and chose to depend only on rations." (SSI53)

However, insecurity may have altered the farming practices and habits of the Anywaa host community, creating a misperception that ration cards are the cause of low engagement in farming. As one participant explains:

"Hosts are worse off than refugees. Things that indicate that hosts are having different levels of challenges compared with refugees is the lack of food in Anywaa community because one thing is going to farm, and the way we cultivate is not actually similar with the way our ancestors cultivated in the past. It is a kind of farming where you would constantly keep glimpsing around and until later that you hurt yourself with the cultivating tool. When you gaze again later then you hear someone screaming there and if you check on them, you find them dead already and 
these are the challenges host community are facing.

These are it, I don't know any more." (FGD33.R5)

Highlanders have continued to migrate to Gambella, recognizing the economic opportunities resulting from refugees' presence in the area. Highlanders first started arriving in large numbers in the 1980s during the Derg resettlement program. Highlanders dominate the economy both in the provision of goods and services but also in terms of gaining employment with NGOs and UN agencies.

"Habesha" people from Amhara, Tigray, Oromia, and all other parts of the country came here because of them [refugees], just to work and change their life." (SSI43)

The arrival of refugees began a process of economic expansion and development in areas close to the refugee camp, particularly Pulkot kebele. The arrival of refugees meant that there was more economic activity within the areas closest to the camp. The arrival of highlanders introduced products not previously found in the market. Shops and restaurants opened, and refugees would come and trade their goods at Mazoria. New financial services became available due to the opening of banks. Transportation improved, and the host community felt the positive externalities derived from the presence of NGOs in the area, such as the availability of medicines, water pipelines, and the construction of metal roofs on houses.

"When they came to this area it was small, but after they came, the area began to have a market, even somebody who was poor before started to get something. Most of the people who have come here have shops. After the refugees came here, we started to have iron sheet shelters. If refugees did not come, where would we get them if refugees did not come? Because we have been in this area for 30 years and they were not there." (SSI44)

65. Habesha is a word used to refer to "highlanders" as a collective, irrespective of their ethnicity or origin.
Some participants have highlighted their concerns over host community youth trading education for economic opportunities brought by refugees.

"Let alone Habesha youths, native youths are changing their life working with refugee youths. But local youths are getting short-sighted. They focus on fast means of earning money rather than focusing on their education. I get worried about them. They have the opportunity to grow up and enjoy the good things. However, daily opportunities created by refugees attract them most at the expense of their education." (SSI43)

This is not the case in Itang town, where the distance from the camps and conflict among citizens results in a decline in interactions with refugees. Itang town is farther away from the refugee camps, and insecurity has made it less desirable for refugees to visit. As a result, unlike Pulkot kebele, Itang town has neither been able to capture both the economic benefits that refugees bring nor the services provided by NGOs in the area.

"Now, they do not come to Itang town very well as they used to do in the past, they do not come to town as it was. They come to town occasionally, sometimes they come to the market for a short time to buy fish. But the way they use to come and socialize in the town has stopped." (FGD33.R5)

"Refugees are the right hand of the town. Refugees are the engine of this town. Their arrival has brought many changes to this town. The benefit refugees also transcend this town, it is also benefiting other places and the woreda as a whole."

\section{Unequal or limited job opportunities for indigenous hosts}

An overwhelming majority of participants from the host community feel that there are unequal or limited job opportunities for indigenous people. It is an oft-cited 
criticism that highlanders get privileged positions with NGOs and state agencies, while members of the indigenous host community who are equally qualified remain underemployed.

"It could be good when our people work with UN. Now, when there is a vacancy, they bring employees from Tigray, Oromia, or Amhara regional states. They come to work here without knowing where the refugees are coming from. The employees do not know the language of the refugees to understand their problems." (FGD28.R1)

Participants also highlight a bias toward people from Gambella, stating that even low-skilled jobs, such as security guards and cleaners, are not filled by people from Pulkot kebele or Itang woreda.

"For employment by NGOs, we have some doubt because all NGOs staff come from Gambella. We try to complain to them that even all the security guards come from Itang or Gambella while they are supposed to be from our kebele." (SSI45)

Moreover, some members of the host community feel neglected when NGOs administer livelihood workshops and trainings only to refugees.

"Our farmers are also marginalized when compared with other farmer groups in the region. The government has expected that we are receiving some agricultural inputs from the $U N$ like refugees do because we are hosting them. Nevertheless, we never receive any agricultural training or agricultural input from UN." (FGD27.R2)

Job opportunities working with NGOs are scarce for the indigenous host community. Running a business or being employed by the government are areas where they find success. Host community members often combine both so they can get by.
"The only way out is to do both business- and government-provided jobs. You usually borrow money to afford something to eat and then pay it back when the government salary is released and you continue just like that." (FGD33.R1)

\section{Migratory patterns of cattle grazing and}

the risks involved

The Nuer are predominantly pastoralist: their annual migration during the dry and rainy seasons affects the levels of interaction they have with the Anywaa, and it is also a source of conflict between the two groups. This is because they spend the majority of the year living along the Baro River (Anywaa territory) during the dry season, October 15 to July 1. The Nuer from Itang face two seasonal threats to their cattle, one from refugees and one from the Anwyaa host community. Moreover, Nuer and Anywaa thieves working together to steal cattle can incite violence between the two communities in the form of retaliatory attacks. A member of the Nuer host community explains the seasonal challenges they encounter.

"During the rainy season, we come to Pulkot kebele with our cattle and refugees steal our cattle. During the dry season, we go for grazing along the Baro River and we also face the problem of the Anywaa stealing our cattle. During the rainy season, the government can negotiate our problems with the Anywaa and we live peacefully but when it is the dry season and we go for grazing, there will be clashes between us and the Anywaa until the government gets involved to resolve such clashes. The cause of our conflict is the presence of thieves who steal cattle and work together. For instance, a Nuer thief can steal a cow from the Nuer side and sell it to an Anywaa thief in the forest, who then takes it to the Anywaa side. If the owner of the cow hears the news, he may think to kill a person from the Anywaa side, and this is always the source of our problems with the Anywaa during the dry season." (SSI45) 


\section{Feelings of disenfranchisement}

There is a sentiment that the host community is not adequately acknowledged for the sacrifices it has made to accommodate refugees. Some members of the host community feel neglected by the government and by NGOs due to the lack of adequate services they receive compared with the services administered to refugees.

\begin{abstract}
"We expected benefits from refugees. We expected government or the UN to construct schools, health services, and access to clean water for the displaced host community, but we earned or achieved nothing. They simply displaced us from our homes and nothing we benefit from them. In fact, we need to have access to the social services. We need to have access to school with sufficient facilities, we need to have access to health care, and we need clean water." (SSI42)
\end{abstract}

Host community members in Pinyudo were displaced from their land to accommodate refugees. In Itang, there is collective resentment directed at refugees, and the host community there expects to be compensated for the land they have lost.

"We say now, after you take our land, what are you going to give us? We told them that you can give us a hospital, we told them, but they did not [build] it. We told them you can give a school, they did not do any of these things." (SSI44)

According to a one key informant interviewee, 570 households were displaced in 2014 to accommodate refugees. The UN responded by building houses made out of aluminum sheets for some members of the host community.

"The UN has compensated us with houses built of aluminum sheet for us." (FGD27.R1)
The host community complains of being more food insecure than refugees and cites the lack of a social safety net as an additional burden. Host members urge NGOs to fill the gaps in service provision that the Ethiopian government cannot cover due to lack of technical know-how or financial resources.

"Refugees are better than us in terms of food security. They regularly receive food rations from the UN. However, for us-the host community-we produce our food by ourselves. There may be an incidence of crop failure due to the erratic nature of the rainfall, but both government and UN organizations never come and solve this problem. We know our government lacks financial capacity to intervene in hazardous events that have been affecting our community." (FGD27.R1)

A common sentiment expressed by host community members in Itang is the feeling that they lack adequate health services and that they wish to benefit from the services provided to refugees by NGOs.

"Finally, health service provision is also insufficient. Therefore, I would appeal to government and nongovernmental organizations to permit us to use the health service provided by nongovernmental organization to refugees." (FGD27.R3)

However, the host community is barred from accessing health services provided to refugees in Itang. As noted earlier, this is not the case for the Anywaa host community in Pinyudo, which freely accesses the health services in the Anywaa side of the camp.

There is a recurrent shortage of water in the host community. In Itang, this is not an accident. Participants highlight that water ponds once reserved for the host community have been allocated to refugees, who use them as baths. 
"We could be provided with water because our drinking places, water ponds, that were dug, now they are used by refugees as bathing places, nobody can use them for drinking." (FGD29.R1)

The host community is pressing for water ponds to be constructed for old and vulnerable members of their community who cannot easily access Baro River to get water.

\begin{abstract}
"During the dry seasons, some of us are unable to migrate to nearby Baro River where we can get enough water. It becomes difficult for us to cope with the existing scarcity of water. (FGD27.R2)
\end{abstract}

Deforestation is a point of contention for the host community. Refugees cut down trees to use as fuel and to sell at the market. The Ethiopian government has protected the forests in Itang town and Pulkot kebele, but refugees still exploit the forest for wood. There are fears that deforestation is expanding closer to the host community.

"Refugees are expanding to Pulkot kebele forest, and when the woreda government catches individual refugees in the forest, the government imprisons them for punishment." (SSI45)

\section{Conflict-sensitive analysis}

Socioeconomic inequalities contribute to insecurity among refugees

Conflicts between refugees do occur in the camps.

"There was a clash in the camp here, and people were killed among us, beginning from January up to March." (SSI35)

Unequal job opportunities and livelihood capabilities are a cause of tension. Not all refugees are employed as incentive workers, nor do all refugees have the same capacity to profit from the limited livelihood opportunities.

"The conflict between refugees are caused by issues of resources, then once these people have no money that they can use to buy things for their entertainment, they will be forced to take people's properties by force." (SSI38)

Host community youth are cited as a source of insecurity, stealing from refugees collecting firewood, or travelling between refugee camps. Shurtas were formed to combat the insecurity in and around refugee camps. Incidences of theft increase during the delivery of rations.

"Host community youth are doing bad things to us. For instance, if you are going to collect firewood outside the camp, they will attack you in the bush. Then, if you have an axe or panga in your hand, they take it. The same if you came back from Nguenyyiel refugee camp from visiting a relative and carry some food grains, money, and many other items." (SSI38)

Theft is a worrying issue due to the wider implications it creates in the form of retaliatory attacks along ethnic lines. An individual transgression between two people from the Anywaa and the Nuer can quickly become a collective issue due to sentiments of collective justice.

"The tensions between communities in this area usually occur when refugees or any host community member steals livestock. Anywaa and refugees are stealing livestock from the Nuer host community. When caught stealing, the host community would see the issue as a collective issue. They may beat them to death. At that juncture, the people who are refugees or the Anywaa may try to get revenge." (FGD27.R2) 
Deviance from traditional practices of marriage are a source of conflict between refugees and the host community

Marriage and adultery can produce conflict. Adultery across communities has been dealt with through meetings between the communities, kebele leaders, ARRA, and the RCC.

\footnotetext{
"Things that seem to cause tensions are issues related to girls; when a girl is impregnated or a woman commits adultery with another man, then the community sits together and meets with unity [community] leaders, and the issues are resolved." (SSI37)
}

An important cause of conflict between Anywaa refugees and the host community is the scarcity of dimui beads for marriage. The traditional dowry among the Anywaa is not cattle but blue glass beads. (Feyissa 2015). The number of dimui one has determines individual or family status and are therefore powerful markers of prestige (Feyissa 2015). This is because there is a finite amount of beads that can be passed on from one family to another at important ceremonies such as weddings (Feyissa 2015). Due to the two different political and social regimes experienced by both ethnic groups across the border, Ethiopian Anywaa have abandoned the practice of using dimui for dowry, choosing to use money instead. This change came about during the Derg regime, when traditional practices such as dimui were deemed antimodernist and were repressed (Feyissa 2015). As a result, the two ethnic groups can be at odds during the cultural process of marriage, and this confusion can cause conflict between the two. As explained by an Anywaa host member at the focus group discussion in Pinyudo:

When young refugee girls get married to the hosts, we refugees demand dowry to be in the form of dimui, and this is one thing that I see hosts complain about, saying that refugees are the ones who bring these beads from Sudan, and if they demand dowry in the form of dimui, then we better take our children back to our home country because we the local people do not have this dimui, we demand money instead. (FGD32.R1)

\section{Avoiding retaliatory attacks as an effective} peacebuilding mechanism

Collective retaliatory attacks are a common practice in the region. Relatives will seek revenge for attacks or transgressions committed against a family member. Similarly, the community will retaliate against acts committed against its members. The host community in Itang is aware of the risks placed on refugees when they have conflict with the Anywaa. As noted, neither community distinguishes between refugee and citizen in each respective ethnic group. Therefore, refugees are often caught in the crossfire during conflicts between Anywaa and Nuer citizens. To mitigate the risk posed to refugees, host community members try to minimize instances of retaliatory attacks.

\section{"If we kill them, they will go and kill people in the camp, and the camp is under our responsibility. We did not respond until now, it means that things have changed. Yes, we say, let us leave these things of the past, let people unite, let us unite with the govern- ment." (SSI43)}

Retaliatory attacks do not have to involve direct acts of violence. The Anywaa are situated by the riverbank and therefore have control over the main water pipeline that supplies water to the host community and refugees. As a result, the Anywaa use water as leverage during times of conflict between the Nuer host community.

\footnotetext{
"Yes, another challenge they face, that we share with them, is whenever something happens [conflict], people on the other side of the river [the Anywaa] would not open the water pipeline, which is located on the river bank, so both refugee and we [the host community] would stay without water for some time." (FGD32.R1)
} 
Anywaa refugees in Pinyudo are also caught in the middle of retaliatory attacks by Nuer refugees. Based on where the camp is located, Anywaa refugees may be easier to get to than the host community. It is therefore not surprising that Anywaa refugees withstand most of the attacks committed by Nuer refugees. The insecurity created from sporadic attacks has caused resentment over the settlement of both groups of refugees.

\footnotetext{
"The hosts started to blame us for the killings of which we are also victims. In fact, Nuer refugees don't differentiate between us although we are refugees together with them. Whatever they do to the local Anywaa, they also do to us." (SSI51)
}

There is no natural animosity between the Anywaa and the Nuer communities. When peace prevails, the communities are tied closely enough to engage with each other on a daily basis.

\begin{abstract}
"When people do not clash, we are always good people. When there are no issues that occur, we can go there to get maize, mangoes, we also interact through religion." (SSI39)
\end{abstract}

The role of government, regional politics, and unity leaders in peace and conflict

"The government of Gambella do not want to protect the refugees. What does that mean? If we were not relocated from that area of Nguenyyiel to Tharpam, this killing could have not happened. Even a single nail of the refugees could never be broken. The former president Gatluak Tut told us to protect the refugee that was the reason why we had established the settlement around Nguenyyiel. However, the Anywaa government wants the refugees to be killed." (FGD28.R1)

The government uses accountability as a peacebuilding mechanism. It holds the host community to a higher degree of responsibility for the area and the safety of refugees. The notion of the government "seeing us" is mentioned by both refugees and the host community, meaning that the government places blame and delivers punishment. The extra scrutiny on the host community by the government decreases retaliatory attacks, which keeps refugees safe but which also prevents a cycle of violence that is common to Gambella.

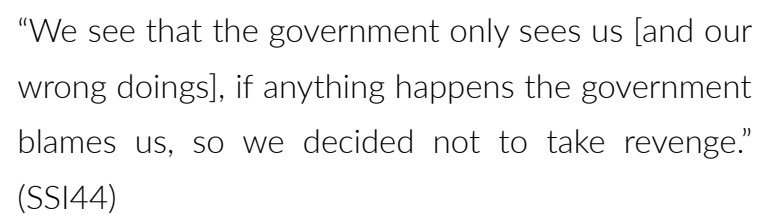

Access to the resources of the federal government and security have driven regional politics. Gambella is important to regional security as conflict between Nuer and Anywaa citizens can act as a catalyst for violence breaking out in other parts of the region.

\footnotetext{
"This information is important in the sense that everything ends at Killil [the regional government]." (FGD29.R2)
}

This has been highlighted by Nuer refugees located in camps in Anywaa territory, such as Pinyudo 1 and 2. Conflict between Nuer and Anywaa refugees in Gambella can have a domino effect, spreading to different parts of the region in the form of retaliatory attacks. Nuer refugees in Pinyudo are especially concerned about the precarious position they occupy and how their personal safety is interlinked with stability in Gambella.

"The cause of the tension started from Gambella, from the citizens, so the citizens, when the citizens of the country quarrel, the Anywaa adapt this thing then they repeat on refugees. So, when one Anywaa is killed from Gambella, also here they repeat this and they revenge, they kill one from the refugees. It always starts from Gambella, then Gambella to here." (FGD36.R6) 
Nuer refugees place their hopes in the government as the main arbitrator of peacebuilding between the Anywaa host community and Nuer refugees in Pinyudo. The fact that the current regional president is from the Anywaa community may be the best chance to negotiate a solution between the two groups.

"The government facilitates all these things, they negotiate peace between Anywaa and Nuer, if they negotiate the peace, and maybe we will be comfortable." (FGD36.R5)

However, the government has been unable to stop the escalation of violence this year. It is important to note that regional politics are complicated in Gambella, and that politics do not always fit neatly into ethnically drawn lines. For example, despite the current president being from the Anywaa community, several protests against the president were launched by Anywaa youth during the course of the field research.

Refugees utilize unity leaders as peace mediators during episodes of conflict at the camps in Itang. In each camp, unity leaders are derived from all four Nuer subclans, which fosters local ownership over conflict resolution mechanisms and negates perceptions of bias.

\section{Social organization}

Despite sharing a common culture, there are very few social organizations where refugees and the Nuer host community interact, possibly because of the lack of community-based organizations in the area or in the whole of Ethiopia. Church is an important site of connection for both groups. Refugees and members of the host community in Itang have joint prayer conferences in Kule camp and Mazoria, organized with ARRA's permission.

"Both communities also interact through the religion. They interact through joint prayer programs in the form of conference. Refugees can go to the host community and the host community can also come to Kule here to have conferences in the refugee camp. Church leaders can simply ask for a permission letter from ARRA and join refugees in the refugee camp until their conference is over." (KII11)

The overwhelming majority of Nuer are protestant Christians. However, refugees celebrate with highlanders on special Orthodox holidays.

\begin{abstract}
"On the occasions of Timkat (Holy Baptism) and Mesqal celebrations, refugees accompany host communities and celebrate with us. Specifically, this year Timkat was special that many refugees celebrated the festivity until 12:00 a.m. They spent the night dancing and playing alongside the host communities. This indicates our interaction is very strong and our needs are similar. We eat and drink together. We invite them for food, and they invite us some other day in return." (SSI43)
\end{abstract}

In Itang, refugees and Nuer host community members have formed a social organization called "Unity," which promotes cohesion between the two groups. It includes refugee community leaders who organize cultural celebrations for all four Nuer groups-whether refugee or host. Unity is the closest example of a community-based organization in Itang.

"Also, members of the host community came because all four sections of the Nuer were informed about the ceremony. They came, and people sat according to their community. Gajiok were told 'this is your place, Gajaak and also Fanjak and Bentiu here is your place, this is your place,' like that, members of the host community joined according to their sections [in which they identified themselves], then you sing your songs-every section sings its own songs. Then when each section is invited to perform, the others would see how they manage their affairs, or the way they live would be seen." (SSI37) 
Events organized by Unity are vital because intraethnic conflict persists among the Nuer, as is evident in the conflict at Kule camp in 2018.

Soccer (football) promotes social cohesion among youthsfrom the host community and refugees. Matches are organized between the two groups. Participants in Itang report relatively few cases of conflict spillover into soccer games.

"They play football [soccer] together, people come from Gambella itself, they come here and play football. In this place, and there are no clashes between people." (SSI39)

However, soccer matches are not enough. Some participants cite the lack of youth centers as a hindrance to building more positive relations with the host community. Plan International is the main NGO supporting soccer in the area.

\footnotetext{
"There are lots of needs for youth to have their recreational centers, which have places to play football [soccer], tennis and other things that could wash out of their minds of memories of a history they left behind back home." (SSI40)
}

Funerals can build positive relationships with the host community. Collective mourning between refugees and the host community is a mirror of the positive relations that they have.

\begin{abstract}
"We interact in various situations. For example, when the person who established this town [who also served as chairman of the kebele] died, all refugees and locals went to the burial, attended the funeral ceremony, and mourned for a week together. Both in good and bad times, we are together." (SSI43)
\end{abstract}

Few refugees engage in Okub, a traditional way of saving money through group membership. People voluntarily join a group and pay the mandatory contribution, after a period of time the common fund is distributed to each individual member on a rotating basis. Although Okub is rare among refugees, they are not barred from the practice.

\section{Economic Interactions}

\section{Trade with the host community}

Refugees have both complementary and competing economic interactions with the host community. The host community supplies refugees with perishable and nonperishable goods, such as vegetables, milk, clothes, and shoes; and refugees sell to the host community items from their rations that are usually very expensive, such as oil and wheat, or that are not easily found.

"For instance, chickpea was not available on the market, but now we easily get from the refugees." (FGD28.R1)

However, some refugees have become shrewd businesspeople, buying vegetables readily available in Mazoria and reselling them in the camp, undercutting the highlander traders.

"We now have business people who are refugees that always go and buy in bulk from highlander traders in order to resell them in the camp." (SSI35)

Refugees also brew local alcohol-a livelihood dominated by women at a much cheaper cost due to the grains that they receive from their rations. This makes it much harder for women from the host community to compete. At the same time, host community members buy traditional alcohol and other items from refugees and resell them at higher prices in areas where refugees find it difficult to access, such as Lare woreda.

The presence of refugees has spurred economic activity in the areas closest to the refugee camps, such as Puklot kebele. Therefore, restrictions on movement during times 
of insecurity have a significant economic cost for both refugees and the host community because the host community greatly benefits from the low price of goods sold by refugees.

\footnotetext{
"You can buy a quintal of wheat (100 kilograms) for $\mathrm{Br} 1,000$ or $\mathrm{Br} 500$ if it is 50 kilograms of wheat from highlander and we buy a single liter of oil for $\mathrm{Br} 70$. But if we buy these food items from refugees, we buy 50 kilograms of wheat for $\mathrm{Br} 400, \mathrm{Br} 300$, or $\mathrm{Br} 250$, depending on the availability of the wheat in the market, and we buy oil for cheapest price like $\mathrm{Br} 40$ per liter." (KII12)
}

Nuer refugees in Pinyudo are suffering from the movement restrictions placed on them. No longer able to access the market in Pinyudo town to trade their rations and livestock, they face idleness and dwindling prospects for earning an income. Some highlanders travel to the camp to buy rationed goods in bulk to resell in Pinyudo town. Fish is a commodity in high demand among refugees, and during times of peace, refugees trade with the Anwyaa, who are mainly located along the Baro River and who still dominate the fishing industry.

"They also have fish, which if you need you can go and buy fish yourself. However, if anything happens there, then these things would not be available to get." (SSI39)

Highlanders dominate the economy in multiple ways. They are the region's primary traders and own most of the shops, restaurants, banks, and commercial buildings. Moreover, highlanders are usually less prone to get involved in conflicts between the Nuer and the Anywaa and therefore do not have any restrictions on their movement or where they decide to relocate. In terms of employment opportunities, highlanders occupy the majority of the positions in UN agencies, NGOs, and federal institutions such as ARRA. Highlanders are the main contributors to the region's financial flows, and they are awarded large tracts of land for agricultural development.

"We interact with highlanders because they have big farms or investors' farms which we work in. We work manually at their farms, and they can pay us based on the work that we do." (SSI38)

\section{Job opportunities for refugees}

Some refugees have managed to take advantage of the burgeoning economy, particularly traders. The refugee traders are a tight-knit group. They meet and celebrate, pool resources, appraise their performances, and collectively plan for the future.

\begin{abstract}
"Last year, all the traders had a celebration, including traders in the host community. We had a celebration, we contributed some money monthly, after 30 days. Then after 2 or 3 years, then we came together, and we asked ourselves if there is anything going wrong in our work. If we see any new ideas, then we could implement it." (SSI37)
\end{abstract}

Some refugee traders even engage in cross-border trade; however, this economic practice requires resources and connections and is not very common.

"There are traders who are importers of clothes, like bracelets, those items from the Sudan. Those who have capacity always go there, to Sudan through border [Ethiopia-Sudan border], to bring them, when they sell them here, they always get something [money]." (SSI37)

The limited number of job opportunities is a challenge for Anywaa refugees, who feel frustrated that educated refugees cannot get jobs that would impact their community, such as teaching positions. Creating employment opportunities for refugees could encourage students to stay in school. However, these positions are usually reserved for highlanders. 
"We frequently raise this issue to ARRA and UNHCR. We would usually ask why our graduates holding diplomas and degrees aren't employed to teach their own children in primary school for refugees?" (SSI43)

Besides trading and brewing local alcohol, refugees engage in jobs such as drivers or shurtas. The success of refugees working outside the camp is also partly due to how difficult it is to distinguish a member of the host community from a refugee.

"Yes, there are refugees who are working as the drivers, they are present. They are working together with host community. The risk may be politics, but for the people, there is no problem between the people, the refugee can do anything they are able to do." (SSI43)

It is a positive sign that refugees are working outside the camp in such a volatile and marginalized area, especially considering policy plans to increase economic participation of refugees under the CRRF. NGOs and ARRA sometimes employ refugees as incentivized workers. This status is a major point of contention for refugees. This is because refugees are severely underpaid as incentive workers compared with Ethiopian citizens-even if the job and qualifications are the same.

"Their [refugees] salaries are Br 700 only. They are paid all equally, it is the same even if you have a Masters, even if you are PhD holder. And that is the case for all organizations." (SSI46)

Therefore, most refugees perceive NGOs as job creators, but very few feel that they benefit from the employment opportunities.

"So, any refugee working with NGOs is being paid only $\mathrm{Br} 700$, whether they are a teacher or nurse, while individual workers from the host community are being paid more money than a government worker. Their payment in NGOs started at $\mathrm{Br}$ 12,000." (SSI41)

\section{Barriers to the economic participation of refugees}

The greatest economic constraints for refugees are lack of identification and lack of capital, which prevent refugees from owning and running businesses. In Pinyudo, the barriers to economic participation include mobility, particularly among Nuer refugees barred from accessing the forest to cut down wood, from accessing Pinyudo town to trade their cattle in the market, and from traveling to Gambella.

In terms of borrowing, refugees have mixed practices. Some refugees are deterred by the concept of paying interest.

"Here, if you borrow money from someone, like if you borrow $\mathrm{Br} 100$, you will repay this money with $\mathrm{Br} 50$ as a charge which we are not familiar with in South Sudan." (SSI41)

Other refugees are quite successful.

"I know refugees who borrow up to $\mathrm{Br}$ 50,000 from Habesha people and return the money right on the date, keeping their word." (SSI43)

Some even engage in Okub.

"We also share some cooperative membership with them. For instance, we collect some money from cooperative members who are from both refugees and citizens. The money collected from all members could be given to one member, and other members will wait for their turn. That is what I would like to add." (FGD27.R4) 
However, in general, borrowing is an individual rather than community-wide practice. This has less to do with a lack of trust and more to do with the limited resources of refugees.

Borrowing is not as common in Pinyudo among Nuer refugees as it is for their counterparts in Kule and Itang. Movement restrictions into Pinyudo town is one barrier. Another is the weak connection with the host community. International Rescue Committee (IRC) attempted to respond to the lack of available finance by running a cashbased intervention in 2017.

"Two years ago, there was one organization called $I R C$, they provided elderly people with money, $\mathrm{Br}$ 3,000, and they told them that 'please, you go and trade that money, after a year you will bring $\mathrm{Br}$ 3,000 back and you will get the benefit."' (FGD.37.R1)

Nuer refugees recognize the importance of finance in forging opportunities for youth. Some participants cite the benefit of a microfinancing scheme for security.

"For the youth, like now, we do have the youth center. Also, they need something like a microfinance group, if they do have money, reduce the interest rate, or they may go and steal somebody else's property."

\section{Conclusions}

Three themes tie the data together: group-based dynamics, conflict fault lines, and factors of social cohesion. These three elements are key to understanding the social dynamics between refugees and the host community as well as for intervention opportunities.

\section{Group-based dynamics}

It is crucial to understand that conflicts between the Nuer and the Anywaa communities are not because the groups have an intrinsic animosity toward each other. Most participants from both the refugee and host communities cite that, during times of peace, the two ethnic groups have positive relations with each other. They trade and visit one another, intermarry, and display forms of solidarity. However, sustained periods of peace have been difficult to achieve because conflict between the two ethnic groups stems from inherent differences that have proven difficult to overcome. These differences, rooted in historical grievances, are mitigated or aggravated by exogenous factors that can easily upset the region's balance and serve as a tipping point toward violence.

Fundamentally, the two ethnic groups have conflicting conceptions of nativity and land ownership, which are central components of integration and social cohesion in Gambella. The Anywaa have historically viewed the Nuer as guests due to the international border established in 1902 that put the two ethnic groups on opposite sides of a border. The status of guest is permanent in Anywaa culture, influencing political discourse and land ownership. For the Anwyaa, land is intimately tied to ancestry. The Nuer, on the other hand, have a more utilitarian view of land. They believe that land belongs to God and ownership is predicated on usage. This raises serious questions about how to implement the integration of refugees. How should land be administered to refugees in a manner that respects Anywaa claims? Furthermore, the two groups have conflicting modes of production. The Nuer are traditionally pastoralists while the Anywaa rely on agriculture, fishing, and hunting. The Nuer are inclined to encroach on Anywaa land in the search of grazing land-a pattern that has been a historic source of conflict between the two groups.

Cross-border kinships between the two ethnic groups has engendered a sense of unity among host community members with refugees from their same ethnic group. This has positive implications in terms of the host community feeling responsible for the safety and wellbeing of refugees and often employing acts of solidarity, 
such as the sharing of food, water, resources, and information. This means that refugee integration into an area where the host community is predominantly from the same ethnic background is highly successful. However, cross-border kinships and ethnic unity can contribute to the instability of the region in the form of retaliatory attacks, which are common to both cultures. Retaliatory attacks not only cause but prolong conflicts between the groups. Therefore, individual clashes can quickly become community-wide conflicts.

This insight has increased the importance of Gambella in regional stability. Beyond its role as the seat of the regional government, insecurity that occurs in Gambella can spread throughout the region. Conflict between Nuer and Anywaa citizens in Gambella implicates refugees in Pinyudo and Itang and places them at the center of retaliatory attacks. This also lessens the willingness of some host community members to integrate with refugees. In Pinyudo, recurring retaliatory attacks between Nuer refugees and the Anywaa community have prompted some to reject the idea of integration of the two refugee groups. Members of the host community in this study, however, are aware of the implications of conflict between the host communities and refugees and express the need to minimize such conflict.

\section{Conflict fault lines}

Exogenous factors play a role in mediating or aggravating conflict between the groups. Deforestation is a major flashpoint of conflict between the host community and refugees but is neglected in policy planning. Limited livelihood opportunities and deficient sources of energy and clean cooking appliances, such as kerosene stoves, push refugees to exploit the forest for fuel and income sources. Deforestation has been a point of contention for the host community; and most refugees describe the forest surrounding their camps as the apex of insecurity. An overwhelming majority of attacks, rapes, and incidents of theft occur in the forest. Moreover, the National Resource Development and Environmental Protection
Department, tasked with protecting the forest, can issue punitive measures against refugees. Yet refugees cannot avoid utilizing the forest for their needs and continue to source firewood despite the present risks.

Unequal job opportunities for indigenous hosts and the incentive worker scheme for refugees increase economic pressure and animosity. An overwhelming majority of participants cite unequal employment opportunities as a source of resentment against NGOs working in the area. Participants do not deny that NGOs have created positive changes in the area, particularly in terms of education and health care. Yet host community members feel marginalized in terms of job opportunities. There are very few indigenous members of the host community that work for NGOs. Most of the higher and lower positions are occupied by highlanders. Indigenous members of the host community feel as if they are not rewarded for the sacrifices they made to accommodate refugees. Service provision alone is not enough-participants demand equal employment opportunities with NGOs. Refugees feel as if the incentive worker scheme is exasperating the economic constraints they already face. Refugees would like to see their earnings be on par with the host community's or at the very least significantly increased.

Theft plays an instrumental role in aggravating conflict in the region. A decrease in rations and limited livelihood opportunities drive refugees and hosts to theft. Groups of thieves comprising refugees and host community members often work together to increase their success rate and to throw off perceptions by making it difficult for local authorities to identify the group at fault. This often leads to host communities acting against the wrong perpetrators, which can lead to incidences of retaliatory attacks and community conflict. Land distribution is a major fault line among the Anywaa, the Nuer, and highlanders. The Ethiopian government's policy of leasing large tracts of land to agribusinesses is potentially decreasing available land to accommodate Nuer refugees and Nuer hosts, whose traditional livelihood is pastoralism. 


\section{Factors for social cohesion}

The presence of refugees has engendered positive economic spillover for the host community. Kule, Nguenyyiel, and Pinyudo 1 have had a positive effect on the development of the host communities in close proximity to the camps. In Pinyudo town and Pulkot kebele, the presence of refugees has increased economic activity in terms of trade and goods available on the market. Participants report that the arrival of refugees transformed Pulkot kebele from a small village to a town with much more economic clout than Itang woreda. Therefore, enhancing the ease of doing business for both refugees and the host community can positively affect integration. Both communities can see each other as mutually beneficial, and having adequate access to finance can supplement local innovations to solve community needs.

Integrating education and health services for refugees and the host community can increase social cohesion. Both refugees and host community members speak of the need for more schools and health centers. Filling this gap and making them available to both hosts and refugees is crucial. Finally, exploring ways for refugees and the host community to collaborate in community-based organizations could ease intraethnic tensions among refugees and the host community.

\section{CRRF: Risks and opportunities}

The rollout of the Comprehensive Refugee Response Framework will encounter fundamental challenges in Gambella. Chief among them is implementing pledge 9, which allows for the local integration of refugees who have been in a protracted situation in Ethiopia for 20 years or longer. Most of the refugees eligible for this are in Pinyudo 1-Gambella's oldest camp-but most members of the host community in Pinyudo would prefer to see the resettlement of refugees over local integration.

Members of the Anywaa host community doubt the benefits of integration. Their primary fear is that further integration would lead to more violence because the three communities would be closer to each other. As one participant explained, when the government engaged in discussions with the host community in Pinyudo about plans for integration, the host community rejected the idea as a policy that could further disrupt their lives.

\begin{abstract}
"When I heard about the plan, it breaks my heart because I thought if our lack of interactions happens while we are living separately then when we are integrated, death will be inevitable. You would just rise and kill your neighbor so easily. This has really brought something very difficult and the atmosphere has also changed in people's lives." (SSI51)
\end{abstract}

Such a sentiment among the host community in Pinyudo is not representative of the entire community. In Itang, the sentiment is markedly different: the host community in Pulkot kebele and the town of Itang did not have such strong reservations about the integration of refugees. However, their knowledge of the CRRF is extremely poor. Misconceptions can work both ways: members of the host community can over- or underestimate the extent of integration planned by the government. Awareness should be raised to include local participation in the rollout of policies that are in line with integration attempts but molded to fit local contexts. Moreover, the politics of demography is a complicated issue that the framework must confront to avoid upsetting the political balance in Gambella.

There is an appetite among refugees for running and opening business and in upgrading their skills. Success depends on the implementation of livelihood programs under CRRF that focus on nontraditional forms of livelihood. The same is true for the host community, which would benefit from joint programs with refugees. In fact, allowing refugees and the host community to join or form joint business associations could go a long way toward improving relations between the two groups. Pairing livelihood programs with aspects of renewable energy could be a way of tackling two significant challenges at once. 
Providing refugees with the proper documentation and financing to be self-reliant could ease tensions, even in challenging areas such as Pinyudo. Granting refugees freedom of movement could give them the choice to relocate to areas where the host community is from the same ethnic group, giving them tools to be self-reliant and to successfully integrate into their new communities.

\section{References}

Abebe, T. 2018. Ethiopia's Refugee Response: Focus on SocioEconomic Integration and Self-Reliance. Institute for Security Studies.

Bahru, Z. 1987. "An Overview and Assessment of Gambella Trade (1904-1935)." The International Journal of African Historical Studies 20 (1): 75-94.

Borkena. 2019. Gambella Regional State

Removed Four Senior Security Officials." Borkena,

July 15. https://borkena.com/2019/07/15/

gambella-regional-state-removed-four-senior-security-officials/

Davidson W. 2016. "Ethnic Clashes in Ethiopia's Gambella Kill

Dozens, Official Says." Bloomberg News.

Erda, F. 2017. Security Implications of Hosting Refugees: The Case of South Sudanese Refugees in Gambella, Southwestern Ethiopia. Kujenga-Amani blog. https://kujenga-amani.ssrc.org/2017/09/19/ security-implications-of-hosting-refugees-the-case-of-south-sudanese-refugees-in-gambella-southwestern-ethiopia/

Feyissa, Dereje. 2010. "The Cultural Construction of State Borders: The View from Gambella." Journal of Eastern African Studies 4 (2): 314-30.
---. 2015. "Power and Its Discontents: Anywaa's Reactions to the Expansion of the Ethiopian State, 1950-1991." The International Journal of African Studies 48 (1): 31-49.

Gebresenbet, F. 2016. Land Acquisitions, the Politics of Dispossession and State Remaking in Gambella, Western Ethiopia. Africa Spectrum.

HRW (Human Rights Watch). 2005. Targeting the Anuak. Human Rights Watch. https://www.hrw.org/reports/2005/ethiopia0305/3.htm.

Jeffrey, J. 2019. "The Ethiopian City Lost in the Shadows of Sudan's War." http://www.ipsnews.net/2019/05/ ethiopian-city-lost-shadow-south-sudans-war/

Lie, J., and Borchgrevink, A. 2012. "Layer Upon Layer: Understanding the Gambella Conflict Formation." International Journal of Ethiopian Studies.

ODI. 2019. The Comprehensive Refugee Response Framework: Progress in Ethiopia. Humanitarian Policy Group Working Paper. London: ODI.

Seide, W. M. 2017. "The Nuer Pastoralists: Between Large Scale Agriculture and Villagization: A Case Study of the Lare District in the Gambella Region of Ethiopia." Current African Issues.

Tadesse, Medhane. 2007. "Gambella: The Impact of Local Conflict on Regional Security." Occasional Paper. Addis Ababa; Pretoria: Institute for Security Studies. https://www.africaportal.org/publications/ gambella-the-impact-of-local-conflict-on-regional-security/.

Young, J. 1999. "Along Ethiopia's Western Frontier: Gambella and Benishangul in Transition." Journal of Modern African Studies. 
UNHCR (United Nations High Commissioner for Refugees). 2018.

Comprehensive Refugee Response Framework: The Ethiopian Model. UNHCR.

---. 2019a. Additional Provisions within the Revised National Refugee Law in Ethiopia. UNHCR.

---. 2019b. Operations Portal: South Sudan Situation. UNHCR.
UNHCR Ethiopia. 2019. Bi-weekly Operational Update: 16-30 April 2019." UNHCR Ethiopia.

https://reliefweb.int/report/ethiopia/

unhcr-ethiopia-bi-weekly-operational-update-16-30-april-2019.

World Bank. 2018. Informing Durable Solutions by Micro-Data: A Skills Survey for refugees in Ethiopia. Washington, DC: World Bank. 


\section{Somali Region}

\section{Context of Displacement in Ethiopia and the Somali Region}

With 905,831 refugees (as of March 2019), Ethiopia is the second largest refugee-hosting country in Africa (UNHCR 2019). Most refugees in Ethiopia live in the 26 camps located at the border in Tigray, Afar, Benishangul-Gumuz, Gambella, and the Somali Region. Since the nine pledges made by the Ethiopian government in 2016, the country has worked toward their implementation by rolling out the Comprehensive Refugee Response Framework (CRRF) and adopting a new refugee proclamation. This lays the foundation for the out-of-camp policy and greater integration of refugees. In addition, Ethiopia has also experienced an unprecedented internal displacement crisis over the past two years, with over 2,235,000 people internally displaced as of August 2019.66

"Displacement in Somali Region dates back to 1991 when the civil war started in Somalia. ... Dynamics were quite complex but finally we had two refugee-hosting areas: one in Jigjiga region, where there are three refugee camps [Kebribayah, established in 1991; Aw Barre in 2007; and Sheder in 2008]. The total refugee population is close to 37,000 . These refugees come from southern and central Somalia. Those who were coming from the Northern part of Somalia, Somaliland, they went back. Most of them are from central Somalia where the situation in terms of security is still very fragile: probably Al Shabab. We cannot guarantee the safety and security over there." (KII17)

66. See the International Organization for Migration's Displacement Tracking Matrix (August 2019) at https://displacement.iom.int/system/tdf/reports/ R17\%20National\%20Dashboard\%20V2.pdf?file=1\&type=node\&id=6412.

\section{Table D.1. Somali Region: Demographics}

\begin{tabular}{|l|c|}
\hline Population (2007 census) & $4,439,147$ \\
\hline Population living in rural areas & $3,817,937(86 \%)$ \\
\hline Population living in urban areas & $621,210(14 \%)$ \\
\hline Pastoralist population & $60 \%$ \\
\hline Agropastoralist population & $25 \%$ \\
\hline Sedentary farmers & $15 \%$ \\
\hline
\end{tabular}

Source: SC-UK and DPPC 2008.

The Somali Region is among those affected by both conflict and disaster; it is also among the least-developed states in the country. Located at the border of Somalia, the Somali Region has received a large influx of refugees since the early 1990 s due to conflicts and droughts. The camps are divided between the southeastern Somali Region (Dollo Ado)-with five camps accommodating 220,000 refugees (Betts 2019b)-and the Fafan zone around Jigjiga, where 37,293 refugees live in three camps: Kebribayah, Sheder, and Aw Barre. ${ }^{67}$ While Kebribayah has been active for nearly three decades, Aw Barre and Sheder were established in 2007 and 2008, respectively. Both camps host more than 10,000 refugees, originating mainly from central and southern Somalia.

The Somali Region is a territory of origin, transit, and destination. The harsh living conditions and limited opportunities encourage local youths to leave the country, often through irregular migration. The region is also an area of transit for many refugees from Somalia, who see their stay in Ethiopia as a first step in their onward migration.

67. See UNHCR, Kebrebiyah Camp Profile, January 2018, https://data2.unhcr. org/en/documents/details/62682; UNHCR, Sheder Camp Profile, March 2018, https://data2.unhcr.org/en/documents/details/62683; UNHCR, Aw-barre Camp Profile, March 2018, https://data2.unhcr.org/en/documents/details/62691. 
"We-as the parents of the youth-also struggle to see our sons back home after four years of university, you feel bad about their situation. It is really demoralizing and forces them to start chewing khat with others who have never gone to school. Some even try to illegally migrate, and we end up paying for them to be released from prison. It is really disheartening to be honest. I would like to see the youth being empowered on both sides." (FGD11.R2)

A characteristic of the in Somali Region's displacement context is the cultural proximity between refugee and host communities. Although their socioeconomic backgrounds are different, both groups are Somalis and thus share the same language, culture, and religion, which has allowed peaceful coexistence between communities and greater integration compared with other displacement settings.

"There is no cultural problem since there is no difference between the host and refugee communities in terms of culture, religion, color, and language. They are Somalis. That is why the integration is good since we share the same language, culture, and religion; we also intermarry. I hope as time goes by, this integration will continue and there will no longer be refugees. The integration has reached the point where people intermarry and you can't differentiate between hosts and refugees. The people who arrive as refugees but stay a long time become part of the community, and you cannot differentiate unless you ask someone whether they have a refugee card or not. They integrated and they become families. There are children aged 10 who have one host and one refugee as parents." (SSI27)

Over the past few years, the internal displacement crisis has strongly affected the Somali Region. According to the International Organization for Migration's Displacement Tracking Matrix, there were 1,166,878 internally displaced people identified in the region in February 2019. Conflicts between communities is the primary cause of displacement, followed by climate. Pressure on humanitarian actors and local authorities has increased, giving rise to claims for more action in favor of host populations.

"Humanitarian aid stakeholders always focus on refugees as the most vulnerable. Locals also have displaced people, displaced because of drought and climate-related factors. So they need care and support, including employment opportunities." (SSI30)

On the political front, the Somali Region has also been affected by the fall of its president, Abdi Mohamoud Omar, paving the way for greater democracy but also giving rise to instability. This political shift, which both refugees and hosts mention, occurred during the democratization of the country.

"The difference between today and the time of Abdi is that at that time, people used to fear the president and look down. Now, both refugees and hosts are more open and have the courage to express their opinions." (FGD16.R5)

After years of closed politics, this new context provides an opportunity to work toward the operationalization of the pledges on local integration.

\section{Study Areas, Groups, and Types of Refugees}

The Fafan zone is a rural area, mainly composed of agropastoralist communities. While Jigjiga is among the fastest growing cities of the Somali Region, the urbanization at the zonal level is recent and remains limited. The area has a semiarid climate and poor infrastructure, making living conditions challenging. Regional droughts regularly result in the internal displacement of people unable to meet their basic needs. Economic opportunities and resources are limited because the private sector is underdeveloped. In such a context, unemployment is high, and a large segment of educated youth remain jobless, resulting in 
the irregular migration of youth looking for a better life abroad (IOM 2018).

The area relies heavily on cross-border trade with Somalia and Somaliland for the provision of goods and livestock. Imported commodities from the ports of Berbera and Bossaso cross the border to supply the Somali Region, which is poorly integrated into Ethiopia's economy (Abdurehman 2014). Most livestock trade takes place through informal channels, connecting pastoralist communities on both sides of the border (Michelson 1999). Pastoralism and petty trade are the main sources of income for the locals, many of whom regularly go to Jigjiga in search of better job opportunities. The presence of the camps has significantly changed the socioeconomic features of the area, with villages turning into towns and attracting businesspeople from throughout the region.

\begin{abstract}
"When the refugees arrived here in 2008, the area was rural, with poor livelihoods, and when we arrived here where the camp is located, the area was made of forest. (...) Before the refugees came, most of the people were ignorant, they couldn't get education, all of them were pastorals who rear livestock." (FGD11.R2)
\end{abstract}

The refugee population is similar in Aw Barre and Sheder; they are originally from southern and central Somalia and mostly from urban areas. Many of them had assets and capital in their country (Carver, Gedi, and Naish 2018) and have experienced a drop in their standard of living:

\footnotetext{
"We came because of the insecurity in our country. We used to have better living standards; we used to live in better houses. We are here just because we feel peace and security." (FGD16.R1)
}

Most of the refugees interviewed came directly from Somalia and had no prior experience with displacement.
Some were initially based in Kebribayah before being resettled in Sheder or Aw Barre when the camps were established. Transfers from one refugee camp to another also occurred, but in rare cases.

Among the respondents, the primary cause of displacement is conflict. 68 The repeated wars in Somalia since the 1990s and the terror inflicted by Al Shabab have pushed thousands of families out of their country:

"Since 1991, we have gone through a long period of instability; we have experienced many types of wars in Somalia. The violence created by the militia [Al Shabab] was the worst; our children could not go to school." (FGD16.R1)

Some refugees explain that they had to leave to avoid being enlisted by terrorist groups.

"I have been here since 2007 until today. In 2019, I was young, I used to live in a hostile area. I have been at risk of being kidnapped by the terrorist groups there or [they would] force me to work for them. Many of our people were killed, I decided to be true to my people and ran away so that I am not influenced to join this terrorist group. I came here looking for peace." (SSI19)

Aw Barre and Sheder camps also accommodate climateinduced refugees, who left Somalia after recurrent droughts and episodes of famine (UNHCR 2018).

The refugees in Aw Barre and Sheder are in a protracted situation, with no prospect for improvements in their country of origin and limited chances for resettlement. The refugee population has been living in the area for a decade.

68. Drought was not mentioned during our interviews: most refugees in Shedder and Aw Barre come from central Somalia, usually urban environments, and most had left Somalia in the early 2000s. 
"in Jigjiga, the refugees are quite protracted, they have been here for a long period of time and because of the country, regional, and local refugee crisis, they have been underfunded." (KII7)

The implementation of the out-of-camp policy as well as programs that foster integration are crucial for such refugee populations.

Given the regulatory restrictions on movement and formal participation in the labor market, refugees remain dependent on food aid (Betts 2019b). Most therefore engage in informal economic activities to improve their living conditions. Refugees in Sheder and Aw Barre herd cattle, engage in petty trade, and work as day laborers. This is similar to the economic activities hosts engage in, except government jobs, which constitute a substantial part of the employment opportunities in Aw Barre, are only available to hosts. However, refugees tend to be better skilled (Carver, Gedi, and Naish 2018) and thus benefit from teaching jobs at private schools. Hosts appreciate their tailoring, construction, home decorating, and electrical skills. Most interactions between refugees and hosts happen as a result of such economic exchanges.

Although they have different socioeconomic backgrounds, refugees and hosts share the same Somali culture, language, and religion. Both groups explain that refugees and hosts "are the same."

"We are all of the same community." (SSI20)

These cultural similarities facilitate interactions, especially as people regularly meet at mosques; however, it does not blur the boundaries between the two communities. Community organizations are specific to each community, and there is a strong sense among many of belonging to one community or the other.

Most of the findings are equally applicable to both study areas, with the main difference being that Aw Barre is a larger town, and the distance between the camp and the town in addition to the lack of a bridge tend to limit social interactions, affecting social dynamics.

\section{Limitations and Constraints}

Access to the camps. Accessing the camps proved logistically challenging due to the poor condition of the road connecting Jigjiga to Sheder and Aw Barre. The team had to be extremely careful about weather conditions as the road becomes impassable when it rains, including leaving the camp earlier than expected when necessary.

Availability of respondents. Some interviews had to be rescheduled in both Aw Barre and Sheder because they conflicted with other activities, such as food distribution, registrations, and trainings provided by UNHCR and other organizations.

\section{Context of Displacement}

\section{Security}

\section{Refugees and hosts feel safe overall}

While insecurity appears to be the main driver of migration for refugees, this is not a problem reported in Jigjiga. Most refugees there find that living in the camps is generally safe, and describe the area as peaceful, both in Sheder and Aw Barre.

\footnotetext{
"We, as refugees, face a lot of problems regardless. But we are very grateful for the peace and security. I feel very safe here and have not had to worry about guns, attacks, and [fear of] any powerful clan [who would] come and cause harm to my family here." (LLI5)
}

Many speak about the hospitality of the locals as one of the positive aspects about living in this area. They acknowledge receiving support from the host community, who provide them with land and offer them food. 
"When we came to Sheder camp, we were really very well received. We were given space to build a house inside Sheder camp, we were given good food including meat, good water and we really appreciated that. And Sheder was a good place to live, for instance it was peaceful. The people living here are very warm, and they took us in like their sisters and brothers. I particularly remember the women in Sheder, they cooked for us and made us feel comfortable." (LLI7)

Refugees also state they can move freely out of the camp and go as far as Jigjiga despite the movement restrictions associated with their status. ${ }^{69}$ Their ability to move has improved since UNHCR gave them refugee ID cards in 2018.

"The refugees are not confined to stay and can freely move around at any time, and the host community plays a key role in maintaining the security of the town." (SSI2O)

Both refugees and hosts in Sheder say that the number of violent incidents is limited, and they do not target a specific community. However, several refugees report attacks happening at night as well as tensions around accessing mobile networks, with refugees being stoned by hosts when going around the camp to find phone service. Refugees describe a sense of hostility from some hosts, who threaten refugees when they move around the host community. Refugees also lament the low priority given to security in the area by the Agency for Refugee and Returnee Affairs (ARRA) and the police.

69. Refugees can move using their refugee ID card as far as Jigjiga and parts of Somaliland, mostly Borama. The only times this movement becomes restricted is when the government declares curfews, usually implemented due to perceived security threats. Other than that, the refugees are allowed to move about, provided they can produce their UNHCR-issued ID cards. These ID cards, which aid their mobility, were put in place in 2018.
"Locals are divided into two. [There] are those who keep refusing us to go anywhere and there are the others, who are good. The [first] ones do not allow us to go to their side to use the network because here in the camp the network is bad. The network is good around them, and people from the refugee community have disturbed them. That is why they keep stoning us, and that is why they don't want refugees to be around them. If you can't have network at night, you will just have to wait until tomorrow. When Abdirisak [camp manager] was here at ARRA, things were better and federals were here, they didn't allow people at night to go there. Now there is no federal police, and nobody cares about them, so they have the right to behave like that for their security." (FGD17.R3)

\section{A recent deterioration of the security situation}

Some speak of a recent deterioration of the security situation following the change of government in the Somali Region. The former regional president Abdi Mohamoud Omar exercised strict control over the region for more than a decade and allegedly violated human rights and maintained order using coercion. His fall was accompanied by uprisings and a rise in crime, which seems to have affected refugees to some extent.

"The security in the area is good. Nowadays, hosts have changed their habits, and refugees feel tensions coming from the hosts. Before [the fall of the former president] they were under pressure, but after the change of Ethiopia in general, particularly in the region, they have started to disturb the refugees in different ways, becoming hostile to them." (SSI29)

Although some refugees said they have recently experienced greater hostility from the host community, the overall security situation seems to have changed with both communities feeling less safe. 
"Before, things used to be different, things were good, we used to go together and buy tomatoes for tomorrow's breakfast and buy whatever we like at night and shops and butcheries were always open. Now they close at sunset. ... So, before things were good and security was ok, we could go at night and buy what we need, now you can't see any open shops at night. Even the hosts fear and close business very quickly. During Abdi's time, there were no groups and no nothing like what is happening now. Now freedom has been used in the wrong way. That is the problem." (FGD17.R5)

\section{More security concerns in Aw Barre}

In Aw Barre, the security concerns are more acute, essentially because of groups of youths in the valley. This area, located between the town and the refugee camp, is a major security concern that also limits interactions between refugees and hosts because people are afraid of crossing to the other side. This sense of insecurity is greater for women and girls, who are particularly at risk when they walk around the camp cutting down trees. Several women refugees cite cases of harassment and rape.

"The host youth are a big safety issue for us young girls living in the camps. We fear for our lives because they are always hanging around in gangs around the valley. This makes me feel unsafe. There are so many girls who have been chased from the valley, when they are going to collect wood." (FGD13.R1)

This does not apply only to refugees, as the host community members are also victims of these groups.

"The insecurity caused by the young violent groups is a general issue; it is not specific to one group, refugees or hosts. They are composed of refugees and host communities, and they are harming both sides in the same way." (FGD13.R2)
Participants also mention youth groups taking drugs and attacking members of both communities. These groups, which are not associated with a particular community, are described as jobless and bored.

"Some of the host youths came to my house, damaged my property, and it is by the grace of Allah I survived and was not killed. The youth are jobless and, as a result, have a lot of time to fight and cause havoc. I am not only speaking of the host youtheven ours here are no better. Some of them are on drugs and cause all types of problems to both." (FGD11.R5)

\section{Governance and programming}

\section{Ethiopian government's perspective}

Refugee programming has been the exclusive territory of ARRA since its creation, while local government bodies have been kept at bay, with very limited knowledge about refugee planning and funding (Carver, Gedi, and Naish 2018). When it comes to the ongoing reforms and the prospect of unified service delivery, local authorities mostly have positive views because they expect such changes to benefit the host community.

\section{Limited knowledge of government plans}

The level of knowledge about the government's plans regarding the integration of refugees is limited among refugees as well as hosts. Some have no relevant information whatsoever; others have heard about job creation opportunities for both communities but without further detail. This limited information can be explained by the lack of clarity around the plans by the relevant actors themselves, as implementation has not yet started at the local level. While the national government has not issued any implementation guidelines, local actors are reluctant to share information with communities for fear of raising expectations. As one key informant explains, the government's 
national-level commitments are positive, but there is a lack of clarity on how it will translate into practice:

"The Ethiopian government has committed to the nine pledges, like offering jobs to refugees [around 10 percent], access to education, free movement, allowing refugees to have their own businesses. They are very good, fantastic, but no action yet. They were endorsed by the parliament, but the law needs to be implemented." (KII7)

\section{Lack of coordination among actors}

Despite the rollout of the CRRF, there is a clear lack of coordination between actors involved in the refugee community and the ones responsible for the host community. As stated by a Danish Refugee Council manager in Jigjiga,

"There is good coordination, but it is not successful. We have key actors, refugee actors, and host community actors, all operating. Sometimes host community actors operate near the refugee camp, but the Bureau of Finance and Economic Development has nothing to do with UNHCR and ARRA. Those who are operating in the refugee camp, they have nothing to do with local actors as well. In the last interagency coordination meeting, I commented that UNHCR mainly focuses on implementing partners [IPs] who are getting funds from them but they don't care about the IPs active in the host community." (KII7)

A CRRF coordination meeting was established to bring together for the first time the various stakeholders involved with refugees and hosts, but there has yet to be a joint assessment, planning, or implementation. The coordination meetings have been limited to informationsharing regarding the projects and activities implemented by each "side." Hosts and refugees highlight this issue.
During community consultation organized in Aw Barre, one respondent expressed the wish to see local authorities and ARRA move toward joint planning for service delivery.

"ARRA is responsible for refugees in terms of health, electricity, water supply, and so on. Public [local] institutions have the responsibility to take care of locals. Both communities require integrated services, but this can be achieved when these two start collaborating so that they are integrated first before providing services to the community." (CC2.R10)

Local administration representatives speak of a positive relationship with ARRA but acknowledge that capacity building is needed:

"I would say that there is a good working relationship between us and ARRA. We also have a relationship with all the Refugee Central Committee [RCC] members brought here today. Isn't this so? Our offices do require more support in building capacity, but I think our working relationships are good." (CC2.R24)

Participants who have heard about the plans express positive views about them, as they acknowledge that both communities need to be equally supported.

"I heard that some refugees will be brought here. I also heard that some [international nongovernmental organizations] are planning to create job opportunities for refugees to minimize their dependence on humanitarian assistance. I have no details on when and how these plans are going to be implemented. I just heard this from other people living in Sheder. Yes, this is a good thing and is part of the changes we would like to see. But also, we would like to see similar support for the hosts as well." (SSI30) 
For local stakeholders, the CRRF is necessary to address the local communities' complaints regarding the difference in treatment between refugees and hosts.

"The government has started this new initiative CRRF because the locals were not happy with the service provided to the refugees in terms of health, education." (KII10)

However, tensions around refugee integration might arise as hosts face competition for job opportunities, which are already limited in this area:

"It might be a problem because it will increase the exposure for the refugees to go here and there and there can be a sort of competition and the host community might not be ok. Unless the number of available jobs increases, unless there are more opportunities." (KII8)

Tensions already exist in sectors where refugees serve as a competitive labor force, such as construction.

"It causes tension yes, there have been some incidents, some fights in the construction area because they feel that this is a threat to the host community. The danger is there, that is true, because the host community may become more aggressive." (KII6)

Hosts are also aware that refugees' skills make them attractive to potential employers, such as for teaching jobs, as expressed by one host who referred to refugees' English skills.

"Being a tutor, I would say there is a lot of competition since a lot of the refugees usually go for the teaching jobs. Some of them have studied in other schools and have more teaching experience. For example, there is a man who is 40 years old and lives in the camp. He speaks very good English like you and your workmates. Of course, when there will be people like him in the community, there will be competition." (SSI2O)

\section{NGOs have been the subject of criticism from the host communities}

Nongovernmental organizations (NGOs) are key players for the refugees, as reflected in the ecosystem model, but they are perceived to pay less attention to the host community. This has created tensions over the past few years. In a location where the host community itself has limited opportunities, the support provided to refugees by NGOs has raised questions, including among local government actors. There is widespread discourse about the host community feeling neglected, which has led to tensions around aid distribution. According to several participants from both communities, locals benefit from 25 percent of the interventions, while refugees receive 75 percent.

"Fair distribution of resources is very important. IRC provides computer training skills. Locals are allocated 25 percent. Last time, when we went to get the locals' share, we were told to wait for the next round of support." (FGD18.R4)

As a result, there is a strong demand in the host community for greater equality:

"The other difference is that NGOs here focus only on refugees. If they plan on creating jobs, they only focus on refugees. There are also needy households in the host community as well. They should support both communities equally and that is what we always suggest during meetings. To avoid conflicts between the two communities, they should be supported equally." (SSI27) 
Hosts feel disadvantaged, not only in terms of interventions, but also when it comes to employment opportunities, as they feel that most of the jobs are given to highlanders (e.g., staff members from Addis Ababa, where the NGOs are based). This has fueled resentment in the host community, as expressed by a respondent during a community consultation:

\begin{abstract}
"There are many graduates from national universities sitting around with no employment opportunities. Organizations are based in Addis Ababa and hire staff from the highlands-Oromos and Amharas and other non-Somalis. There are many employment opportunities in humanitarian organizations. Opportunities are given to people from the highlands. We share this problem with the refugees. Drivers are brought from the highlands where local drivers are not given the chance." (CC2.R21)
\end{abstract}

When asked about NGO interventions, respondents were very vocal about the trainings and in-kind support provided by NGOs. Beneficiaries show great enthusiasm for the trainings on business skills and entrepreneurship and evoke increased motivation as an outcome. Local authorities also express positive views of these activities, which they think have an impact on migration intentions because they keep youth busy and heighten awareness of local livelihood opportunities. According to respondents, the two weaknesses of these programs are: (1) the limited number of beneficiaries; and (2) the amount of aid granted.

"We have been supported by IRC to create small businesses. First, IRC gave people training on computer skills and business. Then they support 50 percent of the trainees based on their performances. The support is not a loan; [instead] they buy goods needed to do business. The amount was $\mathrm{Br}$ 17,000. That amount [is not enough to] be a good investment, but it is helpful to start a business. It is based on the person's experience and hobby, some people opened restaurants, others were given sewing machines, and others made fast foods like biscuits or sweets." (FGD16)

However, community representatives criticize the organizations for failing to provide skills that can be used locally.

"I am an RCC member and I think before we break for prayers, I will tell you that our youth need job creation. They are just idle. We need to have more skills trainings provided to them. Sometimes they are taken to Jigjiga by some organizations to learn some skills, but these skills are not applicable here. Please help us make sure that the youth continue to grow their skills and are able to invest in Aw Barre and not move to other places." (CC2.R20)

In addition, a decline in funding has reduced the number of livelihood programs, including technical and vocational training (UNHCR 2018), although livelihoods are the most pressing concern.

\section{Development interventions to strengthen social cohesion}

Development interventions also play an important role in fostering interactions between the communities. The implementation of integrated approaches through programs such as The Regional Development and Protection Programme (RDPP) play a key role in this regard. It has addressed criticism that the NGOs only give attention to refugees, as the program was designed to address the needs of both communities.

\footnotetext{
"They always feel the interventions from humanitarian organizations are more focused on refugees than the host communities, so this has created a kind of thinking, you know refugees are settling on their lands, they ask questions, and even the government itself was asking these questions, and RDPP was designed to answer these questions." (KII6)
} 
As one RDPP implementing partner explains, beneficiaries are now from both communities. They attend trainings together and receive equal support. While a selected number of beneficiaries in the host community are provided with start-up capital to establish businesses, the regulatory framework makes it impossible to do the same for refugees, who are instead given in-kind support.

"In the past, we would only focus on refugees but now, since the CRRF has been developed, in which the government has started to include the host community and the locals who live around the camps, in that regard we have started working with the hosts using funds from European Union with the project RDPP, it started in 2017. It only focuses on educational livelihoods, we created business-related livelihoods, we gave them three months trainings, and we offered start-ups [support] for them." (KII10)

As explained by a local in Aw Barre, training provided by NGOs are one of the places of interaction between refugees and hosts.

\footnotetext{
"People have interactions differently, during the conferences, trainings, and workshops that NGOs conducted." (SSI24)
}

However, the impact is reduced by the limited number of beneficiaries, especially in the refugee community. In Aw Barre, 1,200 hosts and 150 refugees benefitted from the trainings delivered by NGOs (Samuel Hall 2019). Similarly, the World Bank's Development Response to Displacement Impacts Project (DRDIP) increases social cohesion by primarily focusing on host communities living around camps and thus addressing the recurrent complaints regarding the lack of support for locals.

Recognizing the scale of the need in host communities and the protracted presence of refugees, DRDIP was designed as a response to the request for support from local communities in areas where living conditions are particularly challenging. ${ }^{70}$ The project, which uses a community-driven approach, has three components: (1) social and economic services and infrastructure; (2) sustainable environmental management; and (3) livelihoods. Although the project targets host communities, refugees are the indirect beneficiaries because they benefit from the improved infrastructure and services and the increased opportunities. At the time of this writing, the project team was preparing to request funding for a second phase-as the project ends in December 2019-with the objective of targeting both host communities and refugees, in line with the CRRF.

\section{Ecosystem}

The ecosystem models for refugees and hosts presented below provide a representation of their respective social environments and display the different layers of relationships around them. What stands out most prominently is the greater number of stakeholders for refugees than hosts. This reflects the lack of support evoked by hosts in the interviews compared with the refugees' ecosystem, where we see multiple organizations and actors. Daily interactions in the local market play a key role in the social environment of refugees, but refugee-specific organizations play their part too.

UNHCR. Refugees depend on UNHCR-provided housing and livelihood assistance, and express gratitude toward the organizations that help sustain their lives.

"I am grateful for the humanitarian NGOs such as UNHCR for their hospitality, and they provided us with education, food, health, and shelter." (SSI19)

The provided allowance is often the main source of income for refugees, although many engage in informal economic activities to earn additional income. This impacts local

70. DRDIP is implemented in the four developing regional states of Afar, Benishangul-Gumuz, Gambella, and Somali, as well as in Tigray. 
shop owners because refugees are only able to pay after they receive their allowance from UNHCR.

"[With] my wife, usually when we do not get money from UNHCR on time, we go and borrow from the local merchants, bags of rice and sugar, and we pay him back once the money comes." (SSI19)

World Food Programme. Similarly, the monthly food distribution by World Food Programme punctuates refugees' lives as they rely on the rations, not only to eat but also to get cash by selling the products in the local market. Poor households in the host community witness the distribution without being able to benefit.

"Within the host community, there are poor households that are needy, and when there is a distribution, you need the ration card. They come to the camp, but the process of providing refugees with ration cards has procedures and the committee will examine. All refugees are from Somalia. [The poor households] go through the process and fail because they don't know Somalia and refugee administrations with the collaboration of ARRA will dismiss these needy people. And when the food distribution happens, they can't get a single kilo of ration, but they stay around the distribution site every month." (SSI31)

NGOs. Refugees are aware of the achievements of NGO interventions, which allow them to access basic services as well as livelihood support.

"NGO interventions and activities have made a huge change for the refugees, for example, basic services. They started from scratch and reached all the basic services available, whether this is education facilities, health, water, and livelihood support." (SSI31)
Refugees and hosts see NGOs as potential job providers, and as bringing positive changes to the community.

\begin{abstract}
"NGOs are mostly the reason behind the positive changes, I would say. For example, IRC previously has given trainings to refugees only, but now they equally provide trainings and skills-building to both communities. ... NGOs also provide awareness against harassment and harmful practices." (SSI25)
\end{abstract}

ARRA. ARRA, which is responsible for camp management, is a key player in the environment of refugees, involved in all aspects of their lives. ARRA oversees service provision, is in charge of administrative processes such as documentation, and acts as an intermediary with the host community. It is involved in conflict resolution mechanisms and makes sure order is kept in the camp. ARRA is also on the frontline when it comes to information sharing and awareness raising. As such, it provides information about the policies affecting refugees.

"I heard different information regarding refugees because I participated in different workshops and trainings that have been conducted by ARRA and the administration, and there were also NGOs like NRC [Norwegian Refugee Council] present." (SSI27)

Refugee Central Committee. The main role of the RCC is to represent refugees in consultations and formal communications. The committee serves as the entry point to the camp and acts as a dialogue facilitator, including for conflict resolution.

Another aspect of the social environment of refugees is the presence of relatives living abroad. Many refugees receive support from their families as remittances, which for some is their main source of income. 


\section{Figure D.1. Refugee Ecosystem Model, Somali Region}

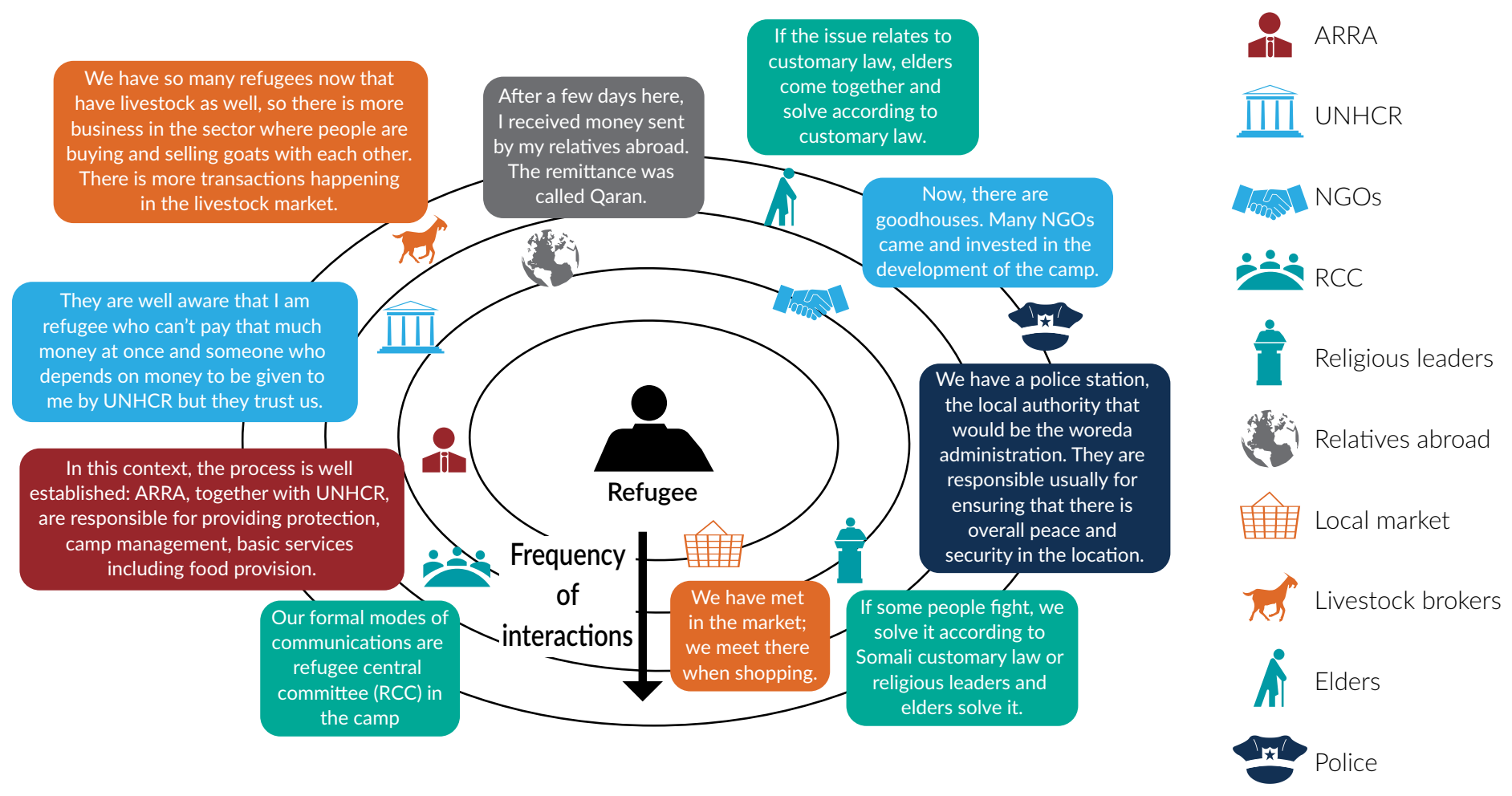

Regarding the ecosystem for hosts, most interactions happen as a result of economic interactions, with local merchants and livestock traders. Religious leaders and elders are key actors in their lives, which is true for refugees as well. The local administration and NGOs are part of hosts' ecosystem but were often described as potential employers rather than service providers. The police appear to be a distant actor, for refugees as well as hosts: this can be explained by the fact that conflicts in the host community are usually resolved by elders and religious leaders. This is also true in the refugees' ecosystem where ARRA and refugee representatives such as RCC play their part in conflict resolution rather than the police.

\section{Findings}

Who are the refugees, who are the hosts?

The refugees interviewed for this study are mostly from the southern part of Somalia, coming from Mogadishu and Lower and Middle Shabelle. Most of the respondents had passed through Kebribeyah and were posted in Sheder and Aw Barre camps by UNHCR during a second phase. The refugees claim that their places of origin tend to be forgotten, as hosts only perceive them as "refugees":

"No, I think we are all the same to them. They look at us and have termed us 'qaxooti,' meaning refugee. So, they do not really care whether you are a refugee from Mogadishu or one from Bosaso-to them you are a 'qaxooti."' (FGD11.R2) 
Refugees and hosts have different backgrounds. Most refugees in Aw Barre and Sheder come from urban settings and are educated, well-networked, and business-oriented (Carver, Gedi, and Naish 2018), while the host community is mainly composed of pastoralists, including nomadic populations. The majority of refugees in the study area have skills and capital, making them an asset to the host community. Unlike refugees, hosts have always lived in rural settings with limited infrastructure and resources. In such a context, unemployment is the main community concern.

"The area is good in terms of health, education. But unemployment is the biggest problem that young people face when they are qualified or completed their education." (SSI31)

As a result, the youth turn to irregular migration. This is true for hosts as well as refugees, as they are facing the same challenges in terms of job opportunities.

In the host community, some clans tend to be marginalized and treated with contempt. This is true for Bantus, Madhibaan, and Gaboye (FGD17.R1; FGD17.R2; FGD18.R3). These clans are not only marginalized in the study area but in the Somali territories as a whole. Intermarriage with members from these clans is considered impermissible.

"There are Madhibaan among the locals, they are marginalized everywhere in Somali areas, there is no intermarriage, they are despised." (FGD17.R1)

Some respondents speak of a greater tolerance toward these groups as a result of the increased diversity following the arrival of refugees.

"Marginalization was there in the host community before. People were divided in age and Goboye, we would never marry Gaboye. Now marginalization is limited. Here all the five regions of Somalia's people are represented, and you can find every tribe of Somali." (FGD20.R5)

to a large extent identities in the Somali culture are clanbased (Ambroso 2002a). In the study area, the host community mainly comprises Gadabursi, also known as Samaron, a subclan of Adan Yonis. These subclans are specific to the Sheder area (Ambroso 2002a). Although relatively homogeneous, the host community encompasses other clans, such as Gabooye, Jaarso, and Gari (SSI30). Refugees and hosts are not from the same clans. Although it does not constitute a major impediment to integration and social cohesion, they tend to claim their identity through their clan belonging.

"Every year, around 100 students graduate from schools or universities. Once a student finishes university he comes back to the camp. He feels wasted and migrates illegally. Just today, actually, my friend was calling me from France. Since he could not get a job, he went to Europe. He encouraged me to migrate using the same illegal route. He told me that he would support me. Not only him, there are many others like him who call me and encourage me to migrate the same way." (SSI27)

The host community was consulted and gave its consent prior to the establishment of the camps. As one local explains:

"The government of Ethiopia settled them here after eight months of discussion and consultation with us, finally we agreed to host the refugee community and warmly welcomed them to Aw Barre district." (FGD13.R3) 
The local administration also raised awareness of the potential benefits of the refugee presence prior to their arrival, and made sure the community was informed. As a former local administration representative explains:

"I was in the administration when refugees came. We informed locals that our brothers from Somalia were coming, [we told them that] they will contribute a lot to our district, and they will contribute in the business sector, in the local economy. We married each other, and this made us one community. I was part of the people who were involved in raising awareness and preparing the rest of the community to mentally and physically be prepared for the arrival of the refugees." (CC2.R1)

This explains the positive welcome consistently described by refugees. The local population gave refugees a warm welcome, both in Sheder and Aw Barre. A ceremony was even organized, with dances and songs, as explained by a host from Sheder, sharing his memories of the arrival of refugees, despite his initial fears.

"I remember the day the refugees were brought here. It was a big ceremony, we had people welcoming them very well. Let no one tell you otherwise. It was a very happy occasion for us, the people of Aw Barre. I remember I was part of the welcoming ceremony, we had songs and dances to welcome them. We really showed them how excited we were to have our Somali brothers and sisters living with us. Initially, if I am being honest, we were happy to have them but I remember a lot of the mothers including myself had this fear in our hearts. This fear was that these people might be Al Shabab and the people that were causing the harm in their own countries. So, we were afraid they would come with weapons and bring insecurity to us here in Aw Barre." (LLI6)
Refugees describe hosts as supportive and are grateful for their generosity. Some have been given food and water; others say hosts gave them access to land:

"The people we found here initially they have welcomed us in a very humane manner. After this welcoming there have been connections and interactions with them in different ways whether through lending us items from their shops. Actually, some also gave agricultural lands for whoever wanted to grow anything." (FGD11.R5)

\section{Identity and aspirations}

The aspirations of refugees and hosts differ due to their divergent statuses and opportunities. The interviews express a mutual jealousy related to future prospects, with hosts expressing their sense that refugees have better opportunities because of resettlement, while refugees lament the lack of possibilities because of their status, which does not allow them to live outside the camp and start a new life.

Many refugees hope to resettle in a third country. Although aware of the limited opportunities to go to the United States, policies have a limited impact on the aspirations and plans of refugees (ODI 2017). Many hope for a better chance in Europe.

\footnotetext{
"I am living in hope; my expectation is to get resettlement in a third country. Even though Trump banned immigration to the USA, Germany has agreed to receive people in small numbers for resettlement. If this plan does not work, I will stay and live here." (SSI29)
}

Being resettled offers the prospect of "leading a better life" (FGD19.R3), as well as getting an education, a major concern among the refugees. 
"For the future, I am really hoping we get accepted to settle in another country where my children can get the best type of education to make something of them. I never got the chance to study, but I have always been interested in education. Maybe one day, I will try and start learning English." (LLI5)

However, some refugees also express their wish to stay and live in Ethiopia and earn a living. There is interest in starting businesses, either with the help of relatives or with NGO support. This is true for young refugees, both male and female-which illustrates the impact of NGO livelihood support interventions on the mindsets and aspirations of refugees:

"My plan is to get a start-up grant, either from my relatives, those who are not here, or with the support from NGOs, I want to open a small business." (SSI31)

Some of the refugees who wish to remain are mothers hoping for a better life for their children.

"I would like to continue building my shop and saving for my daughter's life. I do not want to see her suffer the way I did, and I want to give her the best life." (SSI18)

Some of these women plan to live out of the camp: Jigjiga is an attractive place in this regard, perceived as a city offering more job opportunities.

"I am trying to go to Jigjiga to have more job opportunities because I am good at butchery work and there is a need for this kind of job in Jigjiga. Here in the camp, my business is not doing well. As refugees, our life depends on food distributions, and everything is based on that and we can only lend things because we are not able to pay for anything. I had decided to leave a long time ago and leave this place. Actually, I have decided to leave this place this month because I am a meat professional and I want to go to Jigjiga and find a place to sell meat, while my children continue their education in Sheder. I will do this to survive that is my plan." (SS132)

Self-reliance

Refugees are perceived as better off than the hosts because host communities in Aw Barre and Sheder include poor households that do not receive the support to which refugees are entitled. Even refugees make this point.

"We have our own hospital and have been given housing by organizations while some of the poor do not have a roof over their heads." (SSI19)

Opportunities are limited in Aw Barre and Sheder, where host communities mainly comprise agropastoralists. Infrastructure and services are few in number, and the private sector is not well developed, resulting in high unemployment rates and the presence of educated youth unable to find jobs.

"The only problem I can mention is the unemployment rate is high, and youth don't have working opportunities. There are many people who have different certifications who come back to the camp. Most of the refugees have different qualifications. Most of us have different qualifications, but they are of no use, so we just put them on a shelf. Challenges that we have faced here is just unemployment." (SSI19)

With a local economy heavily relyiant on cross-border trade, a widespread coping strategy for both communities consists of travelling to the border to buy goods and sell them in town. A local explains:

"When it comes to trade relations, both refugees and the host communities go to Wajale [town located at the border] for trade, they both transport goods in the same vehicles. They gather money, buy goods together, and transport them in the same vehicles, 
and all of them get their merchandise. This is integration. This is to help them cope with hardships and make things easier for them and to trade like the host community." (SSI27)

Refugees are in a different situation because their status does not allow them to work formally. However, some refugees engage in income-generation activities because they do not receive enough support to make ends meet. ${ }^{71}$ Some (especially refugee women) have precarious jobs, such as domestic workers for hosts.

"The food we take as support from ARRA is not enough to pay our bills, we do other work such as domestic work like washing clothes, or men go to Jigjiga and work there. Just our life depends on when distribution of food happens here in the refugee camps, and we base everything on it." (FGD16.R5)

Others work as day laborers because refugees represent an inexpensive workforce.

"Daily labor is one of the sources of income: refugees are a cheap labor force. They are hired to work in the construction sector. For example, in Aw Barre, when there is construction, laborers are mostly from the refugee community because it is cheaper and also because the host community has other opportunities." (KII6)

Some refugees opt to partner with host community members to start businesses. Some such partnerships are livestock-oriented, as pastoralism is the dominant Ilivelihood activity. Because refugees do not have land, they have no choice but to forge agreements with hosts.

"I gave land to my friend who is from the refugee camp to grow because we are business partners. Refugees are motivated to raise livestock. They are

71. According to respondents, an individual refugee gets a monthly allowance of Br 200 (US\$6.80) able to find someone in the local community who can assist them in raising livestock. Refugees interacted with locals and established friendships with them. So, you can see refugees having livestock in the countryside." (FGD20.R1)

Refugees and hosts also build partnerships around petty trade, with hosts securing supplies and refugees selling in the camp.

"People also partner in business, like one person lives in Jigjiga and agrees with one person in the camp. That one in Jigjiga will bring fruits and vegetables from the highland [Oromia region] and the one in the camp will sell and retail, when finished, the money will be sent." (FGD16.R5)

As a result of the multiplication of businesses in the refugee camp, a new market has emerged over the past five years, creating competition with the host community's market and providing refugees with a local market for their daily needs.

"Now refugees created their own businesses and come less often to the local markets, they have everything they need in the camp now, and that is why our interactions have decreased recently." (FGD20.R5)

Another widespread practice is selling food rations to invest money. ${ }^{72}$ Such coping strategies contribute to increased self-reliance despite the restrictive regulatory framework.

\section{Services}

The arrival of refugees significantly improved the services available to the host community, whose existing services prior to the camp's establishment were limited. Hosts note that education is an example of a benefit that hosts

72. However, food rations had recently been replaced as part of UNHCR's decision to expand cash-based assistance (see UNHCR 2019b). 
receive because of the presence of refugees, as there are now more schools.

"Before refugees [came], there was only a primary school, the locals used to send their children to Jigjiga and elsewhere to pursue secondary education. Now there are two primary schools and one secondary school. We are also lobbying to get a college or technical school providing technical skills. Therefore, I can say locals have benefited a lot from refugees." (SSI30)

The same is true for medical facilities, which were virtually nonexistent prior to the establishment of the camps.

"About health, there were no facilities before the refugees, even the pregnant woman delivering her baby used to have only traditional midwifery but no facility to deliver but now there are sophisticated materials." (SSI31)

Refugees and hosts express satisfaction with the educational and medical facilities in Sheder and Aw Barre but complain about lack of access to water and electricity.

Access to water is insufficient in both communities. However, according to a local civil society organization representative specializing in water, sanitation, and hygiene (WASH) activities, refugees are better off in terms of their water supply.

"At least the refugees are getting more than 15 liters per person per day. It does not meet UNHCR standards, but when it comes to the host community, it is less than 10 liters per person per day. The main reason is because there are not enough storage tanks in the host community." (KII6)
As a result, host community members go to the camp to access water points, as several participants in Aw Barre confirm.

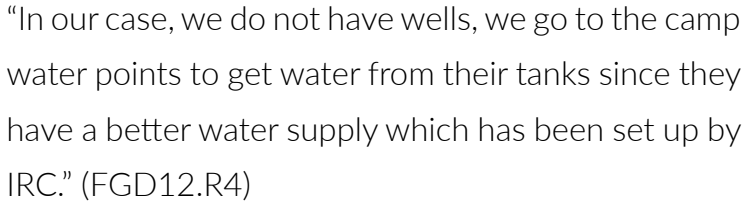

As sources are shared, even water points become places of interaction between refugees and hosts.

Electricity is a major concern for refugees because camps are not connected to the power grid. As a result, only host communities are supplied with electricity, while refugees are left with torches and generators, which are costly and thus unaffordable for many.

"We don't have electricity from the government, but we do have private electric providers with small engines, which is very costly because if we compare to the host community, we pay $\mathrm{Br} 400$ /month while they pay less than $\mathrm{Br} 30 /$ month." (SSI18)

Solar installations have been provided but are insufficient for powering the entire camp and require maintenance. This energy access disparity between refugees and hosts is a source of tension and insecurity. Refugees deplore the lack of response from the authorities despite their recurrent complaints.

\footnotetext{
"They have a more reliable electricity source compared with us. At the camp, we do not have electricity. We use generators where we pay $\mathrm{Br} 400$. We absolutely need electricity, this is very dangerous where we have dogs and oxen walking around at night and we are scared they will enter our houses and for those that have children, it is more dangerous for them. We have spoken to the authorities about this, ARRA in particular, we need someone
} 
to help us and, honestly, we are not getting any support on this. Many times, we raised the issue about electricity. Some of the solar panels are not working, and these are outside the house. There is no maintenance, and they are all shutdown. There is no follow-up ever done by anyone." (FGD15.R3)

Electricity is also a concern of the host community. Respondents complain about the poor quality of the electrical network.

"It is true both communities need integrated services. It is said that the district has electricity, but refugees don't. Even the electricity we have is not good. It is always on and off. There is no quality electricity service." (CC2.R1)

Noting the challenges faced by both communities, respondents for the community consultation express the wish to see integrated services emerge.

"We have the same challenges and need to see improved water and electricity services. We need integrated water supply, we need integrated electricity service, and we need integrated paved roads. We are one community, and we must have integrated service." (CC2.R1)

Hosts and refugees share some services, such as educational and health facilities, although they are not integrated. ARRA manages the school and medical facilities at the camp that cater to refugees. However, hosts can, to some extent, access the services. Similarly, refugees are free to use the services available in the host community. As a result, schools are mixed, and trainings for teachers are shared. A teacher from the host community explains:

"Students from refugees go to local primary school. For example, grade five, there are six students from the refugee community, grade six, five students, grade seven, 10 students, grade eight, 10 students.
There are a few, but they are found in every class. Students from local poor households are many in ARRA school because families get support for school uniforms and books. ... When local teachers have trainings, teachers from ARRA attend and vice versa. We have other meetings as teachers where we discuss challenges and use school materials together." (SSI28)

In terms of education, the lack of teachers is the main concern for both communities.

"Children go to school and play together, some of the refugee children go to the local community school and some local children go to the ARRA school, especially children from poor families because they get support from ARRA for school materials. There are challenges in terms of education, like the lack of teachers, not enough to satisfy the schools' needs. Teaching is the most abandoned job. Teachers look for other jobs and they quit and stop teaching because the salary is too low." (SSI28)

Nevertheless, there is a feeling in the host community that refugees get better services, which can be source of frustration. A host from Sheder explains:

"I would really like to urge the government or organizations here to support us as the host community to improve our basic services as they have done for the refugees. Yes, we understand that they are in need and run from their homes but what about us, the people that have generously given them homes and somewhere peaceful to stay? I do not want to say things that will make me sound like a bad person, but it hurts me inside to know that they enjoy better education services than our own here." (LLI8)

Although medical facilities on both sides cater to the needs of the two groups, ambulances belonging to ARRA 
medical facilities are not allowed to carry patients from the host community. Such a difference in treatment is regarded with incomprehension and indignation by the host community.

"One really painful point is that the authority such as ARRA does not allow the hosts to use some of the services benefitting the refugees. For example, the ambulance doesn't cater to the hosts." (FGD12.R6)

The lack of infrastructure is a shared concern of both communities. In Aw Barre, the lack of a bridge across the valley between the town and the camp is considered a major safety problem.

\footnotetext{
"Once we have an easier way for refugees to cross to us and us to them, we would be able to exchange more goods such as food items. The valley is dangerous when it rains, and this has become a popular spot where people get robbed by the gangs." (FGD12.R1)
}

This has an impact on social cohesion because the lack of bridge limits social interactions and reinforces the isolation of each community.

"The bridge defines the two sides. When there are tensions, everyone automatically stays on its side and so does the other." (FGD11.R6)

Furthermore, the absence of a road connecting both Aw Barre and Sheder to Jigjiga represents a barrier to movement and trade.

Until recently, a significant difference between refugees and hosts was the inability of refugees to access financial services. Prior to their being provided identification (ID) cards in 2018, refugees were not allowed to open bank accounts or access loans.
"We were given IDs, we can access the banks now. Before that, we used to access through someone else from the hosting community. We have sim cards to use Hellocash [a mobile transfer system] for the money that comes from UNHCR." (SSI19)

Nevertheless, a lack of collateral or savings remains a barrier to refugee access to banking services (Betts 2019b). In addition, according to several RDPP beneficiaries, existing financial institutions do not comply with Islamic finance.

"Financial services are not there, you can only open an account and deposit your money in the bank. People here don't try to get loans from microfinance institutions or from other banks. It has an interest and according to the Islamic religion, the interest is not allowed if the loan is paid with cash. So, people don't even try it." (RDPP beneficiary, Au Barre)

As a result, both refugees and hosts tend to prefer the informal savings and lending schemes, such as lqub (savings groups) (RDPP beneficiary, Au Barre).

\section{Coping Mechanisms}

Staying in groups is one of the refugees' primary coping mechanisms. One host explains that refugees tend to "walk together" in Jigjiga and Sheder.

"Remember I mentioned when in Jigjiga the refugee would walk together. Even now when I came back to Sheder I have seen them do the same thing. I have seen them walk in groups, I do not know if it is a defense thing, but this is from my observation." (LLI8)

Indebtedness is common among refugees, according to interviews with members of both communities. Refugees go to shops, take what they need, and pay later after 
they receive food rations or remittances from relatives. A refugee shop explains:

"I have this small business, a kiosk, and all my customers don't pay. They usually take goods on debt with the promises they will pay back at the end of the month. All the refugees take loans because they depend on the food rations [the food they get from ARRA]. All my customers come and take what they want and say 'write it down.' Once the customers pay me back, I go to the local shop where I borrowed the goods I needed, and exactly like my customers do, I pay back." (SSI32)

Although this practice may have consequences for shop owners, most allow refugees to pay them at a later date without asking for a guarantor or collateral. This is the result of greater interaction between communities, as this practice was not initially permitted.

"Before, if you get some money from your relatives, you would have needed to go to Aw Barre, and you would have been asked to have a guarantor, and you may not get anything and come back with nothing. Today, there is no need for a guarantor, you have a full address and you just need to have a block number and a refugee ID." (FGD16.R6)

This reveals that a relationship of trust exists between refugees and hosts, allowing them to engage in economic activities. A key informant interview with a local civil society organization representative confirms this.

"There is trust among Somalis: one of the assets is social networking, it is very important, Somalis can trust each other, even though someone is a refugee." (KII6)

Since the aid provided is not enough to live on, many refugees engage in informal economic activities. Refugees make investments proactively, either by going into debt or by selling their food rations. ${ }^{73}$ As one refugee describes, some brokers will lend livestock without any financial guarantee.

\section{"I started talking to a livestock broker named Aden, I introduced myself and told him about my plan which was lending one goat without guarantor (finan- cial guarantee), he just asked me if I had a refugee card, and I said yes I do have and I showed him. He trusted me, then I took the goods I needed within a day I paid back the goods I took on debt." (SSI32)}

Some earn income by selling their UN-provided food rations.

"Initially, being a business-minded person, I had started off by going to the shops in town to sell the food rations that I was being given by UN officials in order to get money so that I invest. I thought of this idea of investing into something which will generate something to feed my children because the food that UN was offering was little and not very edible. Through this, I did become friends with a few women and men who owned stores in the town. Therefore, the money I started getting from here, I bought a goat then slaughtered. I kept some for my children then sold the rest of it. I realized how quickly this was becoming profitable." (LLI 7)

Furthermore, refugees organize themselves in savings groups to collect money and meet unexpected expenses. This practice is very common among Somali women in both communities:

"There are people, particularly women, who collaborate in savings, they agree to share a certain amount and contribute every Thursday, like $\mathrm{Br} 50$ each or $\mathrm{Br} 100$ if they can, then for three months, one of

73. However, food rations had recently been replaced, as part of UNHCR's decision to expand cash-based assistance (see UNHCR 2019b). 
them may need help, for example, if her family has a wedding or a funeral, then the amount is given to her." (FGD19.R4)

However, savings groups are usually community-specific: refugees and hosts each belong to their own groups. Refugees also receive support from the host community, as a refugee in Sheder explains:

"The host community supports the very poor households in the refugee community, for example, by collecting food for them. We encourage people to help them since they are not in their homeland and people give them what they can get." (SSI27)

This solidarity toward refugees is favored by the local culture.

"In the Somali culture, you can't eat while your neighbor is hungry, you may be affected by the evil eye. These days, it is like that, refugees are borrowing and needs have been met by the local community, because we receive $\mathrm{Br} 200$, small borage and oil, that can't sustain us for 30 days, so you may go to the shop and borrow while you have another loan pending, when you tell him that your children don't have milk, the owner will say take, Allah will bring." (FGD16.R5)

\section{Impact on local actors}

The establishment of the camps has significantly transformed the area. Sheder and Aw Barre used to be small villages with only a few houses and shops and limited services. Changes include social composition: the area was once inhabited by local pastoralists who had limited contact with other communities. A member of the host community in Aw Barre claims that this has made the society more complex.
"If I compare Aw Barre before and now, Aw Barre is a place that hosts refugees, when the first refugee arrived here, we were a simple society with similar needs such as basic education, health; and living standards were just basic. But when we hosted the first refugees, things gradually moved from simple to complex. I say this because there has been a forced integration between people who never knew each other, who have different types of behavior." (SSI20)

This change has required adaptation by locals, who now "share" their hometown with refugees.

"The time I came back to live in Sheder, I found the refugee camp had been set up and now was here with the camp holding so many people. This is now where I had to get used to the fact that there were new people living with us here in Sheder." (LLI8)

Moreover, most of the refugees in Sheder and Aw Barre are educated and come from urban settings as opposed to the host community, which comprises pastoralists from rural areas. As a result, the arrival of refugees has transformed the area and fostered knowledge sharing.

"Before the refugees came, most of the people were ignorant, they couldn't get such education, all of them were pastorals who rear livestock. Since they met people from towns, they got a better knowledge and hosts benefited." (SSI31)

The differences in cultures and lifestyles among refugees and hosts can cause misunderstandings between them.

"Another impact is that we are more modern than the people in Aw Barre, they are just used to living here while we know a lot and have seen a lot considering we have come from big cities like Mogadishu. I usually tell them to change." (SSI18) 
As a result, new practices have developed-some positive, some negative. For example, the arrival of refugees increases diversity and fosters innovation in the community, but Aw Barre's transformation into a town also creates security and safety concerns.

\begin{abstract}
"These youth gangs are a new phenomenon here in Aw Barre. We did not have this culture previously and our youth never acted in groups. You'd always find individuals (youth) who acted alone but now this is something we have observed. We have some of the host communities who have formed their own gangs and now as we speak, we have a few of them in jail. These gangs commit all kinds of crimes, and there is also an equally notorious gang from the refugee camp. For those ones, we usually report them to ARRA who is responsible for either putting them in prison or providing the verdict on what happens to the ones caught in crime." (FGD12.R1)
\end{abstract}

On the positive side, the refugee presence attracts NGO interventions that improve the host community's access to basic services as well.

"NGOs provided support to both host community and refugees, like water supply system, health, and others. It is NGOs like IRC who maintain our water supply, train plumbers, and also they support us from the education sector like school facilities, school feeding ...." (SSI2O)

These NGOs have also created job opportunities for host community members.

"I would say the refugees have benefited the host community a lot. They all work in organizations that started functioning here because of the refugee presence. For example, where I work, there are not many refugees like me who work. There are more host community members who have been employed. It is the same case in the main hospital, schools, and everywhere else. So, you can say that us coming here, having all these amenities, has created job opportunities for their people. Honestly, I do not know why this is the case, but all I know is maybe it is because they are the hosting community, they are given preference over the refugees for most of the jobs available that serve the refugees." (SSI19)

Both Sheder and Aw Barre have grown to become business centers, attracting locals from the region. Local traders and business owners benefit greatly from the economic opportunities associated with the additional demand.

"Aw Barre was a small district before the refugees came; now it's hugely increased after the arrival of these refugees. This has benefited local traders who have accumulated wealth because of the many people buying their items and have expanded their business." (SSI20)

"Before the refugees, the area was zero at everything; you couldn't find a café, nothing was happening here, either in the economic field, business, or all other basic services. When the refugees arrived here, Sheder became a town, and now it is under competition to become a district, so the area has changed a lot over time, and it has grown a lot. The population increased, economic life improved, and the area became green, particularly in the camp because different trees grew and different schools have been constructed, especially high school, that did not exist before." (SSI29)

Some in the host community also express concerns over the negative impacts associated with the refugee presence and the resulting changes in Aw Barre and Sheder. For example, some are alarmed that the rapid development and increase in demand create high inflation, forcing low-income households to leave the area. 
"There was an increase in construction of the Aw Barre resettlement. Two school campuses were built-one for the refugees and the other for hosting community. I have been living here all my life but, nowadays, living in Aw Barre is too costly. If this continues, I will move to another city which might have a lower cost of living than Aw Barre." (SSI20)

The inward population movement has also provoked tensions over land.

"When refugees came here, this town was a very small village. People living here had to migrate to other areas. Refugees contributed to the growth and development of this town. Even those people who migrated came back. Refugees contributed to business growth, enriched social and cultural relations. This contribution has had an impact on the town. But for pastoral people, refugees had a negative impact. Farms and grazing lands were taken for people to reside, and they saw the degradation of lands." (SSI28)

The environmental degradation caused by the refugee presence has forced pastoralists to leave the area.

"Refugees contributed to environmental degradation. Farms where locals used to grow became habitations. This has obviously caused the displacement of locals. These locals need assistance and support in income-generation activities for them to survive. Also, the environment needs to be rehabilitated." (FGD20.R3)

\section{Conflict-sensitive analysis}

Although conflicts are limited overall, hosts and refugees speak openly about the causes of conflict between communities. Deforestation is the primary source of conflict, attributed to refugees cutting down trees around the camp for firewood. Refugees use firewood for lighting, cooking, and heating-a consequence of the camp's lack of energy.

"Here in Sheder, we have a problem of excessive deforestation because of refugees. Refuges are cutting the trees for different purposes, like making houses and cooking." (SSI27)

NGOs provide refugee households with cooking gas, but the supply is irregular, leaving refugees with no choice but to cut down trees. This creates tensions between refugees and hosts, especially when refugees cut down trees on privately owned farms.

"We used to be given cooking gas, but it is no longer there. You may go out to collect firewood from surrounding farms, then you can be beaten and conflicts can arise as a result." (FGD16.R5)

Refugees are left in a situation where they have no choice but to steal, even as they are aware of the risks involved.

"We have been given natural gas, and we use it, but when you miss gas, you may go to the farms in the camp's surroundings to collect firewood. It is stealing someone else's property; you may be harmed unless you beg the owner." (FGD16.R1)

Hosts also complain about the refugees' impact on the environment, arguing that waste proliferates around the camp.

"In the sanitation field, there has been a lot of problems recently. Before, there were organizations working in sanitation, but ARRA has taken over, it is not like before. Previously, we had garbage pits and we used to burn garbage. But now, as you may have seen, there are dumped wastes, plastics, and all 
wastes are dumped around the camp. Rubbish are all around and this is causing problems, livestock may eat them, ..." (SSI27)

Community consultations made clear that the host community considers the environmental degradation attributed to refugees to be a major concern, and calls for rehabilitation projects.

"We need projects for environmental rehabilitation, including galley controls, reforestation, and reserved parks." (CC2.R2)

Refugees and hosts also mention disputes over land used by refugees to graze livestock. Refugees are provided livestock, but they have no land and no way to feed it.

"Well, nothing has happened to me personally in terms of conflict, but I have come across situations where refugees were given so many goats and they decided to graze on other people's lands, and this caused chaos between them because they didn't pay the land owners for the grazing of their goats." (LLI7)

The distribution of job opportunities is a recurrent source of tension between communities. Hosts feel disadvantaged and complain about what they see as the unfair distribution of jobs.

"In terms of work opportunities, there was job creation for both communities. Most of the locals had no capacity at that time. The only opportunities available were teaching positions or watchmen. Locals complained about the distribution of employment opportunities, but this has been solved, and there were promises made to ensure the locals were given opportunities to get jobs." (SSI28)
A conflict of this type arose during the last census, as host community members felt aggrieved. Elders solved the problem by obtaining an equal repartition.

"We have also seen some fights during the last census. Youth from the local community went to the census organizers. They were complaining about employment-sharing because they said locals were neglected. Locals wanted to have an equal share of available temporary jobs or more than refugees. Also, elders intervened and discussed with the youth from the local community. They have been given an equal share and the issue was solved." (SSI30)

Salary discrepancies remain another cause of tension. Refugees are very vocal about what they see as unfair treatment, when host community members receive higher salaries for the same jobs and same qualifications. Because their status does not allow them to work formally, instead of a salary, refugees are given a per diem of no more than $\mathrm{Br} 700$. This is demoralizing to educated refugee youths.

"While his classmates that are from the host community have the chance and become employees either in government institutions or NGOs, occasionally there is a chance or opportunity that he becomes a staff of an organization working in this area. He may not be paid the same salary as the employees from the host community. For example, if the staff from the refugees and host community work in one organization for a similar job, they don't receive the same payment per month. The refugee youth who have a certificate of first degree or Masters would receive an amount of $\mathrm{Br} 700$ per month; whereas staff from the host community working in the same working environment would receive more than that. It resulted, most of the youth are demoralized, while some of them illegally migrated." (SSI31) 
However, host communities are the ones feeling neglected when it comes to NGO support. In the field of education, hosts denounce unfair treatment because the refugee students have easier access to higher education, do not pay university fees, and are provided school materials.

"For the refugee girls, NGOs provided different kinds of support. For example, when the refugee girls don't get good results at the grade 10 or 12 national exams, NGOs would send them to college, while the host community members would not be sent. It may cause tensions between the students. Similarly, at the high school level, NGOs would provide support like uniforms, books, pens, and solar lanterns used for reading; again, students from hosts would not receive the same, and this caused tensions. Group of youth from the host community attacked refugee youth and some people in the community claimed that they don't want refugees to stay here and that they must leave to another place." (SSI31)

Hosts think they should receive support from NGOs to compensate for their contributions to refugees.

"There are people whose farms have been turned to refugee houses in the camp; they have the right to be employed in the refugee camp or supported." (FGD19.R1)

This feeling is reinforced by some host community members who are experiencing more extreme poverty than the refugees.

"I think it would be nice to extend support given to refugees to the poor families in the local community. There are families with bad living conditions, even worse than refugees. They also need support, especially those displaced, whose land was given to refugees." (FGD20.R4)
To alleviate such tensions, hosts suggest that their community should get 50 percent of the NGO support.

"The locals have been used to get 25 percent of the support given to refugees. We recommend increasing this support for local communities to 50 percent. This would ensure peaceful coexistence between refugees and hosts. If poor families in the host community don't get support, it may create problems with refugees. Also, creating job opportunities for hosts will improve the relations with refugees." (FGD20.R1)

Hosts express frustration at seeing vacant positions at the NGOs being filled by staff from Addis Ababa rather than by locals.

"Those people whose farms were taken have the right to have replacement land or compensation. Employment opportunities arise from humanitarian NGOs, and their staff is brought from Addis Ababa. We have employment rights; we would like this issue to be solved. Why is staff brought from Addis Ababa while locals are ready to work and have the capability. Poor people in the host community also need assistance." (FGD19.R1)

Soccer games arose as a common practice, an activity that involves youths from both communities.

"During the football [soccer] game between Sheder and Aw Barre, people were surprised about the way we integrated and said, Sheder has no refugees, all residents are locals. When we are asked "where are you from," we reply from Sheder, and that is why they believed we don't have refugees." (FGD19.R7)

However, games between teams that are segregated by group (refugee or host), can result in fighting. Several 
participants say elders usually settle such disputes in Aw Barre and Sheder.

"I remember once youth had a fight in the football [soccer] field because of a disagreement on the scores. They were playing as refugees versus host community. No big wounds, just slight injuries as a result of the fight. Elders came together, discussed the problem and its causes." (SSI3OZ)

This shows that although soccer games are a powerful means of social integration for youth, they do not necessarily lead to social integration.

According to the Xeer system, elders are responsible for solving conflicts in the community, acting as mediators. Both refugees and hosts trust elders to deal with disputes.

"For the other damages and conflicts that rise, this is usually solved through the Xeer system. This is the system by which the elders come together to solve problems. For example, when the former administration in the region collapsed, the refugees faced serious robbery and damages to their homes. Then elders came together from the hosts and all the materials that have been looted were replaced." (SSI20)

Stakeholders and rules vary depend on the type of issue at hand, for example, religious or customary. Religious matters require the intervention of religious scholars, who will settle the issue according to Islamic principles. If the issue of concern is customary, elders are involved.

"If there is a collision, there is a traditional system that we use to solve issues. If it is something related to religion, we call religious scholars from both sides and solve it according to the Islamic religion. If the issue relates to customary law, elders come together and solve it according to customary law. For example, youth from the two communities may fight because of games. It happened recently, we came together with elders from both sides, we went to their area as they are our guests, we sat there, reconciled youth and solved the problem." (FGD19.R1)

To address conflicts between refugees and hosts, a conflict resolution committee was established. It involves the elders and is based on the model of the Xeer system. The common culture contributes favorably to this because Somali traditions and principles are used to solve issues between refugees and hosts.

"In general, we have a dispute/conflict resolution committee. This committee is responsible for all kinds of disputes. The parties of the conflict will be called and solve disputes in accordance with the Somali traditions." (SSI27)

Authorities are usually involved only as a second step or if the matter presents difficulties. If an issue cannot be solved by these traditional mediators, ARRA seeks to resolve the dispute.

"If the mediation efforts don't work or the issue is big, such as land disputes or divorces, then people go to administrations and ARRA." (FGD13.R6)

ARRA, which is responsible for maintaining good relationships between the two communities, is also preferred as an arbiter when there are community-level tensions.

"I have to make a criticism about them these days, we used to intermarry and integrate well in the past, but now, what happened is that they closed the water supply from us, they come, touch the soil and say this is our land, the people who are guarding the water points are from the host community and they force us to pay. It was just over the last few months. What we did is, we went to ARRA and [they] solved the issue." (FGD17.R3) 
Due to the existence of these mechanisms, the police and justice are rarely involved-as reflected in the ecosystems, although the police are always informed, even if the issue is solved through the Xeer system.

"Usually, people do not protest the ruling of the elders. They are trusted to make the right decision in a fair manner. Most people in Aw Barre prefer this than going to the police station to file complaints." (FGD13.R3)

A police officer confirmed that the police directly handle major crimes, such as murder and rape.

"However, there are some crimes that do not go through the Xeer system but are directly forwarded to us and we use the Ethiopian regulation to sentence the person that committed the crime. For example, rape and murder." (KII with former Sheder police officer)

\section{Social Organization}

The increase in population caused by the arrival of refugees in Sheder and Aw Barre resulted in the establishment of community-based organizations representing various groups, including youth and women. Sheder and Aw Barre were small villages before the camps were established. Hosts speak of the impact of refugees on the social life of their communities, and of their inclusion in local consultation processes.

"Social organization have changed in the course of refugees' stay here, the population has risen, they have come with new ideas and new skills, new social life, they are part of the inhabitants, they have been included in local committees representing themselves, they contribute to decision making." (FGD17.R4)
However, although there are many interactions between refugees and hosts, mostly triggered by religious and economic activities, the two communities do not share and are not part of the same organizations.

"We do not have the same organizations working in the two places. We integrate when it comes to religion-we are all believers of Allah, and this has played a key role in strengthening or even allowing for a relationship to be shared between the host and refugees." (SSI19)

The refugee camp is akin to a society on its own in this regard, with its own representatives, committees, and organizations. The only organizations that are shared with the host community are the ones that play a role in the regulation of the relationship between communities.

"There are community-based organizations in the refugee camps. There are youth organizations, women's organizations, committees, and so on. They are different according to their focus. For example, youth groups focus on employment creation, sports, and entertainment. For women groups, they focus on women's rights, female genital mutilations, and also women's empowerment. There are common ones like conflict resolution committees, but most of them are community-specific." (SSI30)

\section{Places of interactions}

Refugees and hosts meet on various occasions, but markets and mosques are the main places of interaction. Refugees regularly go to Sheder and Aw Barre local markets to meet their daily needs. Respondents from both sides explain that markets are the primary places of interaction.

"People also meet at marketplaces where they interact and buy from each other, markets are the most common places of interaction." (FGD13.R3) 
Religion is a powerful driver of integration and religious spaces act as hubs for social interaction.

"As my brother has just said, there are no programs that bring us together, but it is because of the faith we have and belief in the same God. When we go to the mosques, we meet each other, and you have to love your Muslim brother for the sake of Allah." (FGD12.R1)

When it comes to religion, there is no difference between refugee and host, to the point that refugees lead Friday prayers in the mosque located in the host community.

"I do not have a shop, but I have interacted with a lot of refugees in the mosques. A sheikh-who is a refugee-leads the Friday prayers in Aw Barre in the main mosque. The religion we share has made us care about each other." (FGD12.R6)

Hosts say that refugees contribute to the development of madrasas, as most of the teachers are from the refugee community.

"From the religion side, they have contributed positively by leading prayers at the mosques and teaching madrasa." (SSI24)

Community events, such as weddings and burials, are also places where communities meet. A refugee woman explains:

"We usually attend cultural events and wedding parties together and share special moments; if someone dies, we all attend his or her funeral and send condolences." (FGD13.R6)

Because refugees and hosts share a religion, the population increase has enabled considerable improvements to religious buildings. This is acknowledged by both communities and appears to be a source of pride. Locals explain that scholars from both communities worked together to build a tower on Sheder's mosque:

"In terms of religious occasions, religious elders assigned one place for Eid prayers, Fridays, we pray in one mosque. In the last Eidul Adha, religious leaders announced that the mosque requires a tower, because it is the sign of the mosques. The mosque did not have a tower and it was not different from other buildings. All religious scholars from both refugees and hosts collaborated to build the tower, you can see now, the tower is complete, now we are collaborating in building a new mosque. Both communities are connected and collaborate and work together." (FGD19.R4)

Social services are also crucial to fostering interactions; and integrated schools allow children from both communities to get to know each other.

"Education is also where people meet and establish connections. Sharing social services also because both locals and refugees meet on water points, in health centers ... I have many friends in the refugee camp. Refugees come to us here in the health center. We serve them just like locals." (SSI30)

"Places where the community gather include watering points, for example when some of the boreholes encountered damage and there was a water shortage. If this shortage occurs, the community gathers where water is available-be it at the host community side or refugee side." (SSI2O)

Finally, NGOs and development actors bring both communities together for organized trainings and conferences. 
"Social interactions occur during Eid festivity, during the conferences, wedding ceremonies, burials, trainings, and workshops that the government and NGOs conduct. People interact with refugees at Sheder markets, people also come together at mosques [masajidada] during the prayer times of Fridays and Eid prayers, and people come together during the day of refugees." (SSI32)

\section{Distance to camp}

The distance between the host community and the camp is a key factor of interaction. Host community members living close to the camp rely on refugees more than they rely on the host community.

"Hosts from that side don't come in town, they buy from refugees and go back home, they depend on refugees in terms of business." (FGD19.R2)

However, hosts who live far from the camp interact less frequently with refugees.

"The connection between the refugees and locals is there because now they have lived here for a very long time. Now you see them everywhere walking, working, or taking their livestock. I personally do not have that many connections with them because I work here at the control, the entrance of the town. I see them moving in numbers when they are leaving, but other than Assalamu Alaykum, we do not share anything else." (FGD14.R5)

Distance is a key parameter for service delivery as well. A host explains that geographic location rather than status determines the type of service one uses.

"Both communities have equal access to some services. They have equal access to water, health, and education. No discrimination for refugees or hosts when using these services. It depends on the individuals, on what makes sense for them. If the health center is close to someone, no matter if the person is a refugee or a local, they can access." (SSI30)

In this regard, the valley between the town and the camp in Aw Barre is barrier to integration because the distanceand the absence of a bridge-limits social interactions.

\section{Mixed marriages}

Many refugees have built families through marriage to hosts or other refugees, resulting in an internal increase of the camp's population.

\begin{abstract}
"There are many like me who came here single but now have children-I just want you to understand the population increase doesn't necessarily mean there are people coming from outside, but there is an internal population increase." (SSI25)
\end{abstract}

Mixed marriages have become common practice. Several participants report that refugees and hosts have become relatives and are now a family.

\begin{abstract}
"About social integration, at the beginning we were a little isolated, after a while, when we stayed here for a while and understood each other, we see people getting intermarried, when marriage happens between us people, we become blood related and family." (SSI33)
\end{abstract}

After a wedding, a couple usually lives in the host community, resulting in a stronger integration.

\section{Gender roles}

While gender roles do not appear to have evolved due to the refugee presence, interviews with refugees indicate that some women arrived and live alone in the camp, 
sometimes with children. This puts them in a situation of limited support where they must provide for the needs of their families and themselves, which fosters a form of independence. To a great extent, jobs remain genderspecific for both communities. Women often turn to domestic work, such as laundry and housekeeping. Some also have small businesses, just like men, although the type of business may differ, with women more likely to be selling clothing items and cosmetics. In some cases, men leave for the major cities after arriving at camp, leaving women behind to look after their families using whatever money-if any-they are sent.

\section{Economic interactions}

Economic exchanges are the primary mode of refugeehost interactions, described by refugees and hosts as the first step toward integration. Repeated daily interactions have enabled them to get to know each other. When referring to their relationships with hosts, refugees often mention shop owners as people with whom they have very frequent contact.

Refugees and hosts are interdependent in terms of economic exchange. Refugees drive the demand for goods, and rely on hosts to supply them. In a region highly dependent on cross-border trade, hosts travel to the border to buy goods and sell them in town. Because of their status and movement restrictions, refugees tend to partner with hosts to import products, either from Wajale (located at the border with Somalia) or Jigjiga.

\footnotetext{
"The people in the area living in the host community and the refugees are interdependent. For instance, people are socially interlinked, refugees stay at the camp, and there are some of them who own small businesses in the camp. These businesses have connections with local businesses in Sheder town. Refugee business owners have no permission to buy goods in Jigjiga or Wajale towns. They depend
}

on what the local people bring to Sheder, and then refugees will take goods from them as secondhand. Host community members are wholesalers, and refugees are connected to their stores." (SSI29)

However, some respondents indicate that refugees can now travel to Wajale themselves because hosts now let them use their transportation services.

"In terms of movement, refugees have already been given the freedom to go anywhere they like. They even go to Wajale town for business." (SSI21)

Refugees depend on shop owners from the host community to "borrow" goods and pay for them later, after they receive their food rations.

\footnotetext{
"The refugees depend on the host communities in many ways. The refugees borrow vegetables, rations, and money from the locals. Sometimes, shops in the town give goods to a refugee who sells and then pays back the amount of the goods." (SSI32)
}

Hosts benefit from this arrangement because refugees are their main customers. As a result, shop owners report that they are grateful for the presence of refugees. Refugees are considered valuable clients and are treated accordingly. A businessman from the host community in Aw Barre explains:

"I have many customers who take food items from my shop worth $\mathrm{Br}$ 2,000 monthly, and they pay me back. I know them and trust them. It took a while, but that is what the situation is. There is no refugee who works for me, but I sell my products to shop owners in the camps. When I have new products that have come, I go and advertise in the camps too. I am grateful because my income has increased-I serve a wider population that is modern. We treat them like the host customers, if not better." (SSI21) 
Refugees also rely on hosts to graze livestock because they lack access to land, leaving them with only the option of informal agreements with hosts. Some refugees partner with hosts by offering to take the latter's livestock for grazing. Others receive support from hosts to feed their cattle. These arrangements foster positive interactions between refugees and hosts.

"For example, when my plants grow, there is a man called Ali Abdi who is a refugee who lives in the camp, I give my plants to feed his livestock. He owns a few livestock given to him by-I believe-UNHCR, but there is nowhere for him to take his goats to graze. Therefore, since he doesn't have the feed and I have more of this, so I give them. Ali looks for me because we have gotten to know each other by seeing each other trying to find places to graze, walking around the bridge (doox). He even sometimes sends his livestock to me so that I can add them to mine to go out and graze together. Ali doesn't have children to take his goats for grazing therefore my children do this for him." (FGD12.R4)

\section{Positive economic impacts}

The arrival of refugees has undoubtedly fostered economic development, created economic opportunities, and resulted in the expansion of both Sheder and Aw Barre. A main consequence to economic exchange is the circulation of money due to an increase in the number of transactions. Several hosts and refugees note how limited the number of shops and availability of cash used to be in Sheder.

"In Sheder, when we arrived here it was a very small village. The buildings that you have seen here were not previously here, there were old buildings only and they were just plants growing everywhere and no buildings, you could count the number of shops, it was a small number, there was only one marketplace with a limited number of goods, and if you were to buy you might not receive the change. For example, if you were to buy a biscuit whose price is $\mathrm{Br} 5$ and you give $\mathrm{Br} 10$, you couldn't get the change because they rarely had that much cash flow. You'd have to come back the following day to get your change or you'd have to buy more goods." (SSI32)

The most significant impacts of the increased demand on the host community are the proliferation of shops, the development of services, and the increase in the supply of commodities.

"Before the refugees came, Sheder was a very small village; there were very few people and houses in Sheder. But after refugees arrived, the population has increased here. After the refugees have adapted to this place, we started business exchanges; because the population had increased, the demand for goods increased and a number of businessmen came to open new businesses. The consequences were economic growth and expansion of the town." (SSI26)

The multiplication of businesses has made a variety of goods and services available to the host community, such as food products, clothes, cosmetics, hygiene products, electronic devices, and decorative items.

"When we first came to Aw Barre, we could count the number of tea shops, clothes shops; and everything now has doubled. The community has expanded with more shops. We would say that they have benefitted from us being here." (FGD11.R5)

The host community also reports benefitting from the refugee presence in terms of services, including transportation, which was extremely limited before the establishment of the camp. 
"When the refugees came, in the first five years, refugees and hosts made great social interactions, business increased and expanded, business owners benefited double, and each business became twice as big as before. We got access to transportation services, which was limited before." (SSI26)

Financial services also became more available, including mobile transfer services.

"On the economic side, the host community benefited from refugees, you can easily get information about how this place was before refugees came, and the changes that have occurred. In terms of population and economic growth, financial services opened for remittances, such as Hello Cash." (SSI26)

The arrival of refugees also boosted job creation due to the presence of NGOs and generally improved business opportunities.

\section{Refugees as a source of innovation and skills}

Many hosts say the refugees are a source of innovation and skills. Coming from an urban educated background, refugees settled in Sheder and Aw Barre have capital and networks, and tend to be business-oriented. According to Carver, Gedi, and Naish (2018):

"In Sheder, the presence of a refugee camp in the area has, in effect, created its own host community, as what was a small village has grown significantly. People have been drawn there from different parts of the region to make the most of the new economic opportunities, opportunities associated with the operation itself as well as the capital and skills that well-networked, urban refugees have brought to the area."
The interior design skills of the refugees are particularly appreciated by many in the host community.

"Refugees are people from major cities in Somalia and have their own skills and mindsets; they have contributed in many things, like home decoration, home materials, and appliances." (SSI21)

In terms of clothing, business owners are inspired by new designs introduced by refugees.

"They have really opened our eyes to new ways of making dresses (dira). Before, the community would all have their clothes tailored the same way. When I see them sometimes, I try to copy their clothes designs." (SSI26)

Refugees' skills fill some gaps. For example, hosts say they are fluent in English and proficient with information technology.

"If you look at the schools and madrassas, you will see that the refugee children are always brighter than our students. Our mosques are led by refugee imams and even in language; some of their youth speak fluent English and are proficient in IT [information technology]." (FGD12.R7)

Because of these skills, refugees are hired to teach in private schools, which some hosts perceive as threatening.

"They are causing a burden on jobs for the host communities because some of the refugees are more advanced in technology and language. They teach in private schools, some work in the hospitals, but the majority of them are daily casual laborers." (SSI24) 
The refugee presence fosters knowledge transfer in critical sectors, such as construction and electricity. This contributes to the development of the towns and largely benefits the host community.

"The host community was small, but refugees came from big towns, had good knowledge, now the host community is dependent on the refugees, on their skills, for construction, plumbing, electricity, maintenance. Then the knowledge was transferred, and many host community members have learned electricity, pipe installation, plumbing, or construction; this is also why the town grew up. Many people got knowledge thanks to these people. Especially in Kebribayah and Aw Barre, the people were skilled and trained. The host community will tell you that they were very lucky to have these refugees." (KII6)

The needs and consumption habits of the refugees have encouraged local producers to adapt and diversify their production. While agricultural activities were once limited to animal products, locals now grow vegetables. , as explained by one refugee.

"From 2008 and 2009 to 2011, we used to buy milk, charcoal, and trees used for construction from nomads in this area. Now they started to grow vegetables like pepper, cabbage, onion, and tomatoes and sell them to refugees. We used to bring from Jigjiga, but now it is brought from locals. They have been motivated by refugees' needs, they changed their farms where they used to grow crops, from khat and maize to fruits and vegetables. We used to eat cabbage in southern Somalia, not even in Galkayo in central Somalia; when we found it here, we loved it. They have been motivated by the refugees to grow these things." (FGD16.R1)

\section{Negative economic impacts}

Hosts complain of high inflation, which they attribute to the arrival of refugees. The cost of living was once low in these remote areas.

"Food prices were low at that time, and a sack of charcoal, which costs $\mathrm{Br} 300$ now was around $\mathrm{Br} 5$. A leg of goat meat was $\mathrm{Br} 15$; a cup of milk was $\mathrm{Br} 1$. Even nomads were very close, and we used to go and take milk for free from them." (FGD17.R5)

This increase in prices has led to declining purchasing power, especially among pastoralist populations. Basic items have become unaffordable to a segment of the population.

"Before refugees came, the price of one sack of sugar (50 kilograms) was $\mathrm{Br} 300$ but today it is about $\mathrm{Br}$ 1,280. The income of the people is very low, and the cost of living has become very high, particularly basic food items." (SSI27)

Hosts claim that this inflation is caused by refugees who have more money and do not bargain.

"The refugees had a negative impact on the market prices and the destruction of the forest. There are price hikes-for example, the sack of rice or pasta is now much more expensive. One kilogram of rice was $\mathrm{Br} 5$ and it is up to $\mathrm{Br} 20$ now. One kilogram of sorghum was 1.50 cents; it is now $\mathrm{Br} 10$. A cup of milk was $\mathrm{Br}$ 1, now it is $\mathrm{Br} 15$. That is the difference, as I told you, a sack which was $\mathrm{Br} 20$ is now $\mathrm{Br} 280$. Everything went up. Since the refugees are better off in terms of income sources, some get remittances and do not even ask/bargain prices and pay whatever they are told. Refugees do not bargain." (SSI27) 
Hosts also complain about competition following the recent establishment of a market inside the camp. Refugees have increasingly been opening small businesses, although they rely on the host community for supplies. A host from Sheder explains:

\begin{abstract}
"However, over the last three years, refugees opened small businesses in the camp, some of the refugee customers and local community members living around the camp use that market even though these small businesses depend on the local market."
\end{abstract} (SSI26)

Refugees are now able to travel to Wajale to purchase goods for themselves instead of having to rely on hosts to buy for them. Interviews with hosts reveal concerns about the impact this might have on local businesses.

\footnotetext{
"Under the former government, refugees are not allowed to go out of the camp. Now they can go anywhere and access all places in the country. They are able to buy from as far as Wajale. This will have an impact on local businesses, because refugees used to buy from locals here only. Now they can do their own business, like locals." (SSI28)
}

According to hosts, the new market inside the camp has already impacted local business, which have witnessed a reduction in the number of their customers.

\footnotetext{
"Now things are changing. Refugees started to have their own businesses in the camp. This has reduced the number of customers for local businesses." (SSI30)
}

However, refugees say that the hosts maintain a monopoly on the market.

\footnotetext{
"There is no competition on the market because there is a monopoly owned by the host community."
} (SSI29)
The establishment of a market inside the camp could reduce interactions and thereby lessen social cohesion.

\begin{abstract}
"Although the presence of refugees has been an opportunity to increase the volume of business transactions, now it seems that the market in Sheder is divided into two: the refugee camp business market and Sheder business market. It seems that there is a gap between the two business markets."
\end{abstract} (SSI27)

Furthermore, outside of the camp, refugees are sometimes viewed as competitors for small jobs.

"It is actually competing because as I mentioned to you earlier, I go to the hosts to wash their clothes so does my mother as well. We go together and we usually hear the ladies saying in the hosts that we are better at doing this casual labor as compared with the other hosts. I would assume the ladies who used to do these jobs do not like us very much because we are taking their jobs." (FGD13.R3)

\section{Conclusions}

\section{Sheder and Aw Barre provide examples of peaceful coexistence between refugees and hosts, facilitated by their shared Somali culture, common language, and religion. However, most interactions remain economically} driven: the camp and the hosts remain two communities living side by side, whose members meet regularly but do not share the same organizations and who have different support systems. As a result, there is a strong sense of otherness, revealing limited integration. To some extent, refugees and hosts share the same interests, including job creation and infrastructure investments, such as the road connecting Jigjiga to Aw Barre and Sheder and the bridge between the camp and the town in Aw Barre. Both communities consider these to be their main priorities. Both groups are concerned about instability in the region 
and the country in general. The lack of electricity at the camps is a major problem for refugees and a cause of insecurity, while hosts are connected to the power grid.

A community consultation in Aw Barre reveals a strong desire for an integrated approach.

"I would like to conclude with something which is very important, as we have seen from the beginning of this discussion, and I would like us to all vow and agree that from now on, any group that is approached by implementers, donors-should speak on behalf of the other. For example, if an organization comes and asks us, the refugees, what our main needs are, we will speak of them but also speak on the behalf of the host community and whatever they have shared with us as their main needs. The host community will do the same. Therefore, when we start acting like a joint front, all these implementers will have no choice but to provide more integrated support." (CC, Aw Barre, September)

All of the participants applauded in agreement.

The host community undoubtedly benefits from refugee presence, which has fostered economic development and improved service provision. Nevertheless, one of the most important findings in this study is that there is widespread resentment among hosts toward NGOs and organizations focused solely on refugees while the host community faces major challenges related to livelihoods and access to basic services. Another source of tension is job distribution. Although the legal framework prevents refugees from working formally, they engage in trade; work as daily laborers; and fill skilled positions, including as teachers. As a result, hosts see them as a threat-a feeling reinforced by the fact that they also feel neglected. Because economic opportunities are limited in the area, the additional labor market competition-whether formal or informal-could spark tensions.

Raising awareness on the policies and their benefits for both communities is crucial. To date, limited information has been shared by local authorities, NGOs, and UN agencies, partly due to the many uncertainties regarding the implementation of the CRRF at the local level. However, only systematic sensitization and information campaigns will ensure that information is accessible to and understood by all. The information delivered needs to consider the expectations and concerns of each community.

In terms of programming, integrated approaches, as contemplated in the CRRF, are necessary to avoid tensions. The strong demand for greater equality confirms the need for integrated approaches and equal support. The Regional RDPP has been a precursor in this regard and has shown positive results in terms of social acceptance.

Better coordination is needed among local-level stakeholders, including organizations working with refugees and those supporting host communities. There has been progress in this area, especially through the establishment of the CRRF coordination meetings, but much remains to be done to ensure joint assessment, planning, and implementation. 


\section{References}

Abdurehman E. 2014. Jostling for Trade: The Politics of Livestock Marketing on the Ethiopia-Somaliland Border. Future Agricultures Consortium.

Ambroso Guido. 2002. "Clanship, Conflict and Refugees: An Introduction to Somalis in the Horn of Africa." https://pdfs.semanticscholar.org/9770/bd0979b9622bf74b0659043af1488640f5e8. pdf.

Betts, A., R. Bradenbrink, J. Greenland, N. Omata, and O. Sterck. 2019. Refugee Economies in Dollo Ado: How Somalis Use Aid and the Cross-Border Economy. Oxford: Refugee Studies Centre, University of Oxford. Center, University of Oxford. https://www. rsc.ox.ac.uk/publications/refugee-economies-in-dollo-ado-development-opportunities-in-a-border-region-of-ethiopia.

Carver, Freddie, Ahmed Ali Gedi, and Dominic Naish. 2018. Somali Regional Report: Refugee and Host Community and Context Analysis. Mimeo. London and Addis Ababa: ODI and Danish Refugee Council.

IOM (International Organization for Migration). 2018. Mobility

Overview in the Horn of Africa and the Arab Peninsula. IOM.
Michelson, M. 1999. Border Economics: "Contraband Trade in Ethiopia's Somali Region." ICWA Letters.

ODI (Overseas Development Institute). 2017. Journeys on Hold: How Policy Influences the Migration Decisions of Eritreans in Ethiopia. London: ODI.

Samuel Hall. 2019. Outcome, Learning, and Evaluation for the Regional Development and Protection Programme. Samuel Hall.

SC-UK (Save the Children UK) and DPPC. 2008. Livelihoods and Vulnerabilities: An Understanding of Livelihoods in Somali Regional State, Ethiopia (updated version). Addis Ababa: Save the Children UK.

UNHCR (United Nations High Commissioner for Refugees). 2018. UNHCR Ethiopia. Briefing Note (August). Geneva: UNHCR. https://data2.unhcr.org/en/documents/download/65917

---. 2019a. Ethiopia March 2019 Fact Sheet. Geneva: UNHCR.

---. 2019b. UNHCR Cash Assistance. UNHCR. https://www. unhcr.org/5c5c5acc4.pdf. 


(4) WORLD BANK GROUP 